\title{
UNECE
}

\section{Innovation in the Public Sector}

Country experiences and Policy Recommendations
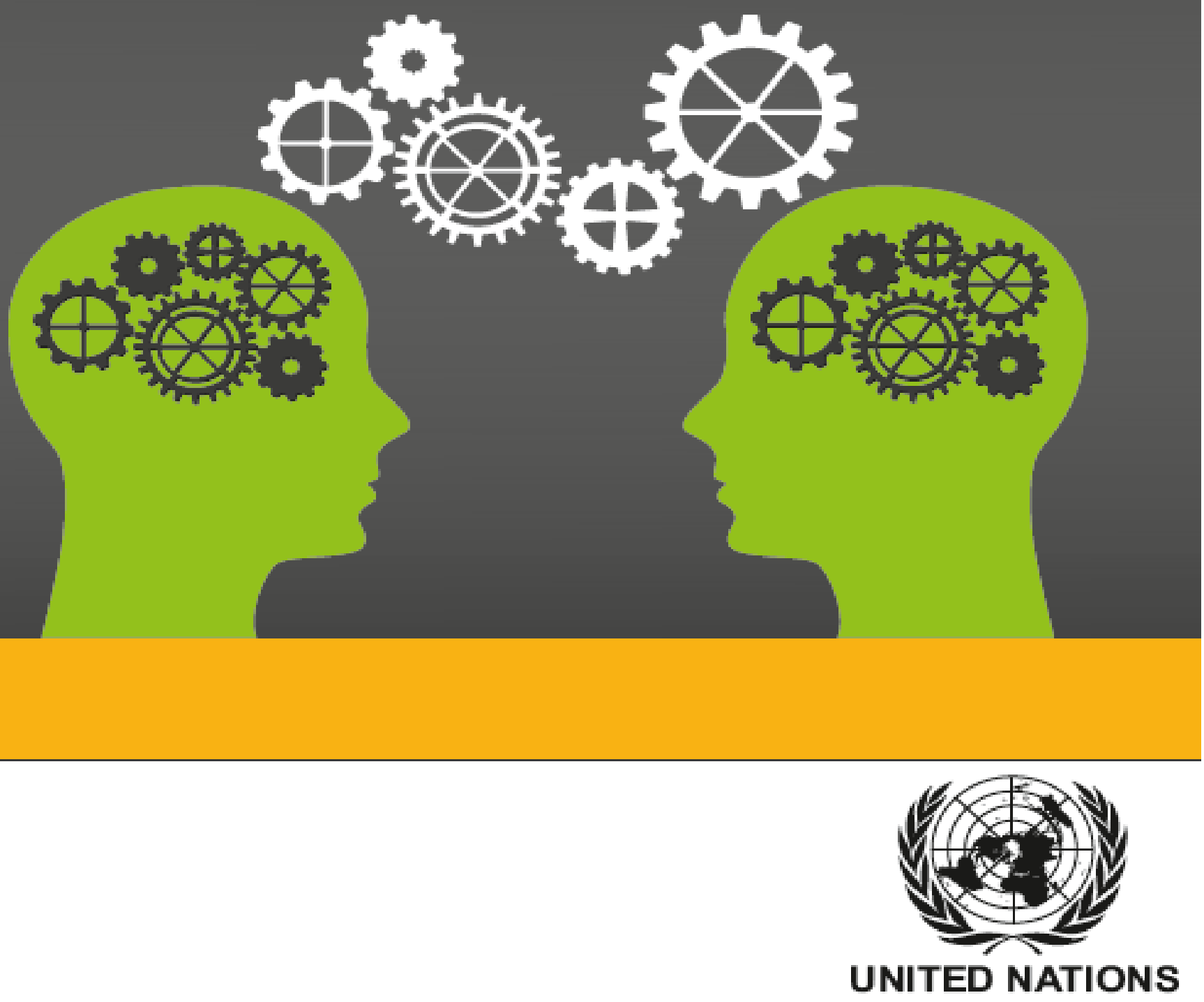



\section{United Nations Economic Commission for Europe}

\section{Innovation in the Public Sector}

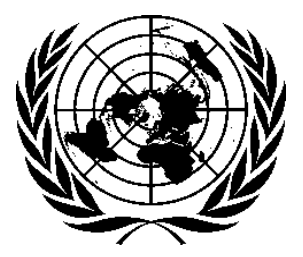

\section{UNITED NATIONS}

New York and Geneva, 2017 


\section{NOTE}

The designations employed and the presentation of the material in this publication do not imply the expression of any opinion whatsoever on the part of the Secretariat of the United Nations concerning the legal status of any country, territory, city or area, or of its authorities, or concerning the delimitation of its frontiers or boundaries.

This volume is issued in English and Russian only.

ECE Information Unit

Palais des Nations

CH-1211 Geneva 10

Switzerland
Tel.: +41(0)2291744 44

Fax: +41(0)229170505

E-mail: info.ece@unece.org

Website: http://www.unece.org

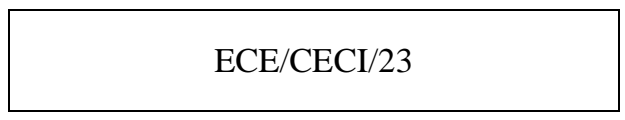

UNITED NATIONS PUBLICATIONS

Sales number E.17.II.E.20

ISBN 978-92-1-117141-9

eISBN 978-92-1-362799-0

ISSN

Copyright (C) 2017 United Nations

All rights reserved worldwide

United Nations publication issued by the Economic Commission for Europe 


\section{FOREWORD}

The public sector plays a very significant role in modern economies. As in the business sector, innovation can be a major source of productivity growth, cost savings and improvements in service quality; benefits which then also positively affect businesses and citizens who rely on an efficient and effective public sector.

The ability of the public sector to innovate is therefore increasingly seen as a critical element of economy-wide innovation performance. However, innovation policies and strategies relating to the public sector are far less developed than those targeting the business sector. There are important differences between the public and the private sector in terms of incentives and motivation, resource allocation, and attitudes towards risk, which are inherent in the different roles played by the two sectors in the economy, and which have a profound impact on how innovation is carried out and how policy can support it.

The collection of contributions in this publication address a wide range of issues related to the promotion of innovation in the public sector as well as policy lessons learned in this area, drawing on the experiences of different countries.

The issues discussed in this publication refer to a relatively new policy area. Countries are at different stages in the conceptualization and implementation of relevant strategies. Overall, there is a need to further develop the understanding of innovation in the public sector and to increase policy awareness. This creates significant scope for policy learning and the exchange of experiences through international multilateral initiatives.

I hope that this publication will contribute to the dissemination of good practices in the promotion of innovation in the public sector and provide a useful reference for policymakers and other innovation stakeholders in their activities.

Olga Algayerova

Executive Secretary

United Nations Economic Commission for Europe 


\section{ACKNOWLEDGEMENTS}

This publication was prepared under the auspices of the UNECE Committee on Innovation, Competitiveness and Public-Private Partnerships as part of the programme of work of the UNECE Team of Specialists on Innovation and Competitiveness Policies. It is the outcome of an applied policy seminar on Innovation in the Public Sector held as part of the series Policies for Innovation and Knowledge-Based Development in the 21st Century. The UNECE Secretariat thanks the authors of the chapters for generously sharing their expertise and the members of the Team of Specialists and seminar participants for their contributions to the discussion. 


\section{CONTENTS}

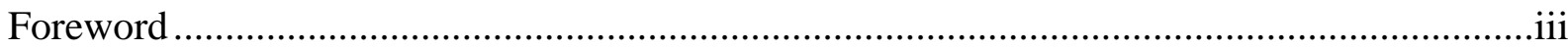

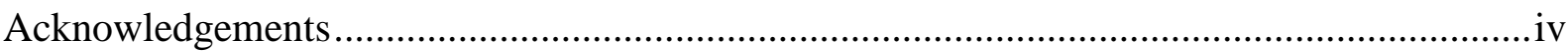

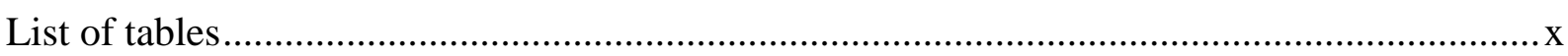

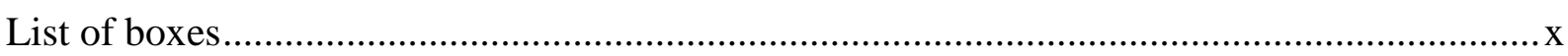

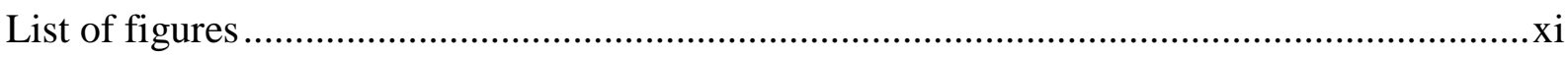

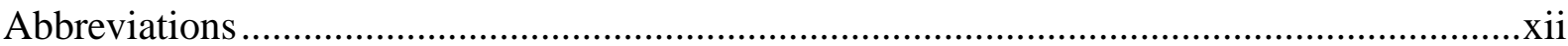

\section{PART I. PROMOTING PUBLIC SECTOR INNOVATION: MAIN ISSUES AND}

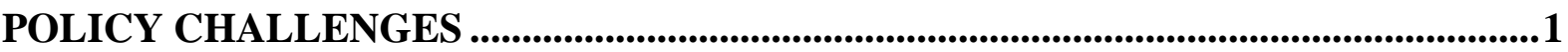

Chapter 1 Innovation in the Public Sector .....................................................................................2

Dennis Patrick Leyden, University of North Carolina at Greensboro, United States of America

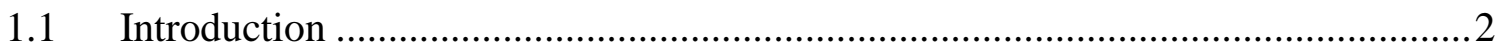

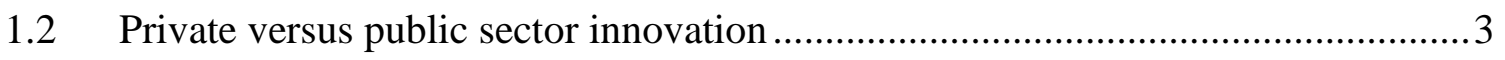

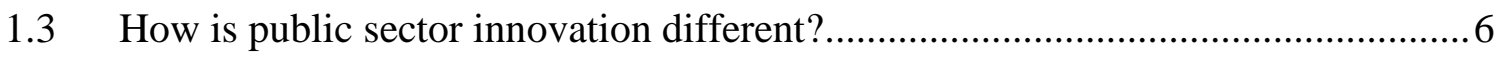

1.4 Creating an innovative public sector environment ............................................

1.5 Why cannot a private sector model of innovation be applied directly to the public

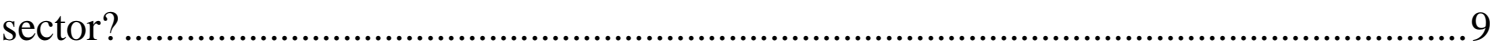

1.6 What are the necessary conditions for public sector innovation? ........................ 11

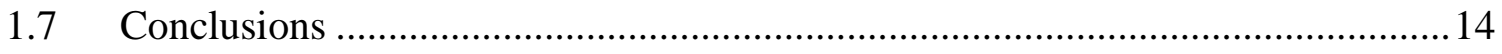

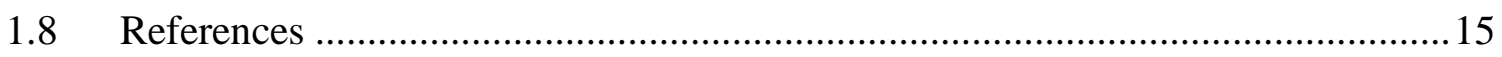

Chapter 2 Towards A Better Understanding of Public Sector Innovation - Piloting the European Public Sector Innovation Scoreboard .......................................................18

Tomasz Jerzyniak, European Commission, Directorate-General for Enterprise and Industry

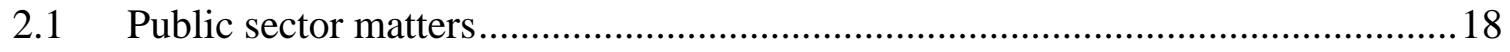

2.2 The need for a better understanding of public sector innovation ......................... 19

2.3 Measuring public sector innovations - key challenges and limitations .................20

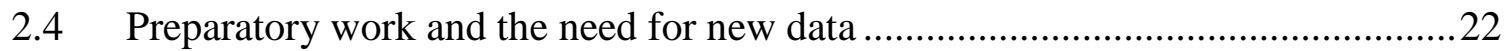

2.5 Towards a pilot European Public Sector Innovation Scoreboard ...........................24

2.6 The pilot EPSIS 2013: The results, key messages and limitations.......................26

2.7 Next steps: Towards a better and policy-relevant measurement of public sector

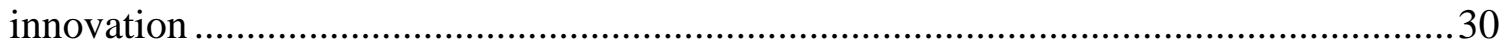

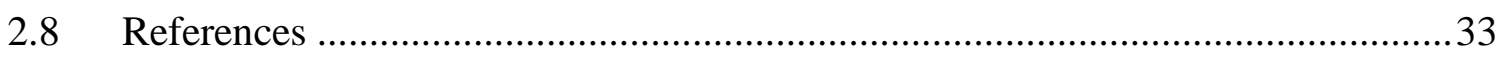

Chapter 3 Promoting Public Sector Innovation: Trends, Evidence and Practices from

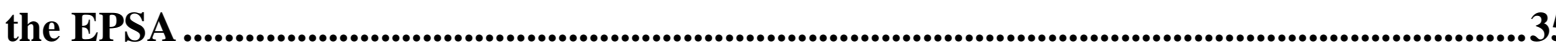


Alexander Heichlinger and Julia Bosse, European Institute for Public Administration

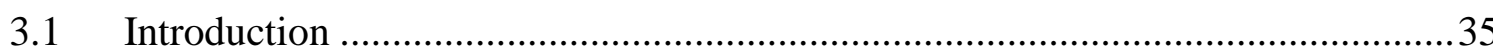

3.2 The EPSA - A strong driver for public sector reform and the search for excellence .

3.3 The Need for a Strategic Framework (for services, partnerships and/or budget

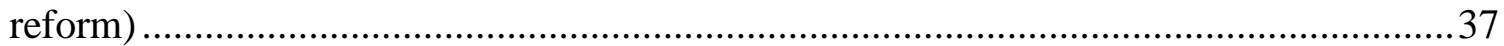

3.4 Transparency and Consensus through Citizen and Stakeholder Involvement .......38

3.5 Importance of commitment/dedication at all levels and bold leadership ...............39

3.6 Continuing emphasis on partnership approaches and its related ownership

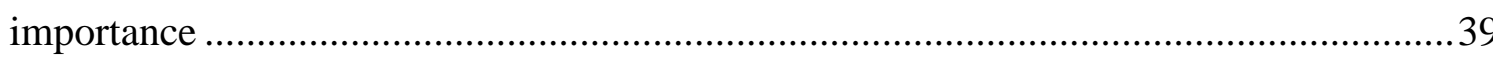

3.7 Intelligent ICT-enabled solutions and architectures to improve service delivery,

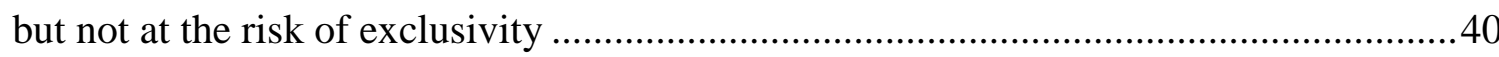

3.8 Innovative cross-border cooperation and driving social inclusion despite (or because of) the crisis.......................................................41

3.9 The trend towards more coordinated and smart procurement modes.....................42

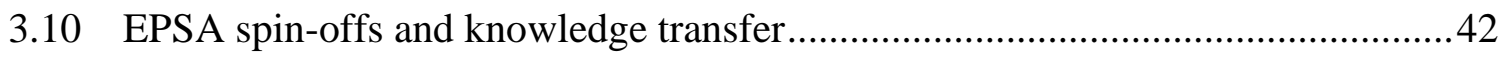

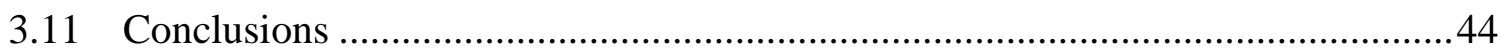

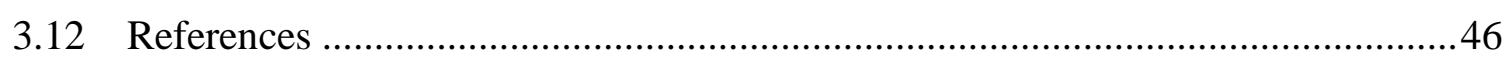

Chapter 4 Exploring the Role of ICT, Skills and Organizational Change in Public

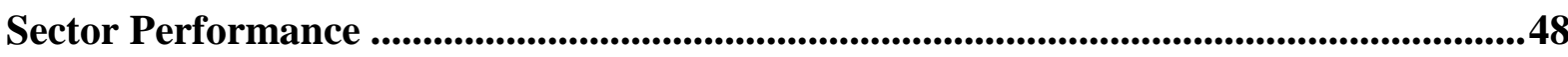

Antonello Zanfei and Paolo Seri, DESP, University of Urbino, Italy

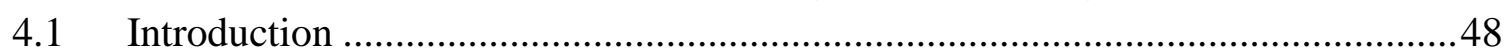

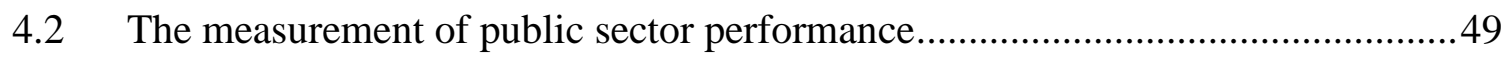

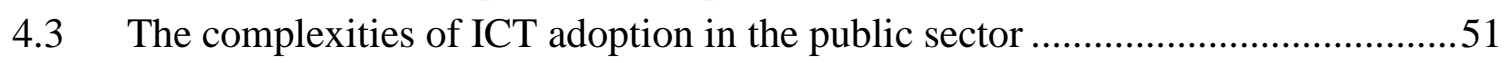

4.4 How the interactions between ICT, skills and organization affect public sector

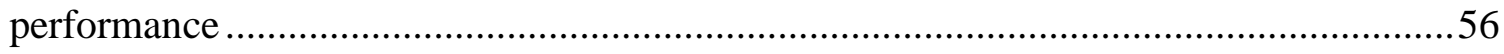

4.5 Beyond traditional approaches to ICT and performance in the public sector .......59

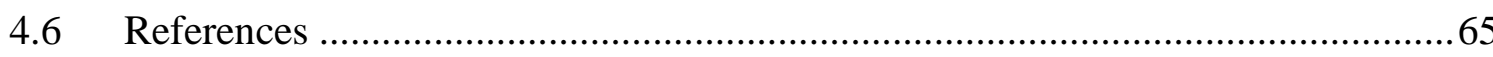

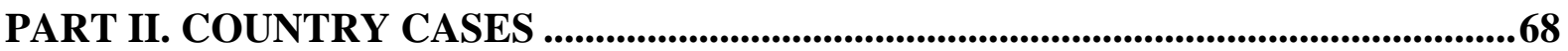

Chapter 5 Mainstreaming Public Sector Innovation through Governance

e-Transformation - Moldova Case Study ................................................................................69

Stela Mocan, e-Government Centre/Government CIO, Moldova

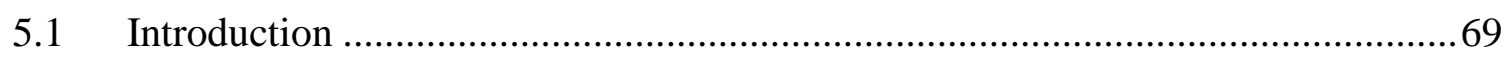

5.2 The Moldova Governance e-Transformation Journey ........................................ 70

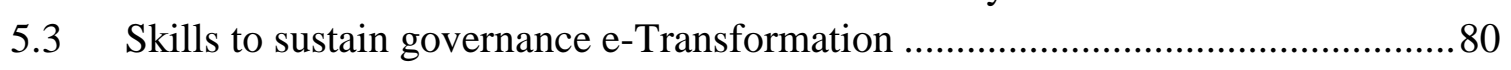

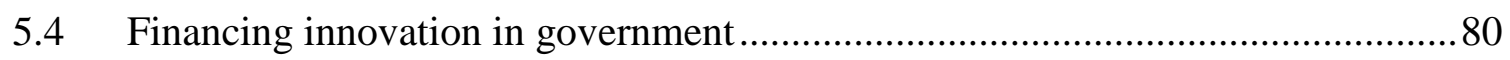

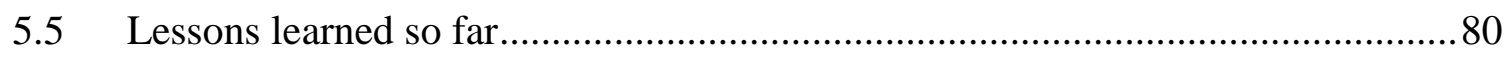

5.6 Immediate priorities and challenges to be addressed ........................................ 81

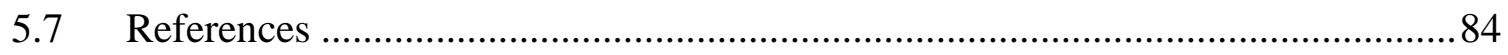


Chapter 6 Innovating in the Public Sector through Citizen Engagement (From eGovernment to Collaborative Governance) .87

Matt Poelmans, CitizenVision, The Netherlands

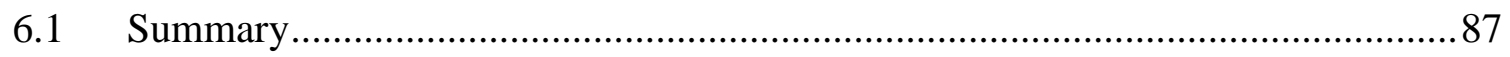

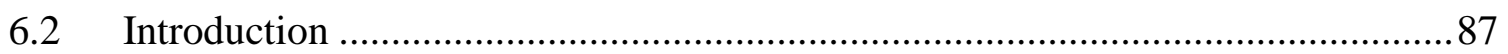

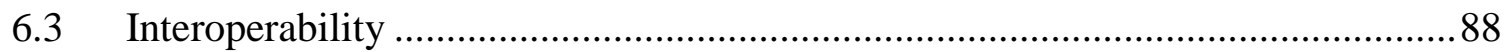

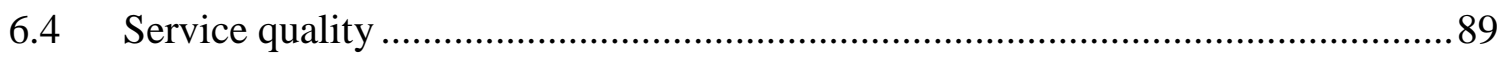

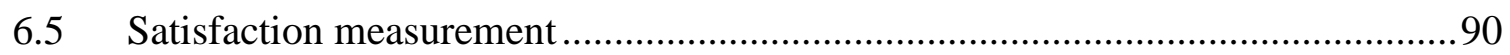

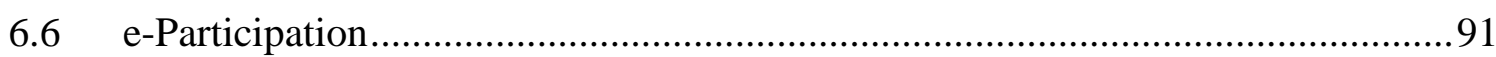

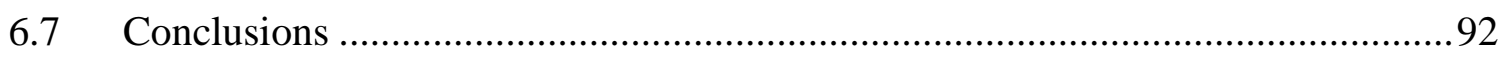

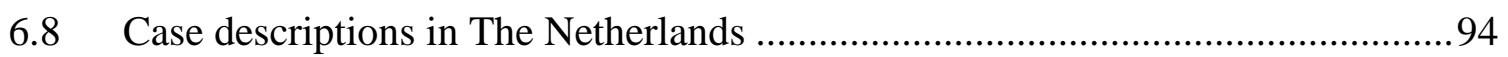

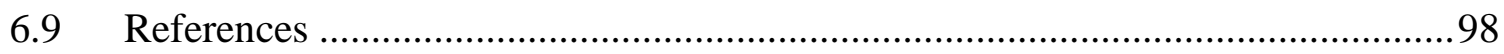

Annex: e-Citizen Charter ..................................................................................... 100

Chapter 7 Innovating to Modernise the Public Sector in France........................................101

Françoise Waintrop and Tanguy Dennielou, SGMAP, France

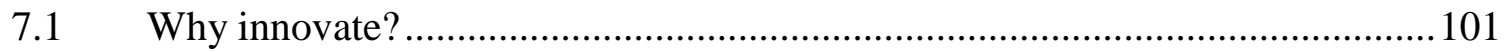

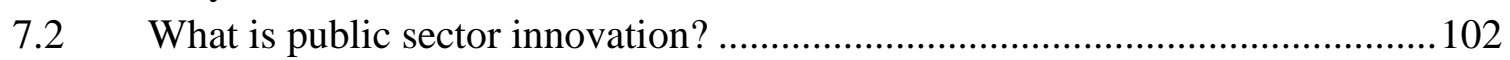

7.3 The French context: An imposing administration ............................................ 104

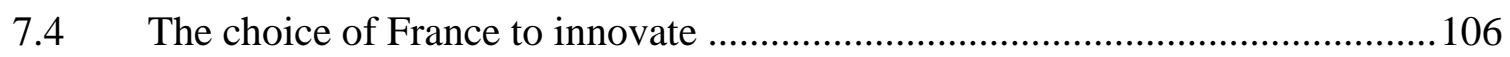

7.5 Some examples of public sector innovation in France ...................................... 109

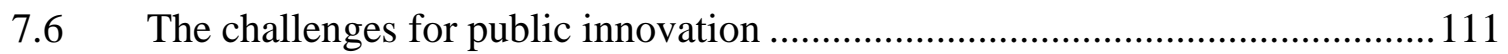

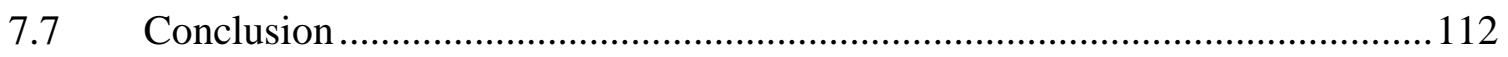

Chapter 8 US Public Sector Innovation Programmes....................................................114

Dennis Patrick Leyden, University of North Carolina at Greensboro, United States of America

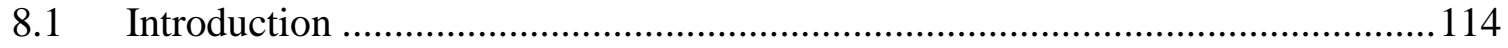

8.2 Potential benefit of United States public sector innovation ................................. 114

8.3 Examples of United States Public Sector Innovation Programmes...................... 117

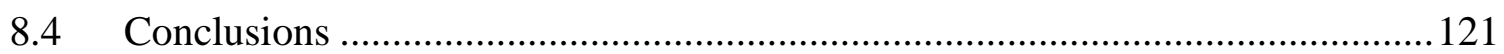

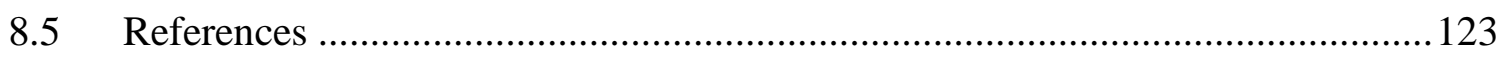

Chapter 9 New Evidence on the Innovation Climate in the Swedish Public Sector ...... 124

Irene Ek, Swedish Agency for Growth Policy Analysis

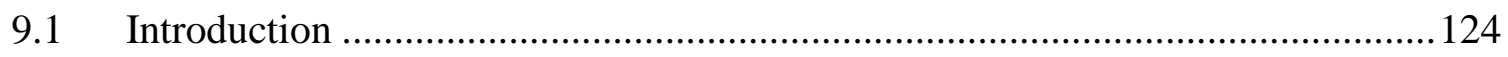

9.2 What constitutes innovation in the public sector and how is it measured? ......... 127

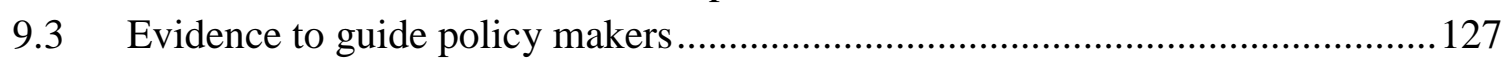

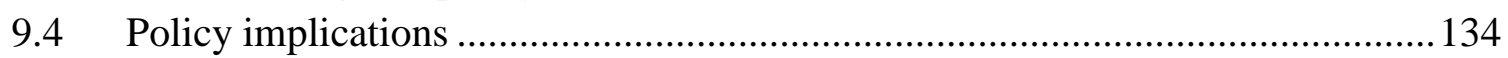

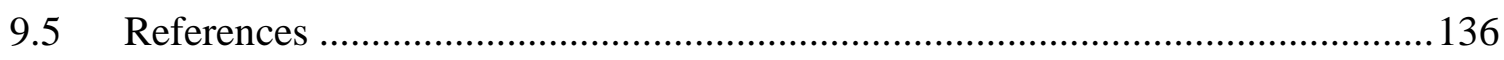

Chapter 10 Swiss Federalism and Public Sector Innovation .............................................137

Peter Grünenfelder and Matthias Schnyder, Canton of Aargau, Switzerland

10.1 Introduction 


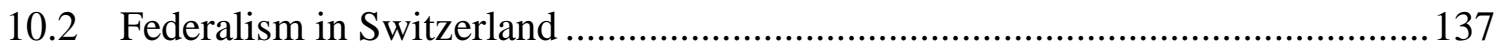

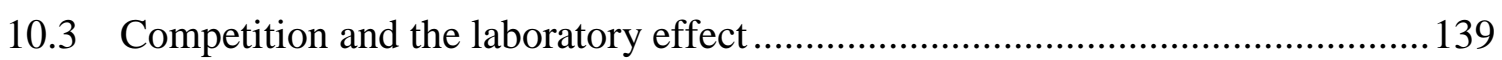

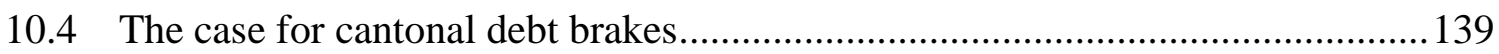

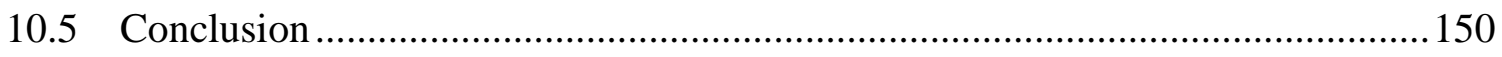

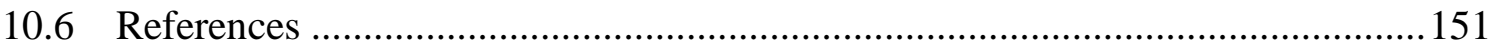

\section{Chapter 11 Innovation in the Public Sector of Ukraine: Problems of Identification,} Measurement and Promotion

Igor Yegorov, Institute of Economy and Forecasting, National Academy of Sciences of Ukraine

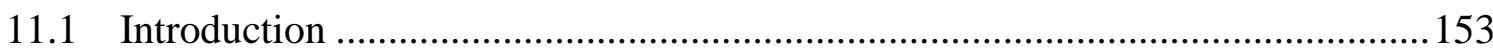

11.2 Identification of innovation in the public sector of Ukraine ............................. 153

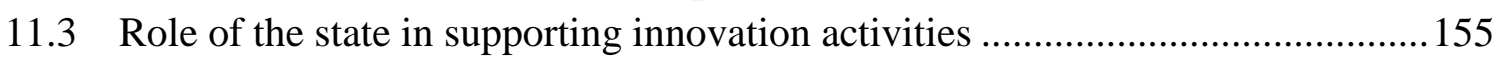

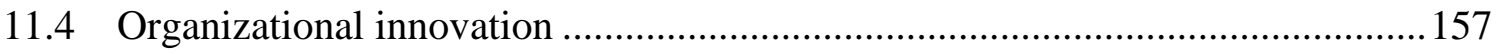

11.5 Private-Public Partnership and innovation in the state sector ............................ 159

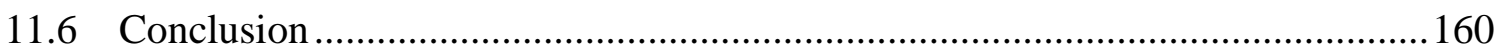

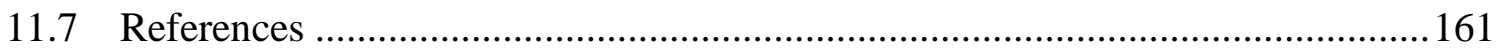




\section{LIST OF TABLES}

Table 1.1 Different views of the private sector entrepreneur 3

Table 2.1 Indicators used in the pilot European Public Sector Innovation 2013 ....................25

Table 2.2 The results of the pilot European Public Sector Innovation Scoreboard 2013 _.......27

2.2 The results of the pilot European Public Sector Innovation Scoreboard 2013(continued) 28

2.2 The results of the pilot European Public Sector Innovation Scoreboard 2013

(continued) .29

Table 4.1 List of e-Services considered by the EU e-Government benchmark .......................61

Table 4.2 The impact of ICT, skills and organizational change on PA performance ..............63

Table 8.1 Examples of public sector innovation programs: public sector initiated...............117

Table 8.2. Examples of public sector innovation programs: private sector initiated............. 120

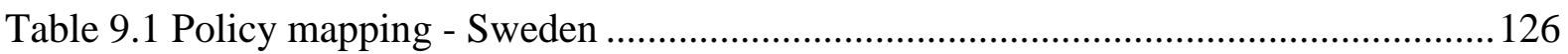

Table 9.2 Comparison of the degree of innovation activity in the public and private sector 130

Table 9.3 Comparison of R\&D expenses in the public and private sector .......................... 131

Table 9.4 Share of innovation activity in procurement contracts ....................................... 132

Table 11.1 Organizations of innovation infrastructure in Ukraine, 2011 ............................. 156

Table 11.2 'High technologies' introduction in Ukrainian economy, 2011 .........................159 


\section{LIST OF BOXES}

Box 9.1. Swedish Government Initiatives .....

.124

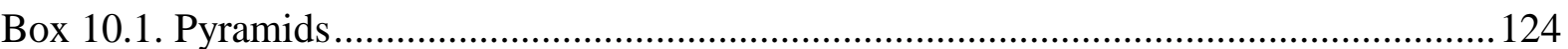




\section{LIST OF FIGURES}

Figure 1.1 Country government expenditures (as \% of GDP) by per-capita GDP, 2011-2012

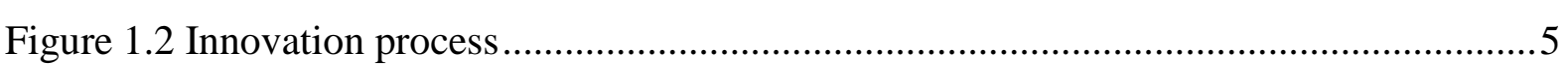

Figure 1.3 Creating an innovative public sector environment ...........................................

Figure 3.1 Seven steps leading to public management excellence ........................................43

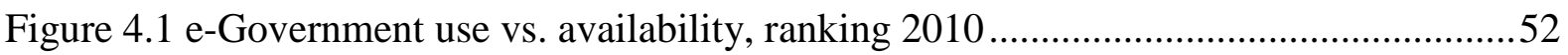

Figure 4.2 e-Gov indexes diverging trends for enterprises ..............................................5

Figure 4.3 e-Gov indexes diverging trends for citizens ..................................................5

Figure 4.4 Citizens using the internet to interact with public authorities by type of activity, 2012

Figure 4.5 Firms using the internet to interact with public authorities by type of activity, 2011

Figure 5.1 Areas for governance e-Transformation 2011-2020

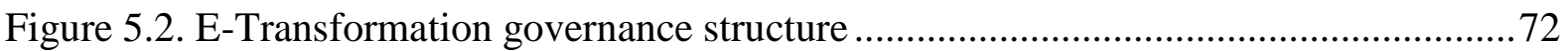

Figure 5.3. E-Transformation Governance Structure ..................................................... 73

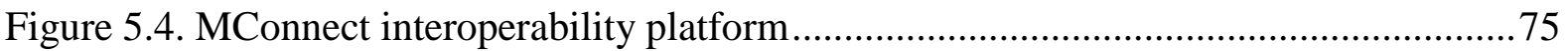

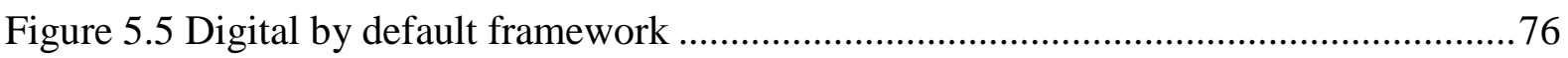

Figure 6.1 Priority matrix 2010, e-citizen charter satisfaction rating ...................................91

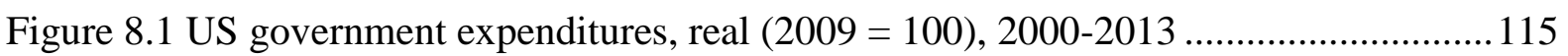

Figure 8.2 US government expenditures (as \% of GDP), 2000-2013 .................................115

Figure 8.3 Annual productivity growth, US federal government, 1968-1994 _......................116

Figure 9.1 Selected results from the on-line service index (OSI) in the UN e-Gov survey .. 129

Figure 9.2 Sweden's values on the four stages of the on-line service index ........................130

Figure 9.3 Comparison between the new innovations partnerships and the old PCP procedure

Figure 10.1 Comparison of cantons with debt brakes and without any or weak debt brakes 141 


\section{ABBREVIATIONS}

BOOST World Bank open budgets portal/access to data initiative

CEFG City Economic and Financial Governance

CeT Coordinator for e-Transformation

CFO Chief Financial Officer

CIO Chief Information Officer / Chief Innovation Officer

CIS Community Innovation Survey

COFOG Classification of the Functions of Government

CROS Consultative Regional Committee of Schiphol

DE Germany

DRF Digital Regional Forum

EC European Commission

ECMP Entreprise Content Management Platform

e-CNAM e-reporting to National House of Medical Insurance

e-CNAS e-reporting to National House of Social Insurance

EERE Energy Efficiency and Renewable Energy

eGC e-Government Centre

EGDI e-Government Development Index

EGOV e-Government

EIF

EIPA

European Interoperability Framework

EIS European Innovation Scoreboard

EPSA European Public Sector Award

EPSAS European Public Sector Accounting Standards

EPSIS European Public Sector Innovation Scoreboard

ES

Spain

ESN Evaluation Summary Notes

ESS European Social Survey

EU European Union

$€ \quad$ Euro

G2B Government to Businesses

G2C Government to Consumers

GCIO Government Chief Information Office

GDP Gross Domestic Product

GNP Gross National Product

HELP High-Level Experts for Leaders \& Practitioners (Moldavia)

IaaS

Infrastructure as a Service

I-Corp National Science Foundation's Innovation Corps

ICT Information and Communication Technology

ICTU Information and Communication Technology Unit

ID Identity Document

IE Republic of Ireland 


\begin{tabular}{|c|c|}
\hline IT & Information Technology \\
\hline IUS & Innovation Union Scoreboard \\
\hline KVED & Classification of Types of economic Activity (Ukraine) \\
\hline LEAs & Local Educational Authorities \\
\hline LU & Luxembourg \\
\hline MCloud & Shared Technological Platform of Moldova \\
\hline MConnect & Technical Interoperability Platform \\
\hline MDS & Mobile Digital Signature \\
\hline MEPIN & Measuring Public Innovation in Nordic Countries \\
\hline MPA & Master in Public Administration \\
\hline MPass & Governmental digital service for authentication and control \\
\hline MPay & Government electronic payment service \\
\hline MSign & Governmental digital signature service \\
\hline NACE & Statistical classification of economic activities in the European Community \\
\hline NASA & National Aeronautics and Space Administration \\
\hline Nesta (UK) & Formerly NESTA, National Endowment for Science, Technology, and Arts \\
\hline NGO & Non-Governmental Organization \\
\hline NHS & National Health Service \\
\hline NIFU & Nordic Institute for Studies of Innovation, Research and Education \\
\hline NPM & New Public Management \\
\hline OECD & Organisation for Economic Cooperation and Development \\
\hline OPSI & Observatory of Public Sector Innovation \\
\hline PA & Public Administration \\
\hline PaaS & Platform as a Service \\
\hline $\mathrm{PC}$ & Personal Computer \\
\hline PCP & Pre Commercial Procurement \\
\hline PISA & Programme for International Student Assessment \\
\hline PPP & Private-Public Partnerships \\
\hline PSI & Public Sector Information \\
\hline $\mathrm{R} \& \mathrm{D}$ & Research and Development \\
\hline REFIT & Regulatory Fitness and Performance Programme \\
\hline S\&T & Science and Technology \\
\hline SaaS & Software as a Service \\
\hline SALAR & Swedish Association of Local Authorities and Regions \\
\hline SEK & Swedish Krona \\
\hline SGMAP & General Secretariat for the Modernization of Public Action \\
\hline SIGEDIA & Electronic Document Management and Records System \\
\hline SIPRI & Stockholm International Peace Research Institute \\
\hline SMEs & Small and Medium Enterprises \\
\hline UBICA & Ukrainian Association of Investment Business Association \\
\hline UN & United Nations \\
\hline UNDP & United Nations Development Programme \\
\hline UNECE & United Nations Economic Commission for Europe \\
\hline
\end{tabular}


UNPSA United Nations Public Service Awards

UNSTAT United Nations Statistical Commission

UNU-MERIT United Nations University - Maastricht Economic and Social Research Institute on Innovation and Technology

USAID US Agency for International Development

US\$ United States Dollars

WCAG Web Content Accessibility Guidelines

WOV Swiss outcome-oriented public management 
Part I. PROMOTING PUBLIC SECTOR INNOVATION: MAIN ISSUES AND POLICY CHALLENGES 


\section{Chapter 1}

\section{Innovation in the Public Sector}

Dennis Patrick Leyden, University of North Carolina at Greensboro, United States of America

\subsection{Introduction ${ }^{1}$}

It is generally accepted that innovation is at the heart of economic growth and prosperity and that, at least in the private sector, innovation occurs through a process of creative destruction that is driven by entrepreneurial action. It is less clear to what extent entrepreneurial action is possible or advisable in the public sector as a mechanism for driving innovation. However, while the public sector has a different institutional structure than the private sector and thus a different set of motivations, risks and rewards, incentives and constraints, it too can benefit from something like private sector entrepreneurial drive as a mechanism for generating public sector innovations that contribute to economic growth and prosperity.

The potential benefit of public sector innovation is large. While public sector size varies by country, Figure 1.1 reveals that the size of the public sector in the average country is a third of that country's economy. Such a size suggests that innovation in the public sector has the potential for contributing significantly to a country's economic growth and prosperity directly by reducing the cost of delivering public services and by increasing the quality and array of those same services, and indirectly by improving private sector productivity through expansion and improvement of publicly-provided infrastructure on which the private sector depends.

\section{Figure 0.1 Country government expenditures (as \% of GDP) by per-capita GDP,} 2011-2012

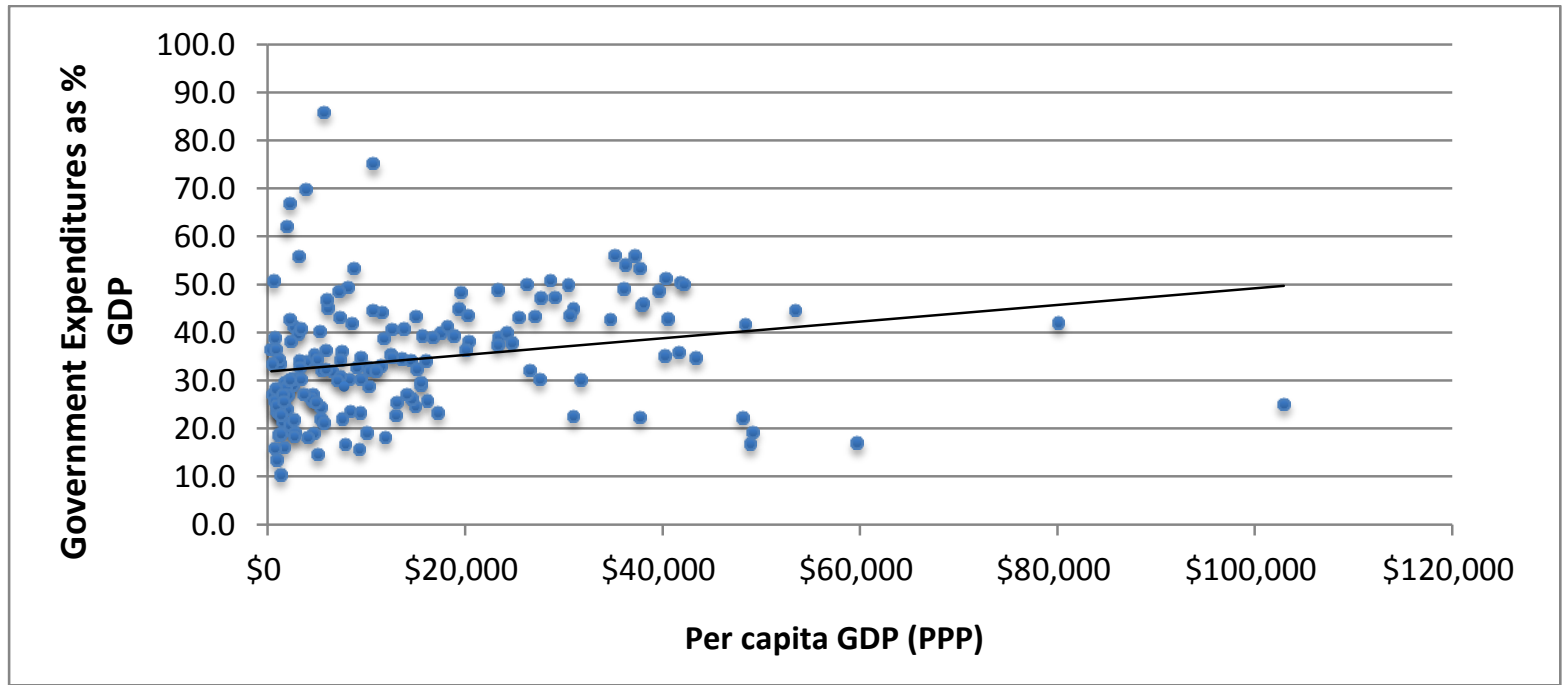

Source: Graph constructed from data downloaded from Heritage Foundation (2013)

\footnotetext{
${ }^{1}$ I would like to thank the participants of the 2013 UNECE applied policy seminar "Innovation in the Public Sector" in Geneva, Switzerland for their comments on an earlier presentation that formed the basis for this chapter. I would also like to especially thank Ralph Heinrich at the UNECE for his helpful guidance in exploring this issue and writing this chapter.
} 
This chapter explores this issue beginning with an examination of the innovation process in the private sector. Through this examination, the fundamental nature of the innovation process and its connection to entrepreneurial action is developed. The chapter then turns to an examination of innovation and entrepreneurial action in the public sector and how it manifests itself despite important differences in the private sector and the public sector environments. The chapter then closes with a discussion of the institutional environment needed to foster public sector innovation.

\subsection{Private versus public sector innovation}

\section{What drives innovation in the private sector?}

The current understanding of the importance of innovation in fostering economic growth and prosperity, and the fundamental role that private sector entrepreneurs play in generating innovations, stems in large part to Joseph Schumpeter (1934 -1950) and his efforts to popularize that argument. As Schumpeter's views have come to dominate the study of innovation and entrepreneurship by scholars of economics, management, and sociology, the works of others have unfortunately become increasingly obscured and forgotten. As Table 1.1 summarizes, the private sector entrepreneur has been viewed quite differently by various scholars.

Table 0.1 Different views of the private sector entrepreneur

\begin{tabular}{|l|l|}
\hline The private sector entrepreneur is a ... & Associated scholar(s) \\
\hline person who assumes the risk associated with uncertainty & $\begin{array}{l}\text { Richard Cantillon } \\
\text { Frank Knight } \\
\text { Johann Heinrich von Thünen }\end{array}$ \\
\hline person who supplies financial capital & Adam Smith \\
\hline innovator & $\begin{array}{l}\text { Richard Cantillon } \\
\text { Nicholas Baudeau } \\
\text { Joseph Schumpeter } \\
\text { Johann Heinrich von Thünen }\end{array}$ \\
\hline decision maker & Carl Menger \\
\hline industrial leader & Jean Baptiste Say \\
\hline manager or superintendent & John Stuart Mill \\
\hline organizer and coordinator of economic resources & Léon Walras \\
\hline owner of an enterprise & François Quesnay \\
\hline employer of factors of production & Amasa Walker \\
\hline contractor & Jeremy Bentham \\
\hline arbitrageur & Israel Kirzner \\
\hline allocator of resources among alternative uses & T. W. Schultz \\
\hline
\end{tabular}

Source: Leyden \& Link (2015)

Beginning with Richard Cantillon (1755 - 1931), who was the first to use the term entrepreneur in its modern sense, the private sector entrepreneur has also been viewed alternatively as a risk taker, a capitalist, an innovator, a decision maker, an industrial leader, a 
manager, a coordinator of resources, an owner, a contractor, or an arbitrageur. ${ }^{2}$ In a given circumstance, the private sector entrepreneur may play any of these roles. However, most of these roles are not essentially entrepreneurial; they are often associated with general business activity and can be delegated to others. But what is essential is not just that the private sector entrepreneur is the one who innovates but is also, as Knight (1921) persuasively argued, one who bears the special type of risk associated with uncertainty. Schumpeter explicitly rejected that argument, ${ }^{3}$ and thus with his popularity has come a failure to appreciate a dimension of the entrepreneur's character - the recognition of which is important to designing effective entrepreneurial policies.

Before examining the private sector entrepreneur's behaviour in detail, it is useful to provide a fuller explanation of the risk associated with uncertainty. Risk manifests itself in two forms. Simple risk occurs when the future is not certain, but the possible outcomes, as well as the probabilities of those outcomes, are known with reasonable certainty. Such risks, such as the chance that a house will burn down, are measurable, can be insured against, and therefore are easily dealt with by markets. However, there are other circumstances where the complete list of outcomes and/or the probabilities of those outcomes are not known. In other words, we don't know what we don't know. This type of risk, which Knight labeled uncertainty, is inherently unmeasurable, uninsurable, and therefore not able to be dealt with by markets. It is this type of risk that gives rise to (positive or negative) entrepreneurial returns for it is the entrepreneur who is the one who is willing to take on this special risk. Moreover, innovation by its very nature - is about creating that which has not been created before. With no past to go by, innovation is therefore inherently an uncertain process. It is about perceiving an opportunity heretofore unexploited and acting on that opportunity.

Given the intrinsic uncertainty of the innovation process, why would someone choose to be a private sector entrepreneur? The usual argument is that the private sector entrepreneur is motivated by the chance of earning entrepreneurial profits. ${ }^{4}$ But when such entrepreneurs are asked about motivation and success, they generally respond that entrepreneurship requires passion and that focusing only on a monetary payoff generally results in failure (Streitfeld, 2012). Thus, while profits may be part of the story, at least as important is the desire to create and to achieve (Nabseth \& Ray, 1974). And it is this psychological drive to create that seems to sustain the private sector entrepreneur when possible future profits, by the very nature of uncertainty, cannot be rationally calculated.

\footnotetext{
${ }^{2}$ For a comprehensive review of this literature, see Hébert \& Link (2009).

${ }^{3}$ Schumpeter was quite explicit in his belief that risk bearing was not an essential characteristic of the entrepreneur (Schumpeter 1934, p. 75): "Nevertheless I maintain that . . . [my] definition [of the entrepreneur] does no more than formulate with greater precision what the traditional doctrine really means to convey. In the first place our definition agrees with the usual one on the fundamental point of distinguishing between 'entrepreneurs' and 'capitalists' irrespective of whether the latter are regarded as owners of money, claims to money, or material goods. . . . It also settles the question whether the ordinary shareholder as such is an entrepreneur, and disposes of the conception of the entrepreneur as risk bearer." It is not clear whether this rejection of the entrepreneur as risk bearer was due to his misunderstanding of Knight's distinction between risk and uncertainty, or to a more fundamental disagreement.

${ }^{4}$ J. H. von Thünen provides the earliest complete characterization of the nature of entrepreneurial profits and their motivating role (Thünen, 1826/1960). In that characterization, Thünen was quite explicit that entrepreneurial return is not the return from capital but rather the return from ingenuity and the willingness to confront the risks associated with uncertainty. In many ways, Thünen presages the work of Knight nearly a century later.
} 
Figure 0.2 Innovation process

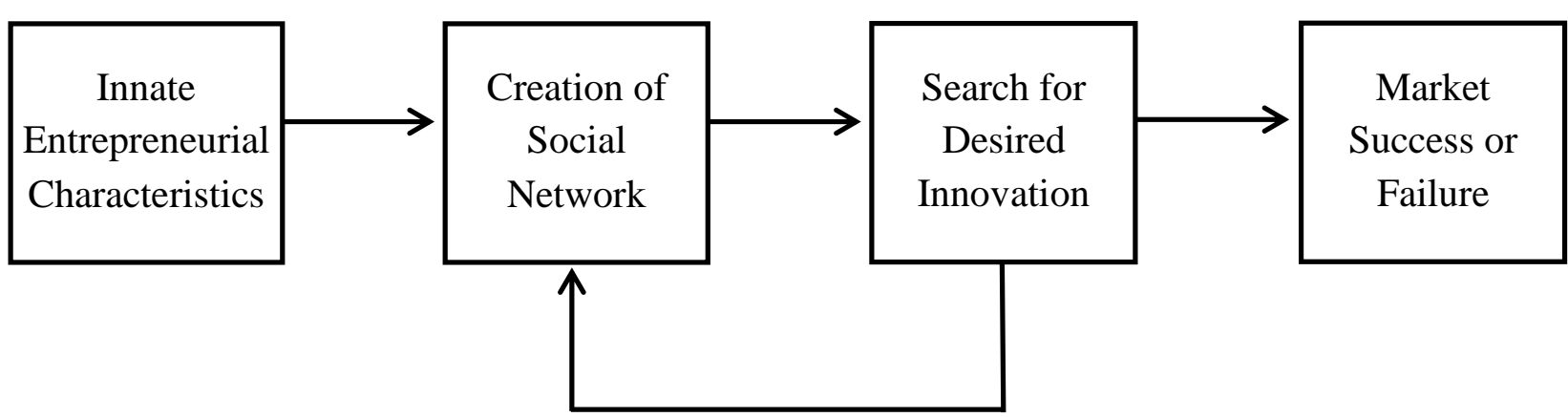

Source: Leyden \& Link (2014)

Given these motivations, the heart of the private sector innovation process (illustrated in Figure 1.2) can be thought of as an iterative two-step process of creation and discovery in which private sector entrepreneurs create social networks ${ }^{5}$ based on subjective expectations about the future effectiveness of those networks, choose an innovation to pursue, and then map out a search process to discover how to bring that innovation to fruition (Leyden \& Link, 2014). ${ }^{6}$

Key to a productive social network is the presence of what Granovetter (1973) and Burt (2005) refer to as strong ties (that is, a focused organization under the control of the entrepreneur) and weak ties (that is, a diffused range of contacts that have a heterogeneous set of knowledge and perspectives). These ties, which make up the private sector entrepreneur's social network, allow the entrepreneur to generate the social capital (that is, knowledge) that is used to identify and bring to fruition an innovation.

The success of the innovation is ultimately determined in the marketplace. Through the competitive process, the entrepreneur learns/receives feedback about the value (or lack thereof) that society places on the innovation through the generation of profits (or losses). Important, of course, to that process is a system of well-defined property rights and access to capital. For entrepreneurs in developed economies, the need for a system of competitive markets with well-defined property rights and access to capital is generally met, and thus current innovation policy tends to focus on stimulating the creation and exploitation of social networks (Leyden \& Link, 2015). ${ }^{7}$ However, in underdeveloped economies, the need for competitive markets, well-defined property rights, and access to capital may be a more fundamental concern. ${ }^{8}$

Innovation is typically associated with small, nascent firms (Acs \& Audretsch, 1998) which can be explained by the relatively greater presence of weak ties (those most closely associated with creative processes) in such firms. Large firms by contrast have a greater

\footnotetext{
${ }^{5}$ The notion of a social network is also referred to as the social dimension of context in entrepreneurial literature (Hoang \& Antoncic, 2003; Welter, 2011; Zahra \& Wright, 2011) and as creative cognition in psychology literature (Ward, Smith, \& Finke, 1999; Shalley \& Perry-Smith, 2008).

${ }^{6}$ There is a long debate (Alvarez \& Barney, 2007) over whether entrepreneurial activity is essentially one of discovery (most notably associated with Kirzner, 1985) or creation (most notably associated with Schumpeter, 1934). However, as Leyden and Link (2014) argue, the debate is a false one. In reality both discovery and creation are present in the entrepreneurial process.

${ }^{7}$ That is not to say that there aren't issues with regard to the quality of property rights and access to capital. Witness, for example, debates about appropriate patent policy and about access to capital for startups

${ }^{8}$ See, for example, Banerjee, Chandrasekhar, Duflo, and Jackson (2013) for an examination of micro financing.
} 
presence of strong ties (needed to exploit existing business opportunities), and hence relatively fewer weak ties. With increased firm size and the greater presence of strong ties (both in absolute and relative terms), individuals becoming separated from the profit motive of the firm and more susceptible to what Burt (2005) refers to as echo and rigidity (in more common terms, group think). ${ }^{9}$ And this results in a general resistance to change by both management and the firm's bureaucracy.

Despite such factors, however, empirical evidence reveals that large firms do in fact engage in innovation, though they may be less efficient at it (Ketchen, Ireland, \& Snow, 2007; Cohen, 2010, Zemplinerova \& Hromadkova, 2012). Common mechanisms for overcoming the natural tendency toward rigidity include the establishment of such things as more formal research processes and larger Research and Development $(\mathrm{R} \& \mathrm{D})$ budgets.

\subsection{How is public sector innovation different}

Despite the common belief that the public sector is not amenable to innovation, recent research (Sahni, Wesson, \& Christensen, 2013; Leyden \& Link, 2015) finds that in fact innovation is taking place in the public sector in a variety of ways and that it is tied to a public sector version of the entrepreneurial activity that is so important to innovation and economic growth in the private sector. In a comprehensive review of public sector entrepreneurship literatures in a variety of academic disciplines (economics, management, political science, and public administration), Leyden and Link conclude that the essential character of public sector entrepreneurship is the same as its private sector counterpart.

Public sector entrepreneurs are innovators who willingly bear the special type of risk that arises from uncertainty, that is, they are those who perceive an opportunity heretofore unexploited and who act on that opportunity.

What differs is the institutional environment in which the public sector entrepreneur operates, and this has implications for the nature of the public sector entrepreneur's motivation and reward, access to capital, and ability to act. While the general desire for personal benefits may be the same for the public sector and private sector entrepreneur, those benefits for the public sector entrepreneur typically manifest themselves in terms of recognition and career enhancement rather than monetary entrepreneurial profits. But the desire to create and to achieve is fulfilled in much the same way as for the private sector entrepreneur, though perhaps associated more with the satisfaction that comes from contributing to the common weal than a private sector entrepreneur would have.

When it comes to access to capital and the ability to act, there are more significant differences. Constitutional and legal constraints may reduce access to funding as well as restrict the ability to act by precluding certain activities, exposing efforts to public scrutiny, and generally slowing down the entrepreneurial process. There are also political constraints that function much the same way and that are due to the general public, and therefore elected and appointed officials, having little taste for the uncertainty and chance of failure associated with entrepreneurial activity. Whether such constraints, which are inherent in the principles of democratic government and responsible public administration, preclude public sector entrepreneurial action is a point of dispute among analysts. Bellone and Goerl (1992),

\footnotetext{
${ }^{9}$ Aulet, dos Santos, Poulsen, \& Wagner (2010) provide a more detailed description of the ways these barriers to innovation manifest themselves: fear of harming existing revenue streams, desire for low risk returns to capital, lack of managerial skill in creative pursuits, and a fear of personal failure by individual managers
} 
however, argue forcefully that such action can and ought to be an integral part of the public sector. $^{10}$

Despite such constraints, however, the range of public sector entrepreneurial activities is broad. Such activities can be categorized as either direct or indirect public sector entrepreneurship. Direct public sector entrepreneurship operates inside the public sector environment and is manifest in the innovative manipulation of that environment (particularly the expenditure, management, and service mechanisms of government), for the public good. Examples of direct public sector entrepreneurship include the creation of new governmental goods and services, improvements in the quality of existing governmental goods and services, increased efficiencies in the production of government goods and services, and improved management of governmental processes. By contrast, indirect public sector entrepreneurship operates by innovatively altering the private sector economic environment to induce desirable behaviours on the part of private sector entrepreneurs, again for the public good. Examples of indirect public sector entrepreneurship are typically manifest in innovative changes in private sector rules of the game (that is, changes in laws, regulations, etc.) that often focus on increasing private sector economic growth and stimulating private sector production of public goods and services through such innovations as privatization and social entrepreneurship.

The focus of this volume is primarily on direct public sector entrepreneurship, though stimulation of private sector production of public goods and services through privatization and social entrepreneurship are also of interest. Keeping in mind that applying known, triedand-true methods where outcomes are predictable (at least probabilistically), is not entrepreneurial though it may be good managerial practice - we can divide direct public sector entrepreneurial activities into three groups:

- Revenue enhancements - finding new sources of revenue,

- Public sector production innovations - providing the same goods and services at lower cost, and

- Public sector output innovations - improving the quality or range of goods and services.

Revenue enhancements, despite a sizable literature in the political science and public administration literatures on the issue (Bellone \& Goerl, 1992), is of limited value to the discussions here because they don't result in qualitative or quantitative productivity improvements in government except perhaps in the relatively narrow domain of revenue collection.

Public sector production innovations, however, are relevant and can take a variety of forms changes in management structures, changes in physical production processes, and changes in delivery systems. In recent years much emphasis has been placed on digitization (that is, eGovernment), throughout the public sector particularly with respect to record keeping, making information available to the public, and "customer" service (for example, voting, voter registration, paying taxes, and issuing licenses). There are, to be sure, reasons for caution with regard to digitization. Particularly with respect to the digitization of services, such innovation has the potential for increasing the level of fraudulent behaviour by those

\footnotetext{
${ }^{10}$ For a sense of the counter argument, see Terry (1993, p. 394) who argues that public sector entrepreneurship is inherently and unavoidably in conflict with democratic values and responsible government administration because of its "heavy reliance on domination and coercion, a preference for revolutionary change (regardless of circumstances), and a disrespect for tradition." As this chapter reveals, this argument is based on a fundamental mischaracterization of the entrepreneurial and innovation process.
} 
using these services. However, resistance to digitization may also occur for more selfish reasons. Control of information and governmental processes is a standard mechanism for bureaucratic control, legal or otherwise. Because digitization raises the possibility of diminished bureaucratic control (and diminished public corruption if present), such innovations may be met with resistance by those within the public sector.

Public sector output innovations are also relevant but are perhaps the most problematic because they deal with the fundamental decision of what goods and services are to be provided by the public sector, a decision that in a democratic society typically rests ultimately with the legislature. While legislatures can, and do, delegate some of their discretion in this regard, there are limits to such delegation. Witness, for example, recent tensions between the US Congress and the US President regarding innovations in health care services and immigration policy.

\subsection{Creating an innovative public sector environment}

Given the uncertain nature of the innovation process, it is not possible to characterize the ideal level of public sector innovation. However, it is possible to characterize the institutional conditions necessary for generating innovation in the public sector, that is, for assuring opportunity recognition and exploitation in the public sector. To understand the nature of these conditions, consider first in detail why a private sector model of innovation cannot be applied directly to the public sector. Figure 1.3 provides a summary of these challenges along with public sector environmental changes to address these challenges. 
Figure 0.3 Creating an innovative public sector environment

Challenge

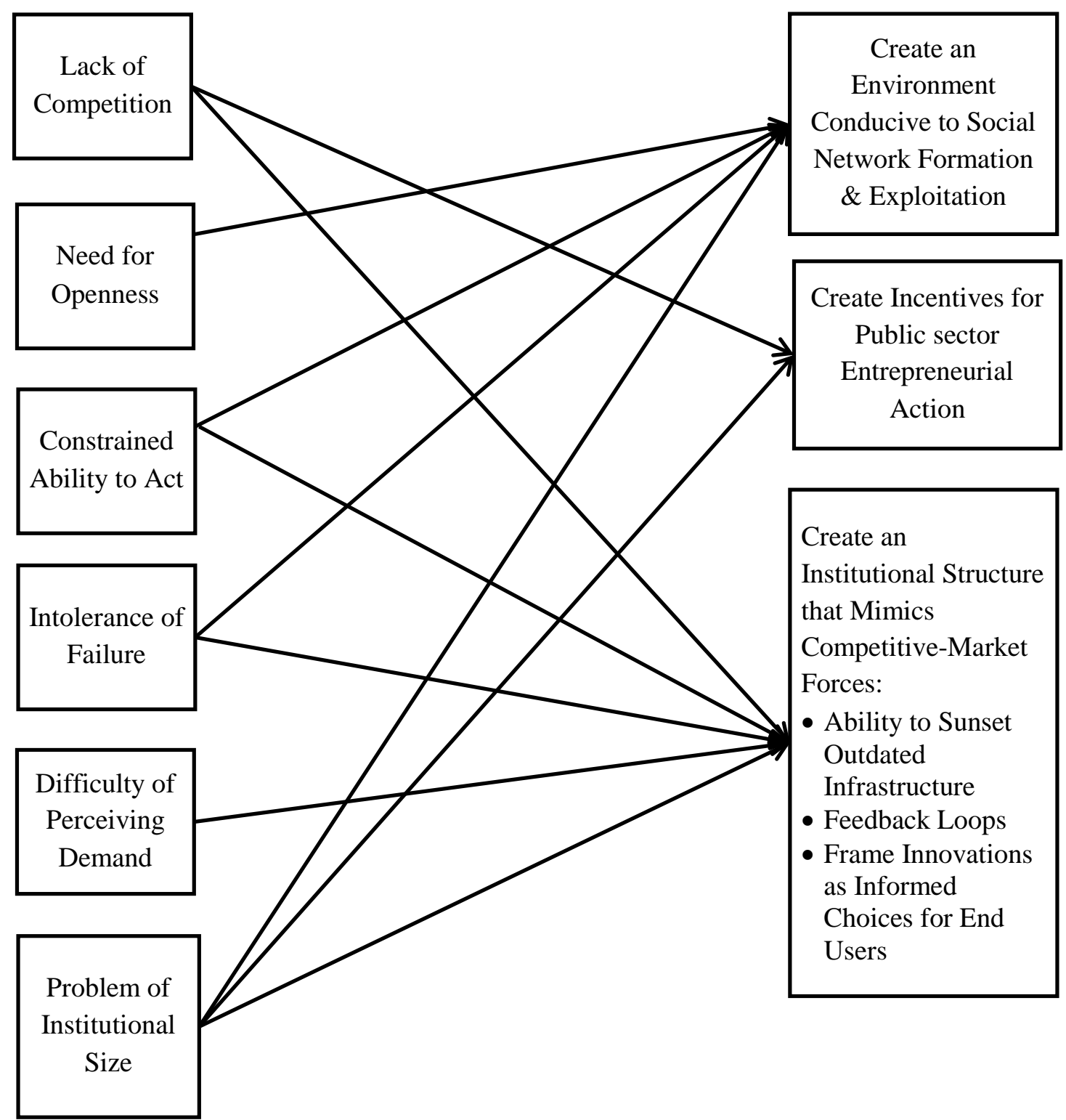

Source: See text

\subsection{Why cannot a private sector model of innovation be applied directly to the public sector?}

\section{Lack of competition}

The desire for success, the promise of financial reward, and the fear of failure that lie at the heart of the private sector entrepreneurial process and that generate innovation, are factors in large part fostered by the creative destruction process that is the competitive market. Innovations that are of value in the marketplace are quickly scaled up and supplant goods and 
services now considered inferior by the market; likewise, innovations that are not valued by the market are quickly eliminated.

The public sector, by contrast, is typically a more stable environment without such competition. Indeed, competition is often viewed as a destructive force in the public sector. Such a view is not without reason. Particularly in a democratic society, success requires that competing views be brought together for the greater common good. But that need for social cohesion reduces the ability of the public sector to encourage innovation through the promise of reward and the threat of failure.

The one notable exception to the lack of competition in the public sector is the competition that occurs between local governments in their attempts to attract residents (Tiebout, 1956). While not as complete as that which exists in the private sector, this competition (which has come to be termed voting-with-the-feet), can result in important efficiencies in the delivery of local public sector goods and services. Mueller (2003) provides a comprehensive review of this argument and the related literature.

\section{Need for openness}

Private sector entrepreneurial activity, which generates the innovations that are so valuable, depends on recognizing what others miss (Knight, 1921). Indeed, it is precisely this ability that creates the entrepreneurial returns that motivate the entrepreneur to innovate. But such aptitude often depends on the ability to act in secrecy. As Bellone and Goerl (1992), argue, democratic institutions generally require a sufficient level of openness to maintain trust with citizens and that makes such secrecy a difficult element to achieve.

\section{Constrained ability to act}

As Schumpeter (1928) emphasized, the ability and willingness to act in the face of opportunity is a distinguishing characteristic of the entrepreneur. But democratic accountability generally requires that such autonomy be constrained in the public sector (Bellone \& Goerl, 1992). As a result, action in the public sector more often than not requires that others (superiors or other branches of government) be informed beforehand and give explicit approval to the action. Add to this a requirement that approved actions follow prescribed procedures (labeled, at its worst, as red tape), and the result is that innovation becomes more difficult to conduct.

\section{Intolerance of failure}

Private sector entrepreneurs willingly take on the risks of uncertainty and the associated chance of failure because it is only through such action that they may achieve the success and profits that they desire. By contrast, in the public sector such exposure to possible failure is seen as being irresponsible; being a good steward of the public good becomes the standard. Add to this the more tenuous link between effort and reward in the public sector and the fact that funding in large part is not voluntary but instead the result of taxation, and the result is that those in the public sector often tend to be risk-averse and intolerant of failure. That is not to say that risks are never taken. But such exposure is more measured and, in keeping with justifiable democratic principles, often only undertaken after public buy-in (Bellone \& Goerl, 1992). 


\section{Difficulty of perceiving demand}

In the private sector, entrepreneurs quickly learn whether the innovation that they have developed is of value through the market process. Profits indicate the innovation is of value and encourage the entrepreneur to increase the delivery of the innovative good or service; losses indicate the innovation is not valued and lead the entrepreneur to reduce production (perhaps to the point of elimination). But this market mechanism does not in general exist in the public sector. To be sure, elections provide some feedback, but because they typically centre on a number of issues and occur infrequently, they do not provide useful feedback for assessing the value of individual policies. Add to this problem the fact that the delivery of goods and services in the public sector is typically separated from the funding mechanism, and the result is that those in the public sector have only a vague sense of the value of the goods and services that they provide. The one possible exception is the delivery of local public sector goods and services by local governments in competition with each other for residents.

\section{Problem of institutional size}

Finally, there is the problem of institutional size. Certainly, this problem is not unique to the public sector, but it is common enough to warrant mention. Many public sector organizations, particularly those at the national level, are quite large (military establishments, health care programmes, and education systems are examples that come to mind) and with that size comes difficulties of organizational management and motivation that are a significant impediment to innovation. As argued in the discussion of innovation in the private sector, these problems are due to the particular structure of the organization (in particular its mix of weak and strong ties), and how the organization manages the flow of knowledge and the interests of those in the organization. As a result, much like large firms in the private sector, there are inherent forces in large public sector organizations that work against innovation.

\subsection{What are the necessary conditions for public sector innovation?}

As the above list suggests, the difficulty with stimulating innovation in the public sector is not the lack of innovative opportunity but rather an institutional environment that does not allow for the recognition and exploitation of such opportunities. However, as successful public sector innovations reveal (Sanhi et al., 2013; Leyden \& Link, 2015), it is possible to develop a more innovative public sector by creating an environment conducive to social network formation and exploitation, creating incentives for entrepreneurial action, and creating an institutional structure that mimics competitive market forces. See Figure 3.

\section{Create an environment conducive to social network formation and exploitation}

As with the private sector, public sector innovation requires a collection of strong and weak ties (what above is called the entrepreneur's social network), that is the source of the creativity needed to generate new ideas and see them through to fruition. As a result, if public sector creativity is fostered, it requires developing an environment in which such ties can be created and exploited, what Sahni et al. (2013) refer to as creating "white space" in which to experiment.

The specific form of that environment can vary. Thus, for example, we can speak in terms of structures in which those in the public sector can experiment with changes, create prototype goods or services, or conduct pilot programmes. Typically, such environments start small and at a level low enough to be close to those who will benefit from the resulting innovation. But, 
as Sahni et al. emphasize, it is important to structure such environments and the ensuing activities in a way that does not disrupt the flow of current goods and services to citizens, keeping costs low, and embedding costs in existing budgets to avoid giving rise to debilitating scrutiny in the name of openness and to concerns over failure. If successful, these efforts reduce the constraints on the would-be public sector entrepreneur and thereby enable that entrepreneur in essence to investigate possible innovations and develop them so that they become viable.

Finally, it needs to be emphasized that the best of intentions will be for naught without legal and administrative support (both managerial and material), from the top down - which is most likely to be successful if that support is part of a systemic cultural change in the public sector.

\section{Create incentives for public sector entrepreneurial action}

Of course, creating an environment in which the public sector entrepreneur can engage in the innovation process has limited value if there is no incentive to engage in that innovation process. To be sure, the personal satisfaction that comes from serving the common weal is of some value as a motivating force. But that force is limited unless reinforced with other forms of incentive. Among those other forms of incentive are individual and organization recognition, opportunities for career advancement, re-appointment or re-election (depending on the nature of the position held in the public sector), and the benefits that spillover from the innovation to other parts of the individual's or organization's responsibilities. Examples of such spillovers include innovations that reduce the cost of delivering goods or services and thereby free up resources for other obligations, innovations that result in end users having less need for other public services, and innovations that serve as a complement to other public sector activities thereby increasing the value of those activities. Together all these incentives can serve as a useful substitute for the role that profits play in the private sector in inducing acts of innovation, but as noted for the case of creating an environment conducive to the formation and exploitation of social networks, critical to the success of such changes is legal and administrative support from the top down.

\section{Create an institutional structure that mimics competitive-market forces}

As the phrase creative destruction suggests, innovation through the competitive process often results in the elimination of older institutions, methods of production, and goods and services. In the public sector, however, the fear of failure often leads to highly conservative attitudes toward public sector institutions and policies. One way to avoid such problems, as Sahni et al. (2013) suggest, is to wait until the innovation is fully vetted and functioning (which makes experimentation all the more important), and to devise changes so as to hold harmless those such as end users and public sector employees affected by the changes.

Another important characteristic of competitive markets is that they provide entrepreneurs with valuable feedback as to the value of their efforts. To create a substitute in the public sector for this feedback, a variety of options are available among which include appropriately designed experiments, prototypes, pilot programmes that involve getting feedback for end users by direct observation of their behaviour or through such mechanisms as surveys, focus groups, and public meetings. In addition, a mechanism that holds great promise is that of eGovernment which generally facilitates communication between the public sector and its citizenry. Particularly when combined with social networking (not to be confused with entrepreneurial social networks discussed above), e-Government has the potential to greatly increase the ability of those in the public sector to receive feedback. 
A third important characteristic of competitive markets - because of its implications for consumer satisfaction - is the freedom of choice that buyers have. To mimic this in the public sector, one can, as Sahni et al. (2013) suggest, change the public sector environment by being sure to frame innovations for end users as matters of informed choice. ${ }^{11}$ Thus, for example, one can offer an innovative service improvement without eliminating the original service and allowing end users to choose. Such framing is important both because it can serve as the precursor for additional feedback and because it provides a way of overcoming citizen risk aversion (or fear of failure) and gives them a sense of choice. Interestingly, to the extent such framing leads to a more satisfied citizenry, the potential for such satisfaction can serve as an additional incentive for the public sector entrepreneur to engage in innovation.

\section{The problem of institutional size}

Finally, there is the problem of institutional size. As noted above, this is a problem shared with large private sector firms. In many ways, the problems associated with size are due to the intensification of the other problems described above. Nonetheless, in its essence the problem of size finds its origins in the imbalance of strong and weak ties that leads to organizational rigidity and thereby a lack of innovation. However, as also noted above, large private sector firms, while less efficient at innovation than smaller firms, also engage in innovative activities though the implementation of more formal mechanisms and greater funding to assure that innovation takes place.

Aulet et al. (2010) describe three programmes adopted by large private sector firms (Danfoss Ventures, Hewlett Packard, and Qualcomm), that have overcome the challenges that large firms face when trying to innovate - and that provide interesting models for public sector organizations that wish to innovate. In the programmes described by Aulet et al., employees, with managerial and resource support, propose innovations that improve the internal management of the firm or create new business opportunities. The best proposals are evaluated by top management, and from among these top proposals some are chosen for further development and implementation. Among the incentives for employees to put together a proposal are the possibility of career advancement and the possibility of managing the accepted innovation. The keys to success for these programmes are the presence of a high level of personal, managerial, and material support for innovation by top management and the presence of clear programme objectives, sufficient resources, and a willingness of the programme to accept failure.

Another possible approach to the problem of size is to develop innovation labs and accelerators within the organization. Such efforts leverage the firm's robust organizational strength (that is, its strong ties), to create entrepreneurial social networks through the creation of (weak) ties with others outside the firm. Notable examples include the Nike+ Fuel Lab (Nike, 2014), Samsung's Smart Things Innovation Lab (Samsung Research America, 2014), AT\&T's Foundry Innovation Centers (AT\&T, 2014), and the (public sector) US National Science Foundation's Innovation Corps (I-Corps). TheI-Corp programme, in particular, is an example of an indirect public sector entrepreneurship programme that is focused on increasing the commercialization of new technology developed through National Science Foundation-funded research. Key components of this programme include I-Corps Teams (the principal investigator and an entrepreneurial lead), I-Corps Nodes (a mechanism for involving academic scientists and engineers), and I-Corps Sites (academic institutions that act as matchmakers for collections of teams and the potential beneficiaries of team commercialization projects). While the objective of commercialization is not relevant to the

\footnotetext{
${ }^{11}$ Sahni et al. (2013) refer to this as creating "budget constraints for end users."
} 
direct public sector entrepreneurship issues being explored here, the structure of this programme with its emphasis on networking, mentoring, and various types of support is relevant.

Finally, a third approach for dealing with the problems of a large organization, exemplified by the organization Prebacked, is to create an organization that serves as a matchmaker, pairing up large organizations and small entrepreneurs to work together on a defined largefirm need (Prebacked, 2014; Puri, 2014).

\subsection{Conclusions}

Public sector innovation, like its private sector counterpart, is driven by goal-oriented entrepreneurial behaviour. And like its private sector counterpart, engaging in public sector innovation is a creative process characterized by uncertainty. Necessary to that public sector innovation process are: An ability to create and exploit an entrepreneurial social network, the presence of incentives to engage in the innovation process, and institutional arrangements that mimic the important forces in private sector competitive markets. And all this requires sufficient legal and administrative support (both managerial and material), to establish and maintain these changes. The most effective support is that which is embedded in a broader cultural change in the public sector. Such change is, no doubt, not easy. But it has the potential for significant benefits for societies and, as empirical examples demonstrate, it is possible. 


\subsection{References}

Acs, Z.J., and D.B. Audretsch, Innovation in large and small firms: an empirical analysis, American Economic Review, 1988, 78(4), 678-690.

Alvarez, S.A., and J.B. Barney, Discovery and creation: alternative theories of entrepreneurial action, Strategic Entrepreneurship Journal, 2007, 1(1-2), 11-26. doi: $10.1002 /$ sej.4

AT\&T, AT\&T Foundry, available at: http://www.att.com/gen/press-room?pid=2949, 25 September 2004

Aulet, W.K., R. dos Santos, S. Poulsen, and W.R. Wagner, Driving innovation in large corporations: harnessing the power of proven entrepreneurial techniques to drive innovation in a large company, MIT Entrepreneurship Review, available at: http://miter-

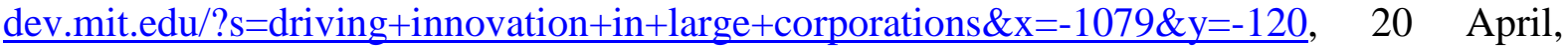
2010

Bellone, C.J., and G.F. Goerl, Reconciling public entrepreneurship and democracy, Public Administration Review, 1992, 52, 130-134

Cantillon, R., Essai sur la nature du commerce en général, H. Higgs, Ed. \& Trans., 1931, London, Macmillan, Originally published 1755

Banerjee, A., A.G. Chandrasekhar, E. Duflo, and M.O. Jackson, The diffusion of microfinance, 2013, Science 341(6144), 1236498, doi:10.1126/science.1236498

Burt, R.S., Brokerage and closure: an introduction to social capital, Oxford: Oxford University Press, 2005

Cohen, W.M., Fifty years of empirical studies of innovative activity and performance, In B. H. Hall and N. Rosenberg (Eds.), Handbook of the economics of innovation, volume 1, 2010, Amsterdam: Elsevier. doi: 10:1016/S0169-7218(10)01004-X

Granovetter, M.S., The strength of weak ties, The American Journal of Sociology, 1973, 78(6), 1360-1380

Hébert, R.F., and A.N. Link, A history of entrepreneurship, 2009, London: Routledge

Heritage Foundation, Macro-economic data (Database: Index2013_data.xls), 2013, retrieved from http://www.heritage.org/index/explore?view=by-variables

Hoang, H., and B. Antoncic, Network-based research in entrepreneurship, Journal of Business Venturing, 2003, 18, 165-187

Ketchen Jr, D.J., R.D. Ireland, and C.C. Snow, Strategic entrepreneurship, collaborative innovation, and wealth creation, Strategic Entrepreneurship Journal, 2007, 1, 371-85

Kirzner, I.M., Discovery and the capitalist process, Chicago: University of Chicago Press, 1985

Knight, F.H., Risk, uncertainty, and profit, Boston: Houghton Mifflin, 1921 
Leyden, D.P., and A. N. Link, Public sector entrepreneurship: US technology and innovation policy, 2015, New York: Oxford University Press

Leyden, D.P., and A.N. Link, Toward a theory of the entrepreneurial process, Small Business Economics, 2003, doi: 10.1007/s11187-014-9606-0

Mueller, D.C., Public choice III, Cambridge, UK: Cambridge University Press, 2003

Nabseth, L., and G.F. Ray, The diffusion of new industrial processes: an international study, 1974, New York: Cambridge University Press

National Science Foundation (n.d.), NSF Innovation Corps, available at: http://www.nsf.gov/news/special_reports/i-corps/index.jsp

Nike, Nike+ Fuel Lab, available at: http://www.nikefuellab.com/ on April 102014

Prebacked, Accelerators get you funded, Prebacked gets you customers, available at: www.prebacked.com on 25 September 2014

Puri, R., 'Reverse accelerator' spurs innovation with less risk, available at: http://techpageone.dell.com/business/reverse-accelerator-spurs-innovation-with-lessrisk/\#.VCSISEBwDwm, 8 September 2014

Sahni, N.R., M. Wessel, C.M. Christensen, Unleashing breakthrough innovation in government, Stanford Social Innovation Review, 2013, 11, 27-31

Samsung Research America, Smart Things Innovation Lab. retrieved from http://www.sisa.samsung.com/research-lab/smart-things-innovations-lab on 25 September, 2014

Schumpeter, J.A., The instability of capitalism, Economic Journal, 1928, 38, 361-386

Schumpeter, J.A., The theory of economic development (R. Opie, Trans., from 2nd German edition, 1926). 1934, Cambridge: Harvard University Press

Schumpeter, J.A., Capitalism, socialism and democracy, 3rd edition, 1950, New York: Harper and Row

Shalley, C.E., and J. E. Perry-Smith, The emergence of team creative cognition: the role of diverse outside ties, sociocognitive network centrality, and team evolution, Strategic Entrepreneurship Journal, 2008, 2, 23-41

Streitfeld, D., As boom lures app creators, tough part is making a living, 2012, retrieved from http://www.nytimes.com/2012/11/18/business/as-boom-lures-app-creators-tough-part-ismaking-a-living.html

Terry, L.D., Why we should abandon the misconceived quest to reconcile public entrepreneurship with democracy: A response to Bellone and Goerl's 'Reconciling public entrepreneurship and democracy', Public Administration Review 1993, 53, 393-395

Von Thünen, J.H., The isolated state in relation to agriculture and political economy, vol. 2, B. W. Dempsey, Trans., 1960, Chicago: Loyola University Press, originally published 1826

Tiebout, C.M., A pure theory of local expenditures, Journal of Political Economy, 1956, 64, 416-424, available at: http://www.jstor.org/stable/1826343 
Ward, T.B., S.M. Smith, and R.A. Finke, Creative cognition, in J. Sternberg (ed.), Handbook of creativity. 1999, New York: Cambridge University Press, 189-212

Welter, F., Contextualizing entrepreneurship: conceptual challenges and ways forward. Entrepreneurship Theory and Practice, 2001, 35, 165-178

Zahra, S.A., and M. Wright, Entrepreneurship's next act, Academy of Management Perspectives, 2011, 25, 67-83

Zemplinerova, A., and E. Hromadkova, Determinants of firm's innovation, Prague Economic Papers, 2012, 21(4), 487-503, available at: http://www.vse.cz/pep/ 


\section{Chapter 2}

\section{Towards A Better Understanding of Public Sector Innovation - Piloting the European Public Sector Innovation Scoreboard}

Tomasz Jerzyniak, European Commission, Directorate-General for Enterprise and Industry ${ }^{12}$

\subsection{Public sector matters}

The public sector accounts for a significant share of economic activity and plays a key economic role as regulator, service provider, public procurer and employer. It accounts for more than 25 per cent of the total employment in the European Union (EU) and it sets and implements rules and regulations that directly impact on citizens, business activity and competitiveness of the overall economy.

The key role of the public sector in the economy, and in particular public administration, has been well recognized and addressed by the European Commission. The pressing need for more responsive and efficient public administration has been already reflected in the "Think Small First. A Small Business Act for Europe" (COM(2008) 394) that was launched in 2008 and called for cutting red tape and creating more conducive conditions to entrepreneurial activity and job creation.

More recently, the Annual Growth Survey 2014 (COM(2013) 800) that launches the European Semester of policy coordination for the third time in a row, recognized modernization of public administration as one of five key priorities, next to such pressing issues as growth-friendly fiscal consolidation, restoring lending to the economy, promoting growth and competitiveness and tackling unemployment and social consequences of the economic crisis. Apart from general recommendations for growth-friendly public sectors, several Member States received specific country recommendations to modernize their administrations.

In addition, over the past few years the Commission has been working towards reduction of the administrative and regulatory burden and has intensified its efforts to cut red tape to citizens and businesses. In 2013 it launched Regulatory Fitness and Performance Programme, REFIT (COM(2013) 685) with the aim to make EU law simpler, 'fit for purpose', and to reduce regulatory costs, so contributing to a clear, stable and predictable regulatory framework supporting growth and jobs.

With the "European e-Government Action Plan 2011-2015", in the context of its Digital Agenda for Europe, the European Commission has been promoting innovation in the public sector and a new generation of for business and citizens. The European regional policy has been supporting administrative capacity in order to strengthen the absorption and smart use of the European Structural and Investment Funds. The European Research Framework

\footnotetext{
${ }^{12}$ The opinions expressed in this article are those of the author alone and not necessarily those of the European Commission. The author has been coordinating and guiding 2011-2014 the launch of the pilot European Public Sector Innovation Scoreboards on behalf of the European Commission, Directorate-General for Enterprise and Industry.
} 
Programmes and successor "Horizon 2020," have been contributing with dedicated grants to research on public sector innovation; and a European Prize for Innovation in Public Administration was awarded in 2013. Several initiatives by the European Union in energy, transport, industry, health, environment and justice, promote renewal of the public sector through public-private partnerships, better regulations, efficient use of resources and empowerment of civil servants.

Modernization of public administration and the promotion of an efficient and innovative public sector is not a very new idea, but only recently has this important issue gained momentum. Although a lot has been already done at the European level, and there are plenty of success stories in the EU Member States, regions and cities, there are still significant efforts needed for the public sector to face successfully global, economic, social and security challenges.

\subsection{The need for a better understanding of public sector innovation}

However, in order to promote renewal and innovation in the public sector, more and better evidence is needed. Policy makers need a better understanding of conditions in which innovation in the public sector happens, specific incentives and barriers, as well as the channels through which the more innovative public sector benefits the economy. The economic situation in the EU in the wake of the financial and economic crisis put enormous pressure on the public sector. To recognize this pressure, the European Commission underlined explicitly the importance of public sector innovation in its Europe 2020 Innovation Union communication $(\operatorname{COM}(2010) 546)$, by stressing that to meet the evolving needs and expectations of public service users against the backdrop of fiscal austerity, the public sector needs to innovate more than ever. The communication also underlined the need to develop a better understanding of public sector innovation, to give visibility to successful initiatives, and benchmark progress.

As a consequence, the Commission committed to start and support substantial actions to explore public sector innovation looking at issues such as measurement and evaluation, financing and other barriers to scaling up and development. The pilot European Public Sector Innovation Scoreboard (EPSIS) was decided as the immediate step to build up a basis for further work to benchmark public sector innovation.

The Scoreboard approach has been already used in other policy areas and is considered not only a tool that provides statistical facts and analysis but also one that generates incentives for a positive competition between Member States. The EPSIS builds primarily on the experience of the Innovation Union Scoreboard (IUS, Commission 2014), previously the European Innovation Scoreboard (EIS). The first edition of the EIS (SEC(2001) 1414) was published in 2001 in response to an explicit request by the Lisbon European Council (European Council 2000). It was regarded as a tool of the Open Method of Coordination approach, adopted by the Lisbon European Council, and is based on the benchmarking of national initiatives - as the means of spreading best practice and achieving greater convergence towards the main EU goals. This new governance method is aimed at helping Member States to progressively develop their own policies based on common objectives and indicators, and by supplementing both legislative and financial instruments. In that context, the EIS has evolved since then and after the 2010 revision, the renamed Innovation Union Scoreboard continues providing annually a comparative assessment of the research and innovation performance of the EU Member States and the relative strengths and weaknesses of their research and innovation systems. The Scoreboard draws on 25 different indicators 
covering the complexity of the national innovation systems. The IUS is now a widely recognized benchmarking instrument that helps Member States assess areas in which they need to concentrate their efforts in order to boost innovation performance. It is also importantly to say that the IUS raises awareness and stimulates public debates on innovationrelated issues. In addition, and in order to help developing innovation policies at the regional level, the IUS is accompanied by a Regional Innovation Scoreboard every two years.

Undoubtedly, the Innovation Union Scoreboard has been contributing to a common understanding of innovation processes and better political awareness that innovation matters and is the key engine of long-term growth and competitiveness. Driven by the experience with the innovation scoreboards, a similar task was given to the European Public Sector Innovation Scoreboard that should encourage and facilitate innovation activity across the public sector in the EU.

\subsection{Measuring public sector innovations - key challenges and limitations}

However, as simple as it might have sounded, the task was anything but easy and quick to implement. The key challenges and limitations in developing the first scoreboard for public sector innovation were lack of EU-wide data and common definitions. Although the topic has been increasingly investigated in the last few years in the academic literature and by means of various analytical reports, the existing evidence is still rather anecdotal and limited to specific sectors or individual countries. While innovation in the business sector has been widely explored in the last decades and codified in the Oslo manual (OECD (Organisation for Economic Co-operation and Development) \& Eurostat, European Commission 2005) for the first time already at the end of 1980s, such guidelines do not exist for public sector innovation.

The key concern that immediately emerges when attempting to analyse the public sector by existing innovation theory standards is that public and private sectors differ from each other considerably. Due to these evident differences, the existing innovation concepts and definitions could have been applied only to a limited extent. Most prominently, the impact of successful innovations in the public sector tend not to be reflected in immediate financial outputs (NESTA, 2011) and market shares, simply because public organizations - typically the primary supplier of services - are not competing in order to maximize profits (Halvorsen et all., 2005). Another aspect that differentiates private and public sectors regards a much higher level of heterogeneity of the public sector. There are not only different levels on which public sector organizations operate, such as international, national, regional and local/municipal, but also the nature and scope of public sector activities show a very high variety. According to the Classification of Functions of Government (COFOG) ${ }^{13}$, there are ten broad objectives that the public sector pursues: General public services, Defence, Public order and safety, Economic affairs, Environmental protection, Housing and community amenities, Health, Recreation, culture and religion, Education, and Social protection. Each of these objectives is further subdivided into a set of more specific objectives that are addressed by a variety of public organizations, agencies and services, sometimes in cooperation with the private sector. Obviously, it does not seem opportune to compare e.g. a regional government or a ministry, with a school, a prison, a hospital or a public research institute. This government entanglement within and across countries called for targeted approaches in analysing and measuring innovation in the public sector.

\footnotetext{
${ }^{13}$ The COFOG classification was developed by the OECD in 1999 and applied by the United Nations; more on http://unstats.un.org/unsd/.
} 
Thus, the services of the European Commission faced two fundamental questions in preparing the pilot EPSIS that needed to be answered. Firstly, it had to be decided how to define innovations in the public sector. According to the Oslo Manual (OECD \& Eurostat, European Commission, 2005), the common feature of innovation in the private sector is that it must be implemented. A new or improved product (or service) is implemented when it is introduced on the market. New processes, marketing methods or organizational methods are implemented when they are bought into actual use in the firm's operations. These definitions were difficult to apply due to the lack of market mechanisms when "producing" goods or services by the public sector.

Secondly, to address the governance complexity there was the need to define the analytical object by answering questions about the government level at which the measurement of public sector innovation should take place (national, regional, local/municipal), the units of analysis (a central branch of the organization, the individual departments or other small functional units), and finally how to differentiate between the different roles of the public sector (government administration, health care, education, social services, defence, etc.,). For example, in the case of a national ministry, should the ministry as a whole be a subject of analysis or rather its individual departments or individual units?

The services of the Commission analysed a number of previous studies, organized a series of expert meetings and concluded an agreement with the OECD to explore how this complexity could be addressed. Two studies were particularly helpful in shedding light on this issue: "A pilot survey for measuring innovation across the public sector" by NESTA (NESTA, 2011) and Measuring Public Innovation in the Nordic Countries' MEPIN (Bugge et. al.) ${ }^{14}$. The NESTA study was a pilot survey conducted in 2010 among two areas of UK government: 64 organizations of the National Health Service (NHS) and 111 local governments. The MEPIN study had a wider geographical scope and surveyed 1,430 public sector organizations in Denmark, Finland, Iceland, Norway, and Sweden. The investigated organizations were national or regional governments as well as a limited extension to public hospitals and schools. For both studies the Oslo manual definitions of innovation and the well-established Community Innovation Survey constituted a point of departure in defining and conceptualizing the innovation and innovation activities in the public sector. For example, the MEPIN study used "communication innovation" instead of "marketing innovation", which is obviously more inherent to the commercial activity of a business. Both studies looked at issues such as Human Resources (innovation personnel and share of employment with tertiary education), Framework Conditions (drivers and barriers, involvement of staff and management), Types of Innovation (goods and services, process, organizational and communication), Resources for Innovation (expenditures, training, consultancy, etc.), Linkages (cooperation with and participation of other stakeholders in innovation projects, use of external information sources), Innovation Results and Public Procurement of Innovation.

\footnotetext{
14 The prime objective of the MEPIN project was to generate a better understanding of how to measure innovation in public sector contexts and to test the measurement framework with respect to validity, potential comparability and usefulness. In addition to generating new knowledge and improving the understanding of how to measure innovation in the public sector, the pilot study also provided a novel empirical result on public sector innovation. More on: http://www.nordicinnovation.org/Publications/measuring-public-innovation-in-the-nordiccountries-mepin/
} 


\subsection{Preparatory work and the need for new data}

In parallel and building on the existing evidence, the services of the European Commission decided to launch two new surveys to gather data directly from the concerned stakeholders. The first study, the Innobarometer 2010 (Commission, 2011), was a unique survey among 4,063 public administration organizations conducted in the 27 Member States of the EU as well as Norway and Switzerland. It was the first attempt ever to investigate public sector innovation in such a large geographical area. To tackle the complexity of the topic and due to limited availability of resources, the exercise was limited to a sample of government organizations that provide general public administration services and organizations that deal with regulation of the activities of providing health care, education, cultural services and other social services, excluding social security. More specifically, the sample covered organizations at level 84.11 and 84.12 of the NACE statistical classification ${ }^{15}$. In each of the larger Member States such as France, Germany, Italy, Poland, Spain and United Kingdom, around 400 organizations were surveyed, while the sample in Cyprus, Luxembourg and Malta included ten organizations in each country. The targeted respondents were senior managers responsible for strategic decision-making, typically general managers or relevant strategic directors. The Innobarometer 2010 followed the logic of the Community Innovation Survey and its main focus was on internal innovation activities in the public sector. However, the interviews were conducted by phone so that the length and complexity of the questions had to be reduced. No detailed questions were asked (e.g. as regards financial numbers), in contrast to the Community Innovation Statistics (CIS) questionnaires. More specifically, the survey looked at:

- Various types of innovation that were introduced in an organization (e.g. new methods of providing services to citizens, or new management systems and organization of internal work and processes), taking into account the involvement of different cooperation partners in implementing those innovations (e.g. private business, not-for-profit organizations or other public sector organizations);

- Work force and skills involved in implementing innovations and innovation activities (e.g. the share of employees directly involved in activities aimed at implementing innovations);

- Positive (and possibly negative) effects of innovation such as e.g. improved user satisfaction, faster delivery of services, simplification of administrative procedures, reduction of costs;

- Drivers to innovation, particularly to explore the incentives for innovation activities (e.g. ideas from management, ideas from staff, feedback from citizens or business enterprises, political mandate, new laws, regulations or policy priorities);

- Barriers to innovation with the aim of identifying obstacles to innovation, e.g. lack of management support, lack of incentives for staff, regulatory hurdles, lack of necessary human or financial resources;

\footnotetext{
${ }^{15} \mathrm{NACE}$ is the statistical classification of economic activities in the European Community and is the subject of legislation at the European Union level, which imposes the use of the classification uniformly within all the Member States. It is a basic element of the international integrated system of economic classifications, which is based on classifications of the UN Statistical Commission (UNSTAT), Eurostat as well as national classifications. More in "NACE Rev. 2 - Statistical classification of economic activates in the European Community”, http://epp.eurostat.ec.europa.eu/cache/ITY_OFFPUB/KS-RA-07-015/EN/KS-RA-07-015EN.PDF.
} 
- Public procurement with the aim to explore the role of public administration in driving innovation uptake through public contracts and to investigate if public procurement of innovation was used as a strategic tool to promote innovation uptake in society;

- Future trends and expectations as regards public sector innovation.

The key results demonstrated that in total $2 / 3$ of public administration organizations introduced a new or significantly improved service in the last three years and 17 per cent of them were classified as leading innovators. The survey also evidenced that innovations improved the work of public administrations: for example, 76 per cent of the surveyed organizations achieved improved user access to information due to service innovations; 71 per cent indicated improved user satisfaction, 63 per cent more targeted services and 61 per cent mentioned a faster delivery of services, 54 per cent offered new services to more or new types of users as a result of innovation. Further, 63 per cent noted that innovations simplified administration and 51 per cent confirmed cost reduction resulting from innovations. However, 78 per cent of the investigated organizations said that they lacked the necessary human or financial resources to advance with innovations. In addition, a rigid regulatory environment was recognized as an important barrier to innovation by 65 per cent of the organizations.

The second study, Innobarometer 2011 (Commission, 2012), assumed a different approach and focused on impact and perception of public sector innovation among companies, thus it explored public sector innovation from the user perspective. That approach was considered particularly relevant in the context of public administration modernization, which is an explicit priority of the Annual Growth Survey. A better understanding of the interactions between public administration and business activity would be highly valuable in the economic climate where public administrations across the EU have been facing the challenge to deliver "more with less". Simplifications of rules for business activity, reduction of red tape and improved quality of legislation are still key challenges to be met by the public sector to help spur entrepreneurship, growth and eventually competitiveness and job creation.

In total, the sample of the Innobarometer 2011 survey included 8,699 companies from the 27 EU Member States as well as Croatia, Iceland, Norway, the Former Yugoslav Republic of Macedonia, Turkey and Switzerland. Similarly to the previous Innobarometer, the sample size varied between countries, ranging from about 100 in the smallest to about 500 in the largest countries. Apart from a few general questions concerning business activity, the survey looked at

- The companies' use of various public services relevant to business activity and the improvement and innovativeness of those services as perceived by their users and;

- The perceived innovativeness of different levels of government and the impact of improved public sector services on business activity;

- Public procurement and innovation with a specific focus on the conditions and opportunities to sell innovative products to public organizations.

As a result, only 17 per cent of enterprises noticed that public services improved, while 48 per cent said they stayed the same, and 16 per cent reported that they even deteriorated. This however, varies extensively across Europe. The dominant opinion was that the public sector was not helping companies to innovate: only 40 per cent of enterprises were of the opinion 
that the public sector was doing a good job in creating the right conditions for innovation. While almost 70 per cent noticed the introduction of measures to enable the completion of government forms or to access information on government services, only 40 per cent noticed a reduction in time and effort needed to complete government forms, 25 per cent of enterprises noticed faster response times for government services and only 19 per cent noticed a reduction in the time required for the issue of permits or licences. Further, 87 per cent of companies said that public services should work harder at becoming more innovative. Regarding innovative public procurement, half of all enterprises considered price to be more important than innovation in a public tender, and only 24 per cent viewed innovation to be more important than price in winning a public tender.

\subsection{Towards a pilot European Public Sector Innovation Scoreboard}

The pilot European Public Sector Innovation Scoreboard published in June 2013 is the first attempt to understand innovation in the public sector across the EU. After a series of consultations with external experts and representatives of national governments ${ }^{16}$, it was decided that the pilot EPSIS should follow broadly the structure of the Innovation Union Scoreboard, i.e. consist of three groups of indicators:

- "Enablers", i.e. the basic building blocks which allow innovation to take place;

- "Activities", i.e. indicators that describe the actual innovation activities and direct drivers and barriers to innovation;

- "Outputs", i.e. indicators that show the results of public sector innovativeness.

Similarly to the IUS and taking into account the complexity of innovation, it was recognized that no single indicator was able, at least at that stage, to appropriately describe public sector innovation. As a result, a larger set of 22 indicators and seven thematic dimensions was employed in the pilot EPSIS.

Given the scarcity of available and well-established data that would explicitly measure innovation in the public sector, the two Innobarometers 2010 and 2011 constituted the main source of statistical information with the emphasis on innovation in public administration, excluding other public sectors. The pilot EPSIS, again due to the lack of sufficient statistical inputs, did not differentiate between different levels of public administrations either. The Innobarometer 2010 was particularly applicable for the development of indicators describing the actual innovation activities and analysing barriers and drivers to innovation in public organizations, whereas the Innobarometer 2010 was valuable in exploring innovation outputs, especially when describing the perceived effects of public sector innovations on business. Other indicators that were used in the pilot EPSIS were built from data sourced from the statistical office of the European Union Eurostat, the World Bank, United Nations, OECD and the World Economic Forum (Table 2.1). 16 The key workshop took place in Brussels in May 2012, for more information see:
http://ec.europa.eu/enterprise/policies/innovation/files/epsis/background-note_en.pdf 
Table 0.2 Indicators used in the pilot European Public Sector Innovation 2013

\begin{tabular}{|c|c|}
\hline Main group / innovation dimension / indicator & Data source \\
\hline \multicolumn{2}{|l|}{ ENABLERS } \\
\hline \multicolumn{2}{|l|}{ Human resources } \\
\hline 1.1.1 Employment share of 'creative occupations' & Eurostat \\
\hline $\begin{array}{l}\text { 1.1.2 Share of employees in public administration with a university } \\
\text { degree }\end{array}$ & Innobarometer 2010 \\
\hline \multicolumn{2}{|l|}{ Quality of public services } \\
\hline 1.2.1 Government effectiveness & World Bank \\
\hline 1.2.2 Regulatory quality & World Bank \\
\hline $\begin{array}{l}\text { 1.2.3 Increased efficiency of government services due to the use of } \\
\text { ICT }\end{array}$ & World Economic Forum \\
\hline 1.2.4 Online availability of public services & Eurostat \\
\hline 1.2.5 e-Government development index (EGDI) & United Nations \\
\hline \multicolumn{2}{|l|}{ ACTIVITIES } \\
\hline \multicolumn{2}{|l|}{ Capacities } \\
\hline 2.1.1 Share of service innovators that innovate in-house & Innobarometer 2010 \\
\hline 2.1.2 Share of process innovators that innovate in-house & Innobarometer 2010 \\
\hline \multicolumn{2}{|l|}{ Drivers and barriers } \\
\hline 2.2.1 Importance of internal barriers to innovation & Innobarometer 2010 \\
\hline 2.2.2 Importance of external barriers to innovation & Innobarometer 2010 \\
\hline 2.2.3 Active management involvement in innovation & Innobarometer 2010 \\
\hline 2.2.4 Importance of external knowledge & Innobarometer 2010 \\
\hline $\begin{array}{l}\text { 2.2.5 Share of employees involved in groups that meet regularly to } \\
\text { develop innovations }\end{array}$ & Innobarometer 2010 \\
\hline \multicolumn{2}{|l|}{ OUTPUTS } \\
\hline \multicolumn{2}{|l|}{ Innovators } \\
\hline $\begin{array}{l}\text { 3.1.1 Share of organizations in public administration with services, } \\
\text { communication, process or organizational innovations }\end{array}$ & Innobarometer 2010 \\
\hline 3.1.2 Share of 'new' services out of all service innovations & Innobarometer 2010 \\
\hline 3.1.3 Public sector productivity & OECD \\
\hline \multicolumn{2}{|l|}{ Effects on business performance } \\
\hline 3.2.1 Improvements in public services for business & Innobarometer 2011 \\
\hline 3.2.2 Impact of innovative public services on business & Innobarometer 2011 \\
\hline \multicolumn{2}{|l|}{ Government procurement } \\
\hline 3.3.1 Government procurement as a driver of business innovation & Innobarometer 2011 \\
\hline 3.3.2 Government procurement of advanced technology products & World Economic Forum \\
\hline 3.3.3 Importance of innovation in procurement & Innobarometer 2011 \\
\hline
\end{tabular}

Source: Pilot European Public Sector Innovation Scoreboard 2013

In the first group of indicators, Enablers, the pilot EPSIS looks at human resources and the quality of public services that capture the basic foundation for innovation to happen. The underlying assumption was that public organizations with a higher share of creative 
occupations and a higher share of employees with a further education degree would be more likely to generate innovations. In the same way, organizations with higher effectiveness and regulatory quality, meaning e.g. the capacity of the civil service and its independence from political pressures, the quality of policy formulation, as well as the ability of the government to provide sound policies and regulations creating an environment conducive to innovation. In addition, a better developed Information and Communication Technology (ICT) environment would be not only an enabling factor in the organization but also contributory to innovation in the business sector and civil society.

The second group of indicators, under the somewhat elusive heading of Activities, represents the internal innovation activities of a public administration organization. The first two indicators look at the capacity of an organization to develop services or process innovation in-house. In this way the indicators show the endogenous capabilities of an organization to generate new solutions for customers (service innovation) as well as for the organization itself (process innovations). The remaining indicators pay heed to obstacles and incentives when innovating or attempting to innovate. The Drivers and barriers dimension looks at the importance of internal and external barriers, involvement of management, importance of external knowledge and the presence of dedicated innovation working groups. In organizations with high internal (e.g. lack of incentives for staff to innovate), or external barriers (e.g. regulatory requirements), innovation is certainly less likely to happen. Thus, the barriers are considered proxies for lower innovation activity and subsequently lower scores in the overall analysis. Presenting another point of view, higher active support from management, more intensive use of external knowledge and the presence of intentional teams tasked with development of new ideas are regarded as proxies for higher innovation activities.

The third group of indicators, simplistically called Outputs tries to elucidate the results of innovation activities as perceived by both the public administration itself and business users, and in forms of public procurement of innovation. Three aspects were examined in this group: firstly, the introduction of new or significantly improved services, communication methods, processes and organizational methods as well as improvement in productivity; secondly, the perception of business users, i.e. the perceived improvements and their impact on business performance; thirdly, public procurement of innovation. The latter aspect is a central issue when it comes to stimulating innovation in public services and through public services. On the one hand, the procurement of innovative goods and services can be a key driver of the modernization of the public sector. On the other hand, it can accelerate the market uptake of innovative goods and services by finding first customers for innovative companies. In that context, public authorities have a very significant role to play in stimulating growth and jobs via the use of public procurement of innovation.

\subsection{The pilot EPSIS 2013: The results, key messages and limitations}

The first edition of the report should be considered experimental; however, it is sufficient to give a sense of the strengths and weaknesses across countries. Furthermore, it does not capture all parts of the public sector or all aspects of innovation. Finally, the pilot EPSIS 2013 does not provide a ranking of countries' performance, since the availability and quality of data is still limited. As an alternative to the ranking, the pilot EPSIS developed a scorecard based on a "traffic light" system assigning three different symbols to the analysed countries depending on their relative scores on the individual indicators. If a member state achieves an above average performance on an indicator, i.e. the indicator score is among the highest 33 per cent of the observed scores for all countries, it is marked with a solid circle in Table 2.2. 
If a member state achieves a close to average performance on an indicator, i.e. the indicator score is among the middle 33 per cent of the observed scores for all countries, it is marked with a semi-filled circle. Finally, if a member state achieves a below average performance on an indicator, i.e. the indicator score is among the lowest 33 per cent of the observed scores for all countries, it is marked with a transparent circle.

Table 0.3 The results of the pilot European Public Sector Innovation Scoreboard 2013

\begin{tabular}{|c|c|c|c|c|c|c|c|c|c|c|}
\hline & $\mathbf{B E}$ & BG & $\mathrm{CZ}$ & DK & DE & $\mathbf{E E}$ & $\mathbf{G R}$ & $\mathbf{E S}$ & FR & IE \\
\hline \multicolumn{11}{|l|}{ Human resources } \\
\hline Creative occupations & ) & & D & 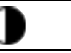 & 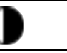 & & O & & O & O \\
\hline University education & D & & D & & D & & O & & O & 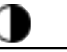 \\
\hline \multicolumn{11}{|c|}{ Quality of public services } \\
\hline \multicolumn{11}{|l|}{ Governm. effectiveness } \\
\hline \multicolumn{11}{|l|}{ Regulatory quality } \\
\hline \multicolumn{11}{|l|}{ Increased efficiency } \\
\hline \multicolumn{11}{|l|}{ Availability services } \\
\hline \multicolumn{11}{|l|}{ E-Government } \\
\hline \multicolumn{11}{|l|}{ Capacities to innovate } \\
\hline \multicolumn{11}{|l|}{ Service in-house } \\
\hline \multicolumn{11}{|l|}{ Process in-house } \\
\hline \multicolumn{11}{|c|}{ Innovation drivers and barriers } \\
\hline \multicolumn{11}{|l|}{ Internal barriers } \\
\hline \multicolumn{11}{|l|}{ External barriers } \\
\hline \multicolumn{11}{|l|}{ Active management } \\
\hline \multicolumn{11}{|l|}{ External knowledge } \\
\hline \multicolumn{11}{|l|}{ Groups } \\
\hline \multicolumn{11}{|c|}{ Innovators in public administration } \\
\hline \multicolumn{11}{|l|}{ Innovators } \\
\hline \multicolumn{11}{|l|}{ New services } \\
\hline \multicolumn{11}{|l|}{\begin{tabular}{|l|} 
Productivity \\
\end{tabular}} \\
\hline \multicolumn{11}{|c|}{ Effects on business performance } \\
\hline \multicolumn{11}{|l|}{ 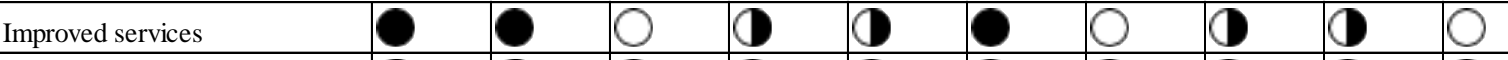 } \\
\hline \multicolumn{11}{|l|}{ Innovative services } \\
\hline \multicolumn{11}{|c|}{ Innovative government procurement } \\
\hline \multicolumn{11}{|l|}{ Procurement driver } \\
\hline \multicolumn{11}{|l|}{ Advanced technology } \\
\hline Innovation procurement & D & & ? & & D & $\mathbf{D}$ & & D & D & 0 \\
\hline
\end{tabular}




\subsection{The results of the pilot European Public Sector Innovation Scoreboard 2013(continued)}

\begin{tabular}{|c|c|c|c|c|c|c|c|c|c|c|}
\hline & IT & $\mathbf{C Y}$ & $\mathbf{L V}$ & LT & $\mathbf{L U}$ & $\mathrm{HU}$ & MT & NL & AT & PL \\
\hline \multicolumn{11}{|l|}{ Human resources } \\
\hline \multicolumn{11}{|l|}{ Creative occupations } \\
\hline \multicolumn{11}{|l|}{ University education } \\
\hline \multicolumn{11}{|c|}{ Quality of public services } \\
\hline \multicolumn{11}{|l|}{ Governm. effectiveness } \\
\hline \multicolumn{11}{|l|}{ Regulatory quality } \\
\hline \multicolumn{11}{|l|}{ Increased efficiency } \\
\hline \multicolumn{11}{|l|}{ Availability services } \\
\hline \multicolumn{11}{|l|}{\begin{tabular}{|l|} 
E-Government \\
\end{tabular}} \\
\hline \multicolumn{11}{|l|}{ Capacities to innovate } \\
\hline \multicolumn{11}{|l|}{ Service in-house } \\
\hline \multicolumn{11}{|l|}{ Process in-house } \\
\hline \multicolumn{11}{|c|}{ Innovation drivers and barriers } \\
\hline \multicolumn{11}{|l|}{ Internal barriers } \\
\hline \multicolumn{11}{|l|}{ External barriers } \\
\hline \multicolumn{11}{|l|}{ Active management } \\
\hline \multicolumn{11}{|l|}{ External knowledge } \\
\hline \multicolumn{11}{|l|}{ Groups } \\
\hline \multicolumn{11}{|c|}{ Innovators in public administration } \\
\hline \multicolumn{11}{|l|}{ Innovators } \\
\hline \multicolumn{11}{|l|}{ New services } \\
\hline \multicolumn{11}{|l|}{ Productivity } \\
\hline \multicolumn{11}{|c|}{ Effects on business performance } \\
\hline \multicolumn{11}{|l|}{ Improved services } \\
\hline \multicolumn{11}{|l|}{ Innovative services } \\
\hline \multicolumn{11}{|c|}{ Innovative government procurement } \\
\hline \multicolumn{11}{|l|}{ Procurement driver } \\
\hline Advanced technology & & & & D & & & & & & D \\
\hline Innovation procurement & & & $\mathbf{V}$ & & & 0 & D & & $\mathbf{D}$ & D \\
\hline
\end{tabular}




\subsection{The results of the pilot European Public Sector Innovation Scoreboard 2013 (continued)}

\begin{tabular}{|c|c|c|c|c|c|c|c|c|c|}
\hline & PT & RO & SI & SK & FI & $\underline{\mathbf{S E}}$ & UK & NO & CH \\
\hline \multicolumn{10}{|l|}{ Human resources } \\
\hline \multicolumn{10}{|l|}{ Creative occupations } \\
\hline \multicolumn{10}{|l|}{ University education } \\
\hline \multicolumn{10}{|c|}{ Quality of public services } \\
\hline \multicolumn{10}{|l|}{ Governm. effectiveness } \\
\hline \multicolumn{10}{|l|}{ Regulatory quality } \\
\hline \multicolumn{10}{|l|}{ Increased efficiency } \\
\hline \multicolumn{10}{|l|}{ Availability services } \\
\hline \multicolumn{10}{|l|}{ E-Government } \\
\hline \multicolumn{10}{|l|}{ Capacities to innovate } \\
\hline \multicolumn{10}{|l|}{ Service in-house } \\
\hline \multicolumn{10}{|l|}{ Process in-house } \\
\hline \multicolumn{10}{|c|}{ Innovation drivers and barriers } \\
\hline \multicolumn{10}{|c|}{ Internal barriers } \\
\hline \multicolumn{10}{|l|}{ External barriers } \\
\hline \multicolumn{10}{|l|}{ Active management } \\
\hline \multicolumn{10}{|l|}{ External knowledge } \\
\hline \multicolumn{10}{|l|}{ Groups } \\
\hline \multicolumn{10}{|c|}{ Innovators in public administration } \\
\hline \multicolumn{10}{|l|}{ Innovators } \\
\hline \multicolumn{10}{|l|}{ New services } \\
\hline \begin{tabular}{|l|} 
Productivity \\
\end{tabular} & D & & D & 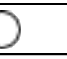 & 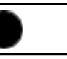 & 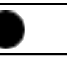 & & (1) & 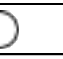 \\
\hline \multicolumn{10}{|c|}{ Effects on business performance } \\
\hline \multicolumn{10}{|l|}{ Improved services } \\
\hline Innovative services & & D & D & D & D & P & O & & \\
\hline \multicolumn{10}{|c|}{ Innovative government procurement } \\
\hline Procurement driver & & S & S & D & & & & & \\
\hline Advanced technology & & S & & D & & & & & \\
\hline Innovation procurement & & D & & $\mathbf{D}$ & D & P & O & O & D \\
\hline
\end{tabular}

Source: Pilot European Public Sector Innovation Scoreboard 2013.

It can be seen that the top five countries, which score above average on more than half the indicators, are Sweden (16 indicators above average), Switzerland (13), Malta (13), Denmark (12), and The Netherlands (12). The countries, where half or more of the indicators score close to average are Slovenia (12 indicators close to average), Belgium (11), and Cyprus (11). The countries that have a half or more below-average score are Czech Republic and Poland (both with 14 indicators scoring below average), followed by Italy (13), Lithuania (13), Hungary (12), Slovakia (12), Germany (11), and Greece (11).

There are however considerable differences between different dimensions. As regards 'Human resources', Estonia, Latvia, Lithuania, Sweden and Norway have full black on all indicators, while Czech Republic, Greece, France, Italy and Austria score below-average on all indicators. While in 'Quality of public services' Sweden and Finland score top on all indicators, with Bulgaria, Romania and Slovakia having all indicators with full white circles. 
Countries with public sectors having the strongest 'capacity to innovative in-house' are Ireland, Malta, The Netherlands, Spain, Switzerland and United Kingdom. The opposite is observed in Czech Republic, Estonia, France, Germany, Lithuania, Hungary and Austria. As regards 'Drivers and barriers', the picture is very mixed, but most of the lowest scores were noted by Italy and Poland (both countries have full white circles on four out of five indicators).

In the 'Innovative outputs' dimension, Sweden and Denmark score "full black" on all indicators. It should be noted that in this section, data is missing for a number of countries. As regards the two business dimensions where the public sector provides either innovative services or acts as an innovation driver through public procurement, the picture is mixed. Denmark and the Netherlands score the highest as regards innovative public procurement, while Poland scores "full white" on all indicators in the same dimension. While Latvia, Malta and Portugal score "full black" for the improvement and impact of innovative public services for business, Czech Republic, Ireland, Slovakia and United Kingdom score "full white" on the same indicators.

According to the pilot EPSIS 2013, the overall results show that public administration in the EU does innovate but it also faces a number of challenges. A smart and innovative public administration offers better, more targeted and faster delivery of services to businesses and citizens. For example, companies appreciated reduction of time and costs, faster responses and better support. However, the results also show that there are still several deficiencies in the public sector, as it could do more to promote innovation through public procurement.

Although the pilot EPSIS consists in total of 22 indicators, their selection was prescribed by the availability of data rather than the need for the ideal set of indicators that could precisely portray public sector innovation. Although all indicators were weighted equally, some dimensions might seem to be under- or over-represented. For example, the fact that there are three indicators covering public procurement of innovation does not necessarily reflect the relative importance of that aspect in the overall innovativeness of public administration. It was not the primary intention to indicate which areas are more or less important when looking at public sector innovation in the individual countries.

\subsection{Next steps: towards a better and policy-relevant measurement of public sector innovation}

The availability of data remains the key challenge in constructing robust and policy-relevant indicators. Even though, the two Innobarometers provided unique and interesting results, the statistical material is based on opinions and the data is not collected systematically, which in case of regularly published scoreboards is of key importance.

Nevertheless, the evidence so far is certainly encouraging and the work on better public sector innovation measurement might usefully continue. The Expert Group on Public Sector Innovation in its recommendations (Commission, 2013) to the European Commission confirms that there is a challenge for providing more data on public sector innovation and its impacts and that scarce data and the random use of the available data acts as a barrier to help drive innovation efforts. The Expert Group supports the view that more efforts are needed to measure and monitor innovation in the public sector at different organizational levels. In particular, the Expert Group states that potential innovation mainstreaming efforts should further develop how current scoreboards, such as the EPSIS, are designed, implemented and communicated in order to drive public sector innovation. It also pays attention to the 
activities that should support Member States in interpreting and drawing up concrete actions in response to scoreboard results.

In fact, the services of the European Commission continue their work on better measurement of public sector innovation. In order to monitor the role of the public sector in driving business innovation, the Commission actively participated in the Community Innovation Survey 2012 and 2014 Task Forces ${ }^{17}$ to take the opportunity to survey enterprises. The link between the public sector and business innovation has not been previously exploited. The CIS 2012 , for which data was scheduled for availability by the end of 2014, introduced some new questions regarding the role of the public sector in business innovation activities - firstly as a source of information and secondly as a cooperation partner (Questions 6.1 and 6.2, CIS 2012). Furthermore, the questionnaire is investigating the cost of meeting government regulations or legal requirements as a possible obstacle to enterprise innovation activity. Finally and also for the first time, questions regarding public support to innovation through public procurement were asked. These issues will be also included in the future CIS 2014 edition.

In 2013-2014, the Commission launched another Innobarometer 2014 (Commission, 2014) to look into the role of public support in the commercialization of innovations. The results are in line with the Innovation Union Scoreboard 2014, which confirms that the EU is still lagging behind global leaders. Notably, while innovation performance overall is improving in all Member states, the commercialization of innovation (SMEs - Small and Medium Enterprises introducing product innovation / sales of new to market and new to firm innovations), is making progress only slowly. Among key barriers to commercialization of innovation is lack of financial resources but also the very low role of public procurement in enhancing innovation uptake.

The services of the Commission are working towards preparation of another pilot European Public Sector Innovation Scoreboard 2015 with some new data. However, the challenges faced by the first edition remain still valid. For the near future, the most exigent need is the development and adoption of international standards for public sector innovation measurement similar to those applied in business innovation. The upcoming revision of the Oslo Manual offers an excellent possibility to develop international guidelines for collecting and interpreting public sector innovation data. This is an indispensable prerequisite for systematic and policy-relevant data collection. As long as such guidelines do not exist, there is a risk of methodological inconsistencies and policy misunderstandings.

Most notably, public sector innovation needs to be well-defined by taking into account public sector specificities (e.g. lack of profits and market, innovations driven by political mandates and priorities). Further, clear definitions need to be adopted on how the public sector innovates, including specific innovation activities, linkages, the role of barriers and drivers, availability of human and financial resources. Equally crucial and necessary are definitions of the statistical (observation) units in order to distinguish among and between different public sector activities (at 2- and possibly lower digit-levels of the NACE classification), and

\footnotetext{
17 The Community Innovation Survey (CIS) - based innovation statistics are part of the EU science and technology statistics. Surveys are carried out every two years by EU member states and a number of European Social Survey (ESS) member countries. Compiling CIS data is voluntary, which means that in different survey years different countries are involved. The CIS is a survey of innovation activity in enterprises. The harmonized survey is designed to provide information on the innovativeness of sectors by type of enterprises, on the different types of innovation and on various aspects of the development of an innovation, such as the objectives, the sources of information, the public funding, the innovation expenditures etc. For more see: http://epp.eurostat.ec.europa.eu/portal/page/portal/microdata/cis
} 
functions of government taking into account the multi-level nature of public sector organizations. An issue of the provision of public services should be addressed as in different countries (or even municipalities in the same region), with the same service provided either directly by a public organization or contracted out to a private company.

It is also important to differentiate between innovation "in" and innovation "through" the public sector. In the first case, the focus is on internal innovation aspects, for instance organizational and management issues (workplace innovation); while in the second case the focus is on the role of the public sector in driving business and social innovations, for instance through public procurement, targeted funding for research or entrepreneurship, cocreation with citizens and the third sector.

Another key aspect is a definition of public sector innovation outputs and their impact on users and society. A clear link between an innovative public sector and the benefits to the economy and competitiveness must be examined.

Finally, the common definitions and guidelines should ensure that the collected data is not only robust but also relevant and useful for the policy making process. Similarly, important is the regularity of data collection and provision. Including all these issues in the next edition of the Oslo Manual seems to be a necessary step for further legislative changes for new data collection at the EU - and preferably also international - level.

Given the policy efforts made up to now and the soaring interest in the topic, it can be expected that public sector innovation and modernization of public administration should remain high on the policy agenda of the new European Commission. Certainly, a comprehensive and a well-coordinated strategy for public sector innovation at the EU level would be a vital contribution to exploit the full potential of the modern and innovating public sector in Europe. 


\subsection{References}

Bugge, M., P.S. Mortensen, and C. Bloch, Measuring Public Innovation in Nordic Countries: Report on the Nordic Pilot studies - Analyses of methodology and results, MEPIN project, NIFU Step, 2011

European Commission: Communication from the Commission to the European Parliament, the Council, the European Economic and Social Committee and the Committee of the Regions, Think Small First. A Small Business Act for Europe, COM (2008) 394 final, 25 June 2008

European Commission: Communication from the Commission, Annual Growth Survey 2014, COM (2013) 800 final, 13 November 2013

European Commission: Communication from the Commission to the European Parliament, the Council, the European Economic and Social Committee and the Committee of the Regions, Regulatory Fitness and Performance (REFIT): Results and Next Steps, COM (2013) 685 final, 2 October 2013

European Commission: Communication from the Commission to the European Parliament, the Council, the European Economic and Social Committee and the Committee of the Regions, Europe 2020 Flagship Initiative Innovation Union, COM (2010) 546 final, 6 October 2010

European Commission: Innovation Union Scoreboard 2014, report prepared for the European Commission by the Maastricht Economic and Social Research Institute on Innovation and Technology (UNU-MERIT)

European Commission: Innovation Scoreboard, Commission Staff Working Paper 2001, SEC (2001) 1414, 14 September 2001

European Council: Presidency Conclusions, Lisbon European Council, 23 and 24 March 2000

European Commission: Flash Eurobarometer 305, Innobarometer among public administration organizations in the EU27, Switzerland and Norway; 2011, http://ec.europa.eu/public_opinion/flash/fl_305_en.pdf

European Commission: Flash Eurobarometer 343, Innovation in the public sector: Perception in and impact on business, 2012, http://ec.europa.eu/public_opinion/flash/fl_343_en.pdf

European Commission: European Public Sector Innovation Scoreboard 2013 - a pilot exercise, 2013; Maastricht Economic and Social Research Institute on Innovation and Technology (UNU-MERIT) and Technopolis Group

European Commission: Report of the Expert Group on public sector innovation, Powering European Public Sector Innovation. Towards a New Architecture, 2013

European Commission: Flash Eurobarometer 394, The role of public support in the commercialization of innovations, 2014, http://europa.eu/rapid/press-release_MEMO-14$\underline{384 \text { en.htm }}$ 
Halvorsen, T., J. Hauknes, I. Miles, and R. Røste. On the differences between public and private sector innovation, PUBLIN project on Innovation in the Public Sector, Publin Report No. D9, NIFU STEP Oslo, 2005

Hughes, A., K. Moore, and N. Kataria. Innovation in Public Sector Organizations. A pilot survey for measuring innovation across the public sector, NESTA 2011

OECD \& Eurostat of the European Commission, Oslo Manual: Guidelines for collecting and interpreting innovation data, Third edition, 2005 


\section{Chapter 3}

\section{Promoting Public Sector Innovation: Trends, Evidence and Practices from the EPSA}

Alexander Heichlinger and Julia Bosse, European Institute for Public Administration ${ }^{18}$

\subsection{Introduction}

The European Public Sector Award (EPSA) is a European-wide scheme which rewards projects that address relevant public challenges and are crucial drivers for innovation and change in the way public actors operate in the 21 st century. The EPSA is a unique platform in Europe as well as a powerful source of best practices ('case-maker') from Europe's public sectors. It responds to two key challenges for innovation in the public sector. The first challenge is how to provide incentives to policy makers and other officials to make the effort and upfront investment and to accept the risk inherent in innovation. The second key challenge is how to identify, scale up and spread successful innovation.

In the business sector, the incentives for successful innovation are immediate in the form of higher quality in products and/or services and subsequent increased profits. The market weeds out unsuccessful innovations, and channels resources to the successful ones in the form of higher profits, or the expectation thereof. Thereby it enables these successful innovations to be scaled up. In the public sector, incentives are typically much more attenuated. Public goods and services are usually provided either free of charge or on a costrecovery basis. Different mechanisms are therefore needed to encourage and reward innovation in the public sector. Unlike in the business sector, successful innovators in the public sector cannot necessarily expect to be rewarded automatically with larger budgets and/or more resources. Different mechanisms are therefore needed in the public sector to steer resources towards successful innovations and to stimulate their growth and dissemination.

The EPSA showcases the best, most efficient and most innovative performers of Europe's public sector. It has become an important promoter (and more) for public sector innovation as it not only rewards outstanding public achievements, but fosters knowledge transfer and mutual learning. In doing so, it provides incentives for innovation through public recognition of success stories, and encourages the dissemination and scaling up of these successes through positive demonstration effects. In the following, the authors will highlight the power in driving innovation in the public sector of the EPSA and related initiatives in which the European Institute for Public Administration (EIPA) takes the lead or is deeply involved in, and will describe trends in public management that have crystallised from the different EPSA rounds.

\subsection{The EPSA - A strong driver for public sector reform and search of excellence}

"The EPSA has emerged as a framework for mapping innovative practices, including a comprehensive set of criteria, definitions and categories. This provides a basis for carrying

\footnotetext{
${ }^{18}$ Respectively - senior faculty member, expert and research assistant at EIPA. Alexander Heichlinger is the Manager of the European Public Sector Award (EPSA) scheme and team.
} 
out meaningful analysis and comparisons of countries. Through collecting and sharing these practices EPSA is adding genuine European value, encouraging learning and inspiring a culture of public sector innovation" (László Andor, European Commissioner for Employment, Social Affairs and Inclusion, 2013).

As is widely known, EPSA is a unique and prestigious platform in Europe as well as a powerful source or supplier of best practices ('case-maker') from Europe's public sectors. It rewards projects that address relevant European public challenges and are crucial drivers for innovation and change in the way public actors operate in the $21^{\text {st }}$ century. With more than 800 cases from 36 European countries and institutions which have been thoroughly assessed by external and independent evaluators since 2009, and which provide an insight into the proactive approaches of hundreds of public administrations, EPSA makes these (best) practices transparent, transferrable and available to all public administrations.

Since its beginning, EPSA has continued to address topical thematic areas which are at the heart of concern to - one may say with few exceptions - all public administrations within Europe and also beyond. These topics were from 2009 to 2013:

- Performance Improvement in Public Service Delivery

- Citizen Involvement

- New Forms of Partnership Working

- Leadership and Management for Change

- Smart Public Service Delivery in a Cold Economic Climate

- Opening Up the Public Sector Through Collaborative Governance

- Going Green: Concrete Solutions from the Public Sector

- Weathering the Storm: Creative Solutions in a Time of Crisis

As a consequence, EPSA has built up and offers a rich "data/information source and treasure" and the possibility to transfer this knowledge while ensuring the extraction of lessons learnt and the understanding of respective trends in public reforms and modernization. The widelyknown EPSA Transfer by EIPA covers various formats like training, advice or research (and publications).

To ensure the quality of its various results and outputs, as an award scheme fostering public sector innovation and modernization, EPSA contains an independent, impartial and sophisticated four-step evaluation process during which all eligible applications are evaluated against eight criteria. 'Innovation' is one of these and defined as 'novelty of the solution; degree to which the case shows a leap of creativity in the practice of public administration; something that goes beyond what currently exists'. This definition includes the transfer and adaptation of innovative and working solutions from one setting to an entirely new and different public sector environment as well as completely novel solutions, processes and practices that have not been applied in the public sector before. Consequently, highly ranked EPSA cases - best practices, nominees and award winners - all contain elements of public sector innovation.

While innovative cases often have not reached their full level of maturity yet, the EPSA assures that awarded practices have already shown tangible and proven results by applying additional evaluation criteria (as defined in the 2013 round), such as 'impact/results', 'sustainability' and 'learning capacity and transferability' in addition to 'appropriateness of actions taken', 'stakeholder support', 'social equity' and 'effect on economic growth'. Therefore, the awarded EPSA best practices combine innovation with working solutions and are identified as leading European best practices. 'They are considered to be 'unique', often in relation to a cultural, ethical, legal, national and/or organizational context, as well as being 
visible and distinctive, i.e. they have a clear identity and are recognized, at least in the region or country of location'. ${ }^{19}$

\section{The EPSA as an observatory of innovative solutions in the public sector - key lessons and practices from the EPSA editions}

The period of the last three EPSA editions has been marked by the upsurge of the financial and economic crisis, its aftermath and continuing pressures for public administrations, especially in the areas of health and social care budgets. The last EPSA edition - EPSA 2013 - showed that significant challenges remain, particularly to promote business innovation and growth and to remove barriers to it. For now, there is little evidence that the crisis on public finances will alleviate in the short term.

Nevertheless, the 230 creative and innovative responses received in the last 2013 edition and the 801 cases in total since 2009, especially those of the nominees and best practices, indicate that the European public sector is willing and capable to adapt to these challenges and pressures and - what is more important - that innovative (policy) responses are potentially within the reach of all public administrations, regardless of the size, level or (politicoadministrative) structure. Our analysis shows that successful processes happen at all levels of government and in different political systems. There is no indication or evidence per se that such reviews or reforms are easier or more difficult in a specific form of governmental structure (centralized, decentralized etc.). However, some questions have arisen about the extent to which smaller sub-national entities are likely to have resources to pursue reforms or whether they will have to apply these solutions in partnership with other administrations and stakeholders to dispose the adequate means and know-how. ${ }^{20}$

The last three EPSA rounds managed by EIPA thus constitute a rich source of creative and innovative public sector practices, out of which several key lessons, drivers and enablers for successful modernization and innovation in the public sector can be drawn. The dissemination of these is one of the main goals of the EPSA as a learning platform for public administrations, as explained above. The key messages highlighted briefly in the following section have a common linkage, i.e. they have been identified in all cases submitted to the EPSA, although to varying degrees.

\subsection{The need for a strategic framework (for services, partnerships and/or budget reform)}

The different best practices clearly demonstrate that the likelihood of success of a modernization or reform project is linked to the clarity of objectives and the outcomes the review, change or (new) service aims to achieve. This involves asking crucial questions about the objectives before embarking on a project. In the case of a budget review for instance, this means identifying, for example, the level of public sector expenditure, which is still sustainable, the level of service standards, which are still acceptable, and expenditure scenarios arising from different service standards and levels. For a partnership, this involves clarity about the opportunity costs of the partnership - that is to say a clear justification of why this partnership addresses a concrete public service issue better and more effectively than alternative forms of cooperation. For this reason, the clarity of objectives goes hand in hand with prioritizing, ideally including priorities that are of a broad concern to the majority

\footnotetext{
${ }^{19}$ Heichlinger, A., ed. EPSA Trends in Practice. Driving Public Sector Excellence to Shape Europe for 2020, European Institute of Public Administration, Maastricht, 2011, pp. $8 \mathrm{f}$

${ }^{20}$ Bosse, J. et al., eds., Weathering the Storm: Creative Solutions in a Time of Crisis, European Institute of Public Administration, Maastricht, 2013, pp. $38 \mathrm{f}$
} 
of citizens, but also addressing difficult issues. ${ }^{21}$ An excellent illustration in this respect is the 2011 winning project Political Management Based on Economic Stringency and Strategic Budgets submitted by the City of Bilbao, which is the city's political management strategy based on stringency and economic austerity. This overall system included (1) strategic planning with the help of the Governance Plan 2007-2011 and related strategic budgets, which was controlled through (2) a balanced scorecard system and the implementation of an Austerity and Efficiency Plan, (3) increased transparency at the City Hall, (4) enhanced citizen participation and the ultimate goal of (5) zero borrowing. This initiative was paramount as a political agreement and overall strategic framework since it expressed in clear terms the transfer of political objectives into action plans with specific monitoring and control indicators.

Many of the best practices also showed holistic and cross-sectoral approaches when trying to change the culture, way of working in government or treating cross-cutting issues like services for the disabled and elderly, or wellbeing and civil safety.

\subsection{Transparency and consensus through citizen and stakeholder involvement}

Especially in harsh economic times, it is of utmost importance to secure a wider consensus for decisions taken by public administrations. Involving citizens through well-presented information, consultation and active participation is essential to build trust in government and to be informed about citizens' needs. This is illustrated, for instance, by the EPSA 2013 national winner project 'The Compass of Transparency' submitted by the Department for Public Administration in Italy which thwarts corruption by giving citizens the possibility to monitor online and in real time the implementation of all data and information requirements imposed by Italian law on the websites of administrative bodies (more than 20,000). In this way, citizens have uniform access to information, data and services while at the same time contributing to a quality improvement of public sector websites in view of transparency and completeness of provided information. In addition, this flexible online tool creates a healthy kind of 'competition' among public administrations. The system puts the citizen first, both as a user of transparency and as a contributor to the increase of transparency in public administrations: It is a perfect example of checks and balances.

Co-design and co-production and self-management of outcomes, in particular for personalized services such as health care, can be effective tools regarding stakeholder involvement and are often a tool for balancing costs. ${ }^{22}$ Many excellent projects exist across all EPSA editions ranging from participatory budgets, over co-decision in the usage of green spaces and neighbourhood transformations, co-creation with citizens to fight school drop-out and social exclusion, to patient empowerment and self-reliance, city charters and open data projects.

The EPSA cases showed that 'true' involvement of users is most likely to happen at the local level because of an administration's physical proximity and relevance to the everyday lives of citizens. ${ }^{23}$ In general, enhanced citizen and stakeholder involvement, self-management of

\footnotetext{
${ }^{21}$ See Heichlinger, A. and M. Burnett, New Forms of Partnership Working, In: Heichlinger, A. and M. Pröhl, eds., Taking the Pulse of European Public Administrations. Key Findings of the European Public Sector Award 2009, European Institute of Public Administration, Maastricht, 2009, pp. 88f and Burnett, M., Smart Public Service Delivery in a Cold Economic Climate, In: Heichlinger, A., ed. EPSA Trends in Practice. Driving Public Sector Excellence to Shape Europe for 2020, European Institute of Public Administration, Maastricht, 2011, p. ${ }^{22}$ See Ibid

${ }^{23}$ Heichlinger, A., and J.O. Vanebo, 'Public Sector and the New ('Old') Technology', Busch, T. et al., eds., Public Management in the Twenty-first Century. Trends, Ideas and Practices, Universitetsforlaget, Oslo, 2013, p. 96.
} 
outcomes and the delegation of service provision to non-profit entities leads to the role of the state or region being increasingly seen as that of a 'facilitator rather than service deliverer'. ${ }^{24}$

\subsection{Importance of commitment/dedication at all levels and bold leadership}

'All of the best practice examples were driven by creative and dedicated thinkers, whether political, administrative or from civil society'. ${ }^{25}$ This statement from the theme 'Citizen Involvement' of the EPSA 2009 continues to hold true for the majority of best practices in subsequent editions. Leadership is essential to kick-start reform or change processes within administrations, but also to launch new projects, even if they are on a small scale. Change or reviews are, in the end political decisions, so political support is essential. While political leadership and support is decisive, fully-fledged reform processes are more successful if they involve in the design process those responsible for making it work at the middle management and operational level (bottom-up approach), rather than the process being imposed on a topdown basis. The commitment and enthusiasm of people 'from the ground' is crucial to carry out reform processes. Thus, good working relations and communication between the political and administrative level are key to fruitful change.

Such political leadership and cultural transformation were crucial success factors in the EPSA 2011 nominee project 'Change2 - Achieving More Together' submitted by the City of Mannheim in Germany, which was initiated by the Mayor himself and supported by the full City Council. This five-year reform project aimed to stabilize the city finances, to improve the delivery of public services using strategic and operational outcome-based targets and to develop a better model of future planning by improving democracy in the City Council and the City Advisory Council. The whole change programme was accompanied by a fullyfledged cultural transformation process to secure the commitment of city leaders and employees. Thus, a non-redundancy policy was agreed right at the start of the modernization project, guidelines on leadership, communication and cooperation laying down the city mission and understanding of leadership were introduced and employees were involved in, among other measures, quarterly polls ('climate checks') and discussion rounds with the Lord Mayor. 'In the context of German public administrations it is a very innovative project because of its outcome-focused, authority-wide approach and the very high level of employee participation in the process. 26

\subsection{Continuing emphasis on partnership approaches and its related ownership importance}

The EPSA editions also show a clear trend towards continuing partnerships, mergers and other collaborative venture forms of cooperation between different public administrations, but also public administrations, citizens and other stakeholders to improve the quality of services and guarantee their maintenance. Collaboration and private-public-partnerships (PPP) can grant, on the one hand, more influence and involvement to the public sector and citizens, and, on the other hand, result in greater administrative efficiency and financial benefits. The EPSA 2011 nominee project Little Bird submitted by the City of Heidenau in

\footnotetext{
${ }^{24}$ Bosse, J. et al., eds., Weathering the Storm: Creative Solutions in a Time of Crisis, European Institute of Public Administration, Maastricht, 2013, p. 39, and see also T. Bass, and M. Pissarius, Citizen Involvement, In: Heichlinger, A., and M. Pröhl, eds., Taking the Pulse of European Public Administrations. Key Findings of the European Public Sector Award 2009, European Institute of Public Administration, Maastricht, 2009, p. 61 ${ }^{25}$ Ibid

${ }^{26}$ Burnett, M., Smart Public Service Delivery in a Cold Economic Climate, In: Heichlinger, A., ed. EPSA Trends in Practice. Driving Public Sector Excellence to Shape Europe for 2020, European Institute of Public Administration, Maastricht, 2011, p. 30
} 
Germany is an excellent example of a successful PPP in the area of childcare. Voluntary cooperation has a clear potential to counteract pressures and bottlenecks created by the economic crisis, which has been demonstrated by several cases submitted to the three editions. As already observed in 2009, partnerships between public and third sector organizations are increasingly based on equality, whereby the third sector organizations are considered as partners and not merely as contractual service providers as was previously the case. $^{27}$

As indicated already above, the issue of ownership has been identified repeatedly across several EPSA themes and editions as a key ingredient of successful partnerships and modernization processes. ${ }^{28}$ Commitment and dedication to modernization often go hand in hand with a shared feeling of ownership of the process between the main stakeholder groups. Through enhanced citizen and stakeholder involvement, the ownership of decisions and processes shifts increasingly from government bodies to individuals or collectives. However, this does not mean that the responsibility of decision-makers changes. It still lies with the public administrations, but what changes is the level of openness of the process.

Collaborative and open government 'does not change the traditional balance of power, but secures acceptance, ownership and quality. ${ }^{, 29}$

In this respect the regional EPSA 2013 winner project Development of Wellbeing and Civil Safety in Municipalities submitted by the State Administrative Agency for Lapland serves as an outstanding example of how municipal services in the area of wellbeing and safety can successfully be complemented and improved by creating a cross-sectoral and interjurisdictional network of public administrations, third sector organizations, research and education organizations, businesses and other stakeholders and bringing in their resources. The strength of this network lies in its open character and equal treatment of partners coupled with a proactive approach, high commitment and outcome orientation. Partners meet at the same level and appreciate one another for their different contributions and complementary areas of expertise. This project addresses successfully the big challenge of exploding costs in the health and social welfare sectors, which is a big challenge across Europe.

\subsection{Intelligent ICT-enabled solutions and architectures to improve service delivery, but not at the risk of exclusivity}

ICT is a well-established component in many intra-administrative reform processes (back office improvements) as well as in multi-stakeholder partnerships, consultation processes and services (front office improvements). This is also reflected in the EPSA rounds, where 42 per cent of all entries have been ICT-supported (34 per cent in 2009, 50 per cent in 2011 and 42.7 per cent in 2013). Interestingly, the percentage of ICT-based applications within the best

\footnotetext{
${ }^{27}$ See Heichlinger, A., and M. Burnett, New Forms of Partnership Working, In: Heichlinger, A. and M. Pröhl, eds., Taking the Pulse of European Public Administrations. Key Findings of the European Public Sector Award 2009, European Institute of Public Administration, Maastricht, 2009, p.89

${ }^{28}$ See for instance Ibid, p. 88 and Bass, T. and M. Pissarius, Citizen Involvement, In: Heichlinger, A. and M. Pröhl, eds., Taking the Pulse of European Public Administrations. Key Findings of the European Public Sector Award 2009, European Institute of Public Administration, Maastricht, 2009, p. 88 and Malterud, T. C. and S. Benito, Opening Up the Public Sector Through Collaborative Governance, In: Heichlinger, A., ed. EPSA Trends in Practice. Driving Public Sector Excellence to Shape Europe for 2020, European Institute of Public Administration, Maastricht, 2011, p. 59, and Unfried, M., Going Green: Concrete Solutions from the Public Sector, In: Heichlinger, A., ed. EPSA Trends in Practice. Driving Public Sector Excellence to Shape Europe for 2020, European Institute of Public Administration, Maastricht, 2011, p. 85

${ }^{29}$ Malterud, T. C., and S. Benito, Opening Up the Public Sector through Collaborative Governance, In:

Heichlinger, A., ed. EPSA Trends in Practice. Driving Public Sector Excellence to Shape Europe for 2020, European Institute of Public Administration, Maastricht, 2011, pp. $59 \mathrm{f}$
} 
practices and nominees group has increased from 35 per cent in 2009 to 51 per cent in 2013. These figures suggest that firstly there is a wide-range of ICT tools which can be applied to public sector challenges and that secondly there is a great potential for ICT to enhance trust in government at all levels, to improve significantly service delivery, reduce costs and enhance citizens' experience with the public sector (streamlining of documentation procedures, online access to services, consultation, etc.). ${ }^{30}$ This was prominently applied in the EPSA 2011 project and best practice recipient Tallinn City Services One-Stop-Shop which is one of the city's flagship projects, providing access to citizens to all direct and indirect city services since 2007 (a total of 560 services, out of which many are $5^{\text {th }}$ level ). In order to ensure a high take-up rate, the City of Tallinn put great efforts into inward (e.g. staff training and information sessions), and outward communication (public information, online advertising campaigns, city and district newspapers, introductory events for new services, dedicated programmes on municipal TV etc.).

Nevertheless, it should be stressed that ICT is a very useful tool to enable modernization, but not a goal in itself, with costs having to be increasingly weighed against benefits. Since it still contains a risk of exclusivity (precluding socially disadvantaged people, elderly, etc.), alternative forms of interaction with citizens should also be secured. EPSA practices showed that projects embracing a more holistic approach, that is to say involving target groups already in the planning and designing stage of services, and combining traditional values and forms of personal contact with innovative web tools are generally stronger and have a longerterm impact. In addition, well-designed and efficient ICT-supported processes do not automatically lead to high take-up rates by citizens. Communication and supporting measures such as promotion campaigns, awareness-raising and easy-to-use descriptions are of crucial importance.

In the case of the EPSA's Tallinn example, the city is fully aware of the fact that the digital divide can be best tackled by offering diversified channels to citizens. Smart TV-based services for the elderly are one example of how it is planned to enhance the inclusiveness of services.

\subsection{Innovative cross-border cooperation and driving social inclusion despite (or because of) the crisis}

In spite of the unabated storm of the economic and financial crisis, there is continuing pursuit of active strategies to promote economic growth and social inclusion. For instance a large number of EPSA 2013 submissions showed the ability to enhance social inclusion, such as strengthening women's groups, focusing on physically disabled people, age-related mobility, labour market entry or social housing. ${ }^{31}$ In addition, projects proved that employee-friendly outcomes do not have to be in conflict with public sector service orientation. For example, a project demonstrating imaginative cross-border cooperation in an area that requires bold decisions is in prison management - with capacity in Dutch prisons temporarily in use for Belgian detainees (EPSA 2013 best practice project Nova Belgica). This emerged despite (or because of) the crisis.

A further excellent cross-border project is the winner of the EPSA 2013 Honourable Mention of Cross-Border Cooperation The Creation of a New Economic Zone in Southern Luxembourg: Efficient Urban Planning and Social Integration through Cross-Municipal, Cross-Border and Cross-Sectoral Cooperation submitted by the Municipality of Esch-sur-

\footnotetext{
${ }^{30}$ Bosse, J.,et al., eds., Weathering the Storm: Creative Solutions in a Time of Crisis, European Institute of Public Administration, Maastricht, 2013, p. 38

${ }^{31}$ Ibid
} 
Alzette in Luxembourg. This project is an innovative cross-border initiative which gives a boost to urban economic development with a strategic and holistic approach. It successfully re-converted a former industrial wasteland shared by the municipalities of Esch-sur-Alzette (LU) and Sanem (FR) into a national research hub, including the University of Luxembourg, public research centres, innovative companies and residential and leisure facilities. The project is clearly supported by neighbouring communities and local stakeholders across the French border and by the national authorities in Luxembourg.

\subsection{Trend towards more coordinated and smart procurement modes}

Centralised, green and/or more coordinated procurement and service management were elements of many EPSA cases to achieve efficiencies and better services - whether horizontally or in specific sectors such as health or business services. This trend will be supported by recent reforms of the European public procurement regime. ${ }^{32}$ One example in this regard is the EPSA 2013 project Portugal did IT: The National Public Procurement System - Developing and Implementing an e-Procurement Solution, which is an initiative in parallel to a new public procurement law and led to the creation of a national procurement agency and central purchasing body. These newly created bodies give effect to mandatory eprocurement in Portugal by making available a platform through which public procurement procedures could be applied using standard tools.

Another showcase of the EPSA 2011 scheme was the award winner Ökokauf Wien ECOBUY Vienna, a forerunner project in green procurement on an impressive scale. It is a comprehensive cross-departmental programme to enhance the environmental compatibility of the city's procurement system in line with the principles of climate protection and EU procurement regulations. Texts for invitations to tender and more than 100 criteria catalogues have been developed in this framework as procurement guidelines. ECOBUY Vienna is used across different municipal departments and relies on a network of more than 200 experts from all spheres of the city administration, plus external experts. Through this vast and holistic programme covering all areas of public procurement, the City of Vienna managed to save around $€ 17$ million and 30,000 t of $\mathrm{CO}^{2}$ emissions each year.

\subsection{EPSA spin-offs and knowledge transfer}

Alongside its strategic mission and as mentioned initially, EIPA pays special attention to sharing and exchanging these good practices from the EPSA scheme with the aim to minimize both wastage of resources in the public sector and wastage of time spent 'reinventing the wheel'. The EPSA Transfer by EIPA covers various formats and transferroutes like (classical) training, research, advice or consultancy roles or matching and broker roles (among participants). ${ }^{33}$

In brief, three bold examples of its rich harvest of knowledge-transfer are highlighted: One is the 'joint journey in search of local public management excellence' and cooperation of seven European cities -all former EPSA rewarded applicants - the Cities of Bilbao (ES) who commissioned the assignment, Birmingham (UK), Mannheim (DE), Milan (IT), Tallinn (EE),

\footnotetext{
${ }^{32}$ Bosse, J., et al., eds., Weathering the Storm: Creative Solutions in a Time of Crisis, European Institute of Public Administration, Maastricht, 2013, p. 39

${ }^{33}$ Heichlinger, A., ed. EPSA Trends in Practice. Driving Public Sector Excellence to Shape Europe for 2020, European Institute of Public Administration, Maastricht, 2011, p. 10.
} 
Tampere (FI) and Trondheim (NO), which resulted in a publication accessible to all public actors (and available in English, German and Spanish). ${ }^{34}$

The objective of this assignment was to examine, compare and contrast the successful local management models of seven partner cities. Telling their success stories in the different areas of local public management in Europe allowed their knowledge and know-how (routes) to be transferred to other public administrations. By highlighting their local experiences, these seven cities also boosted the accountability and legitimacy of their actions, whilst enhancing the visibility and supporting the building of capacities throughout Europe. Each city case was analysed in terms of background, strategy (for change) development, 'journey', results and innovation power (key enablers and drivers) ("... the making of ...") and the work concluded by presenting seven common steps (or "road-map") leading to excellence in public management as outlined in Figure 3.1.

Figure 0.4 Seven steps leading to public management excellence

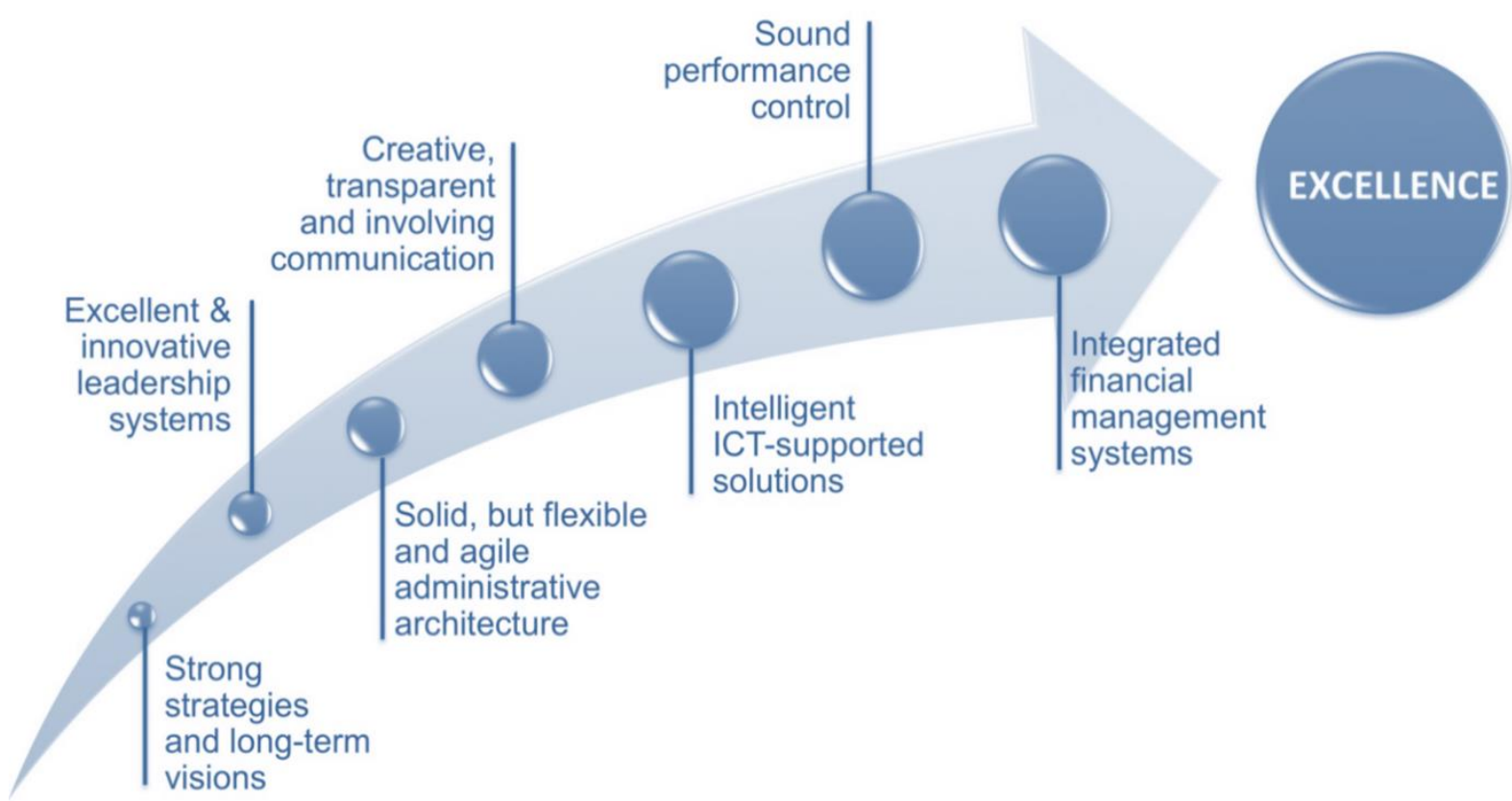

Source: See text.

A second prominent example of the EPSA knowledge transfer and contribution to public sector modernization, this time from both an academic/theoretical as well as practice angle, was the cooperation among several European Universities and the EIPA resulting in an publication by the Oslo University Press named 'Public Management in the Twenty-first Century - Trends, Ideas and Practices'. Research questions such as - 'What kind of ideas are behind the remodeling of the state and public sector, and how have these ideas materialized in practice? Why have public management reforms become such a prominent issue? Which relevant models and methods have been influential?' - have inspired recent debates in this field. In this book the authors' ambition was to contribute sophisticated answers and to illustrate what are the driving forces behind the huge number of public management reforms

${ }^{34}$ See http://publications.eipa.eu/en/details/\&tid=1852. 
over the last three decades, validating their findings against 16 EPSA (best) practices from across Europe. $^{35}$

Finally, a most recent flagship example of an EPSA spin-off is the high-level 'City Economic and Financial Governance (CEFG) Group - A leap towards transparency, accountability and sustainability of public finances' initiated and powered by the City of Barcelona (ES) in partnership with the Cities of Dublin (IE), Hamburg (DE), the City of London (UK), Milan (IT) and Vienna (AT), representing a total metropolitan accumulated population of just over 30 million. This partnership between six larger European cities - and again former EPSA participants, including winners and nominees - aims at benchmarking and creating a space for mutual learning in the field of local economic and financial governance. The Chief Financial Officers (CFOs) and finance managers of the six cities will discuss and analyse within this initiative relevant issues such as budget practices, integrated financial management systems, financial accounting practices in relation to the European Public Sector Accounting Standards (EPSAS) as well as national accounting systems.

Taking into account that in 2012, the 600 top economic cities generated 60 per cent of the global Gross Domestic Product (GDP), while being home to only 20 per cent of the world's population and that in Europe, 67 per cent of GDP is produced in metropolitan regions, the progress and development of cities will determine the future territorial, (socio-)economic and spatial development worldwide, and thus also across Europe. At the same time, growth and prosperity of cities critically depend on the way the evolving challenges of cities are managed.

This timely initiative - the European CEFG Group - has already raised great interest in the European environment and is thus supported through active participation by the European Commission - Eurostat as it coincides with their efforts to formulate the EPSAS and to apply them EU wide. The benefits of this project lie in the mutual administrative capacity-building approach, with inputs of real cases and practices from the city level in parallel to provide ' $a$ leap for transparency, accountability and sustainability of public finances' (the group's overall motto). ${ }^{36}$

\subsection{Conclusions}

The EPSA has proven - and has prominently been mentioned on several occasions - to be a valuable and powerful framework to disseminate and transfer innovation in, and of, the public sector. Despite its voluntary-based participation and questions which are sometimes raised in view of the effect of such schemes and their public funding (as evidence of the positive effects are hard to prove), there is no doubt that the EPSA fulfils and achieves several unique functions and motivations, and thus brings back to the public administrations a set of benefits and impacts.

In fact, in a 2014 survey carried out by EIPA among the EPSA 2011 and 2013 Best Practice recipients (105 in total) on the impact/benefits of the award scheme for applicants - with an impressive response rate of 69 per cent - several beneficial effects could be identified and demonstrated.

For example, 45 per cent of applicants considered the process of writing the application (in English) as highly beneficial (promoting a form of autodidactic approach including making contact with other departments etc.), while the same percentage of respondents replied that

\footnotetext{
${ }^{35}$ See the book flyer at http://www.eipa.eu/files/Public\%20Management\%20flyer\%20v2.pdf

${ }^{36}$ For more information please consult the website www.cefg.eu (forth-coming).
} 
their project received reinforced internal attention leading to further developments and improvements thanks to the EPSA award, (i.e. internal recognition and further review). Following on from these answers, 34 per cent of applicants also reported that they considered the Evaluation Summary Notes (ESN) - the written results and feedback of the four-step external evaluation process returned to each applicant participating in the scheme - to be very valuable (i.e. the external consultants' assessment delivered free of charge) and 30 per cent agreed that they gained inspiration from exchanging with other Best Practices (i.e. networking).

In addition, external visibility clearly emerged as the most valued impact by applicants of participating in the EPSA, which went hand-in-hand with the effects of scaling-up the project to a higher administrative level/larger geographical area, securing enhanced funding or including a broader range of topics in several project cases. In summary, the positive answers by the majority of Best Practice applicants (102 compared to three); clearly show that the EPSA is perceived to bring about positive change and impact for awarded projects. ${ }^{37}$

Hence, EPSA can be considered a combination of both awarding and learning (as a platform), a "reservoir" of practices for the entire range of public administrations (like the United Nations Public Service Awards (UNPSA) and OECD Observatory). Both targets are interrelated and contain also benefits for the (potential) applicant. Considering that public administration learning methodologies differ greatly, ranging from an autodidactic approach, involving internal and external consultants and advisors to networking, the EPSA and similar schemes contribute directly and indirectly to all these forms of learning. ${ }^{38}$

In a nutshell, there is no shortage of good practices as the many applications rewarded by the EPSA scheme show - similar to other international award competitions and related publications/manuals ${ }^{39}$. They are highly rewarding and valuable for applicants (directly and indirectly), and provide the capacity for a faster adoption process of innovative solutions for other public administrations due to their dissemination potential and power. Excellence through innovation will thus be continued as a core of the next edition - the EPSA 2015.

\footnotetext{
${ }^{37}$ One has to note that this evaluation may slightly differ if including the non-awarded projects, although the potential benefits of external feedback, the reflective process included in the writing of the application (if not outsourced) and learning through best practices also apply directly to them.

${ }^{38}$ Hofmeister, A., Working Group: Learning Platform, PowerPoint presentation in the framework of the 2nd EPSA 2013 Steering Committee meeting 26 September 2013.

${ }^{39}$ E.g. UNDESA \& UN-HABITAT, A Guide for Transfer and Adaptation of Innovation in Governance. Practical Tools and Steps, United Nations, New York, 2007. http://unpan1.un.org/intradoc/groups/public/ documents/un-dpadm/unpan046742.pdf.
} 


\subsection{References}

Bass, T., and M. Pissarius, Citizen Involvement, In: Heichlinger, A., and M. Pröhl, eds., Taking the Pulse of European Public Administrations. Key Findings of the European Public Sector Award 2009, European Institute of Public Administration, Maastricht, 2009, 33-65

Bosse, J. et al., eds., Weathering the Storm: Creative Solutions in a Time of Crisis, European Institute of Public Administration, Maastricht, 2013, available at:

http://www.eipa.eu/files/repository/product/20131128114334_EPSA_2013_PublicationWeb. pdf

Bosse, J. et al., In Search of Local Public Management. Seven Journeys to Success, European Institute of Public Administration, Maastricht, 2013, available at:

http://www.eipa.eu/files/repository/product/20140204081902_BilbaoBook_web.pdf

Burnett, M., Smart Public Service Delivery in a Cold Economic Climate, In: Heichlinger, A., ed. EPSA Trends in Practice. Driving Public Sector Excellence to Shape Europe for 2020, European Institute of Public Administration, Maastricht, 2011, 19-38

Busch, T. et al., Public Management in the Twenty-first century - Trends, Ideas and Practices, Universitetsforlaget, Oslo, 2013

European Commission, Government finance statistics, April 2014: http://epp.eurostat.ec.europa.eu/statistics_explained/index.php/Government_finance_statistics

European Commission, Powering European Public Sector Innovation: Towards a New Architecture. Report of the Expert Group on Public Sector Innovation. Luxembourg, 2013, available at: http://ec.europa.eu/research/innovation-union/pdf/PSI_EG.pdf

Heichlinger, A., ed., EPSA Trends in Practice. Driving Public Sector Excellence to Shape Europe for 2020, European Institute of Public Administration, Maastricht, 2011, available at: http://www.eipa.eu/files/repository/product/20111123132521_ResearchReport_web.pdf

Heichlinger, A., and M. Pröhl, eds., Taking the Pulse of European Public Administrations. Key Findings of the European Public Sector Award 2009, European Institute of Public Administration, Maastricht, 2009, available at:

http://www.eipa.eu/files/repository/product/20091222110622_EPSA2009_ResearchReport[1] . .pdf

Heichlinger, A., and M. Burnett, New Forms of Partnership Working, In: Heichlinger, A. and M. Pröhl, eds., Taking the Pulse of European Public Administrations. Key Findings of the European Public Sector Award 2009, European Institute of Public Administration, Maastricht, 2009, 67-90

Hofmeister, A., Working Group: Learning Platform, PowerPoint presentation in the framework of the 2nd EPSA 2013 Steering Committee meeting 26 September 2013

Määttä, S., and T. Ojala, A Challenge for Balanced Success in the Public Sector - Towards More Proactive Strategic Management, Ministry of Finance, 1999

Malterud, T. C., and S. Benito, Opening Up the Public Sector through Collaborative Governance, In: Heichlinger, A., ed. EPSA Trends in Practice. Driving Public Sector Excellence to Shape Europe for 2020, European Institute of Public Administration, Maastricht, 2011, 41-61 
OECD, Observatory of Public Sector Innovation, available at: http://www.oecd.org/gov/public-innovation/observatory-public sector-innovation.htm.

Pollitt, C., and G. Bouckaert, Public Management Reform, Oxford University Press, 2004

Rivera León, L., P. Simmonds, and L. Roman, 'Trends and Challenges in Public Sector Innovation in Europe', Technopolis, Brussels, 2012

Unfried, M., Going Green: Concrete Solutions from the Public Sector, In: Heichlinger, A., ed. EPSA Trends in Practice. Driving Public Sector Excellence to Shape Europe for 2020, European Institute of Public Administration, Maastricht, 2011, 63-87

UN Public Service Awards, available at http://www.unpan.org/dpadm/unpsdayawards/unpublicserviceawards/tabid/1522/language/en -us/default.aspx. 


\section{Chapter 4}

\section{Exploring the Role of ICT, Skills and Organizational Change in Public Sector Performance}

Antonello Zanfei and Paolo Seri, DESP, University of Urbino, Italy

\subsection{Introduction}

An extensive range of empirical literature over the past decades has shown that the adoption of ICTs fosters new organizational practices and requires new labour skills. Only actions simultaneously involving all these three variables can positively affect economic performance and avoid the so-called Solow paradox, i.e. an insignificant, or even negative, impact of ICT diffusion on the firm or sector competitiveness and productivity (Brynjolfsson et alii., 1997; Bocquet et al 2007; Caroli, 2001; Jorenson et al., 2005; Bartel et al., 2007).

Such investigations, however, remain largely confined to private sectors. While important insights can be drawn from this relatively wide range of studies, to the best of our knowledge there is very limited systematic evidence on the complementarities in the case of Public Administrations (PAs thereafter).

The lack of research on the links between ICT, organizational change, skill structure, and performance of the public sector is due inter alia to the conceptual and analytical problems encountered when estimating output for non-market sectors. Moreover, proper proxies of skill composition and organizational change are even harder to obtain for PAs than for private sectors. The result is that scant attention has been devoted to the investigation of the ICT effects on Public Administration (PA) productivity, or to the accompanying changes taking place among the organizational structures and skills composition of PAs.

Recent research has indeed highlighted different aspects of the complementarity puzzle in the case of PAs. This effort is reflected in the more comprehensive measures of public sector performance that account for the quality of inputs or innovativeness of outputs. Moreover, there is a growing number of qualitative and quantitative analyses of the complexities of ICT adoption in public organizations. Going deeper along this line has also led to explicit evaluation of the co-evolution of ICTs, skills and organization and their effect on public sector productivity, thus helping explore the specificities of the Solow paradox in the case of PAs (Seri and Zanfei, 2013).

This paper accounts for such developments and offers some insights on the conceptual and empirical issues that are raised when moving in this direction of research.

To examine the role of ICT, skills and organizational change in public sector performance, three separate sets of conceptual and empirical issues need be tackled. First, one has to address the serious analytical problem of measuring performance in the case of the public sector. Second, one needs to evaluate the specific role of ICT in public sector modernization. And third, the interactions between ICT, organizational change and skills should be examined more explicitly to assess their joint impact on public sector performance. 


\subsection{The measurement of public sector performance}

The analysis of performance in service sectors has traditionally posed a number of conceptual and methodological problems (Griliches, 1984). In the case of the public sector, this task is even harder to tackle. One may mention at least three specific sets of largely unresolved issues (Baxter, 2000; OECD, 1999; Della and Gallous, 2008). First, public services are commonly provided free of charge or at modest prices that do not cover the costs of production. Hence, price and tariffs, when they exist, are not reliable measures of the unit value of output. Second, assessing public sector output in terms of quantities is a difficult task as standard units of analysis and measures are seldom available. Indeed, one can hardly single out universally recognized tasks to be accomplished for each individual public function, associate volume measures to each individual task, and aggregate them into consistent sets of data to allow comparative analyses across countries. Third, even in the presence of comparable measures of output quantities (or values, when prices are available), evaluating quality is even harder. In fact the perceived quality of public sector output depends on social and economic objectives which differ across countries and depend on the actors being considered, whether they are providers or users of public services. Significant differences also exist across actors along the supply chain (e.g. the Ministry of Health vs. the director of a hospital vs. individual doctors), and across user categories (e.g. tax payers indirectly taking advantage from externalities created by a hospital, vs. patients directly using health services). The quality of output is thus undetermined unless one adopts the view-point of a specific set of actors.

A survey of extant literature (World Bank, 2011; Jorgenson, 2010; Simpson, 2009; Dean, 2009; Murray, 2010; Della and Gallous, 2008, EC2013) makes it possible to distinguish between the following families of empirical strategies to tackle the above mentioned sets of problems:

\section{a. Use of inputs as a proxy of output}

One way of dealing with the difficulties of measuring output quantities and values is to rely on inputs, which can be more easily quantified and priced. In most international comparisons input data are used as a proxy for output of non-market services. This procedure has long been used in many publications, including Dean (2009) and World Bank (2011). A major limitation is that this method implicitly assumes that PAs are equally productive in utilizing inputs. In line with this criticism, Dean (2009) maintains that "the use of input ratios to compute output ratios, with no adjustment for productivity differences and no other adjustment, is incorrect. It is surely time to end this procedure, for which no defensible rationale can be presented."

A more acceptable variant of this method would then be to consider input costs and correct them for some proxy of differences in efficiency of PAs. Some scholars propose to use labour productivity data as calculated for market sectors - where labour productivity is measured as output per employee - to estimate outputs in non-market sectors (see e.g. Dean, 2009 and Simpson, 2006). More direct proxies of PA efficiency would be desirable but are often difficult to find. One procedure that has been followed (see e.g. Lina et al., 2010) is to adjust input costs for some measure of quality of service activities, which would allow us to better differentiate public sectors in terms of their actual performance. 


\section{b. Measuring output in terms of service activities}

Indicators of public sector output have been introduced by several countries into their national accounting systems. However, the shift to substitute input-based measures with output indicators is a relatively recent one, with the partial exception of the UK which started producing activity based statistics for public services in the mid 1980s (Ashaye, 2001). As mentioned earlier, the generalized introduction of output indicators and their use for comparative analyses across countries would require an effort to standardize units of analysis and measurement procedures (OECD 1999, Pritchard 2003, Handler et al. 2005). This effort is complicated by the heterogeneity of activities composing a given public service both within and across countries, and by the absence of reliable price indexes to assign a value to such activities ${ }^{40}$. The fact that comparable data are not always available for a large set of public sector activities constitutes a serious hindrance to the use of this type of indicators. Even in the case when service activities can be considered relatively good proxies of public sector output as a whole, one may question whether and to what extent such indicators actually capture the performance of PAs. Indeed, the interpretation of changes in output levels measured in terms of service activities will depend on the (technological and/or organizational) context in which such changes occur. For instance, shorter hospital stays could be considered as a reduction of output, but this could be the result of improved organization and hence reveal an improvement of performance. This would also be the case of the introduction of ICTs leading to a lower number of paper-documents processed by a public administration: this reduction of output should also be interpreted as a sign of better performance. While measuring output and performances is per se a difficult task to accomplish in the case of public services, the fact that indicators of increasing (decreasing) output may be interpreted as worsening (improving) performance adds further complexity to the analysis of public sector activities.

\section{c. Capturing the quality of public sector activities}

This is a hard exercise in general, and it is even harder in the absence of market prices as proxies of quality. Eurostat (2001) has identified three methods of taking quality into account in the case of non-market services. The first such method is based on ad hoc measures of the quality of output produced by means of surveys on how effective services are perceived to be either by; users, providers or inspecting/regulatory institutions. A major limitation is that data collected from these surveys often reflect a specific point of view (the one of the evaluator), and are more effective at assessing the quality of the production process than the quality of output (see e.g. Atkinson Review 2011 of the UK Office for National Statistics).

The second method to approximate the quality of output consists in measuring the quality of inputs. From this perspective, workers' qualifications and wages are taken as measures of output quality. Much like the first family of approaches recalled earlier (using inputs as a proxy of output), this method is based on the heroic hypothesis that all changes in input quality will translate into output quality.

The third method addresses the issue of quality by investigating outcomes, i.e. by assessing the ultimate results of public sector activities. Of course the closer indicators get to the outcome end, the more controls are necessary for additional factors, other than public sector

\footnotetext{
${ }^{40}$ An agreement needs to be found on: which service activities should be covered (e.g. no universally accepted standards exist in terms of tasks to be performed by government servants); which volume-based measures should be used (e.g. number of hospital beds provided, number of pupils per school class, number of documents processed); which weights should be adopted to aggregate different volume-based activities (e.g. costs of individual cases treated).
} 
characteristics or decisions, that may affect them. To illustrate, the number of students graduating from university in a given year might be considered as a good outcome indicator, but this will depend, inter alia, on the quality of students which is not only affected by teaching activities (e.g. the income level of their families will also play a role). The complexities and country specific nature of such measures entails that the choice of a qualitybased index to adjust inputs should be considered with particular care.

An important variant of this line of empirical research is to consider measures of innovation to account for the quality of public sector output. Arundel and Huber (2013) identified 17 studies using large scale datasets to evaluate public sector innovation in developed economies distinguishing between using three methodological approaches: 1) An object-based method examining specific innovations (the object), 2) Business practice surveys asking public sector managers about their use of specific innovative business practices and technologies, and 3) Innovation surveys asking about a range of innovation activities and types of innovations implemented over a defined time period. Over time, the focus has shifted from the first two approaches to the use of innovation collecting data on a wider range of data than object-based and business practice surveys, and with a greater interest in external information sources, incentives, sources of innovative ideas, and outcomes (see EC 2013 for a recent survey on these methods).

Apart from a general criticism on the use of input-based estimation in the absence of some control for PA efficiency, at present there is no clear agreement on the methodology one should follow to carry out empirical studies on public service performance. To carry out analyses of output and productivity in the public sector across a relatively large number of countries, we are forced to exclude the second (activity-based) approach. As observed, only a few countries have been producing activity based statistics covering an extensive set of services and using comparable classification criteria.

\subsection{The complexities of ICT adoption in public sector}

The second set of analytical issues to be dealt with when analyzing determinants of public sector performance has to do with the role of ICT in the case of PAs. ICT has long been considered as a trigger of modernization in public administrations (Van de Donk and Snellen, 1998). During the 1990s many studies described ICTs as an "attractor" of organizational changes within and between public administrations (Van de Donk and Snellen, 1998). From this perspective, information and communication technologies should: i) facilitate adoption of modern techniques and methods in public management; ii) contribute to enhancing accountability, openness, and transparency; iii) promote interactive government-citizen processes. Indeed, Van Reenen et al., (2010) show that public institutions are among the largest adopters of ICT, with an average of 1.32 computers per employees in 2005-2008, as opposed to 0.64 in manufacturing and 1.18 in business services (differences are significant at the one per cent level). Within the public sector, the most ICT intensive sectors are by far Education (SIC 82) and National Security (SIC 92), while the least ICT intensive are Health Services (SIC 80). These broad averages hide considerable variation across European regions and countries, with the highest overall intensity in Northern Europe (1.75 computers per employees in the public sector) and the lowest in Eastern and in Southern Europe as expected (1.00 and 1.01 respectively). At the country level, the ICT intensity of the Education sector ranges from a minimum of 0.60 computers per employee in Poland and Slovenia, to a maximum of seven computers per employee in Austria (Van Reenen et al., 2010). In a similar vein, Ebbers and Dijk (2007) and Seri, Bianchi and Matteucci (2014) illustrate an 
extreme variety of patterns of e-Government development and Cepparulo et al., (2013) observe an extremely high heterogeneity in the diffusion of several categories of public.

Figure 0.5 e-Government use vs. availability, ranking 2010

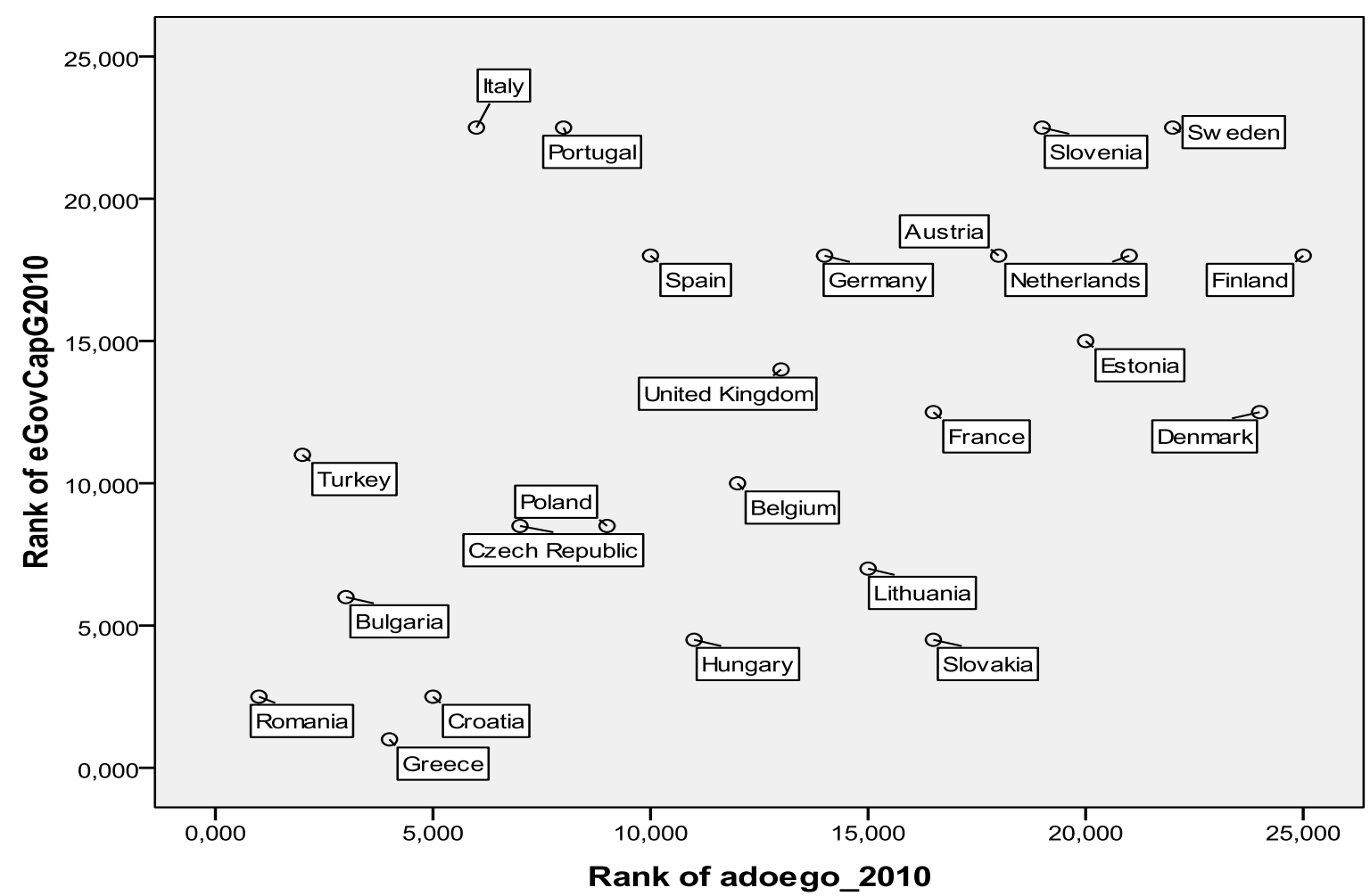

Source: Authors' calculations based on Eurostat data

While the digitalization of PAs and the subsequent availability of public e-Services are generally making strong progress, the actual use of the latter lags behind in many countries. Figure 5 orders the relative scores of European countries based on Eurostat data on e-Service availability and adoption.

The case of countries positioned in the high-left area of this chart reflects a general rule that applies inter alia to the diffusion of e-Government in Europe: "You can lead a horse to water, but you cannot make it drink". In these cases, PAs are most likely to have devoted more resources to 'opening up the e-Shop', than to organization design, skill development, back office support, digital literacy, interface friendliness, and consideration of user needs. 
The two sets of charts below (fig. 4.2 and 4.3) show the more specific indicator of availability and use of e-Government services for citizens and enterprises (Eurostat 2003-2012). A gradual convergence of the two lines indicates the global effectiveness of delivered eServices, while strong separation of the two lines can be interpreted as a lack of effectiveness, thus revealing that the Solow paradox is in action in the case of PAs. In some circumstances, abrupt separation of the two lines can also indicate a measuring problem (the level of availability might be overstated by governments for the sake of "marketing" reasons).

Figure 0.6 e-Gov indexes diverging trends for enterprises

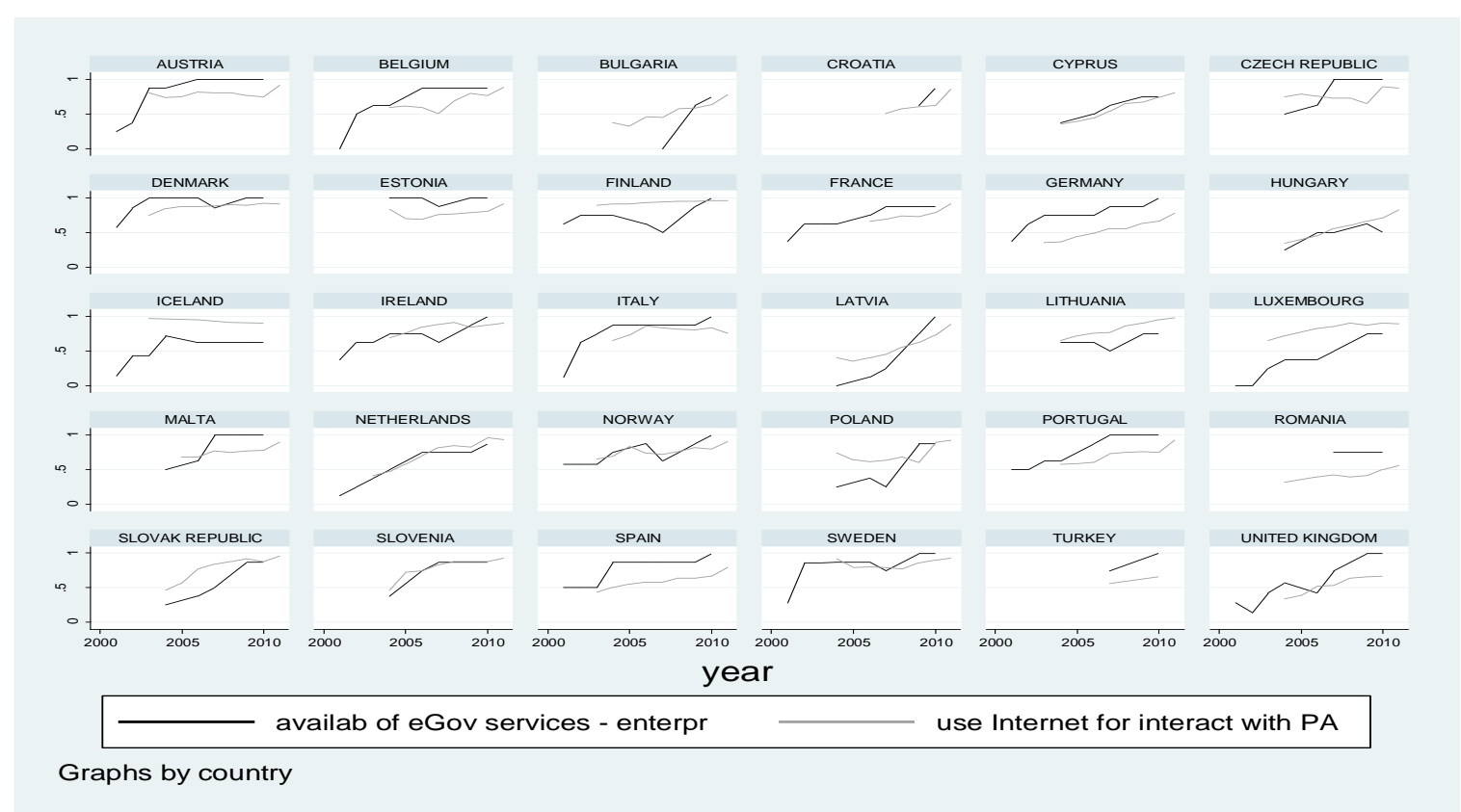

Source: Authors' calculations based on Eurostat data

Figure 0.7 e-Gov indexes diverging trends for citizens 


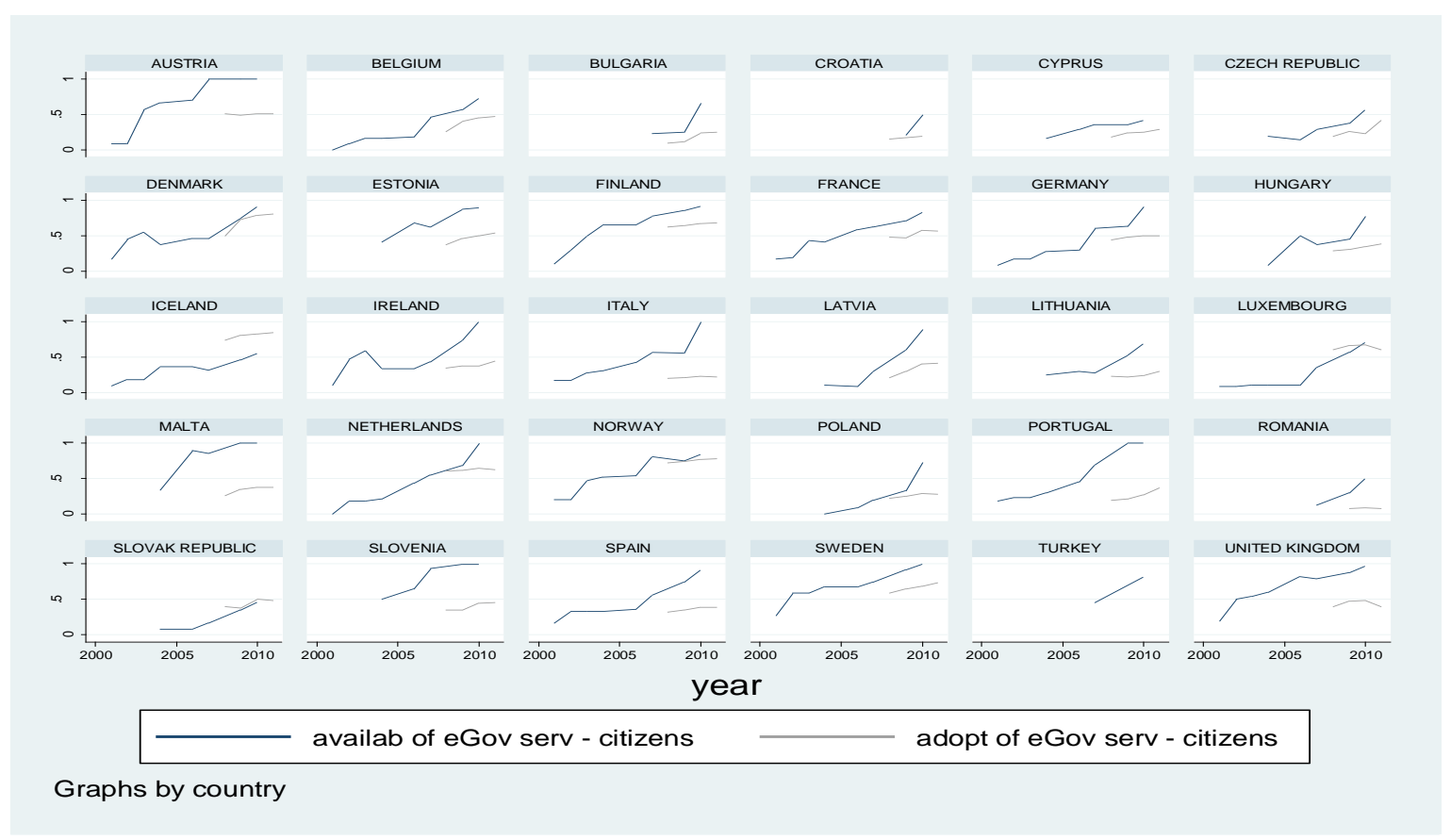

Source: Authors' calculations based on Eurostat data

Italy exhibits a strong bifurcation between the formal availability and the actual use by firms and citizens of public e-Services. This emerges also from more detailed data produced by Istat (2013) $)^{41}$, which carried out two surveys in 2009 and 2012 on ICT equipment and use in Italian local PAs. Comparing data between surveys highlights that Italian PAs have significantly increased the introduction of most ICT devices, but the presence of internal bodies and staff specialized in ICT is still very limited and low (and decreasing) resources are devoted to ICT training of personnel. Twenty per cent of local PAs have organized training courses in 2012, and only 6.3 per cent of employees have received training in this field over the past year (7.7 per cent in 2009).

Remarkable differences also exist between institutions according to their size. Most Regions and Autonomous Provinces (21 out of 22), and 80 out of 100 Municipalities with more than 60,000 inhabitants have this office, compared to 6 per cent of Municipalities with no more than 5,000 inhabitants. For some activities such as the management of accounts, payments, tributes and, only for Municipalities, Registry of marital status and Population Registry, a good level of digitalization and integration between different software applications is reached. Other activities, such as the management of contracts and tenders, are still poorly networked. "Basic" technological equipment is used by almost all local administrations but the adoption of more sophisticated technologies - such as mobile ones - is once again limited to large PAs: 70 out of 100 of the largest Municipalities and only eight out of 100 smallest ones use mobile devices (tablets, smartphones, netbooks, etc.). Almost all local PAs offer web-services to the users, but the possibility of submitting forms on-line is circumscribed to 36 per cent of PAs, and completing the whole administrative process electronically is limited to 19 per cent, even less in the case of on-line payment procedures.

This scenario is consistent with the evidence offered in Figures 4.4 and 4.5. Here Italy, notwithstanding its high performance in e-Services availability, ranks very low in the effective use of e-Services by citizens and firms. More generally speaking, these figures

${ }^{41}$ http://www.istat.it/en/archive/91815 
confirm that a significant gap exists between availability and actual adoption of public eServices, especially when usage by citizens is considered, with numerous countries exhibiting percentages well below the OECD average.

Figure 0.8 Citizens using the internet to interact with public authorities by type of activity, 2012

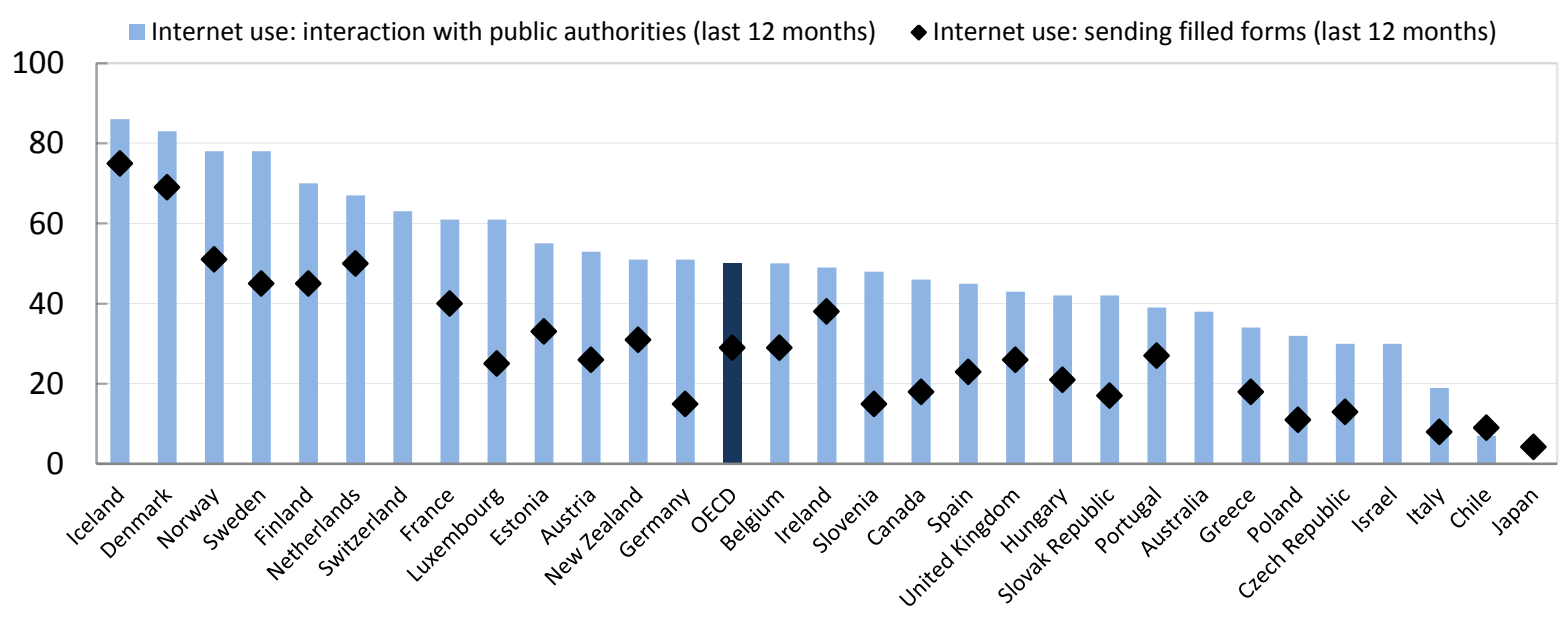

Source: Eurostat Information Society Statistics (database)

Figure 0.9 Firms using the internet to interact with public authorities by type of activity, 2011

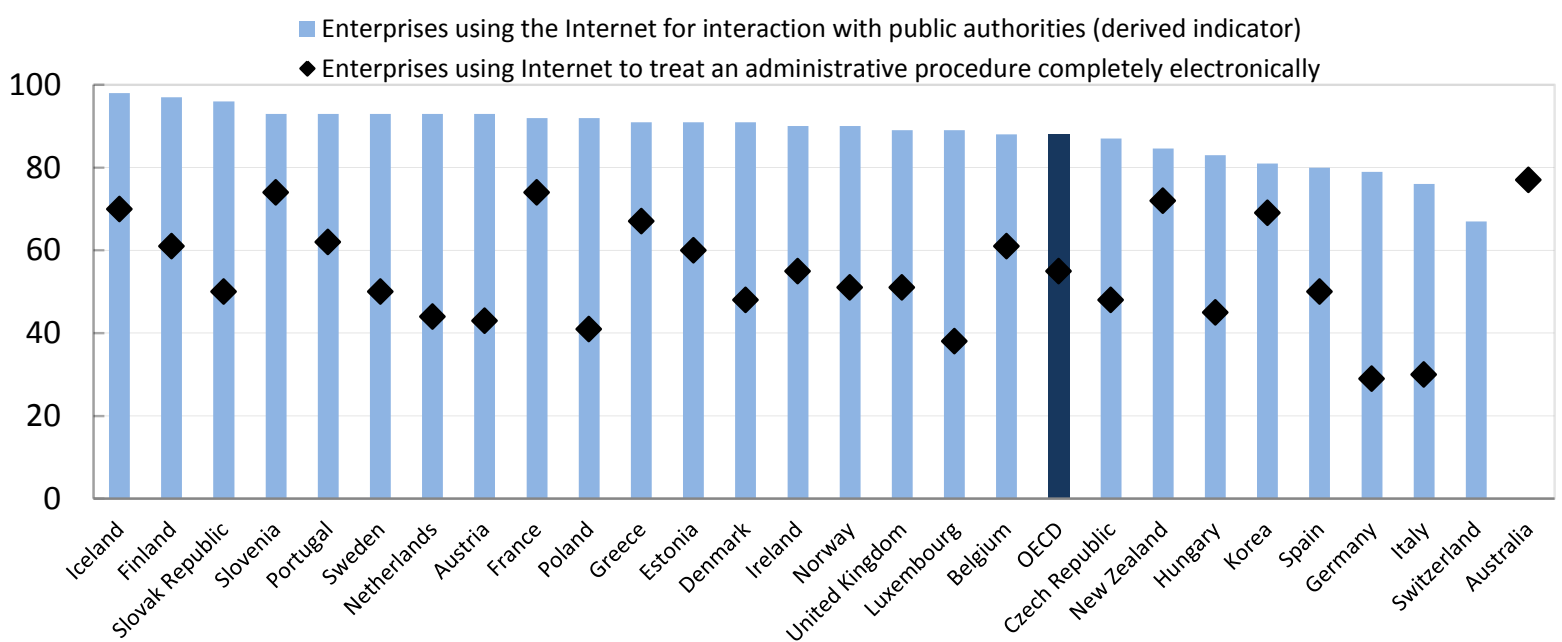

Source: Eurostat Information Society Statistics (database)

When it comes to examining how effective the introduction of ICT is in public organizations, the scenario is quite blurred. Sorrentino (2004), examines 138 co-financing proposals put forward by numerous Italian public bodies within the context of a national e-Government plan, and concludes that these types of initiatives are not really likely to improve organizational performance. Shaun Goldfinch (2007) in his paper on "Pessimism, Computer Failure, and Information Systems Development in the Public Sector," shows that the majority of information systems developments in public administrations are unsuccessful. This is especially the case of large ICT investment projects which have a higher complexity and are often harder to manage. He argues that, despite the persistence of this problem for decades 
and the expenditure of considerable amounts of money, computer failure has received surprisingly little attention in public administration literature. The portrait of public officers that emerges from Goldfinch's analysis is that of a recalcitrant, suspicious, and sceptical adopter of information technologies, who is most likely to act as a barrier to, rather than a promoter of, innovation in PAs.

Consistently with the abundant empirical literature on ICT adoption in business sectors, it is often held that, also in the case of the public sector, the successful exploitation of these technologies requires the presence of a wide range of skills and organizational practices. Dunleavy et al., (2006) highlight four main challenges which might hinder the efficiency impact of ICT in the public sector. First, due to their sheer size and complexity combined with exposure to political pressure, public administrations generally exhibit what has been dubbed organizational inflexibility. This consists in a greater resistance to absorb laboursaving technology and in a generalized tendency of public institutions to overcome barriers to the introduction of ICT by means of large-scale investment programmes rather than piecemeal, cumulative changes (the "big-bang cycle" approach). Second, growing pressures on governments to increase their market orientation as to achieve greater cost-efficiency, have induced PAs in many countries to outsource a large fraction of ICT activities. This has determined an additional layer of technical inflexibility to the already rigid organizational features we have just recounted. Third, while the development of digital network services and defence-related technologies allowed the public sector to attract large numbers of highly skilled ICT specialists in the 1960s and 70s, private firms and ICT system companies have thereafter gradually overtaken governments in terms of ICT and digital technology innovation. This has significantly reduced the attractiveness of the public sector for qualified workers and caused an endemic lack of skilled ICT specialists, further increasing the costs of adapting new systems to the specific characteristics of public organizations. Fourth, the shortage of in-house specialized ICT and the increasing outsourcing trends mentioned above are often coupled with a lack of competition in the ICT supply for public organizations. This is likely to generate distortions in the quality or quantity of ICT supplied to the government, hence reducing the effectiveness of ICT within the public sector.

\subsection{How the interactions between ICT, skills and organization affect public sector performance}

The empirical relevance of these constraints to the exploitation of ICT in the public sector can hardly be evaluated with robust statistical methods due to scarcity of data on output, organizational practices and skill composition in the public sector (Van Reenen et al., 2010). A few works have been able to overcome these constraints and provide a convincing analysis of the role played by ICT, although this has been done mainly with reference to specific public sector activities, and most often focusing on individual countries.

Machin, McNally and Silva (2007) examine whether the adoption of computers in UK schools over the 1999-2003 period has increased student educational outcomes. In sharp contrast with most previous studies across US and European schools, Manchin et al., find a strong relationship between ICT investments and educational performance in primary schools, especially in the teaching of English and science (not of mathematics). To overcome endogeneity problems they use a quasi-experimental setting and observe student performance before and after a major change in the rules about how ICT funds were allocated to different Local Educational Authorities (LEAs). Unfortunately, since this paper is based on area-level variation, the authors are not able to provide any direct insight on the key characteristics of the schools which were most affected by ICT adoption, or whether significant school 
organizational or skills complementarities may have impacted the ultimate effect of ICT on performance. Nevertheless, they find more indirect evidence of the impact of skill levels within schools, as they observe that LEAs benefiting the most from the policy change were those with lower overall expenditure per pupil, but better educational standards (as measured by exam pass rates and truancy rates). It thus appears to be the joint effect of large increases in ICT funding and a fertile background for making efficient use of it, that led to positive effects of ICT expenditure on educational performance.

Garicano and Heaton (2010) examine the relationship between ICT, organizational change and productivity across some 8,600 US police departments using a panel data set that covers the 1987-2003 period. They find that when considered alone, increases in ICT are not associated with reductions in crime rates, increases in clearance rates, or other productivity measures. These results persist across various samples, specifications, and ICT tools (PCs, mobile data terminals, mainframes and servers). ICT investments are, however, linked to improved productivity when they are complemented with particular organizational and management practices.

They first show that ICT adoption is associated with a variety of organizational changes within a department, including an expansion of personnel (primarily in technical support roles as opposed to field operations), an increased use of special units, and enhanced training and educational requirements. Thus, departments that expanded ICT use have also modernized their own activities in other important ways. They next identify agencies that simultaneously implemented high levels of ICT, specialization, and education. In panel regressions that control for underlying organizational and ICT measures, they illustrate that agencies implementing this combined set of practices experienced statistically significant drops in crime rates. To further test the complementarity hypothesis, they also study the impact of ICT when it is adopted together with techniques characteristic of the police department's Compstat performance management system, including raising skill levels, new problem-solving techniques, extensive use of "output" information in evaluation and deployment of officers, and a geographic-based structure. Although the data available for testing this hypothesis are much shorter and more limited, they clearly endorse this hypothesis. Overall results are also confirmed by a number of robustness checks.

A few papers carry out in-depth cross-country studies on how the diffusion of digital network technology affects the performances of public organizations. Caldas, David and Ormanidhi (2005) provide perhaps one of the most extensive analyses of the effects of ICT on general government activities in eight European countries, capturing the interplay of technology adoption, organizational change and performances of PAs. The authors exploit a large and very detailed dataset based on a survey of more than a thousand public sector organizations, which was conducted in 2003. First, they find that while larger PAs have easier access to budgetary and technical resources, thus favoring digital network technology adoption, size per se may be not explain their performance. Caldas et al., (2005) identify clusters of public organizations with different characteristics in terms of territorial distribution and hierarchical positions in the decision-making processes which are associated to different technological profiles, largely independent of size. Second, they analyse a sub-sample of public organizations and compute a measure of performance that combines the relationship between their adoption and mode of utilization of e-network technologies, on the one hand, and, on the other hand, the rates of improvement that their managers perceived had occurred in the average number of cases resolved per employee. They obtain approximate estimates of the implied rate of growth in the sector-wide average number of "cases resolved per employee" during the period 2003-2008. 
While Caldas, David and Ormanidhi develop an extremely rich and promising line of research, they can shed only a limited light on the complementarity issue in the case of PAs. In fact, they provide very detailed data and analyses on how technology adoption interacts with the ability of PAs to "resolve cases". In order to do so, however, they are forced to focus on a subsample of organizations that do perceive a change of performances, thus reducing the possibility of generalizing their results.

Other cross-national analyses address the links between ICT and public sector performance with reference to specific areas of service activity. A number of such studies focus on education, due to the availability of extensive surveys carried out for OECD countries within the Programme for International Student Assessment (PISA) administered since year 2000 (OECD 2009). Nevertheless, in most cases experimental and quasi-experimental analyses are not feasible and instrumental variables are not available, due to data limitations, so that analysing correlation relationships is often the only feasible strategy. This is the case of Fuchs and Wößmann (2005), Notten \& Kraaykamp (2009), and Luu \& Freeman (2011) who find a positive and significant correlation between the availability of computers at school and student performance in PISA tests, although the estimated correlation is reduced when additional variables are brought into the regression as controls. In a study that uses the 2006 PISA ICT familiarity questionnaire, Spiezia (2010) tries to go beyond a simple correlation analysis and, controlling for the potential endogeneity of treatment, finds that a greater frequency of computer use is positively associated with higher PISA test scores in science in all countries (with large cross-country differences in the estimated coefficients). He also offers indirect evidence on the role of skills and organizational factors by controlling where computers are used (home vs. school). In fact, according to computer location, one might infer both how ICT based training is organized (dispersion vs. concentration of educational services) and how skilled users are (as home usage implies a higher acquaintance than usage at school only). Spiezia (2010) shows that the positive relationship between intensity of use and the PISA science test score is much stronger for those who use computers intensively at home than for those who use them intensively at school (the association between test scores and intensity of computer use at school is not significant for many countries). While these results point at the low efficacy of ICT policies directed solely at schools, one may also suggest that they provide insights on the importance of organizational innovation and skill accumulation as a complement to ICT investment.

Biagi and Loi (2013) exploit the possibility offered by the 2009 wave of PISA to evaluate student performances not only as a function of computer usage but also as a function of the breadth of learning activities. After having categorized computer use into a set of different activities according to the skills they involve, the authors correlate student PISA test-scores with an index capturing the intensity of use for each of these activities and with the total number of learning activities they perform. Overall, Biagi and Loi find that student PISA test scores in reading, mathematics and science increase with the intensity of computer use for Gaming activities while they decrease with the intensity of computer use for activities that are more related with school curricula (i.e. Communication and Collaboration activities; Technical Operations/Info Retrieval activities; Creation of Content and Knowledge Problem Solving activities). However, the number of learning activities (and hence the diversification of these activities), irrespective of the intensity of computer use, is positively correlated with student proficiency in all three PISA domains in the vast majority of the 23 countries examined. This is consistent with a framework in which the different activities are complementary in building competences that are relevant for the PISA tests. It remains that Biagi and Loi's analysis cannot be considered as a proper impact assessment based on counterfactual evaluation, as the PISA test scores obtained by students using ICT cannot be 
compared with test scores obtained by students of an appropriate control group. Indeed, finding such a control group is almost impossible, especially in countries (such as Nordic countries) where most students declare having access to and using computers both at home and at school.

To summarize, public sector activities in general appear to be significantly ICT intensive, and even more so than their private sector counterparts. However, there are relatively few studies analysing how ICT and other key factors affect public sector performance with rigorous statistical methods. Some of them do provide rich evidence on the complementarity between ICT, skills and organizational change. The most comprehensive and robust analyses of these complementarities have been carried out with a narrow focus in terms of public sector establishments and activities (e.g. primary schools or police departments), and in terms of country coverage (normally individual countries). Due to data shortage, the more analyses are extensive in terms of public services and country coverage, the less conclusive is the extant evidence of the actual impact of ICT on public sector performance.

\subsection{Beyond traditional approaches to ICT and performance in public sector}

Different from the extensive stream of research on individual sub-sectors of PAs, they conduct a cross-country analysis on the aggregate of PAs (net of defence). Moreover, they integrate different data-sources that allow them to evaluate patterns and determinants of performance for all public sector organizations in the examined countries, and not only the ones that innovate in their practices (different from Caldas et al., 2005). Seri and Zanfei (2013) propose an index-based approach to the measurement of PA performance relying on the adoption of public e-Services as a proxy of revealed output quality, and provide an econometric analysis of how the co-evolution of ICT, skills and organizational factors affects Government effectiveness. This implies correcting the traditional approach of measuring output in terms of inputs (first family of empirical strategies illustrated in section 2) by taking into account differences of effectiveness of PAs (consistent with the third family of empirical strategies). More precisely, their quality-adjusted index of output combines two country level indicators: (a) per-capita PA expenditures net of Defense (PA_SPENDING) ${ }^{42}$; (b) a measure of e-service adoption. The second set of data (b), which they use to qualify input costs, is a combination of four indicators of actual utilization (by citizens and enterprises) of public eServices by country, as supplied by Eurostat (eSERV ADOPTION ${ }^{43}$. The authors consider this proxy of public e-service adoption as an indicator of public service quality. On the one

\footnotetext{
${ }^{42}$ EU-KLEMS (http://www.euklems.net/) provides data on Gross Output measured in terms of input costs at current prices (in millions of Euros) by country from 1970 to 2007 for all sectors. Data supplied under the label: "PUBLIC ADMIN AND DEFENCE; COMPULSORY SOCIAL SECURITY" include all public sector activities except health and education. The SIPRI Military Expenditure Database (http://www.sipri.org/databases) provides data on defence sector costs expressed both in terms of US\$ values at constant and current prices and as a percentage of gross domestic product. To check the consistency of the SIPRI dataset with EU-KLEMS, Seri and Zanfei (2013) computed an additional proxy of defence expenditures by calculating the percentage provided by SIPRI on EU-KLEMS Output values. They were thus able to compute two measures of PA expenditure net of defence, by alternatively subtracting the one of two measures of defence expenditures from EU-KLEMS Gross Output values for public sector. They ran the same regressions illustrated in section 4 using either measure of PA spending net of defence as a basis to calculate the dependent variable and obtained similar results, which are available from the authors upon request.

${ }^{43}$ Data are drawn from http://epp.eurostat.ec.europa.eu/portal/page/portal/statistics/search_database; See the folder "Computers and the Internet in households and enterprises" in "Information society statistics". One of the four indicators refers to individuals using the Internet to interact with PAs; and three other indicators capture different aspects of enterprise usage of the Internet to obtain information or interact with PAs. The measure used by Seri and Zanfei (2013) is a weighted means of the four indicators, calculated with alternative weights to check the robustness of empirical relations tested.
} 
hand, it denotes the ability of PAs to introduce new services that are per se innovative. In fact, the deployment of public e-Services requires: a non-trivial effort to adapt existing services, and design new ones, in order to deliver them though the Internet; an overall restructuring of both back-office and front-office activities; and a fundamental change in the approach to customers/users (Serrano Cinca et al., 2003, Arduini et al. 2010). On the other hand, adoption indicators reveal that the introduction of these relatively new services has survived a selection which is not only based on their cost-effectiveness but also on the satisfaction of user needs. In other words, the transformation of existing services into Internet-based government activities will be associated with a sunk cost that users will have to bear in case of adoption. It is assumed that, especially in a pre-paradigmatic phase of eServices development, users will only adopt "high quality" services, i.e. services that are really worth bearing this extra cost.

The quality adjusted output index PA_ADJ_OUTPUT, is thus obtained as PA_SPENDING * e-SERV_ADOPTION. As such, it reflects the amount of input costs sustained by Public Administrations (in terms of capital services, labour services and intermediate inputs, either purchased from domestic industries or imported), but will turn out to be higher the greater the level of public e-Service adoption. PA_ADJ_OUPUT is used as a dependent variable in the econometric exercises.

Due to crossed/missing values between the sources utilized to construct the two sets of measures - (a) PA expenditures net of defence and (b) public e-Service adoption - the analysis needs be restricted to 16 European countries (Austria, Belgium, Czech Republic, Denmark, Finland, France, Germany, Hungary, Ireland, Italy, Netherlands, Portugal, Slovenia, Spain, Sweden, United Kingdom) for which a full panel of consistent data are available over the 2003-2007 period.

In order to examine the complementarity issue in the case of public sector in Europe data on ICT investments, human capital and organizational change were also collected.

Data on ICT investment (PA_ICT) and on skill levels of employees (PA_SKILL) are drawn from the EU-KLEMS dataset. While information on the first two sets of variables can be derived under reasonable assumptions from EU-KLEMS's data (see Seri and Zanfei 2013 on this), measuring organizational change is by far the most complex task to accomplish. In fact, public sector activities involve a variety of organizational levels - within individual PAs, across PAs and between PAs and users of services - all of which interact with human capital accumulation and ICT investments. Since direct (and homogeneous) measures of all of these organizational dimensions in non-market sectors do not exist at the country level, the authors use an indirect measure based on the availability and sophistication of e-Services. 
Table 0.6 List of e-Services considered by the EU e-Government benchmark

\begin{tabular}{|l|l|}
\hline 1. Income taxes \\
2. Job search services \\
3. Social security benefits \\
3.1. Unemployment benefits \\
3.2. Child allowances \\
3.3. Medical costs \\
3.4. Student grants \\
4. Personal documents \\
4.1. Passports \\
4.2. Drivers licence \\
5. Car registration \\
6. Application for building permission \\
7. Declaration to the police \\
8. Public libraries \\
9. Birth and marriage certificates \\
10. Enrolment in higher education \\
11. Announcement of moving \\
12. Health-related services
\end{tabular}

Source: CapGemini et al 2010

Their measure of organizational change (PA_ORG) is obtained as the weighted average of Public e-service Online Availability Index computed by Capgemini et al., (2010) for the European Commission, where weights are represented by the degree of sophistication of services provided according to a five-stage maturity model (see Capgemini et al., 2010). See Table 4.1 for the complete list of e-Services monitored by Capgemini et al., (2010). The idea is that, much more than the provision of standard services, the introduction of web-based services imply an overall change in the organizational structure of PAs; and organizational change required will be even deeper the higher the level of "sophistication" (i.e. the degree of interactivity) of such e-Services. As suggested in the recent UN "e-Government Survey 2012":

"Small-scale ICT activity - development of a website as an additional information channel may not require complex supporting changes. Far reaching organizational change will be required when:

1) The website begins to offer deeper, more complex services. 
2) Agencies are asked to work together to deliver services according to the needs of citizens and not their structure.

3) New work styles - tele-working, virtual teams - emerge.

4) With increased data-sharing and communication:

- particular data holdings become redundant

- more decisions are made at the lower organization levels

- special units are established for government-wide projects" (UN 2012) ${ }^{44}$

The introduction of e-Services is generally associated to all four circumstances listed by the UN. By using PA_ORG as a proxy of organizational change, it is thus assumed that, once controlled for ICT investments and human capital composition, a higher provision of sophisticated e-Services reveals that PAs will have undergone a profound change in their organizational structure and behaviour.

Seri and Zanfei 2013 extensively discuss limitations of these assumptions on the role of both e-Service adoption and provision as indicators of service quality and organizational innovation respectively, and address different technical issues including complementarity tests, controls for endogeneity of variables used, robustness checks and tests on fixed vs. random effect models.

They regress their quality-adjusted measure of PA output (PA_ADJ_OUTPUT) on their key explanatory variables (ICT investments, skill composition and our proxy of organizational change), and other controls (per capita GDP, infrastructural endowments and educational attainment of population).

Tab. 4.2 shows the results of regressions with one of the specifications of the dependent variable, i.e. the one wherein the output quality adjustment is calculated in terms of a simple means of the four indicators of e-Service adoption (see Seri and Zanfei for other specifications and robustness checks). In column 1 we test how the three explanatory variables of our baseline model - investment in skilled personnel, organizational change and ICT spending - singularly taken, influence our PA quality-adjusted output measures. It is shown that the proxies for human capital and for organizational change significantly affect our measures of output. Although the proxy of organizational change used is quite rough, adding a control on the delivery of sophisticated e-Services for any given level of ICT expenditure and labour qualification (and other contextual factors such as per capita GDP and broadband penetration) should capture the PAs' ability to introduce significant changes in its organizational structure and behaviour. ICT expenditure per se does not significantly impact on PA performance. This is consistent with what has long been observed in the extensive literature on the business sector (and in the scantier works on PAs reviewed in section 3), i.e. the effect of investment in these technologies can hardly be seen in productivity statistics, which is also the case in the public sector.

Similar to findings in extant literature focusing on business sectors, one may also assume that ICT expenditure will eventually translate into PA output changes only in the presence of key complementary factors, such as organizational change and a qualified human capital. This hypothesis is tested in columns 2, 3 and 4 of Table 5, where the following interactions are added respectively: the interacted term PA_SKILL* PA_ICT, which allows us to capture the impact of joint investment in ICT and human capital sustained by PAs in the observed countries; the interacted term PA_ORG * PA_ICT, which should highlight the impact of joint

${ }^{44}$ http://unpan1.un.org/intradoc/groups/public/documents/un/unpan048065.pdf 
investment in ICT and organizational change; and the interactive effect generated by all of the three factors together: PA_SKILL* PA_ORG * PA_ICT (independent variables are centered on the mean as suggested in Jaccard and Turrisi, 2003).

Table 0.7 The impact of ICT, skills and organizational change on PA performance

\begin{tabular}{|c|c|c|c|c|}
\hline & (1) & (2) & (3) & (4) \\
\hline VARIABLES & PA_ADJ_OUTPUT & PA_ADJ_OUTPUT & PA_ADJ_OUTPUT & PA_ADJ_OUTPUT \\
\hline \multirow[t]{2}{*}{$\begin{array}{c}\text { PA_SKILL } \\
\text { (L) }\end{array}$} & $32.36 * * *$ & $32.70 * * *$ & $20.87 * *$ & $25.29 * *$ \\
\hline & $(10.99)$ & $(10.85)$ & $(9.112)$ & $(10.15)$ \\
\hline \multirow[t]{2}{*}{ PA_ORG $(\mathrm{O})$} & $0.251^{* *}$ & $0.250^{* *}$ & $-0.995 * * *$ & 0.0294 \\
\hline & $(0.124)$ & $(0.122)$ & $(0.278)$ & $(0.131)$ \\
\hline \multirow[t]{2}{*}{ PA_ICT (I) } & -0.132 & -0.281 & -0.384 & -0.0546 \\
\hline & $(0.421)$ & $(0.428)$ & $(0.341)$ & $(0.380)$ \\
\hline \multirow[t]{2}{*}{$\mathrm{L}^{*} \mathrm{I}$} & & 0.0895 & & \\
\hline & & $(0.0625)$ & & \\
\hline \multirow[t]{2}{*}{$\mathrm{I}^{*} \mathrm{O}$} & & & $0.0370 * * *$ & \\
\hline & & & $(0.00771)$ & \\
\hline \multirow[t]{2}{*}{$\mathrm{L}^{*} \mathrm{I} * \mathrm{O}$} & & & & $0.00442 * * *$ \\
\hline & & & & $(0.00139)$ \\
\hline CONTROLS & Yes & Yes & Yes & Yes \\
\hline $\begin{array}{c}\text { TIME } \\
\text { DUMMIES }\end{array}$ & Yes & Yes & Yes & Yes \\
\hline Observations & 64 & 64 & 64 & 64 \\
\hline R-squared & 0.760 & 0.772 & 0.850 & 0.810 \\
\hline $\begin{array}{l}\text { Adjusted R- } \\
\text { squared }\end{array}$ & 0.612 & 0.622 & 0.752 & 0.685 \\
\hline $\begin{array}{l}\text { Number of } \\
\text { countries }\end{array}$ & 16 & 16 & 16 & 16 \\
\hline
\end{tabular}

Note: Standard errors in parentheses; *** $p \leq .01 ; * * p \leq .05 ; * p \leq .10$

Source: Seri and Zanfei (2013).

The results show that the last two interacted terms turn out positive, and add significance to the model, with respect to the factors taken singularly. This can be interpreted as a partial confirmation of the complementarity thesis. This procedure is broadly consistent with the one followed by Brynjolfsson et al., (1987) in the case of the impact of ICT on the performance of the US manufacturing industry; and by Antonioli et al., (2010) who examine how the links between ICT, training activities, and organizational change - including the introduction of labour flexibility and changes in industrial relations - affect the economic performance of small and medium sized manufacturing firms in Northern Italy. Using a terminology that mirrors the one adopted by Antonioli, et al. (2010), we can thus posit that interacting ICT with organizational and human capital variables "compensates" for the insignificant impact of ICT on our PA effectiveness indexes. More specifically, we show that while ICT does not per se have any effect on public sector performance, its combination with organizational change does (column 3). Furthermore, joint investments in ICT, organizational change and skills appear to positively affect public sector performance as well (see column 4). 
In other words, it is not ICT investment alone, but its combination with qualified labour and far-reaching organizational change, that affects PA performance. It is worth noting that this appears to be the first explicit test of the complementarity issue in the case of PAs, across a large number of countries and with reference to a broad set of public sector activities.

What seems to be specific of Public Sectors with respect to business, as shown in the data, is the role of both labour qualification and organizational change, which have a strong and significant impact on performance also when considered in isolation from investments ICT. One may interpret the importance and significance of these variables as confirming that performance is heavily affected by the ability of Public Sector organizations to qualify their labour forces and effectively handle complex relationships within individual PAs, across PAs and between PAs and users.

These results thus suggest that PA performance is largely driven by human capital and organizational change. This is likely to reflect the extreme complexity of information flows and decision-making levels that characterize the provision and adoption of public services. The key implication is that the ability to improve the quality of the labour force and handle organizational challenges is a distinctive factor affecting the performance of Public Administrations, over and above their investments in ICT. In a way, ICT might be seen as a factor that both stimulates investment in human capital and organizational change, and moderates their impact on PA performance, as its introduction imposes new challenges and compelling requirements in the management of public sector activities. 


\subsection{References}

Antonioli, D., M. Mazzanti, and P. Pini, Productivity, innovation strategies and industrial relations in SMEs. Empirical evidence for a local production system in northern Italy, International Review of Applied Economics 2010, 24 (4), 453-482

Arduini, D., F. Belotti, F. Denni, G. Giungato, and A. Zanfei, Technology adoption and innovation in public services. The case of e-Government in Italy, Information Economics and Policy, 2010, 22, 257-275

Arundel A., and D. Huber, From too little to too much innovation? Issues in measuring innovation in the public sector, Structural Change and Economic Dynamics, 2013, 27 (4) 146-159

Ashaye, T., Recent developments in the measurement of general government output, Economic Trends, 2001, 76, 41-44

Bartel, A., C. Ichniowski, and K. Shaw, How does information technology affect productivity? Plant-level comparisons of product innovation, process improvement, and worker skills, Quarterly Journal of Economics, 2007, 122(4), 1721-1758

Baumol, W., Macroeconomics of unbalanced growth: the anatomy of urban crisis, The American Economic Review, 1967, 3, 415-426

Baxter, M., Developments in the measurement of general government output, Economic Trends, 2000, 562, 3-5

Biagi, F., and M. Loi, Measuring ICT use and learning outcomes: evidence from recent econometric studies, European Journal of Education, 2013, 48(1), 28 - 42

Bocquet, R., O. Brossard, and M. Sabatier, Complementarities in organizational design and the diffusion of information technologies: An empirical analysis, Research Policy, 2007, 36(3), 367-386

Brynjolfsson, E., A. Renshaw, and M.V. Alstyne, The Matrix of Change, Sloan Management Review, 1997, 38, 22-40

Caldas, A., P.A. David, and O. Ormanidhi, Digital Information Network Technologies, Organizational Performance and Productivity: an Exploration of IT Diffusion in Europe's Public Sector. Oxford Internet Institute Working Paper, October 2005

Capgemini, IDC, Rand Europe, Sogeti and DTi, Digitizing Public Services in Europe: Putting Ambition Into Action, 9th Benchmark Measurement, European Commission, Directorate General for Information Society and Media, Bruxelles 2010

Caroli, E., and J.V. Reenen, Skill-biased organizational change? Evidence from a panel of British and French establishments, Quarterly Journal of Economics, 2001, 116, 1449-1492

Cepparulo, A., D. Arduini, L. Reggi, and A. Zanfei, Patterns of e-service development across European cities, 2nd EIBURS-TAIPS Conference on Innovation in the Public Sector and the Development of e-Services, University of Urbino, 18-19 April 2013 
Dean, E., International comparisons of non-marketed output: the role of productivity data, World Bank, available at: http://siteresources.worldbank.org/ICPINT/Resources/270056$\underline{1255977254560 / \text { InternationalComparisonofNonMarketedOutput_E.Dean.pdf }}$

Djellal, F., and F. Gallouj, Measuring and Improving Productivity in Services: Issues, Strategies and Challenges, Edward Elgar Publishers 2008

Dunleavy, P., et al., Digital Era Governance. Oxford: Oxford University Press 2006

Ebbers, W. E., and J.A.G.M. Van Dijk, Resistance and support to electronic government, building a model of innovation, Government Information Quarterly, 2007, 24: 554-575

European Commission, European Public Sector Innovation Scoreboard 2013 - A pilot exercise, European Union, DG Enterprise and Industry, Bruxelles 2013

Eurostat, Handbook of Price and Volume Measures in National Accounts, European Commission 2001

Fuchs, T., and L. Wößmann, What accounts for international differences in student performance? A re-examination using PISA data, Empirical Economics, 2007, 32, 433 - 464

Garicano, L., and P. Heaton, Information technology, organization, and productivity in the public sector: evidence from police departments, Journal of Labour Economics, 2010, 28(1), $167-201$.

Goldfinch, S., Pessimism, computer failure, and information systems development in the public sector, Public Administration Review, 2007, 67(5), 917-929

Griliches, Z., (ed), Output Measurement in the Service Sectors, The University of Chicago Press 1984

Handler H., B. Koebel, P. Reiss, and M. Schratzenstaller, The size and performance of public sector activities in Europe, WIFO (Osterreichisches Institut Für Wirstschaftsforschung), Working Papers $n^{\circ}$ 246, 2005

Jaccard, J., and R. Turrisi, R., Interaction Effects in Multiple Regression, second ed. Sage Publications, Thousand Oaks 2003

Jorgenson, D.W., Designing a new architecture for the U.S. national accounts, The Annals of the American Academy of Political and Social Science, 2010, 631(1), 63-74

Jorgenson, D.W., M.S. Ho, and J. Stiroh, A retrospective look at the U.S. productivity growth resurgence, Journal of Economic Perspectives, 2005, 22(1), 3-24

Liana P., S. Pekkola, J. Ukko, and H. Melkas, Defining and measuring productivity in the public sector: managerial perceptions, International Journal of Public Sector Management, 2010, 23(3), 300-320

Luu, K., and J.G. Freeman, An analysis of the relationship between information and communication technology (ICT) and scientific literacy in Canada and Austria, Computers and Education, 2011, 56, 1072-1082

Machin S., S. McNally, and O. Silva, New technology in schools: Is there a payoff? Economic Journal, 2007, 117(522), 1145-1167 
Murray, R., Measuring output from the public sector: A critical examination of the Atkinson Review, Review of Income and Wealth, 2010, 56(2), 413-423

Notten, N., and G. Kraaykamp, Home media and science performance: a cross national study, Educational Research and Evaluation, 2009, 15, 367-384.

OECD Productivity measurement in the general government sector, Expert meeting, 18-19 March 1999, Paris, PUMA/HRM/M (99)1

OECD, PISA Data Analysis Manual: SPSS, Second Edition, Paris, OECD, 2009

Pritchard, A., Understanding government output and productivity, Economic Trends, 2003, $596,27-40$

Seri, P., A. Bianchi, and N. Matteucci, Diffusion and Use of Public e-Services in Europe: An Assessment of Country Level Indicators, Telecommunication Policy, 2014, 38(5, 6), 496-513

Seri, P., and A. Zanfei, The Co-evolution of ICT, Skills and Organization in Public Administrations: Evidence from new European country-level data, Structural Change and Economic Dynamics, 2013, 27(4) 160-76

Serrano Cinca, C., C. Molinero, and A. Queiroz, , The measurement of intangible assets in public sector using scaling techniques, Journal of Intellectual Capital, 2003, 4(2), 249 - 275

Simpson, H., Productivity in public services, Journal of Economic Surveys, 2009, 23 (2), 250-276

Sorrentino, M., The implementation of ICT in public sector organizations. Analysing selection criteria for e-Government projects, Proceedings of 17th Bled e-Commerce Conference, Bled, Slovenia, June 21-23 2004

Spiezia, V., Does computer-use increase educational achievements? Student level evidence from PISA, OECD Journal: Economic Studies, 2010

United Nations, E-Government Survey 2012, UN Department of Economic and Social Affairs, Geneva 2012

Van de Donk, I., and W. Snellen, Public Administration in an Information Age: a Handbook, IOS Press, Amsterdam 1998

Van Reenen J.V. et al., The Economic Impact of ICT, Final Report, CEP, London 2010

World Bank, ICP-2011-Government Collective Services, Compensation and Productivity Adjustments, Washington DC, 2011, available at:

http://siteresources.worldbank.org/ICPINT/Resources/270056-1255977007108/6483550-

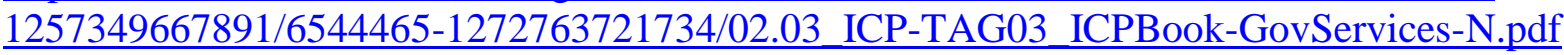




\section{Part II. COUNTRY CASES}




\section{Chapter 5}

\section{Mainstreaming Public Sector Innovation through Governance e- Transformation - Moldova Case Study}

Stela Mocan, e-Government Centre/Government CIO, Moldova

\subsection{Introduction}

Public sector innovation is a multi-dimensional effort, and technology plays a crucial role in the generation and dissemination of innovation in government. The Internet and other digital technologies have proved to be powerful enablers of innovation, changing the way governments innovate.

Social Media, Mobile, Cloud and Big Data are reshaping our reality and disrupting the way we live, work and learn! Change is the norm in the age of hyper-connectivity, mobility and digital consumers. Citizens have become used to $24 / 7$ availability of services and information in the digital world.

Governments should harness the power of digital technologies to be able to adapt and respond efficiently and effectively to challenges and demands coming from people. EGovernment tools play a key role in reshaping the way governments engage with people, deliver better and personalized services, and embed new ideas and behaviours such as collaboration, citizen-centred, co-creation in the DNA of the public administration. Governments are to embrace change and not fear it, to stay relevant to the people they serve.

Moldova ranks 1st among the 12 "innovation learners", according to the Global Innovation Index 2014 and demonstrates rising levels of innovation results because of improvements made to institutional frameworks, a skilled labour force, and better innovation infrastructure ${ }^{45}$. Our country has one of the best-wired Internet connections, being among the top 20 countries with the highest speed of Internet access, and one of the cheapest in terms of price per $\mathrm{Mbit}^{46}$. The household computerization rate is 64 per cent, about 62 per cent of households are connected to Internet ${ }^{47}$, and the mobile penetration rate represents 123.7 per cent $^{48}$. Moldova has the necessary ICT infrastructure and digital consumers, ready to communicate, engage and interact with the government through digital channels.

By launching the Governance e-Transformation agenda, the Moldova government has opened up for innovation and digital tools, in order to respond to citizen demands, to improve service quality, increase administrative efficiency and transparency, and to reduce corruption.

\footnotetext{
${ }^{45}$ Global Innovation Index 2014, available at https://www.globalinnovationindex.org/content.aspx?page=press$\underline{\text { release }}$

${ }^{46}$ Ministry of Information Technologies and Communication- update note on ICT sector indicators http://www.mtic.gov.md/news_eng/167224/

${ }^{47}$ National Annual Survey 2013 “Citizens' perception, uptake and support for the e-Transformation of Governance in the Republic of Moldova", available at http://egov.md/images/sondaje/Re2 Final_REPORT_EGov_ENGL-Febr\%202014.pdf

${ }^{48}$ National Regulatory Agency for Electronic Communication and Information Technology of the Republic of Moldova, Market Evolution: Mobile Communications, Annual Report for 2013, available at http://en.anrceti.md/files/u1/telmob_2014tr1en.pdf
} 
Transparent, efficient and innovative governance is a precondition for Moldova's social and economic development and competitiveness in a global digital economy. The Government of Moldova is committed to lead by example and harness the power of digital technologies to increase transparency and productivity of government institutions, improve public service delivery, and to decrease transaction costs for dealing with government bureaucracy. Governance e-Transformation is a critical contributor to Moldova's technology-enabled development and its endeavor to join the European Union and EU Market/Digital Market.

\subsection{Moldova governance e-transformation journey}

\section{Vision and mandate for action}

The Government of Moldova launched the governance e-Transformation in $2011^{49}$ with a clear vision and mandate for action, committed leadership, and a proactive, enthusiastic and innovative delivery team.

The advisory panel of High-Level Experts for Leaders and Practitioners (HELP) for eTransformation, set up by the World Bank for Moldova in 2010, enabled us to engage and learn from global leaders in e-governance, define our own vision and agenda for action, and facilitated collaboration with government counterparts from Singapore, United Kingdom, United States, Estonia, Austria, Belgium and European Commission.

The Moldova government has applied an integrated approach to reform governance and public service delivery through business process simplification and digitization, institutionalization of innovative initiatives and practices, policy and legal redesign, capacity building and knowledge sharing all across the government, communication and awareness building.

The Strategic Program for Technological Modernization (e-Transformation) is the first government technology strategy and provides for modernization of public services and government institutions through business process reengineering and ICT enabled tools and platforms.

The technology strategy defines 13 priority areas for governance e-Transformation (Figure 5.1) aligned with the government's public administration and public services reform agenda, as provided in the Government Decisions No. 797 from 26.10.2012 and No. 122 from 18.02.2014.

Governance e-Transformation aims to equip government institutions with the relevant stateof-the-art digital tools and platforms, open up efficient, effective and open government for innovation, as well as enabling service redesign and digitization, Data exchange and reuse, interoperability of government IT systems, cloud computing and shared platforms, plus mobile and social media platforms have all been used to develop government e-Services delivery infrastructure, which is to help us overcome departmental silos and enable government as a platform.

\footnotetext{
${ }^{49}$ Government Decision No. 710 from 20.09.2011, Strategic Program for Governance Technological Modernization, available at http://egov.md/images/normative/Strategic_Program_for_Governance\%20_Technological_Modernization_ENG .pdf
} 
Figure 0.1 Areas for governance e-Transformation 2011-2020

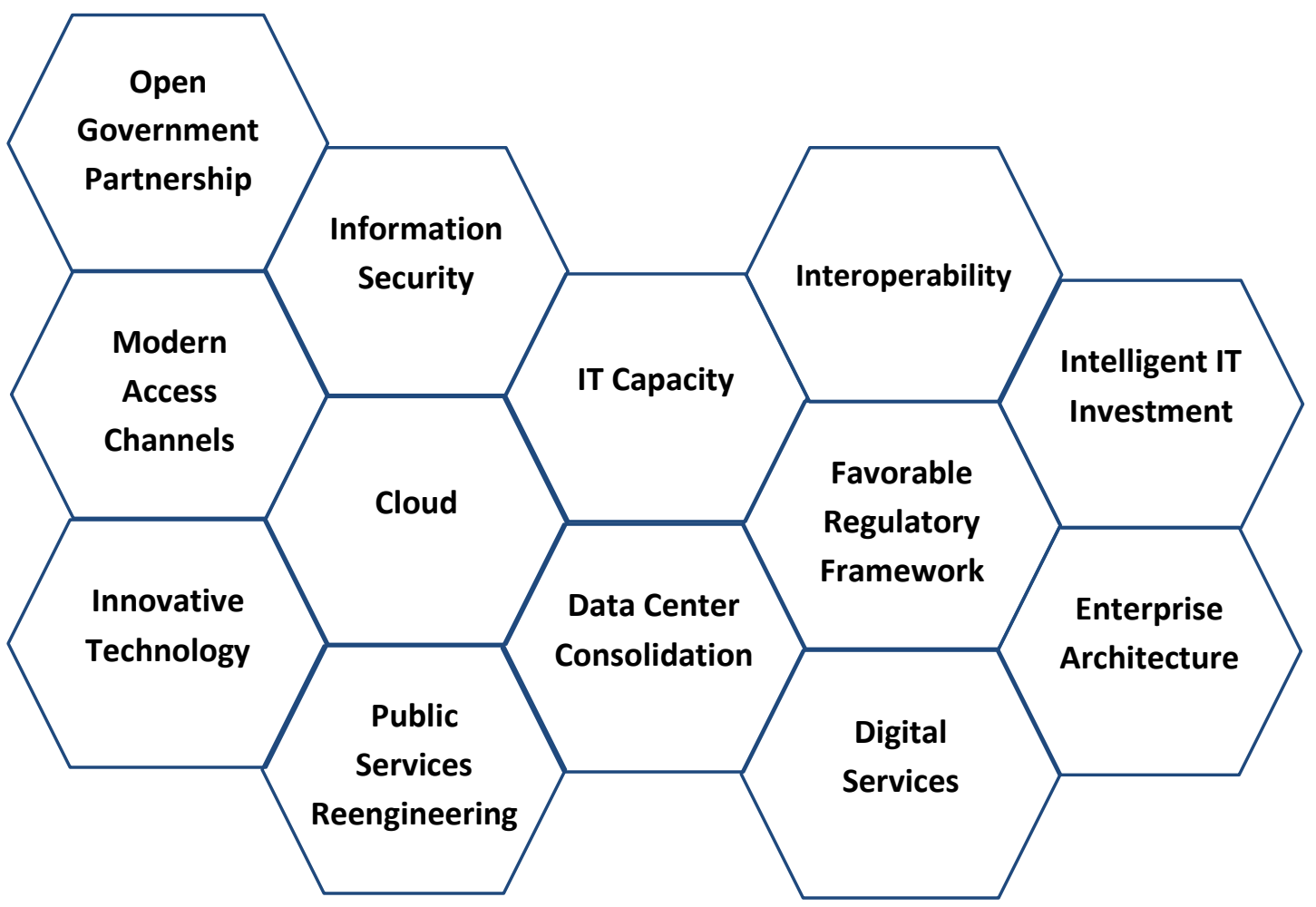

Source: See text.

The Government's goal is to digitize all services that can be delivered online by 2020, and make them accessible through a single government platform. Citizens and business shall easily access public services via various channels: Internet, mobile, kiosks, others. The Strategic Program states that services highly demanded by citizens and business but also crucial for Moldova European integration, shall be reengineered and digitized first ${ }^{50}$.

\section{Leadership and delivery team for governance e-transformation}

Government leadership and commitment of the Prime Minister's Office were determinant in launching, overcoming the "traditional" barriers to change, and driving forward the Governance e-Transformation.

The Government set up a multi-stakeholder governance structure to ensure alignment on both cross-sectorial and sectorial levels and drive digital transformation across all central government agencies and ministries (Figure 5.2).

The National Commission for e-Transformation, chaired by the Prime Minister and comprising representatives of government, private sector, academia and civil society, provides the vision and leadership for Governance e-Transformation and approves major government initiatives and programmes.

\footnotetext{
${ }^{50}$ Government Decision No. 710 from 20.09.2011, Strategic Program for Governance Technological Modernization, available at http://egov.md/images/normative/Strategic_Program_for_Governance\%20_Technological_Modernization_ENG .pdf
} 
The e-Government Centre - the Government Chief Information Office (eGC/GCIO) was established as part of the State Chancellery, Prime Minister's Office in August $2010^{51}$. eGC is in charge with the strategy and technical design of e-Government architecture and implementation of $e$-Services delivery infrastructure to enable Governance e-Transformation all across the government. The Centre guides the process of setting the proper legal and institutional frameworks, facilitates the deployment and adoption of e-Services delivery platforms, knowledge exchange and capacity building activities under the e-Transformation Agenda. ${ }^{52}$

To facilitate the sectorial e-Transformation, the Government established in each ministry a new position of the Coordinator for e-Transformation (CeT) and the e-Transformation division $^{53}$. The sectorial $\mathrm{CeT}$ is also a member of the Council of e-Transformation Coordinators, which ensures alignment and coordination of sectorial e-Transformation actions and initiatives ${ }^{54}$.

\section{Figure 0.2. E-Transformation governance structure}

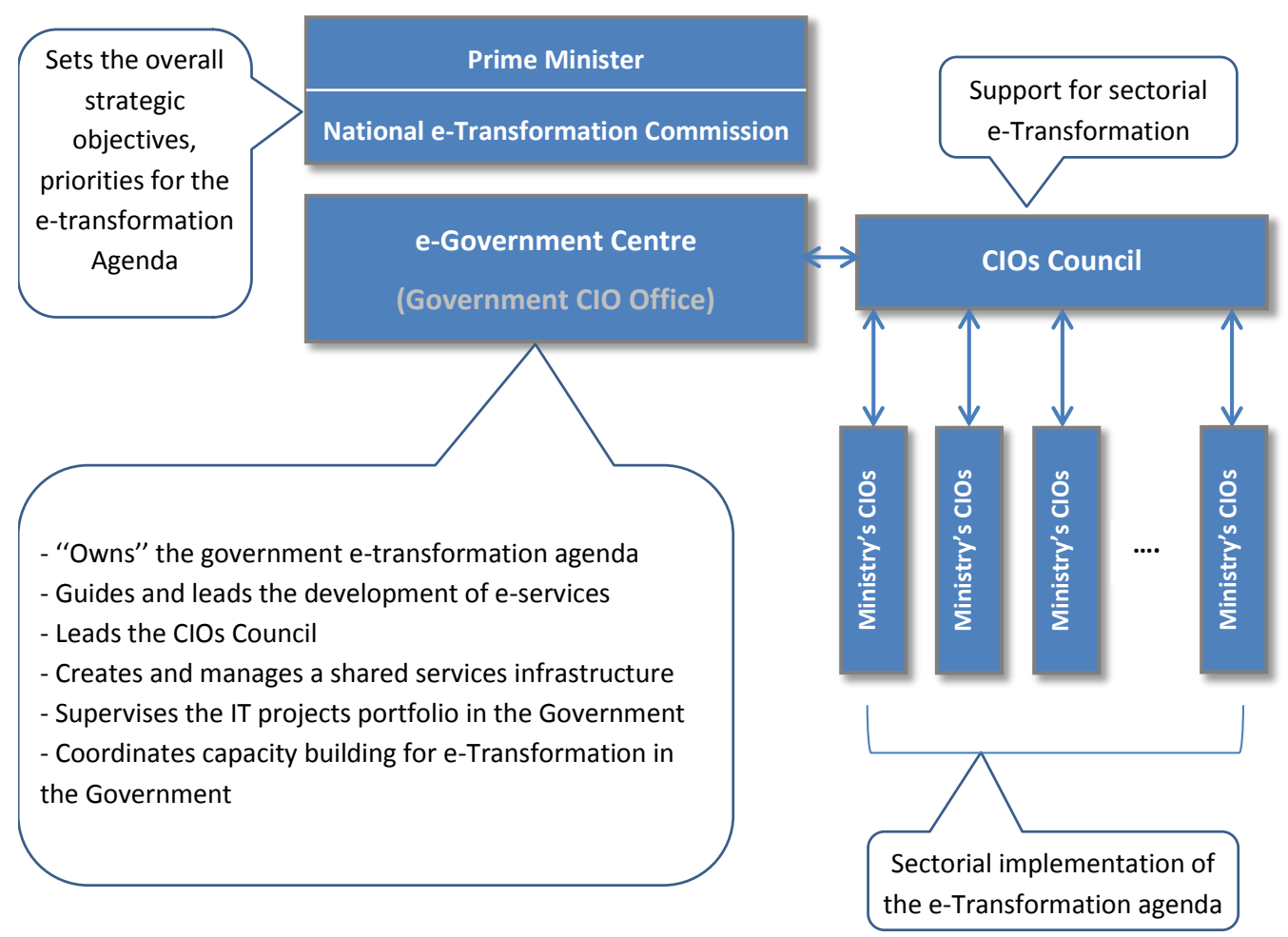

Source: See text.

\footnotetext{
${ }^{51}$ Government Decision No. 392 from 19.05.2010 on the establishment of the e-Government Centre available at http://lex.justice.md/index.php?action=view\&view=doc\&lang=1\&id=334627

${ }^{52}$ Government Decision No. 760 from 18.08.2010 Statute of the Public Institution Electronic Government Centre, available at http://egov.md/images/normative/HG 760 din 18.08.2010 Statute eGC ENG.pdf

${ }^{53}$ Government Decision No. 499 from 06.07.2012 on the establishment of e-Transformation Division, available at http://lex.justice.md/viewdoc.php?action=view\&view=doc\&id=344035\&lang=1

54 Government Decision No. 222 from 01.04.2011 on the establishment of the Council of e-Transformation Coordinators, available at http://lex.justice.md/index.php?action=view\&view=doc\&lang $=1 \& i d=338053$
} 


\section{Governance e-transformation: results achieved}

e-Services Delivery Infrastructure developed and operational

Since 2011, the e-Government Centre in partnerships with public and private sector partners has developed and implemented the $e$-Services delivery infrastructure, to enable "government as a platform" and catalyse the digitization of public services across the central public authorities (Figure 5.3).

\section{Figure 0.3. E-Transformation Governance Structure}

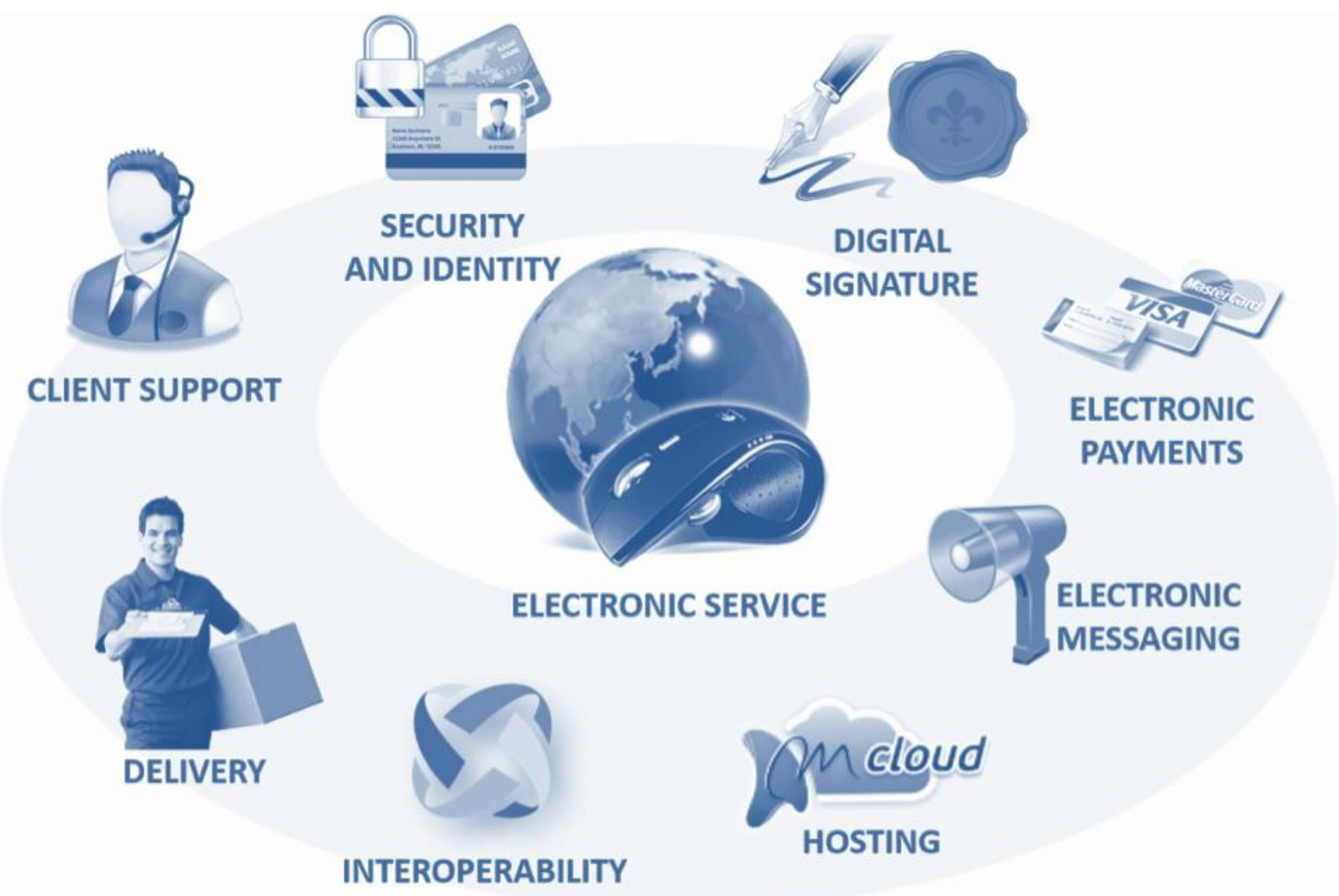

Source: See text.

To ensure secure online electronic transactions, service delivery and exchange of information, the e-Government Centre implemented the government digital service for authentication and access control MPass (mpass.gov.md) and the government digital signature service MSign (msign.gov.md).

MPass and MSign provide secure authentication and digital signing platforms for public and private sectors, individuals and organizations. Citizens may use the single digital authentication service MPass to access a range of public services. MSign allows citizens and business to sign documents, reports and declarations via Digital Signature, Mobile Digital Signature and National electronic ID. Through MPass and MSign government agencies and ministries can bring new services online and integrate them with the servicii.gov.md in a standardized and more efficient way.

To address the demands of a highly mobile population and harness the advantages of mobile technologies, the government launched the Mobile Digital Signature (MDS) service, in partnership with Orange and Moldcell/TeliaSonera mobile operators in September 2012. 
Mobile Digital Signature allows citizens to access e-Services and sign documents securely via mobile devices. The government entered into these public-private partnerships with mobile technology companies deliberately, relying on their commitment to innovation, quality customer service and capacity to issue MDS to citizens all over the country. The Mobile Digital Signature won the GSMA "Best m-Government Initiative Award" in February 2013.

The government electronic payment service MPay (mpay.gov.md) launched in partnerships with the National Bank of Moldova, the State Treasury, the Ministry of Finance and private banks, offers citizens the possibility to pay online for public services with different payment methods ${ }^{55}$. To ensure fast and effective implementation of the electronic payment services, for the first time, the government did not invest time and money in the software development but procured from the market the MPay as a service. Fourteen public services are integrated with the MPay service ${ }^{56}$ and 330,000 transactions have been carried out through MPay since its launch in September 2013.

Government ministries and agencies are required to integrate all sectorial e-services with the MPass, MSign and MPay services to ensure secure digital transactions and data exchange in the cyberspace ${ }^{57}$.

To enable smart IT investment, efficient use of IT resources in government, and secure delivery of e-Services, the Government of Moldova adopted Cloud-Computing technologies in 2013.

The shared technological MCloud platform ${ }^{58}$ is a private governmental cloud and provides to central government agencies and ministries Infrastructure as a Service (IaaS), Platform as a Service (PaaS) and Software as a Service (SaaS).

Twenty government agencies and ministries (Ministry of Education, Ministry of Justice, Ministry of Internal Affairs, Ministry of Agriculture, Ministry of Health, etc.) use MCloud Platform to deliver sectorial e-Services. Major MCloud products - IaaS, MPass, MSign and MPay are all experiencing rapid take-up, both by government clients and citizens.

To improve resilience and security, the government is in the process of expanding the MCloud infrastructure. The "Cloud in a Box" (MCloud 2) will extend our self-service capabilities, provide new backup and archiving services, and mark another level of innovation in the use of Cloud Computing by governments. Cloud-First Policy and Regulation were approved by the Government to institutionalize and ensure adoption of Cloud Computing across the central government agencies. ${ }^{59}$ The e-Government centre in close consultations with sectorial CIOs, has drafted the MCloud Strategy and Roadmap, which will be approved by the government and will guide IT investments decisions for the upcoming three to five years.

\footnotetext{
${ }^{55}$ Government Decision No. 329 from 28.05.2012 regarding the government electronic payment service MPay, available at http://lex.justice.md/index.php?action=view\&view=doc\&lang=1\&id=343404

${ }^{56}$ Source Government electronic payment service mpay.gov.md

${ }^{57}$ Government Decision No. 1090 from 31.12.2013 regarding the government electronic service for authentication and access control MPass available at http://lex.justice.md/index.php?action=view\&view=doc\&lang=1\&id=351035; Government Decision No. 405 from 02.06.2014 regarding the government service for digital signature MSign, available at http://lex.justice.md/index.php?action=view\&view=doc\&lang=1\&id=353239

${ }_{58}$ Government shared platform MCloud mcloud.gov.md

${ }^{59}$ Government Decision No. 128 from 20.02.2014 regarding the government shared technological platform MCloud, available at http://lex.justice.md/index.php?action=view\&view=doc\&lang=1\&id=351760
} 
Data exchange, reuse, and interoperability of government IT systems are critical in ensuring efficient and effective government operations and high quality public service delivery, tailored to the needs of citizens and business. The government initiated in September 2012 the process of implementing the governmental Interoperability Framework ${ }^{60}$, in line with EU Directive 2003/98/EC on the re-use of public sector information and underlying principles of the European Interoperability Framework (EIF) for European public services ${ }^{61}$. Through the implementation of the interoperability framework, the government aims to transform the paradigm of data exchange within the public sector, increase the quality and security of data exchange, eliminate redundancy and enforce the "only once" principle of data provision by citizens and business to government.

The implementation of the piloting phase of technical interoperability platform MConnect ${ }^{62}$ was launched in partnership with major public sector data providers and data consumers in July 2014. MConnect platform is a key element of the e-Services delivery infrastructure. It is based on an enterprise service bus (Figure 5.4) and is part of the common government technology platform MCloud. The piloting will result in amendments to the legal and policy framework, as well as, to provide clarity on the technical rules and procedures on data exchange and interoperability at the organizational, semantic and technical levels for efficient delivery of digital services in the public sector.

\section{Figure 0.4. MConnect interoperability platform}

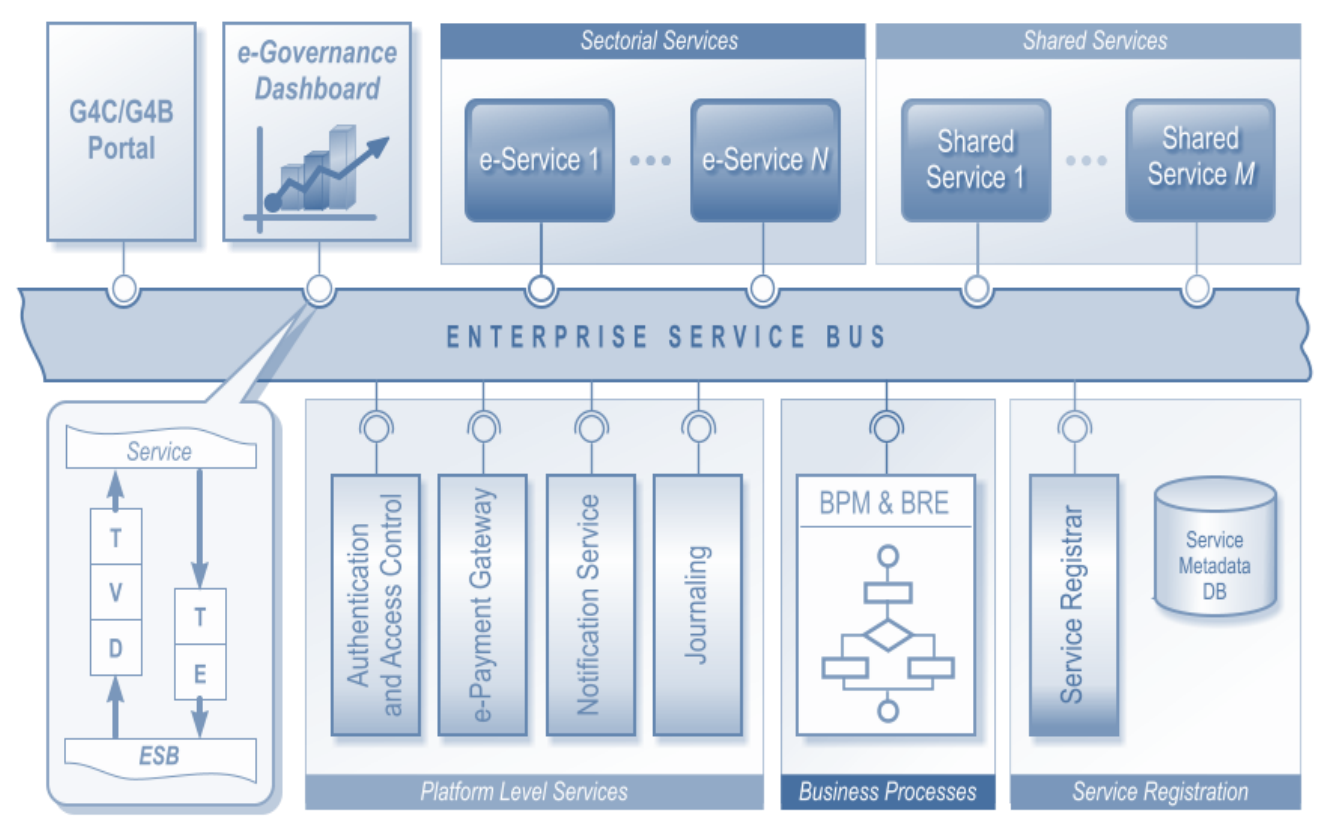

Source: See text.

\footnotetext{
${ }^{60}$ Government Decision No. 656 from 05.09.2012, On Approving the Interoperability Framework Program, available at http://egov.md/images/normative/Moldova_Interoperability Framework Program.pdf

${ }^{61}$ Annex 2 to the Communication from the Commission to the European Parliament, the Council, the European Economic and Social Committee and the Committee of Regions 'Towards interoperability for European public services', Brussels 16.12.2010 COM (2010) 744 final, available at http://ec.europa.eu/isa/documents/isa_annex_ii_eif_en.pdf

${ }^{62}$ Government Decision No. 404 from 02.06.2014 regarding the piloting of the government interoperability platform, available at http://lex.justice.md/viewdoc.php?action=view\&view=doc\&id=353238\&lang=1
} 
The Moldova government has the needed e-Services delivery infrastructure, innovative tools, polices and implementation structures to transform governance, deliver high quality services, and address effectively most pressing development challenges and people's demands.

\section{Sectorial governance e-Transformation launched}

Moldovan citizens are ready and open to transact with the government through digital channels. According to the annual national survey "Perception, assimilation and support by the population of the e-Government transformation in Moldova", conducted by the eGovernment Centre in November 2013, 63 per cent of respondents declared their willingness to use online public services and around 43 per cent of respondents were satisfied with the quality of electronic public services ${ }^{63}$. The e-Services uptake rates show impressive dynamics during the first two years of the Governance e-Transformation process: for G2B services 45 per cent to 95 per cent, and for G2C services - up to 96 per cent of customers requested services online. The e-Government Center publishes a monthly Barometer with the uptake data for e-Services launched as part of the Governance e-Transformation Agenda $^{64}$.

Under the governance e-transformation, the government committed to apply the "digital by default framework" (Figure 5.5), as a basis for the e-Services delivery model. The sectorial ministries and government agencies are required to streamline and digitize public services based on the "digital by default framework" and re-using the e-Services delivery infrastructure.

\section{Figure 0.5 Digital by default framework}

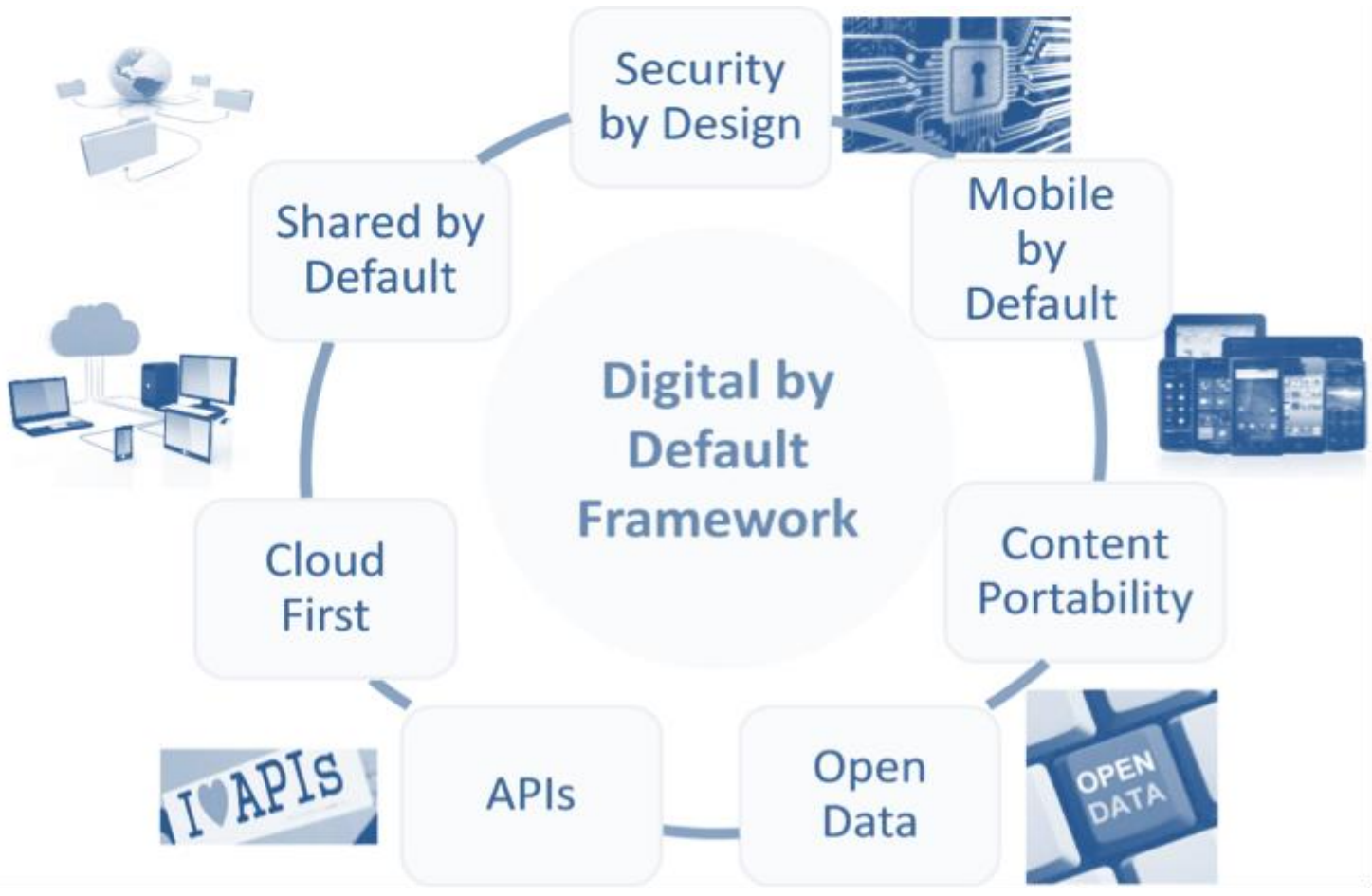

\footnotetext{
${ }^{63}$ National Annual Survey 2013 "Citizens' perception, uptake and support for the e-Transformation of Governance in the Republic of Moldova", available at http://egov.md/images/sondaje/Re2_Final_REPORT_EGov_ENGL-Febr\%202014.pdf

${ }^{64}$ Barometer Uptake of e-services launched as part of the Governance e-Transformation Agenda, available at http://egov.md/index.php/en/resurse-en/barometer\#.VABQ_ry1Y08
} 
Source: See text.

As part of the e-Services delivery infrastructure, the government launched in May 2012, the government services platform - servicii.gov.md - conceived as the single entry point to all public sector services and information provided by central public authorities ${ }^{65}$. The platform will present a complete rethinking and redesign of the ways in which government presents information and interacts via the Internet. Servicii.gov.md 2.0 will set new standards for simplicity, accessibility and integration of online services across government, including those provided by local governments.

As of 1 September 2014, out of 419 public services provided by central public authorities, 91 are accessible in electronic format through the servicii.gov.md platform ${ }^{66}$. The government chose and committed to digitize first, public services delivered to business to decrease corruption and administrative burden. Since 2012, government agencies launched electronic services for business: e-Reporting to National House of Social Insurance (e-CNAS) and National House of Medical Insurance (e-CNAM), e-Application for license, e-Fiscal invoice, e-Fiscal services. Citizens can request online copies of their civil service documents, submit their income declarations and pay taxes online ${ }^{67}$, as well as certify their documents through the e-Apostil service ${ }^{68}$.

Public services are subject to business process reengineering first and then digitized based on the Digital by Default Framework. Sectorial ministries are responsible to draw up plans for the digitization of public services to achieve governance e-Transformation objectives. The Ministries of Justice, Health, Agriculture and Transport have all developed sectorial strategies and actions plans, with specific objectives for sectorial e-Transformation and public services reform, based on the one-stop-shop approach and Digital by Default Framework. ${ }^{69}$ In 2015, the government will offer to farmers, business and citizens the possibility to apply online for subsidies, food safety import/export permits, commercial activity and construction permits; register real-estate transactions, open up and close up a business online. Young people will be able to apply to universities and certify their diplomas online.

To further enable sectorial e-Transformation, the e-Government Centre designed and implemented the government shared enterprise content management platform (ECMP), which is available for re-use to central public authorities to accelerate the reengineering and digitization of public services and registries, at higher speed and lower costs. So far, the ECMP platform was used by the State Chancellery and Ministry of Environment to launch the electronic registry of inspections (controale.gov.md) and a one-stop-shop for water use permits (autorizatiimediu.gov.md), respectively. The Ministry of Agriculture is developing the digital registry of agriculture, to serve as a digital backbone for implementing eAgriculture in Moldova and the Ministry of Transport is implementing the one-stop-shop for e-Transport permits.

Sectorial digitization of services is supported by government-wide efforts to digitize registries and archives. Digitization of the Civil Service Archive was launched in 2013 and

\footnotetext{
${ }^{65}$ Government Decision No. 330 from 28.05.2012 regarding the administration of Government Services

Platform servicii.gov.md, available at http://lex.justice.md/viewdoc.php?action=view\&view=doc\&id=343406\&lang=1

${ }^{66}$ Source government for citizens platform servicii.gov.md

${ }^{67}$ Source government for citizens platform servicii.gov.md

${ }^{68}$ Source apostila.gov.md

${ }^{69}$ Government Decision No. 122 from 18.02.2014 regarding Public service reform programme for 2014-2016, available at http://lex.justice.md/md/351705/
} 
was due for completion by 2016. So far, four million, out of a total of 12 million of civil service acts were digitized. Digitization of the Cadastre Archive was also launched in 2014. A total of 60 million cadastre documents will be digitized, which will allow for a more efficient data exchange and reuse across government agencies and online delivery of services, both to citizens and business, at a lower cost and higher quality ${ }^{70}$.

To increase operational efficiency in public administration, the government launched the implementation of the Paperless Government Initiative ${ }^{71}$, and is piloting the Electronic Document Management and Records System (SIGEDIA) in eight ministries and the State Chancellery. To enhance transparency and efficiency of the decision-making process, by the end of 2014, the e-Cabinet application for organizing and conducting Government meetings will be launched for piloting.

\section{Opening up government through small and consistent actions}

Moldova joined the Open Government Partnership in 2012 and committed to open, use and re-use government data to increase transparency, improve service delivery and catalyse innovation.

In April 2011, Moldova became one of the first countries in the region, and among the first 16 countries in the world, to launch an Open Data portal, which brings together disparate and disconnected government datasets. Government agencies have released so far, 767 datasets on date.gov.md, with total downloads of 107,646 in $2014^{72}$. Public expenditure information under the World Bank's BOOST initiative and income declarations for civil servants and public officials are published online. Moldova Open Data represents one of the few initiatives initiated by government in the region, according to United Nations Development Programme (UNDP) study ${ }^{73}$.

To overcome resistance, bureaucratic norms of secrecy and information silos, the Government institutionalized the Open Data Initiative by requesting central government agencies and ministries to designate Open Data coordinators, responsible for publication of government data, and release at least three datasets on a monthly basis, in accordance with the Prime Minister's Directive No. 43 from April 2011 74 .

Further on, the Government fulfilled its open government commitments and approved on August $25^{\text {st }}, 2014$, the Open Data Policy and the Methodology of publishing government data on-line on the open data platform date.gov. $\mathrm{md}^{75}$. This policy provides for open data

\footnotetext{
${ }^{70}$ Government Decision No. 1096 from 31.12.2013 regarding the Annual Action Plan for Governance eTransformation, available at http://lex.justice.md/index.php?action=view\&view=doc\&lang=1\&id=351125

${ }^{71}$ Government Decision Nr. 975 from 22.12.2012 regarding Paperless Government Initiative, available at http://lex.justice.md/index.php?action=view\&view=doc\&lang=1\&id=346061

${ }^{72}$ Source date.gov.md http://date.gov.md/en/stats/yearlydl?field_organization tid=All\&date filter\%5Bvalue $\% 5 \mathrm{D} \% 5 \mathrm{Byear} \% 5 \mathrm{D}=2014$

${ }^{73}$ UNDP Report "Open Data Initiatives in Eastern Europe and the Commonwealth of Independent States, UNDP Bratislava Regional Center, 2011, available at

http://issuu.com/undp_in_europe_cis/docs/social_media_report_-_external

${ }^{74}$ World Bank Report "The Journey of Open Government and Open Data in Moldova”, May 2014, available at http://blogs.worldbank.org/ic4d/the-world-bank-published-report-on-the-journey-of-open-government-andopen-data-moldova

${ }^{75}$ Government Decision No. 700 from 25.08.2014 regarding Open Data Policy, available at http://lex.justice.md/viewdoc.php?action=view\&view=doc\&id=354533\&lang=1 Government Decision No. 701 from 25.08.2014 regarding Methodology of open data publication, available at http://lex.justice.md/index.php?action=view\&view=doc\&lang=1\&id=354534
} 
principles to be applied nationwide and defines the minimum open data requirements to guide ministries and other central public authorities in releasing government data.

Opening up government data by default, stands out among the principles instituted by the Open Data Policy. Protecting of sensitive data, opening up primary data, in the formats collected from the source, with the highest possible granularity level, disaggregated and unchanged, and publishing data online, timely and in automatically processable formats on the open government data portal date.gov.md ${ }^{76}$, are principles to be followed by government agencies and ministries. The Open Data Policy aims to facilitate access to both, citizens, business and government to valuable public information through the re-use of data, in line with the EU Directive 2003/98/EC on the re-use of public sector information ${ }^{77}$, Moldova Law No. 305 on the re-use of public sector ${ }^{78}$ and the Government Decision No. 886 defining the terms of public sector information re-use ${ }^{79}$. The policy requires central public authorities to identify the open data that may be published and made available for re-use free of charge, and what government data will be provided for re-use for a fee, the size of the fee and how it is calculated. To reduce the time for and cost of responding to claims by publishing structured primary data online and facilitate the publishing by public institutions of government data in open and computer-processable formats for re-use by the public, all new government information systems will be designed to allow automated publishing of government data.

Moldova Open Data Initiative was largely 'supply-side' driven. To ensure its sustainability and impact on service delivery, government operations and economic development, and to promote citizen-centric innovation, the e-Government Centre, the Moldova Open Government Institute and development institutions have partnered to foster the 'demand-side' of Open Data ${ }^{80}$. TechCamps, Hackathons, Open Innovation Contests and events were organized to engage business, civil society, journalists and international experts to "stimulate demand and recognize the value of leveraging Open Data to achieve social and commercial value $" 81$.

Opening up government data is enabled through policy provisions and available $e$-Services delivery and data exchange infrastructure, which facilitate collection, archiving, maintenance and release of data. Our key priority has been to fully harness these enablers and release government data that is relevant to citizens and business and can be used to create economic value and improve the quality of governance.

\footnotetext{
${ }^{76}$ Government Decision No. 700 from 25.08.2014 regarding Open Data Policy, available at http://lex.justice.md/viewdoc.php?action=view\&view=doc\&id=354533\&lang=1

${ }^{77}$ Directive 2003/98/EC of the European Parliament and of the Council of 17 November 2003 on the re-use of public sector information, available at http://eurlex.europa.eu/LexUriServ/LexUriServ.do?uri=OJ:L:2003:345:0090:0096:EN:PDF

${ }^{78}$ Law No. 305 from 26.12.2012 regarding public sector information re-use, available at http://lex.justice.md/viewdoc.php?action=view\&view=doc\&id=347200\&lang=2

${ }^{79}$ Government Decision No. 886 from 08.11.2013 regarding the Regulation of enforcing the Law Nr. 305 on public sector information reuse, available at http://lex.justice.md/index.php?action=view\&view=doc\&lang=1\&id=350277

${ }^{80}$ World Bank Report “The Journey of Open Government and Open Data in Moldova”, May 2014, available at http://blogs.worldbank.org/ic4d/the-world-bank-published-report-on-the-journey-of-open-government-andopen-data-moldova

${ }^{81}$ Ibidem.
} 


\subsection{Skills to sustain governance e-transformation}

\section{Digital transformation is not about technology, it is about the mindset}

Any transformation effort faces the resistance of the "status-quo" and requires anchoring new, innovative capacities in the systems subject to change. It needs attitudes, capabilities and skills that are challenging to grow and sustain in the private sector, and even more difficult in government. But no transformation can succeed unless it empowers the agents of change that are inside the system, ready and eager to support the change process.

To grow the support base for governance e-Transformation inside government and empower public servants and government officials to participate, own and commit to the change agenda, the e-Government Center launched knowledge and capacity-building initiatives in partnerships with development partners and government counterparts.

The E-Governance Knowledge Sharing Platform, launched in mid-2011, targets government CIOs, IT managers, public servants and private sector representatives, and facilitates sharing of domestic and global experience and best practices in e-government. World Bank, IDA International (Singapore), e-Governance Academy (Estonia), FEDICT (Belgium), General Directorate for Information Technologies (European Commission), Digital Austria/Federal State Chancellery (Austria) have been contributing to building Moldova government capability to transform governance through innovation and digital tools. Courses on eGovernance for two hundred government CIOs and other public servants were organized. A module on basics of governance e-Transformation was included in the mandatory curriculum for public servants starting February 2013 at the Academy of Public Administration.

Technical Seminars for government CIOs and IT managers on e-Services delivery platforms are organized on a monthly basis, to build ministries' capacity to adopt and re-use MPass, MSign, MPay, MCloud, and ECMP in advancing sectorial e-transformation.

Monthly consultation meetings and seminars are organized in partnerships with technology companies, both, to learn from and adopt the latest technology breakthroughs, and to inform and enable the private sector to participate as co-creators in advancing governance digital transformation.

Countrywide trainings and information sessions on the e-Transformation agenda, available eServices and digital tools, are organized in partnerships with Moldova Digital Libraries/Novateca Programme, (supported by the Bill \& Melinda Gates Foundation) and Regional Information and Services Bureaus (established with the support of UN Women).

To address digital security issues, the Moldova Government is organizing every October, the cyber security in government month, as part of the EU Cyber Security Month initiative. The initiative is organized in collaboration with government agencies and ministries, technology companies, foreign government counterparts and international organizations.

The government's ability to leverage peer-to-peer knowledge exchange and undertake capacity-building efforts for government representatives have contributed significantly to achieving results in the first three years of Governance e-Transformation implementation. It 
helped to reduce resistance and expand the space for change and innovation in government, and strengthen the foundation for advancing further with the e-Transformation agenda.

\subsection{Financing innovation in government}

The Moldova Government engaged and leveraged the strategic partnerships, knowledge exchanges and advisory missions with its government counterparts from leading countries in e-Governance, like Singapore, Estonia, Belgium, Austria, and the European Commission, to start the Governance e-Transformation. Bilateral cooperation enabled sharing of expertise and experience that proved decisive for the e-Government Centre in defining the digital transformation vision and strategy. Through development assistance provided by the U.S. Agency for International Development (USAID), World Bank, Governments of The Netherlands and Estonia, the Moldova Government conducted the needed feasibility studies and developed strategic policies to guide and drive the implementation of the digital transformation. These concerted efforts allowed the government to secure a World Bank loan of US\$20 million to finance and support the implementation of the e-Services delivery infrastructure and ensure digitization of government business processes and services, as well as to generate efficiency and savings to continue and advance with the large scale Governance e-Transformation.

The government also decided to adopt cloud computing technologies, re-use e-services delivery infrastructure and government-shared platforms of MCloud, MPass, MSign, MPay, MConnect, and engage in strategic partnerships with private sector and technology companies. All these strategic principles defined the Moldova Government's approach in funding and implementing innovative Governance e-Transformation. Cloud-first, re-use of data and e-Government platforms, open data by default policies passed by the government since 2011, provide for government centralized financing of the e-Services delivery infrastructure (MCloud, MPass, MSign, MPay, and MConnect). Ministries and government agencies are responsible to invest their resources in optimization and digitization of internal processes and public services, and ensure their integration with the e-Services delivery infrastructure. Development assistance, state budget funding and partnerships with the private sector are to support sectorial governance e-Transformation harnessing and re-suing existing e-Government platforms and tools. In this regards, the Public Procurement Agency requests sectorial ministries and agencies to attach to any IT public procurement notice, a No Objection Letter from the e-Government Centre, to eliminate duplication and ensure smart investments in IT in government. This approach aims to redefine and adopt an Intelligent Government IT Investment Framework ${ }^{82}$, which is to ensure value for money and contribute to sustainable financing for innovation and the advance of e-Transformation in the public sector.

\subsection{Lessons learned so far}

Launching a government-wide digital transformation effort in a developing country is challenging. In government, technology is rarely the problem. The problem is the culture,

\footnotetext{
${ }^{82}$ Government Decision No. 710 from 20.09.2011, Strategic Program for Governance Technological Modernization, available at http://egov.md/images/normative/Strategic_Program_for_Governance\%20_Technological_Modernization_ENG .pdf
} 
institutional legacies and vested interests that resist everything that is "new" and are averse to risk-taking and innovation.

Governance e-Transformation has required political and administrative leadership and a strong delivery team at the top to fight the deep-rooted "status-quo" and implement change. The delivery team should connect and empower change agents inside and outside the public sector, in applying the top-down approach.

Strong partnerships and the alignment of resources with the private sector, academia, development organizations and civil society have been crucial to build support, share the burden and speed up the governance e-Transformation process. Multi-stakeholder collaboration facilitated the adoption of innovation and technological breakthroughs in designing and deploying cutting-edge government digital infrastructure. Implementation of egovernance projects jointly with the private sector is crucial for achieving results fast, and in securing the credibility and support to advance with technologically enabled innovation in government.

No government business process or public service should be digitized, unless it has been streamlined and simplified. Sequence and synchronization of public service reform with governance e-Transformation is one of the key preconditions to ensure qualitative benefits to citizens and business, and cost-effectiveness of government investments.

To decrease opposition and resistance for innovative and IT-enabled initiatives, customized capacity building and communication efforts for public sector and citizens must accompany governance e-Transformation from the beginning of the journey. Knowledge activities should also be synchronized with enacting new policy decisions and legislation. The "20th century" legal and policy framework has been holding back innovation and technology adoption in government. To ensure implementation and adoption of e-Services delivery infrastructure, the e-Government Centre had to institutionalize and "package" all innovative platforms and services in policies and regulations approved through government decisions.

It is also clear that the government should provide the needed funding to start and drive Governance e-Transformation. The government should be open to new ways of doing business and to new partners to succeed in modernization of the public sector. Private-public partnerships, alongside collaboration with counterparts from the public sector and business should be leveraged to support the e-transformation and fill in the skills and funding gaps. Clear government vision, goals, and coordination are needed to ensure alignment of resources and funding from state budget, development partners, multi-lateral organizations and the private sector to support effective implementation. All these are among the key determinants to address capacity and financing constraints, and to ensure smart and sustainable innovation in government.

\subsection{Immediate priorities and challenges to be addressed}

To achieve tangible results in governance quality and get value from money invested in building the e-Services delivery infrastructure, the government should ensure its adoption and re-use by sectorial ministries and push for speeding-up service delivery simplification and digitization efforts. The government has the necessary digital tools and platforms to support public sector innovation and transformation. 
People's digital literacy will remain a top priority for government, in order to ensure increasing uptake of government e-Services and platforms and support of the Governance eTransformation.

Technology-enabled innovation is to be reinforced by engaging citizens and business as coproducers and drivers of public sector innovation.

To mainstream innovation in government, the e-Government Center has launched the Social Innovation Hub, in partnerships with UNDP Moldova, private sector partners Moldcell and Union Fenosa in August 2014. Our goal is to strengthen the ecosystem of change and innovation in the public sector through close engagement with 'customers, and involve people and the private sector as co-producers and drivers of development solutions.

Together, we are to spot the 'real' problems, generate solutions through engagement and crowd-sourcing, develop and test solutions through design-thinking techniques, gaming, behavioral science, open data, digital and mobile technologies. The Social Innovation Hub will act as a multi-lateral platform, opening up government agencies and engaging actors from public, private and non-profit sectors, in unhindered discussions of problems and opportunities, as well as experimenting and spotting the future.

To pilot this innovative approach, we have engaged with the Ministry of Health and the National House of Social Insurance, launching the process of redefining public services through design-thinking and behavioral science techniques. UNDP Moldova has facilitated access to knowledge and expertise from MindLab (Denmark), Nesta and FutureGov (United Kingdom), and the UNDP Global Centre for Public Service Excellence. Based on achieved results, we will scale-up the Social Innovation Hub' initiatives across the government, mainstream innovation in the public service reform process and transform government through innovative and 'networked governance' solutions.

Partnerships with supporters, both inside and outside the public sector, should be the default modus operandi, in order to grow and nurture the government innovation ecosystem and advance the Governance e-Transformation. So far, the Government has harnessed partnerships with governments leading in e-governance, technology companies, private sector, civil society and development organizations. The World Bank, Singapore IDA International, U.S. Agency for International Development, UNDP, International Council for Information Technology in Government Administration (ICA), Open Government Partnership, Estonia e-Governance Academy, Belgium FEDICT, European Commission, UN Women, Moldcell/TeliaSonera, Orange, Moldova Association of ICT Companies have all been supporting and contributing to the Moldova Governance e-Transformation Agenda. We will continue to engage with our people and nurture cross-sectorial collaboration to disrupt and dismantle outdated and inefficient government processes and practices through innovation and digital technologies. 


\subsection{References}

European Commission, Towards interoperability for European public services, Communication from the Commission to the European Parliament, the Council, the European Economic and Social Committee and the Committee of Regions, Annex 2, COM, 2010, 744 final, available at http://ec.europa.eu/isa/documents/isa_annex_ii_eif_en.pdf

Barometer, Uptake of e-Services launched as part of the Governance e-Transformation Agenda, 2015, available at http://egov.md/en/resources/infographics/uptake-e-governmentproducts-launched-under-e-transformation-agenda-situati-4

European Union, Directive 2003/98/EC of the European Parliament and of the Council of 17 November 2003 on the re-use of public sector information, available at http://eurlex.europa.eu/LexUriServ/LexUriServ.do?uri=OJ:L:2003:345:0090:0096:EN:PDF

Global Innovation Index 2014, available at https://www.globalinnovationindex.org/content.aspx?page=press-release

Government of Moldova, Government Decision Number 392 of 19 May 2010 on the establishment of the e-Government Center, available at http://lex.justice.md/index.php?action=view\&view=doc\&lang=1\&id=334627

Government of Moldova, Government Decision Number 760 of 18 August 2010, Statute of the Public Institution Electronic Government Center, available at http://lex.justice. $\mathrm{md} /$ viewdoc. .php?action=view\&view=doc\&id=334627\&lang=1

Government of Moldova, Government Decision Number 222 of 01 April 2011 on the establishment of the Council of e-Transformation Coordinators, available at http://lex.justice.md/index.php?action=view \&view=doc\&lang=1\&id=338053

Government of Moldova, Government Decision Number 710 of 20 September 2011, Strategic Program for Governance Technological Modernization

Government of Moldova, Government Decision Number 329 of 28 May 2012 regarding the government electronic payment service MPay, available at http://lex.justice.md/index.php?action=view\&view=doc\&lang=1\&id=343404

Government of Moldova, Government Decision Number 330 of 28 May 2012 regarding the administration of Government Services Platform servicii.gov.md, available at http://lex.justice.md/viewdoc.php?action=view\&view=doc\&id=343406\&lang=1

Government of Moldova, Government Decision Number 499 of 06 July 2012 on the establishment of e-Transformation Division, available at http://lex.justice.md/viewdoc.php?action=view\&view=doc\&id=344035\&lang=1

Government of Moldova, Government Decision Number 656 of 05 September 2012, on Approving the Interoperability Framework Program, available at http://egov.md/en/legislation/decision-approving-interoperability-framework-program-no-656$\underline{05092012}$

Government of Moldova, Government Decision Number 975 of 22 December 2012 regarding Paperless Government Initiative, available at http://lex.justice.md/index.php?action=view\&view=doc\&lang=1\&id=346061 
Government of Moldova, Government Decision Number 886 of 08 November 2013 regarding the Regulation of enforcing the Law Number 305 on public sector information reuse, available at http://lex.justice.md/index.php?action=view\&view=doc\&lang=1\&id=350277

Government of Moldova, Government Decision Number 1090 of 31.12 .2013 regarding the government electronic service for authentication and access control MPass, available at http://lex.justice.md/index.php?action=view\&view=doc\&lang=1\&id=351035

Government of Moldova, Government Decision Number 1096 of 31 December 2013 regarding the Annual Action Plan for Governance e-Transformation, available at http://lex.justice.md/index.php?action=view\&view=doc\&lang=1\&id=351125

Government of Moldova, Government Decision Number 122 of 18 February 2014 regarding Public service reform program for 2014-2016, available at http://lex.justice.md/md/351705/

Government of Moldova, Government Decision Number 128 of 20 February 2014 regarding the government shared technological platform MCloud, available at http://lex.justice.md/index.php?action=view \&view=doc\&lang=1\&id=351760

Government of Moldova, Government Decision Number 404 of 02 June 2014 regarding the piloting of the government interoperability platform, available at http://lex.justice.md/viewdoc.php?action=view\&view=doc\&id=353238\&lang=1

Government of Moldova, Government Decision Number 405 of 02 June 2014 regarding the government service for digital signature MSign, available at http://lex.justice.md/index.php?action=view\&view=doc\&lang=1\&id=353239

Government of Moldova, Government Decision Number 700 of 25 August 2014 regarding Open Data Policy, available at http://lex.justice.md/viewdoc.php?action=view\&view=doc\&id=354533\&lang=1

Government of Moldova, Government Decision Number 701 of 25 August 2014 regarding Methodology of open data publication, available at http://lex.justice.md/index.php?action=view\&view=doc\&lang=1\&id=354534

Ministry of Information Technologies and Communication, Update Note on ICT Sector Indicators

National Annual Survey 2013, Citizens' perception, uptake and support for the eTransformation of Governance in the Republic of Moldova

National Regulatory Agency for Electronic Communication and Information Technology of the Republic of Moldova, Market Evolution: Mobile Communications, Annual Report for 2013, available at http://en.anrceti.md/files/u1/telmob_2014tr1en.pdf

Republic of Moldova, Law Number 305 of 26 December 2012 regarding the public sector information re-use, available at

http://lex.justice.md/viewdoc.php?action=view\&view=doc\&id=347200\&lang=2

UNDP, Study on the Role of Social Media for Enhancing Public Transparency and Accountability in Eastern Europe and the Commonwealth of Independent States: Emerging Models, Opportunities and Challenges, UNDP Bratislava Regional Center, 2011, available at http://issuu.com/undp_in_europe_cis/docs/social_media_report_-_external 
World Bank, The Journey of Open Government and Open Data in Moldova, 2014, available at: http://blogs.worldbank.org/ic4d/the-world-bank-published-report-on-the-journey-of-opengovernment-and-open-data-moldova 


\section{Chapter 6}

\section{Innovating the Public Sector through Citizen Engagement (from e- Government to Collaborative Governance)}

Matt Poelmans, CitizenVision, The Netherlands

\subsection{Summary}

According to the UN E-Government Survey 2014, The Netherlands rank on top in the eParticipation Index, the same place as in the previous edition of 2012. Even taking into account that rankings are not the final judgment of excellence, it means that the country performed comparatively well. So the experience gained and the lessons learned are worth sharing.

This chapter is based on several publications and blogs by the author on the topic of citizen participation. It gives an overview of Dutch national policy, describes international dissemination and documents several good practices.

From its very beginning, Dutch e-Government policy has aspired to be citizen-centric. Over the years several approaches have been followed to induce citizen centricity. By far the most effective way turned out to be formulating quality requirements for e-Government. The socalled e-Citizen Charter has been used as tool for measuring satisfaction and stimulating participation - gaining both national support and international recognition.

E-Government has contributed to public sector reform by digitizing and simplifying procedures for a mainly passive customer. However, web 2.0 assumes an active citizen who wants to be engaged in increasing government performance. In order to cope with these expectations, we need a new paradigm (Collaborative governance) and corresponding Rules of Engagement (Citizenvision 2.0). A number of cases illustrate how this new paradigm can be implemented.

\subsection{Introduction}

\section{Cooperation}

During the last 15 years, almost every country has adopted a kind of e-Government strategy. Although these strategies differ according to nation and culture, there is a remarkable similarity. Not surprisingly most governments have been preoccupied with efficiency, since it will save costs for the supplier and reduce administrative burdens for citizens and businesses. Also there is much emphasis on digitization.

However, by now everyone knows that e-Government is not about technology, but about organization (workflow and process) and about people (skills and attitude). So the main task ahead is procedural change and business redesign. This means designing new ways in which to serve the customer, instead of automating existing products and processes. Moreover, government agencies cannot change separately. Both the challenge and the benefit lie in cooperation, within and between public organizations. 


\section{The Citizen}

Although most e-Government strategies claim to take the citizen into account, many strategies are rather supply-oriented. This is not only so because the focus is on infrastructure, but also since it is the administration that selects and decides on the projects. Moreover, there is a tendency to focus on service delivery, whereas this is only one area of contact between citizen and government. This neglects the fact that the citizen is not only a customer, but also or even more so, an inhabitant or a participant. e-Government should take this wider, multipurpose relationship into account. Moreover, citizens should be given more opportunity to present their views on topics like quality, satisfaction and involvement

\subsection{Interoperability}

Many public organizations strive to improve their services by trying to make them citizen centric. The good news is that they are discovering the customer. The bad news is that each organization is inventing this on its own, forgetting that each of us is a customer of many organizations.

An organization's drive to improve its own performance is not enough or can even be counterproductive. It may very well result in transforming the paper bureaucracy of the past into a virtual bureaucracy in the future. Chain service delivery is the road to citizen satisfaction. So the real option is to design modular solutions which can be combined and connected according to the needs of the customer. Common solutions based on standards are needed.

Interoperability is both necessary and helpful. Without it there is no e-Government in the real sense of the word. This will lead to the realization that each government official is not the one and only person having to cope with all changes. His or her counterpart in different organizations and other countries is dealing with the same problem. Together they can solve it better and only together will they succeed. This is both a comforting and challenging thought.

Interoperability should be at the basis of any policy for modernizing government. In the wider context of the European Union and its Member States, it is a method of harmonization that combines the advantages of integration without the disadvantages of centralization. Seamless or joined up services are not feasible without agreements on interoperability.

\section{Citizenlink}

From its very beginning, Dutch e-Government strategy has aspired to be citizen-centred. Actually the first initiative, started in 1996, was the one-stop-shop service delivery programme called OL2000 (Overheidsloket 2000/Public Counter 2000). It promoted the concept of "Thinking and working from the citizen's perspective". At the end of the 1990s it was accompanied by several other programmes dealing with other aspects of government reform. (Poelmans 2001, Bongers, Holland and Poelmans 2002).

In 2001, it was decided to merge the then existing 20 separate programmes into ICTU, a joint implementation organization for ICT in the public sector. In ICT Units (ICTU) all tiers of Dutch government (state, provinces, municipalities and water boards) have pooled their efforts and resources for Research \& Development in the field of e-Government solutions.

During 2002, the minister responsible for Government reform conceived the idea of an independent forum which would look critically into these developments from the citizen's 
point of view. To that end the e-Citizen Programme was started in 2003 with the task of being a critical evaluator of e-Government solutions. For five years it acted as the "Conscience of eGovernment" (Poelmans 2008).

However, since2008 it has been succeeded by Citizenlink, an initiative of the Dutch government to improve public performance by involving citizens. This programme has run for three years as part of ICTU with the following tasks:

- Promote Service Quality (Adoption of e-Citizen Charter \& Quality Codes)

- Measure Customer Satisfaction (Conduct Annual National Survey about Life Events)

- Stimulate Citizen Involvement (Organize an annual e-Participation Award and develop e-Participation Instruments)

\subsection{Service quality}

\section{e-Citizen charter}

Almost every organization will tell you that it wants to improve its quality, but what exactly is good (or rather excellent) quality? Usually a selection of ambitions is made, resulting in a random number of goals. However, since cooperation is the name of the game, organizations have to agree on one quality standard in case they intend to provide integrated services.

The Dutch e-Citizen Forum has developed a so called e-Citizen Charter. This charter consists of ten quality requirements for digital contacts, written from the citizens' perspective. Each requirement is formulated as a right of the citizen and a corresponding obligation of government. The charter is meant for both citizen and government. It allows citizens to call their government to account for the quality of digital services. Government can use the charter to examine external quality of its public performance. The requirements are based on research into existing quality systems and several surveys of citizen expectations. (Poelmans, Thaens and Boogers 2004, see Annex for the full text).

\section{Implementation}

The charter is not mandatory, but was adopted as a common standard for public service delivery by a so-called Administrative Convention between all tiers of government: national (the ministries, agencies), regional (provinces, water boards) and local (municipalities). The majority of these administrations have implemented the charter in one way or another. Moreover, it was incorporated in the national e-Government Interoperability Framework. A workbook explaining the idea has been widely used for training purposes in civil service.

To be meaningful for customers, the ten requirements actually have to be made specific and formulated in a Quality Code. Each public organization in The Netherlands is supposed to have adopted in the year 2012 such a code containing concrete promises about service quality and an offer to provide for compensation in case of non-compliance (Poelmans 2006, Poelmans 2007).

The Dutch charter was spontaneously copied by other countries in their policies for public sector reform. After receiving the European e-Democracy Award 2007, Citizenlink has been invited all over the world to present the charter. In the same year it was nominated for the EU e-Government Awards at the ministerial conference in Lisbon. Estonia took it as an example to base its e-State Charter on. France used it in the Administrative Modernization Programme. The EU Institute for Public Administration (EIPA) uses it for e-Government 
seminars in Greece and trainings in the Balkan. OECD recommended implementation in their reports and in 2011 the UN Convention Against Corruption selected it as an instrument to enhance social accountability in developing countries. To date the e-Citizen Charter has been translated into 22 languages.

\subsection{Satisfaction measurement}

\section{Life events}

It does not suffice to proclaim quality requirements without monitoring and measuring adherence. Citizen satisfaction however does not only result from digital or quick delivery of individual products or services. According to several surveys, the main complaint about government is that people don't know what the solution is to their problem and if they do, they don't know where to apply for it.

In order to assess citizen satisfaction about government performance as a whole, in the years 2008 - 2010 a national survey was conducted in which satisfaction was measured by asking citizens about real experiences with solving life events. Evaluation was based on the ten criteria of the e-Citizen Charter (Poelmans 2009).

The survey differed from traditional systems in that it did not look at the delivery of a separate service or the performance of a single organization. Instead it looked at covered life events and measured whether or not the citizens having experienced those situations were satisfied about the way they were treated. The reference was the extent to which the ten requirements of the charter were fulfilled. Some interesting conclusions are: the longer the service chain (i.e. the greater the number of organizations involved), the lower the satisfaction rate. And when citizens do have a choice in the way their problem is solved, their satisfaction rate is higher. It must be noted that there are big differences in rating between the life events.

\section{National survey}

The Dutch Government's aim, as set out in its policy programme, is for public services to score at least seven (on a scale of one to ten) during its term of office. The baseline was measured in the spring of 2008, when people were asked about the services provided in connection with life events.

The survey covered all services provided in connection with 55 life events, ranging from 'having a child', 'beginning a course', 'starting a business', 'long-term illness', 'going abroad', 'changing housing situation' and 'being fined' to 'death of a nearest and dearest'. These events had a high recognition factor for respondents, who were selected on the basis of actual experience of the various events. Over 10,000 persons were screened, leaving a final net sample of 1,400 to take part in the survey. The sample was raised to 3,000 in subsequent years in order to gather more specific data on each life event. The results are thus representative of Dutch residents who had contacts with government in connection with one of the life events during the past 12 months. They were asked to rate the service provided by the associated 'chain', i.e. the service experienced from organizations with which people come in contact in that connection. This is not a specific product but a 'combination of different but related activities, products and services to meet the needs of particular customers'.

People who had contacts with more than one organization rated cooperation between the organizations concerned at 6.3. We find that these people often give a low rating for 
cooperation because they believe it is actually non-existent. They also say there is frequently a lack of communication between the organizations themselves or between the organization(s) and the private citizen, with the result that they are required to fill in the same forms to provide information that the organizations already have. There is still a lot to be desired, then, from the point of view of the public.

Satisfaction varies from one life event to another. There would seem to be a strong correlation between the type of life event (how serious it is, how much it interferes with normal life, how long it lasts, and so on) and the evaluation of the government service provided. For each life event - and for all of them together - a Priority Matrix was drawn that indicates the relative importance of the ten requirements and the rating these received. See Figure 6.1.

Figure 0.6 Priority matrix 2010, e-citizen charter satisfaction rating

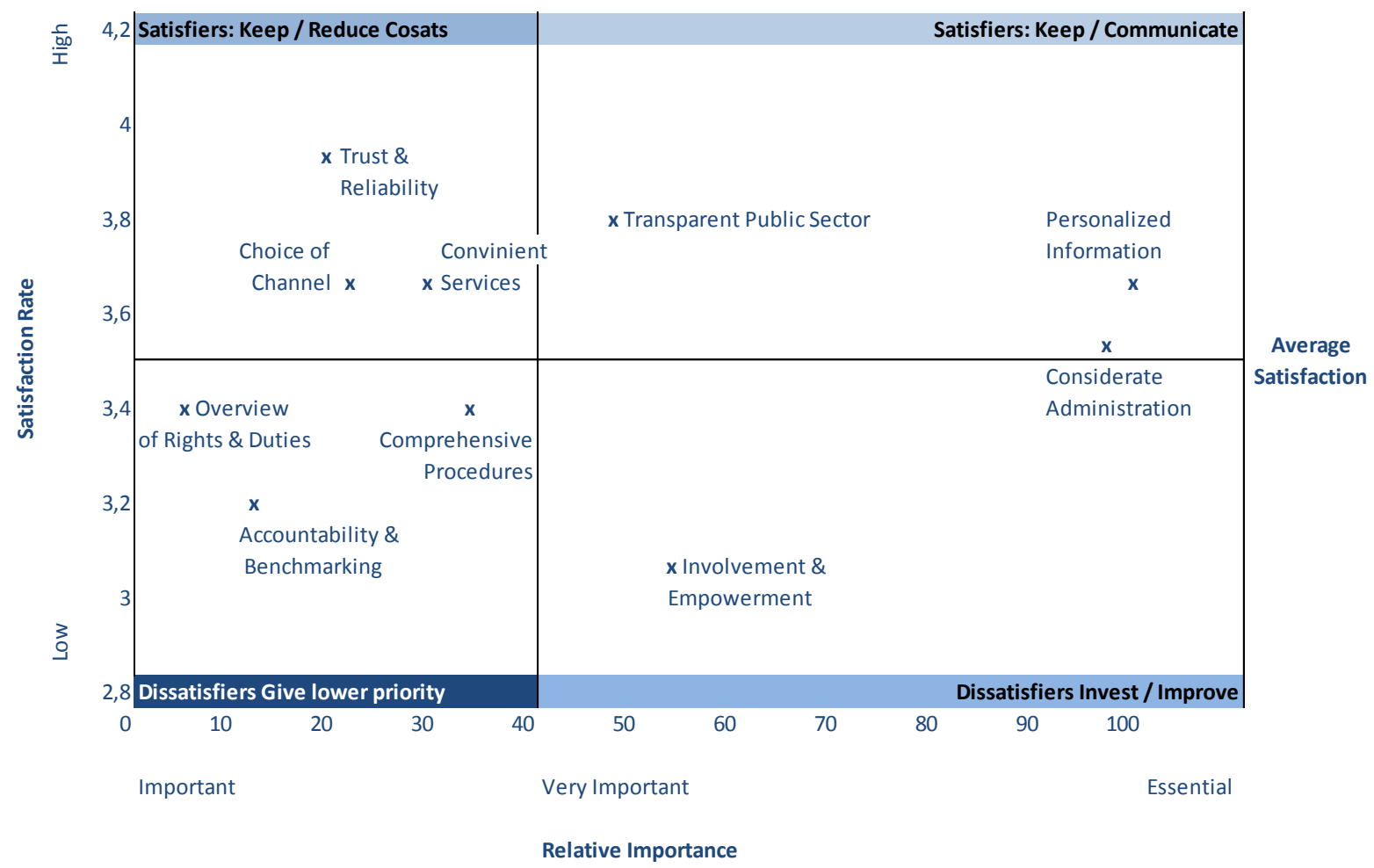

Source: Adapted from Citizenlink/TNS-NIPO, 2010 (not to scale)

\section{Customer journey mapping}

The survey actually measured the satisfaction on three levels: about the individual organizations involved, the service chain for a given event and government as a whole. In the 2010 survey, the aggregate marks were: $6.9,6.7$ and 6.4, meaning that there is a "loss" of quality perceived when collaboration is required.

The figures on the performance of a single organization have been compared with the outcome of already existing measurement frameworks. These turned out to be roughly the same. That the mark for the chain is lower than the one for the single organization is mainly due to contradictory information and lack of cooperation.

Since the rating of single organizations being part of the service chain differs quite a lot, "the good ones suffer from the bad ones". This very outcome created consensus for the next step: 
how to improve performance together. The Customer Journey Mapping approach does exactly what is says: mapping step by step with people from both supply and demand what happens to the "victim". In this way previously unknown chain deficiencies were discovered. In order to remedy these, a number of life events were selected that were deemed critical (low rating or high exposure) such as Bereavement, Unemployment and Moving. Lessons learned (also from successes) were subsequently applied to other life events. (Citizenlink 2010b)

\section{6 e-Participation}

\section{Participative democracy}

Because of its origin in administrative reform, e-Government until now has very much concentrated on service delivery. But supposing the new virtual infrastructure is in place, how can it enhance citizen involvement? What can it add to democracy and inclusion?

e-Participation is conceived of as using new media to involve citizens in improving service delivery and democratic decision making. There are those who expect a breakthrough in involvement, whereas others stress the fact that much remains to be seen. As for democracy, some basic issues should be considered.

Democracy in modern nation states is representative democracy. Although there is much talk about the democratic deficit or gap, there are not many advocates for direct e-Democracy. Before looking into promising ways of revitalizing representative democracy, a word of warning might be appropriate. For when applied in this area there are some concerns.

First of all, the present state of the technology is far below what is necessary. Internet is inherently unreliable, chip cards can simply be hacked, and identity fraud is easily committed, to name just a few problems. Because of this vulnerability, all e-Voting projects in The Netherlands have been abandoned. Actually from 2010 onwards all elections have been - again - by paper ballot.

Secondly, among the general public sufficient e-skills and awareness is lacking and accessibility is not guaranteed. Several surveys in The Netherlands show that a large number of people cannot find basic information on their rights and obligations or file a complaint. So access and inclusion is not only a problem for handicapped, deprived or disabled people, but also for ordinary citizens (Poelmans and Van der Linde 2009).

Thirdly, data protection that is already a hot issue in service delivery is more sensitive in political participation. Issues of data retention, data mining, preventing infringements and misuse have not been properly identified.

Finally, politics basically is about solving conflicts of interest or bridging different views. This means that informed decisions have to be made and politicians must face the consequences of their behaviour. Ordinary citizens who may have wise opinions can be invited to share these, but cannot be held responsible for their choices on policy issues. Whatever the criticism of political parties and how necessary a role-change might be, there is yet no alternative to this model.

\section{Standardization}


These basic issues have to be discussed - and the problems solved - before large scale operational e-Democracy services can be introduced. In the meantime, there is room for experiments and pilots.

The present state of affairs in e-Participation can be characterized as "Let many flowers blossom". Looking at the maturity cycle that is common in innovation, in due time a number of feasible projects will survive. The Citizenlink approach in The Netherlands consisted of modeling and standardizing promising instruments in the field of information, services, politics and cohesion. Some examples are briefly described. These address the goals of increasing transparency, reducing complexity of decision-making and supporting involvement (Citizenlink 2010a).

\section{Issue feeds}

Government is generally able to collect information about popular opinions and preferences as they are published or distributed in the analogue world. In order to be able to do the same in the digital world, an instrument is designed that helps civil servants find the relevant information about issues in the "second society".

\section{WeEvaluate}

Copying the example of rating websites who gather information about commercial services (like restaurants) and thereby create (or destroy) a reputation, a website has been launched on which citizens can evaluate public services. They can design their own rating system or they can use a simplified model of the National Citizen Satisfaction Survey mentioned before.

\section{TrackYourCouncil}

One of the Dutch successes in using the Internet during elections has been the Voting Assistant. This provides a comparison between the programmes of political parties on the basis of 30 main issues. It helps voters to make their choice. At the recent national elections about five million voters used the assistant (almost half of all those eligible to vote).

Since it is more helpful to make your electoral choice on actual behaviour than on future promises, another instrument is being developed: a Voting Tracker which assembles the voting record of parties and politicians and thus makes transparent what their positions have been on certain issues.

\section{e-Petitions}

According to Dutch law, citizens are entitled to start a 'citizen initiative'. If enough people support the issue, it can be tabled with a representative body like a city council or the parliament, which is obliged to discuss it. This is similar to the right of petition. The Internet can be a considerable help to gather the required number of signatures, so a website to this end has been started. A number of Dutch municipalities have created their own portal on this website.

\subsection{Conclusions}

\section{Performance improvement}

Recent Dutch surveys about progress in e-Government show a wide gap between the availability and the actual use of e-Services. Even though the number of e-Services increases over time and broadband penetration grows, take up does not accordingly. There remains an unused potential of about 50 per cent. International comparisons show that all countries face 
this problem. Actually in the top ranking countries in e-Government this very gap is even wider. Although there are indications that getting used to e-Services may induce more people to use them, one cannot assume that this will eventually bridge the gap. Real take up will be dependent on the introduction of so-called user-driven services.

Burgerlink (Citizenlink) is an example how this is done in The Netherlands. Its integrated three-step approach for standardization of quality requirements, measurement of customer satisfaction and stimulation of citizen engagement helps public organizations to perform better. This is necessary to stay reliable and remain trustworthy.

In order to reap the benefits of citizen-centric e-Government, public organizations need to adopt an integrative and iterative approach. The "Citizenlink Performance Improvement Incentive" recommends public organizations take the following steps (by the appropriate group):

- $\quad$ Adopt the e-Citizen Charter as the Standard (City Council)

- Specify a Quality Code for all Departments that serve Customers (Executive Board)

- Measure Citizen Satisfaction regularly (Departments)

- Involve Customers (Citizens)

- Account annually for Improvements (Mayor).

\section{Collaborative governance}

E-Government as we know it tries to improve the working of the existing public infrastructure. As such it is a change process in administration, and a tough one at that. However, when only conceived of in this way, such an approach lacks the necessary vision to create a new relationship between society and government. Even when in the best of his interests, the citizen "is being put in the centre" by government, the question arises: Shouldn't it be the other way round?

We need a new paradigm in which e-Government is being reinvented according to the future needs of an e-society. This is not about convenience but about creating public value. To give just one example, a building permit is not a "product" which should be delivered as easily as possible to the applicant, but a guarantee that my neighbour does not act against my interests by building a monstrous roof vault that takes away my sunlight. So the question is not how to implement a digital transaction, but how to design a new model for implementing the "social contract" that the government is to guard in the common interest.

Therefore, e-Government needs first of all to shift focus from service delivery to other public tasks, such as political decision-making and societal inclusion. Secondly it should be reinvented from the point of view of what is erroneously termed the end-user but is essentially the start-user: the e-Citizen.

\section{Citizenvision 2.0}

The Dutch citizen (and for that matter any citizen anywhere) has to deal with a lot more public organizations than he or she is aware of. Someone may not go the City Hall or visit the municipalities' website very often, but when it comes to living, healthcare, education, transport, safety, etc. one is left in the hands of the public services of the various governmental departments. This is not any different for companies and social institutes either.

Fortunately, all of these governmental organizations are busy with improving their service delivery. They do get results; however, a real breakthrough has yet to come. The main reason 
for this is that they do many things by themselves, from their own perspective. They also insufficiently get structural feedback from their customers. In order to change this, joint vision and action are necessary.

Past e-Government strategies and their subsequent revisions have remained very much focused on internal Public Sector Reform. So we need a new "citizenvision" that helps to redefine the relationship between citizen (including business and institution) and government from a Society 2.0 point of view.

Developments like Web 2.0 do provide citizens with new ways to communicate and contribute to their neighbourhood, city, country and the world. This is a major challenge for the public sector as a whole. Representative bodies, public managers and civil society organizations have to create a joint platform for interaction.

The e-Citizen Charter covers all aspects of the relationship between citizen and government (information, transaction and participation) and does not consider the citizen as a passive customer, but as an active member of society. So it is still applicable today in the field of web 2.0 and social media. Therefore, it can play an important role in the transition from Electronic government (public services) to Collaborative Governance (public value).

The charter deals with four major topics, which have to be reconsidered from a new angle in the light of new developments:

- Website becomes Platform: The website is no longer the default channel, a variety of delivery channels should not only be available for choice by the citizen, but also a platform for permanent interaction on the initiative of the citizen

- Information becomes Open Data: Apart from providing information upon request, all kind of Public Sector Information (PSI) will be voluntarily released, to be used for applications and other purposes

- Transaction becomes Cloud Computing: Apart from delivering a number of predesigned services, government facilitates third parties to solve problems perceived by civil society (Government App store?)

- Participation becomes Social Media: One-way participation on the initiative of and under the conditions set by government will be supplemented by permanent interaction (interference?) initiated by society.

A Citizenvision 2.0 acting as the successor to the e-Citizen Charter should describe these "New Rules of Engagement" for the next phase.

\subsection{Case descriptions in The Netherlands}

\section{Citizen Assessment Tool for Dutch Public Services}

\section{What is the Citizen Assessment Tool?}

A simple tool for citizens and customers of digital public services to report what they like or dislike, and if the latter is the case, what is wrong in their opinion.

\section{Why a Citizen Assessment Tool?}

Both the public sector and the market sector are increasingly implementing digital services. There is nothing wrong with this, provided that such services are designed accessibly and user-friendly. Unfortunately, that is not always the case. Excepting good examples, in many cases major deficiencies occur. Many people don't want to go to the trouble to complain or 
cannot find the right address, so valuable feedback is missed. A single digital counter is easy to find.

\section{How does the Citizen Assessment Tool work?}

Anyone who happens upon an example of bad (or particularly good) service is invited to report this to the Dutch Accessibility Foundation. One can fill out a form providing information about the incident or experience. A mobile app is also being developed. Information consists of a short description, a rating, an indication to the relevant quality requirement of the e-Citizen Charter. Preferably also the weblink is requested and if available, a screen print or photo can be attached.

\section{What happens with the Citizen Assessment Report?}

The Dutch Accessibility Foundation ensures that the complaint (or praise) will be communicated to the public body which is responsible for the service. The foundation will track and trace the case, keep the submitter informed about the progress and publish the outcome. However, uUsing the Citizen Assessment Tool does not take the place of a formal complaints or objection procedure with the official public body.

\section{Problems dealt with}

- Parking: unfair terms \& conditions

- Pharmacy: safe ordering of repeat prescriptions

- Public Transport: OV chipcard account travel details

- Public Library: difficulties lending eBooks

\section{Kafka Brigade: first aid for bureaucratic breakdown}

The Kafka Brigade is called into action when citizens and public servants become tangled in a web of dysfunctional rules, regulations and procedures.

The Kafka Brigade is an independent, not-for-profit action research team, comprising a network of action researchers from Amsterdam and The Hague (NL), Boston (USA), Northern Ireland and Wales (UK). Our mission is to tackle the bureaucratic dysfunction and red tape which prevents people from accessing the services they need, and which constrains and frustrates public service staff.

Franz Kafka wrote about the strangling and depersonalizing effect of bureaucracy. The Kafka Brigade reminds us that people using services have a lot to say about improving them - if only we would listen.

All public (or semi-public) organizations exhibiting serious signs of bureaucratic overload and dysfunction can benefit from the Kafka Brigade's expertise.

\section{Web Accessibility Chartermark}

The Web Accessibility Chartermark guarantees the visitor to a website that this website is compliant with the current standard on digital accessibility. The chartermark is issued by the Dutch Web Accessibility Foundation Drempelvrij.nl ("No Threshold"). This foundation has "translated" the international WCAG (Web Content Accessibility Guidelines) into Dutch. The foundation has a Board composed of independent experts, IT-professionals and citizen representatives from several sectors (including handicapped people and senior citizens). A 
Group of Experts and a Committee of Users maintain and update the set of guidelines. The foundation is an independent Non-Governmental Organization (NGO). Its work is financed by a small fee paid by the holders of an accessibility compliance certificate.

Organizations, whether public bodies or private companies, can contract an examination carried out by registered examiners. These have an accreditation with the Dutch Accreditation Council. The contractor can comply on either one of three levels: basic, intermediate or full. Upon successful completion of the examination, a certificate is issued which will be published on their website. This digital certificate links to the report by the issuing body. A complaints form is attached to facilitate visitors who have questions or dispute the level of compliance.

The Netherlands is the only country that has created such an independent and comprehensive system to promote adherence to international guidelines. As of 2010 all public websites on the national, regional and local level are obliged to conform to the public standard called Webrichtlijnen (Webguidelines). The web accessibility Chartermark is a good example of public-private partnership. Public bodies don't have to hire specialized employees and citizens can trust independent conformity claims (instead of self-declarations of conformity which are easily disputed).

\section{Schiphol Airport Environment Council (ORS)}

As of January 1, 2015, the Schiphol Environment Council will be the stage where all issues, interests and parties around the development of Amsterdam Schiphol Airport within its environment come together. The three parties involved are government bodies, the aviation sector and residents. The Council is the successor to the current Alderstafel Schiphol and Consultative Regional Committee of Schiphol (CROS).

\section{Why an airport environment council?}

Schiphol Airport is an important economic activity for the international competitiveness of The Netherlands with a relatively large impact on the environment. The balance between the development of aviation, increasing the quality of the environment and the potential for use of the space around the airport is a process where a lot of parties and their interests are involved. The Schiphol Environment Council is the place where all the parties and issues come together to negotiate, inform and consult.

\section{What does the Schiphol Environment Council look like?}

The Council consists of a Consultative Committee and Regional Forum. These two bodies each have their own tasks and work. The Consultative Committee and the Regional Forum will be led by a chairman. The main objective of the Consultative Committee is negotiating and advising on the strategic framework of the development of the airport and its surroundings. The focus at the Regional Forum is primarily on the provision of information and the wider dialogue on developments in the vicinity of Schiphol.

\section{Consultative committee}

The Consultative Committee is an advisory body to the ministers of the Ministry of Infrastructure and Environment. Furthermore, all parties can themselves table issues and submit requests for advice. The Consultative Committee is permanent and will meet about four times a year. The Committee focuses on issues of spatial planning, infrastructure and regional economic policy, insofar as they relate to the development of the airport and its surroundings. 
The Consultative Committee consists of the following parties: government bodies (on national, regional and local level), aviation sector (airport, airlines, traffic control) and residents' organizations.

\section{Regional forum}

The Regional Forum is the place where parties meet to inform each other and to discuss the developments in the vicinity of Schiphol. Whereas the Consultative Committee is intended primarily for negotiation and advice on the strategic frameworks, the Regional Forum deals with current issues regarding the operation of the airport (including noise reduction) and the spatial economic development of the region. In addition, there is specific focus on broad consultation of knowledge and ideas in the area. This will be done through various forms of consultation: (knowledge) meetings, workshops, field visits and online discussions. The Regional Forum consists of the same parties as the Consultative Committee.

\section{Citizen participation}

From the perspective of local residents, the three key improvements are:

1. Residents get an independent delegation: the citizen representatives are elected by the people and not as before appointed by municipalities

2. Involvement will be transparent and accountable: discussion and adoption of positions is no longer done in secrecy

3. Modern engagement \& services will be introduced: a Digital Regional Forum supports information exchange and interaction, opinion polls, one-stop services, using social media, etc.

As a resident in the Schiphol area one can participate in the Schiphol Environment Council in three ways:

- Registering a residents' association

- Joining an existing residents' association

- Using the Digital Regional Forum

One can register a residents' organization as a grassroots organization of the Schiphol Environment Council via the registration form on its website. This applies to existing organizations with more than 100 unique members, but also for newly-established organizations that are still trying to recruit members. They can sign up as a candidate organization.

If a resident is not yet a member of any organization, then one can join one of the registered grassroots organizations. By joining one of these community organizations as a member one can make one's voice heard.

The Digital Region Forum (DRF) has a dual function. It can contribute in general to the involvement of local residents in the discussion on the Schiphol area. In addition, it provides an excellent opportunity for the cluster representatives to communicate with constituents. The DRF will make information currently scattered over various organizations and websites more accessible. Moreover, it opens up the possibility of a "residents' initiative" and can stimulate public debate on a number of topics. 


\subsection{References}

Bongers, F., C. Holland, and M. Poelmans, Public Counter 2000, A Birds' Eye View, OL2000, The Hague 2002

Burgerlink/Citizenlink, eCC Workbook, 2006

Burgerlink/Citizenlink, Onderzoek naar de kwaliteit van overheidsdienstverlening vanuit levensgebeurtenissen (Public Service Quality Survey based on Life Events), TNS-NIPO, 2010a

Burgerlink/Citizenlink, The Citizen as an Impulse for Customer Focused Government, ICTU, The Hague (ISBN 978-90-815202-2-5), 2010b

KING 2011, New Media: opportunities for service delivery \& interaction, 2011

OECD, e-Government Studies - The Netherlands, OECD, Paris 2007

Poelmans, M., Citizen-centred government, the Dutch approach, in: J.E.J. Prins (ed.), Designing E-Government, Kluwer Law International, The Hague, 2001, 173-175

Poelmans, M., M. Thaens, and M. Boogers, Making e-Government work: the content and the significance of an e-Citizen's charter, in: Connected Government, Premium Publishers, London, 2004, 78-89

Poelmans, M., The e-Citizen Charter, e-Quality promoting Equality between Citizens and their Government, in: Innovation and the Knowledge Society, IOS Press, Amsterdam 2005, 660-666

Poelmans, M., The e-Citizen Charter as an Instrument to boost e-Government, in: Exploiting the Knowledge Economy, IOS Press, Amsterdam 2006, 531-538

Poelmans, M., Reinventing public service delivery by implementing the e-Citizen Charter, in: Expanding the Knowledge Economy, IOS Press, Amsterdam 2007, 531-538

Poelmans, M., The Conscience of e-Government: The Netherlands' e-Citizen Program (20022007), Conference Proceedings EEGOV, Prague, 2008, pp 453-459

Poelmans, M., and X. Van der Linde, The e-Citizen Charter as a Tool for Measuring Citizen Satisfaction on the Basis of Life Events, IIMC 2009

Poelmans, M., It's high time for a Citizenvision 2.0, blog, 3 April 2012 (2012a)

Poelmans, M., Citizen Measurement System as good as those of the Aviation Sector, Burgermeetsysteem even goed als dat van Schiphol, in: VK Opinie, 22 August 2012 (2012b)

Poelmans, M., Von elektronischer Verwaltung zu gemeinschaftlicher Governance, in: eGovernment und Netzpolitik im europäischen Vergleich, NOMOS Verlag, Baden Baden $2012(2012 c)$

Poelmans, M., No relaxation on accessibility guidelines, in: Binnenlands Bestuur, 2013

Poelmans, M., The e-Citizen Charter as a tool for Public Sector Innovation through Citizen Engagement and Social Accountability, in: UNECE Public Sector Innovation Newsletter, Geneva, 2014 
United Nations Public Administration Network, e-Government Survey 2008, New York, 2008

United Nations Public Administration Network, Final Report, Marrakesh Workshop on Citizen Engagement, 2011

United Nations Public Administration Network, UN e-Government Survey 2014, New York, 2014 


\section{Annex: e-Citizen Charter}

1. Choice of Channel - As a citizen I can choose for myself in which way to interact with government. Government ensures multi-channel service delivery, i.e. the availability of all communication channels: counter, letter, phone, e-mail, Internet.

2. Transparent Public Sector - As a citizen I know where to apply for official information and public services. Government guaranties one-stop-shop service delivery and acts as one seamless entity with no wrong doors.

3. Overview of Rights \& Obligations - As a citizen I know which services I am entitled to under which conditions. Government ensures that my rights and obligations are at all times transparent.

4. Personalized Information - As a citizen I am entitled to information that is complete, up to date and consistent. Government supplies appropriate information tailored to my needs.

5. Convenient Services - As a citizen I can choose to provide personal data once and to be served in a proactive way. Government makes clear what records it keeps about me and does not use data without my consent.

6. Comprehensive Procedures - As a citizen I can easily get to know how government works and monitor progress. Government keeps me informed of procedures I am involved in by way of tracking and tracing.

7. Trust \& Reliability - As a citizen I presume government to be electronically competent. Government guarantees secure identity management and reliable storage of electronic documents.

8. Considerate Administration - As a citizen I can file ideas for improvement and lodge complaints. Government compensates for mistakes and uses feedback information to improve its products and procedures.

9. Accountability \& Benchmarking - As a citizen I am able to compare, check and measure government outcome. Government actively supplies benchmark information about its performance.

10. Involvement \& Empowerment - As a citizen I am invited to participate in decisionmaking and to promote my interests. Government supports empowerment and ensures that the necessary information and instruments are available 


\section{Chapter 7}

\section{Innovating to Modernise the Public Sector in France}

Françoise Waintrop and Tanguy Dennielou, SGMAP, France

\subsection{Why innovate?}

In the early 21 st century the idea of a "new public management" emerged, a paradigm shift towards a public service of high quality, efficiency and transparency ${ }^{83}$. But, as many researchers have noted ${ }^{84}$, in practice public management in France has been modernized only little. Public administrations continue to work too often in "silos", isolated from each other and from those they are supposed to serve. Citizens and enterprises have lost confidence in the administration because they still suffer under excessively complex and expensive rules and procedures rooted in tradition. The problem has been exacerbated by the recent economic crisis, which has forced France like most Western countries to reduce government spending at all levels. The oft-used strategy of indiscriminate budget cuts has done nothing to modernize administrative practices in a sustainable way.

Apart from the economic crisis, several other factors can explain why attempts to introduce a "new public management" have not been more effective so far:

- A top-down approach which is too rigid and which does not make sufficient allowance for local conditions and competing interests;

- The self-centeredness of an administration which examines its own processes without taking into account the vision of stakeholders and in particular of users;

- The fact that the expectations and needs of users are far from uniform, a fact which implies that marginalised groups need more support, while sophisticated users need more flexibility and autonomy.

To take into account all these elements, the public sector needs to open up to the reality of society and to organize public administration in such a way that it can build, together with users and other stakeholders, ingenious and flexible solutions that respond to the challenges of simplification, better management and a higher quality of public service.

The Internet and other digital tools enable this transition. They present a formidable opportunity for modernization because they make it possible for the public sector to listen to and to take into account the needs of users. Digital technologies make it possible to re-invent public policy in a more inclusive way (socially, geographically, culturally) based on the notion of the public good. They enable co-creation with users, and thereby innovation, on a new scale.

\footnotetext{
${ }^{83}$ Cf. the "Loi organique relative aux lois de finance", adopted in 2001, for implementation by 2006 of a change in culture from a resources-oriented to a results-oriented administration including performance reports detailing goals and indicators of efficiency, quality of service and impact.

84 Notably Gert Bouckaert (2003), La réforme de la gestion publique change-t-elle les systèmes administratifs ?» Revue française d'administration publique 2003/1-2 (no 105-106), and Christopher Pollitt (2000), Is the emperor in his underwear? Routledge 2000 vol 2.
} 
At the beginning of the 21st century the goal of public sector innovation was more efficient public management and more strategic public spending. Today, the aspiration is to better respond to the expectations of users, to understand them by using novel methods - immersion into local conditions, collaborative platforms, design thinking - to identify the complexity of the situation and to find fast, cheap and consensus-based solutions.

\subsection{What is public sector innovation?}

In 2004, at the fourth European conference on the quality of public services in Finland, researchers and practitioners concluded that we would need to enter into the "era of co", i.e. co-production, co-design and co-evaluation, in order to re-gain the trust of citizens and to generate new services responding better to new opportunities arising from new technological developments and to new demands of society. The latest digital tools allow the public sector very rapidly to solicit the ideas and the pressing needs of citizens. Two crowd-sourcing examples illustrate this new era.

In France the collaborative platform "Faire-Simple" has been launched to collect ideas for the simplification of administrative procedures and services from the general public. Numerous campaigns have been launched on this site like "the relationship between the young and the administration", "simplification for enterprises" or the "20 procedures which poison the life of citizens", etc. The day-to-day experience of citizens and enterprises is thus made an essential element of innovation for the public sector which, by "walking a mile in the shoes of the users", discovers numerous opportunities for improvement and transformation.

Citizens can also put pressure directly on their administrations through crowd-sourcing movements. In Russia, the website "Ross Yama" allows citizens to react to the bad state of roads by creating communities which unite to denounce the main dysfunctionalities, and to exchange films, photos, and means of action. The site also automatically generates complaints to be sent en masse to public decision makers. These actions transform the relationship between the latter and the citizens and allow for a better quality of service.

Whether intended or not, this new relationship with citizens presents a radical evolution in the way in which public services and policies are conceived. The classical tools, i.e. regulation, taxation, and the provision of information without taking into account the new patterns of communication and behaviours of citizens, are less and less effective, as evidenced by the rich experiences at the global level.

All these new practices also show the importance of location. To improve for instance the responsiveness of an administration, why not embed it on the ground in order to understand the demands, the needs, the behaviours of the users, and how the service relationship forms at the point of contact between citizen and administration? From this $360^{\circ}$ analysis of the useradministrator relationship, down to the layout of the offices, can result a new organization which is more flexible, more human, more efficient.

The idea of flexibility is at the heart of innovation. It has led, both at the international level and in France, to a "laboratory" approach which allows us to rapidly diagnose the demand for a service or a policy, and then to devise and test it before it is scaled up. A culture of experimentation is thus fundamental. But a culture of experimentation requires that we recognize a "right to error" because experiments may turn out to be ineffective - and not suitable for scaling up. As such, experimentation is very much at odds with the traditional French culture of equality which implies that every citizen should benefit from the same services irrespective of his or her situation. 
The culture change which these new methods require does not come about on its own. It depends on a great deal of work on the ecosystem. Pressure from citizens, new forms of relationships created by digitization, ideas from the private sector, all these are powerful levers that must be used to open up the administration to new ideas - knowing that the most powerful lever will still remain the management. The foremost factor of transformation is the capacity of public sector employees to avail themselves of these new working methods. It is therefore increasingly important to create and use new competencies based on the management of innovation.

It is also useful to raise awareness about innovations and innovators and to put them in the limelight in order to promote the diffusion of successful innovation projects. This has to be organized at the national level. In France, many ministries (Interior, Justice, Defence, etc.) and agencies (e.g. the Social Security Administration) have put in place innovation prizes to ensure that successful local innovations are scaled up, and to show appreciation for the innovators. It is also possible to organize expositions to illustrate projects (for example the "Futur en Seine" project). The goal of events such as these is to learn more about initiatives on the ground, to identify what can be scaled up, to disseminate the achievements, to reward the innovators, and to show that there is a groundswell of innovation culture.

\subsection{The French context: an imposing administration}

When discussing what it takes to encourage innovation within a national administration, it is important to consider and analyse the strengths and weaknesses of the institutions of the country under consideration. In France, the foremost characteristic is the importance of the civil service as a profession. The size and the long tradition of the public sector may seem to be a weakness with respect to the need for flexibility and speed. But behind this image of an "ocean liner" which can change course only very slowly (the public sector represents 57 per cent of GDP) are historically notions of professional independence and modernity.

France has focused very early on creating a modern civil service, so that the "State" would be able to stand up to political power and would be protected from favouritism and arbitrary decisions. In 1946, the statute on the public duties of all state officials was adopted by Parliament. This law has enabled France to create a civil service which is honest, professional and impartial, at the level of the national state as well as the regional and local levels and in public agencies. Today, there are about 5.2 million civil servants: 2.4 million in the national government, 1.8 million in regional and local administrations, and 1.1 million in the health care and social sectors.

The civil service, which represents 20 per cent of employment in France, has maintained its standing and hence attractiveness over time. The level of education and professional training is higher in the public than in the private sector.

All this reminds us of how big the economic stakes are for promoting innovation in the public sector. It also reminds us that France can rely in this on a large stock of human capital, on a well-educated civil service which is independent of party politics.

Another asset of France when it comes to public sector innovation is its digital infrastructure. New digital technologies constitute today one of the prime areas of innovation. They can facilitate the utilization of massive amounts of data via open data applications. They can also facilitate the creation of online services and automatic information exchanges between different parts of the public sector. The potential of these technologies is known and understood. But to realize this potential requires significant investments in high-quality 
digital infrastructure so that digital services become effectively accessible to all. With highspeed Internet access available to more than 99 per cent of the population ${ }^{85}$, France possesses this infrastructure and is thus able to develop digital services for users and digital tools for civil servants.

Innovation needs to be linked to academic research. This is obvious in the case of industrial innovation, particularly at the cutting edge of knowledge. But it also holds true for innovation in public (and private) services. New methods like immersion and design thinking have emerged from the academic world, and the partnership between public administration and research is creating value. The quality of public sector programmes depends on studies and research on key public policy issues. The quality and strength of university research are assets for the public sector in its quest for innovation.

For the public sector to have a constructive dialogue with stakeholders, it is useful to have a strong civil society. France benefits from a vibrant civil society, and in some sectors like health care and sports, non-governmental organizations (NGOs) are numerous and powerful. There are more than one million associations in France, and a quarter of the population participates in charitable activities. ${ }^{86}$

Despite the above advantages in the quality and independence of the civil service, the quality of the digital infrastructure and of university research, and the vibrant civil society, the sheer weight of French bureaucracy limits the innovation capacity of both public and private actors. Over-regulation constitutes the primary obstacle. With 400,000 regulations in force, the legal and regulatory framework in France is extremely strict and inflexible. According to economic analyses carried out by the OECD, regulations on average impose a cost equivalent to three to four per cent of GDP on enterprises.

Another obstacle arises from the recruitment standards for civil servants and the "corporatist ethos" they promote. This ethos does not encourage cooperation with the private sector and civil society. The fourth European conference on the quality of public services promoted codesign and co-creation, i.e. a cooperation across sectors in the design and delivery of public services. But in practice the cooperation between the private sector and civil society on the one hand, and the public sector on the other, remain often limited to a delegation of tasks and stops well short of true co-construction.

The third obstacle is compartmentalization. With more than 100 central administrative agencies overseen by 16 ministries, the coordination and coherence which is indispensable for successful innovation and for new solutions to emerge is often difficult to achieve.

This overview of the French public sector and the environment in which it operates provides the necessary background for understanding how to take advantage of its strengths, i.e. the quality of the civil service, the digital infrastructure, university research, and civil society, and how to overcome its weaknesses. An analysis of the whole system is needed in order to create a strategy for public sector innovation.

\footnotetext{
85 Public Report of the Regulatory Authority for Telecommunications and Postal Services (Autorité de régulation des communications électroniques et des postes ARCEP) 2013, p.71. ${ }^{86}$ Recherches et Solidarités (2014), La France bénévole en 2014, p.8 (http://www.recherches-
solidarites.org/media/uploads/la-france-benevole_2014.pdf).
} 
The French state needs to create more flexibility and agility in its professional - but sometimes intimidating - civil service and to open up "spaces" of freedom which will allow it:

- to radically and efficiently transform public management, and

- to facilitate cooperation and create synergies between existing initiatives, while accepting that the public sector can no longer meet the needs of citizens and enterprises on its own.

\subsection{The choice of France to innovate}

In order to overcome the three obstacles described above, France in December 2013 launched a programme to promote public sector innovation. The programme "Futurs Publics" spearheads a larger movement to invigorate public services. It rests on two large pillars:

- implementing specific innovative projects;

- creating an ecosystem favourable to public sector innovation.

In contrast to other countries, the administrative framework in France is such that what is effectively a laboratory for public sector innovation had to be created inside the public administration. The culture of French administration would probably not have allowed for the creation of a structure external to the administration, be it in the form of a non-governmental organization or in private ownership.

\section{A different way of managing public sector innovation projects: the Lab}

The best way of demonstrating the merits of creating new public services in an innovative way is through specific projects. For this reason, the programme "Futurs Publics" has from the beginning incorporated a "Lab", in other words a project incubator which allows for experimentation with new public services.

How is this "Lab" different from the other activities managed by the General Secretariat for the Modernization of the Public Sector (SGMAP) and by the ministries? How and why is a project designated a "Lab"? Who implements it? How do we ensure that it is viable?

The first series of projects has shown that it is important to have a clear and transparent mechanism for selecting projects. This is achieved through a committee which selects projects for "Futurs Publics" based on their potential. Among the first innovation experiments have been projects on improving access to local public services, on the use of digital tools in classrooms, and on assistance to disabled people. All projects carried out in the framework of "Futurs Publics" share one or several of the following characteristics:

- corresponding to government priorities;

- $\quad$ radically transforming people's lives;

- $\quad$ improving the day-to-day working conditions of government employees;

- $\quad$ reducing public deficits;

- $\quad$ introducing new, more participatory forms of delivering public services.

Another feature which distinguishes the projects carried out within the "Futurs Publics" programme is that they are disruptive innovations in terms of the solutions they propose and the methods they use. To make this possible, innovators are given the freedom to experiment with arrangements, solutions and services which would be normally be impossible to try 
within the current administrative frameworks. Some projects may require exemptions from laws and regulations, others may require a temporary step outside the existing ICT architecture, while still others may require simply that senior management accepts an exploratory approach where it is at first unknown where it will lead and what will be found.

Yet another feature shared by all projects is that they start small and local. Projects conceived initially as "laboratory experiments" cannot be carried out immediately at the central, national level. They have to be co-created with future stakeholders and both implemented and tested at every stage of their development together with the users on the ground. Communities have to emerge which drive the projects and ensure that they meet user needs.

The project leaders have a particularly important role to play in this. They need a lot of room to manoeuver and they need to have an entrepreneurial spirit to build the project with all partners. They need to be able to mobilize and link at different stages of the project expertise from areas as diverse as design, sociology, ethnography, quantitative and qualitative analysis, even architecture or philosophy.

The final feature required of all projects is that they must offer a realistic prospect for being scaled up and being integrated into the existing administrative practice. In France, it is not uncommon to see projects developed on an experimental basis which have no future because they lack systematic evaluation and have no plan for the diffusion of results and lessons learned.

The programme "Futurs Publics" thus focuses on a limited number of projects, not more than six at a time, and on a compressed time schedule of not more than eight months. The former condition allows for full mobilization of teams and ensures a high-quality follow-up on all current projects. The latter condition avoids projects which lose sight of their objectives and which die a slow death on someone's desk.

When considering the resource requirements of "Lab" projects, the goal of eventually integrating these projects into wider administrative practice has to be kept in mind. The resource requirements must be in line with what the administration could realistically mobilize to sustain an experimental project on a larger scale. Another important consideration is that experimental projects which are place-based and which are carried out by partnerships of local users and providers can often not be replicated elsewhere one-to-one. It is therefore crucial to think about how these projects can be scaled up, taking into account local contexts and the need for specific partnerships.

It is not always possible to guarantee that these principles will be respected, be it because of conflicts of interests, changing priorities or delays in implementation. However, there is one condition which is more fundamental than the others: administration buy-in. An administration which struggles to identify fields for experimentation and a project leader will be unlikely to fully embrace the results of the experiment.

\section{Creating an ecosystem favourable to public sector innovation}

Because it depends on partnerships, public sector innovation can flourish only within an ecosystem. In the "Futurs Publics" programme, this ecosystem is built at several levels.

On a first level, experts from ministries and agencies (such as an employment agency, social security administration etc.) meet regularly as a community of practice. This community provides a forum for exchanges of experience and for cooperation. It has produced two reports, on "Participatory Innovation" and on "The use of social networks within public 
administrations". The community of practice is first and foremost a platform for dialogue and disclosure, where experiences can be shared and difficulties addressed. New cooperation can also be agreed on at this level.

This first level has expanded progressively to include certain regional and local administrations which have entered the field of public sector innovation based on their placebased competencies. Thanks to support from associations like the " 27 th region", 87 several programmes of transformation of local public services have been launched in recent years based on the method of design thinking.

The second level of the ecosystem encompasses the natural partners of the public sector, i.e. researchers in humanities and social sciences and in management, designers of services, and any other professionals whose competencies may be relevant to public sector innovation. It also includes the non-profit sector (associations, social entrepreneurs, social innovators ...) and drivers of technological innovation (start-ups, incubators ...). Depending on their fields of expertise, these may be called upon to contribute to the projects carried out by "Futurs Publics". They may also participate in discussions on new public sector management practices.

The third level, finally, includes international partners:

- The public administrations of other states which invest in public sector innovation and the international organizations which offer dialogue platforms on this subject.

- The United Nations which collects good practices from all Member States and leads a discussion on tools and methods.

- The OECD and its Observatory of Public Sector Innovation (OPSI) deserves special mention. Through a collaborative platform ${ }^{88}$, this observatory reviews the innovations put in place in its member states and offers a space for dialogue among practitioners of public sector innovation.

Enterprises may round out the ecosystem on a case by case basis. In certain respects, innovation in the market sector is similar to innovation in the public sector. ${ }^{89}$ The collaborative nature of the innovation process and the scaling up of successful experiments are cases in point. This is why it has been possible to carry out participatory innovation in partnership between public administrations and private enterprises.

The programme "Futurs Publics" also has the capacity to invest in projects of French ministries and administrations. Beyond the implementation of specific projects, "Futurs Publics" is able to disseminate broadly methods and techniques of public sector innovation through calls for project proposals. The financing is made conditional on satisfying terms of reference which reflect the key requirements for the successful implementation of public sector innovation projects. Calls for project proposals also allow stimulating complex interministerial projects where the risks are too great for a single administration to bear or where

\footnotetext{
${ }^{87}$ The association " $27^{\text {th }}$ region" was founded in 2008 by the Association of the Regions of France and the Deposit and Consignment Fund. It promotes a vision of the transformation of public policies based on a multidisciplinary approach bringing together public actors, researchers (sociologists, ethnographers ...) and professionals from the creative industries (designers, film makers ...).

${ }^{88} \mathrm{https}: / /$ www.oecd.org/governance/observatory-public-sector-innovation/

${ }^{89}$ See also Chapter 1 above.
} 
the gains are diffused too widely between administrations for any one of them to quickly generate an adequate return on investment on its own.

\subsection{Some examples of public sector innovation in France}

Since its inception in December 2013, the programme "Futurs Publics" can already be credited with several specific innovations. It should be added, though, that this programme does not have a monopoly on the development of innovation initiatives, and some were supported by the ministries themselves.

\section{Developing innovative digital pedagogical applications: the project "Connected High Schools"}

In the project "Connected High Schools", which was launched in 2013, the French Ministry of National Education, Higher Learning and Research has provided digital pedagogical tools to 23 high schools in order to enable them to better integrate digital elements into their teaching and the general life of the schools.

But these tools have not always been used because they have not been completely in tune with the needs and uses of teachers and students. Digital interactive blackboards sometimes are used only as video projectors or as traditional blackboards, and the tablet computers issued to students sometimes stay in the back of their desk drawers.

Since the launch of the initiative, "Futurs Publics" has supported teachers in order to enrich the use of digital pedagogical tools through innovative practices. In two high schools, project leaders from SGMAP and researchers from a research centre specializing in education have cooperated in a three-stage process:

- A stock taking of existing digital practices and unexploited potentials based on 50 interviews and some twenty in-class observations.

- A co-conception phase where teachers and their supervisors invent new digital classroom sessions.

- An experimentation phase to test these new uses and to think about prototype tools and pedagogical resources to facilitate digitisation.

In the two schools involved in the project, workshops have resulted in the co-creation together with students of a history course using the interactive digital blackboard, and of an "inverted class", a learning method where students work out theories at home based on multimedia content and classroom exercises.

Remarkably, this project succeeded only by mobilizing the teachers of the two selected schools, without any additional digital resources other than those provided by the ministry to the "Connected High Schools". The project might perhaps not sound very ambitious. But it creates ownership of change in a way that is sustainable and can be replicated in other schools, rather than merely creating a showcase which is disconnected from the work reality of teachers. 


\section{Forging partnerships with social and technological innovators to invent new services: "Innovative Connections"}

The responses to public service challenges are increasingly co-created, with users first and foremost, but also with social and technological innovators. These enterprises, associations and groups challenge the traditional modes of public service delivery through the solutions they develop, the flexibility they bring, and the new models they invent. Sometimes they also propose novel solutions at the margins of the system, when the responses of the public sector to the needs of certain populations (job seekers, high school dropouts, elderly people without family...) appear not or no longer satisfactory.

An example is the "inter-generational housing" developed by certain associations. These offers bring a solution to the isolation of the elderly and to the housing shortage for students in metropolitan areas, despite the initiatives being at first met with indifference or even resistance from public administrations. But little by little the administrations have been won over by positive experiences.

In order to mobilize these actors and to facilitate this type of cooperation, SGMAP has developed, in the framework of the programme "Futurs Publics", the format "Innovative Connections". Practitioners from the public, business and non-profit sectors meet to exchange their experiences, to learn to understand each other, and to invent new solutions to the needs of users.

These meetings work off observations of behaviours and descriptions of uses based on methods inspired by ethnography and design thinking. The moderation techniques applied encourage cooperation between participants with diverse backgrounds. As a result of these meetings, new ideas can be prototyped and tested with users.

A first meeting organized on the theme of helping the elderly to remain autonomous and to be able to stay in their own homes brought together more than 50 people. The participants prototyped services to prevent the isolation of the elderly and to connect everyone who provides assistance, including the families, the physicians, and domestic help.

\section{Using service design to sketch the contours of the administration of tomorrow}

Several of the projects led by "Futurs Publics" have used techniques from the discipline of service design. ${ }^{90}$ This discipline is based on methods and tools such as evidencing which involves creating objects and images exploring the way a proposed design innovation will look and feel (a brochure presenting the proposed service or an entry ticket for instance).

Customer journey mapping ${ }^{91}$ and wire frames are two other instruments of service design. The former creates a story board with the various stages the user goes through when using the service, while the latter is a method inspired by web design aiming to create a mock up of a future web page.

One of the projects carried out with these methods was a so-called "residence" on local public services. The "residence" is a format invented by the association "27th Region" to evaluate public policies. Over the course of several months, an interdisciplinary team made

\footnotetext{
${ }^{90}$ This is the application of methods and skills originating from industrial design to the development of services. It is a practical and creative approach to improve existing and create new services.

${ }^{91}$ See also chapter 6.
} 
up as appropriate of designers, sociologists, architects, social innovators and researchers, spends a few weeks in a community. In the case of the project carried out by the "27th Region" and SGMAP on access to local public services, the expert team immersed itself locally for four weeks as follows:

- In the first week, they met with local public service providers in order to analyse and create a basic understanding of the issue;

- In the second week, they developed proposals for short-term measures which could be tested during the residence period, for medium-term measures to be put in place by the local public service providers, and for more long-term projects;

- In the third week, these action lines were further clarified and developed;

- The fourth week, which was organized in Paris, gave a national dimension to the work of the "Residence" by sharing with relevant national administrations the lessons from the experiments and by preparing the ground for scaling up those measures which have a potential for national significance.

At the end of this first experiment, other projects now are mobilizing design. For example, a seminar "Innovation by Design" organized to imagine the future of the Gendarmerie in the context of the development of digital uses.

For five days, multidisciplinary teams of designers, plus students from engineering, marketing and/or human resources proposed their illustrated vision of a "digital police". The focus was a new look to change ways of thinking, to break taboos and to propose missing solutions. The imagined projects also questioned the relationship of the police with its environment, drawing new partnerships and a more collaborative public service.

\section{Innovating to simplify}

The "Simplified Public Market" is a web application which allows companies to respond to a public tender with a few mouse clicks, where previously they had to provide numerous documents.

This service rests on the principle of a priori trust. The documents required to confirm the contract between the public sector entity and the company will be provided by the administrative offices which have them or will be requested only from the company that has won the tender. The "Simplified Public Market" was developed like a start-up out of workshops with the administrative offices keeping the information necessary to confirm procurement contracts, the companies and the public sector buyers.

\subsection{The challenges of public innovation}

Because innovation is often created and tested locally, it faces the challenge of scaling up to the national level. The "laboratory mode" is flexible and fast, but how can we move from test to general application? Many countries are wrestling with this conundrum.

- The first manifestation of the conundrum is the question of how to disseminate knowledge about local innovations. For an experience not to remain solitary, it must be moved out of the shadow so that other organizations can copy it. For example, the national police is doing this with its performance workshops, in which it informs about 
significant innovations and makes them available to all local police forces. Moreover, some innovation prize competitions have given rise to additional prizes for copying which recognise the administration which best duplicated the initial experience. Finally, events like the French "Public Sector Innovation Weeks" provide occasions for publicizing local innovations worth disseminating. ${ }^{92}$

- A second manifestation of the conundrum is that the right to error is essential to any innovation process, yet is difficult to implement in the sometimes rigid environment of the public sector. Once a decision has been taken to implement a new policy or method, it is often tested at the local level and then rolled out nationally with some improvements if necessary. But it is hardly ever re-assessed completely. By contrast, to innovate properly means to accept that the result of an experiment may be negative, and so the initiative should be stopped. To some experts, the main role of laboratories like "Futurs Publics" is actually to experiment with some seemingly good ideas in order to de-mine the road for the rest of the administrations! Is not error the first step towards success?

- Innovation does not yet come naturally to the public sector, because its administrative structure is often rigid by necessity. The natural instincts of public sector organizations need to be challenged. This is critical in order for the public sector as a whole to advance and to improve. And it often depends on the intelligence and ingenuity of one or a few individuals. It is therefore important to listen to these people and to support them even if their ideas run counter to the way things have always been done. Taking an idea forward and trying it out poses a risk. Our public processes often rest on avoiding all risk, even if it would potentially add value.

- It is also important to promote a management style which allows good ideas to rise to the top: listening to employees and supporting innovators by giving them the means to implement their ideas, and creating channels for communication among innovators and for spreading innovative practices.

- Another factor for the development of innovation in the public sector is international cooperation. Knowledge of the innovation projects of other governments can play the role of catalyst of ideas. The Observatory on Public Sector Innovation of the OECD goes even farther in allowing a dialogue among innovators and a cross-fertilisation of ideas and projects.

\subsection{Conclusion}

Today, virtually all governments pursue public sector innovation. But this is not without contradictions. We have shown in these pages the various challenges which public sector innovation faces: to develop agile administrations in an environment that is still quite rigid; accepting the right to error in a culture founded on risk aversion; supporting innovators against the natural instincts of public sector organizations to prefer the status quo; to discuss innovation, to market good practices in a sector which, except for the case of votes for landmark legislation, is rather silent; to be inspired not only by top-down orders from the ministries but also by bottom-up ideas from the field; to be pragmatic and to test and experiment before implementing projects.

\footnotetext{
${ }^{92}$ A Public Sector Innovation Week was organized for the first time nation-wide on 12-16 November 2014.
} 
If political leaders want to support innovation in the public sector, they need to take into account all these challenges. Innovation creates value by disrupting; this is its rationale. And so we need to write a new story of government reform, based on a multitude of local experiences, and relying on stakeholders to design the public services of tomorrow. 


\section{Chapter 8}

\section{US Public Sector Innovation Programmes}

Dennis Patrick Leyden, University of North Carolina at Greensboro, United States of America

\subsection{Introduction ${ }^{93}$}

It is commonly believed that the public sector is not amenable to innovation. However, as argued elsewhere in this volume (Leyden, 2015), public sector innovation, like its private sector counterpart, is driven by goal-oriented entrepreneurial behavior, and necessary to that public sector innovation process is a public sector environment supported by a legal and administrative framework enabling those in the public sector to create and exploit an entrepreneurial social network, containing within it incentives to engage in the innovation process, and a set of institutional arrangements that mimic important competitive-market forces ${ }^{94}$.

This chapter illustrates how such an environment might be created through an examination of a number of public sector innovation programmes in the United States. While the examples examined differ in their details and the mechanisms that they use, what they share is that they change the existing public sector environment in a way that encourages entrepreneurial social networking, incentivizes the innovation process, and/or mimics important competitive-market forces to foster an increased level of innovative activity.

\subsection{Potential benefit of United States public sector innovation}

Because of its three-level federal structure, the US public sector is a complex one. ${ }^{95}$ At the national level, the federal government focuses generally (but not exclusively) on public services of national scope. The biggest spending categories that together comprise roughly two-thirds of all expenditures are defence, Social Security (the national retirement programme), and Medicare/Medicaid (health care for, respectively, the elderly and the poor). Below the national government are 50 state governments whose biggest budget categories are public welfare and insurance, education, health care, and transportation. Finally, there is the local level, a diverse collection of more than 89,000 smaller, sometimes overlapping geographic entities (counties, cities, special districts, etc.). The largest expenditure categories at the local level are education, health care, transportation, public safety, and utilities.

\footnotetext{
${ }^{93}$ I would like to thank the participants of the 2013 UNECE applied policy seminar "Innovation in the Public Sector" in Geneva, Switzerland for their comments on an earlier presentation that formed the basis for this chapter. I would also like to especially thank Ralph Heinrich at the UNECE for his helpful guidance in exploring this issue and writing this chapter.

${ }_{94}^{94}$ More specifically, the public sector environment needs to mimic the creative destruction process whereby nolonger-valued firms are eliminated, the profit/loss process by which firms are kept informed of the value that society places on their output, and the consumer sovereignty process by which consumers make voluntary, informed choices in the marketplace. As discussed in Leyden (2015), these processes can be mimicked by putting in place mechanisms that allow for ability to sunset outdated programmes and institutional infrastructure, and provide for feedback loops, and that frame innovations as informed choices for public service end users.

${ }^{95}$ The statistics in this section are taken from, or calculated based upon, data in Barnett \& Vidal (2014), Bureau of Labor Statistics (2014), Congressional Budget Office (2014), and US Census Bureau (2012)
} 
The potential benefit of public sector innovation in the United States is large - both for the public sector itself and for the broader US economy. As Figures 8.1 and 8.2 illustrate, total government spending in the United States since 2000 has gradually risen in real terms and as a share of US GDP and now (2013) stands at \$5.4 trillion, or 32.3 per cent of GDP. Moreover, as of 2013 almost 22 million people or approximately 16 per cent of the US civilian labor force are employed by US governments, with nearly $2 / 3$ of that number working for local governments.

Figure 0.7 US government expenditures, real $(2009=100), 2000-2013$

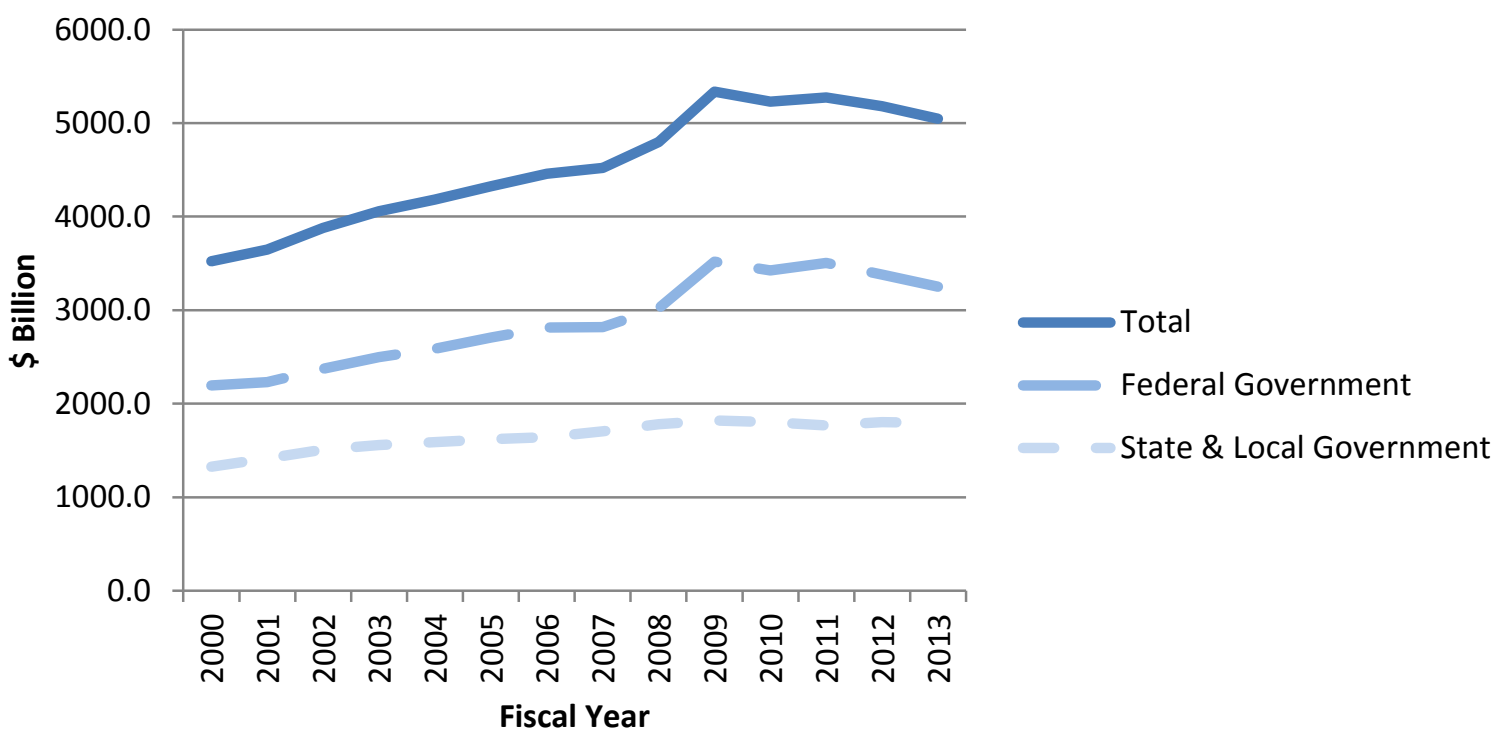

Source: Graph constructed from data downloaded from Congressional Budget Office (2014)

Figure 0.8 US government expenditures (as \% of GDP), 2000-2013

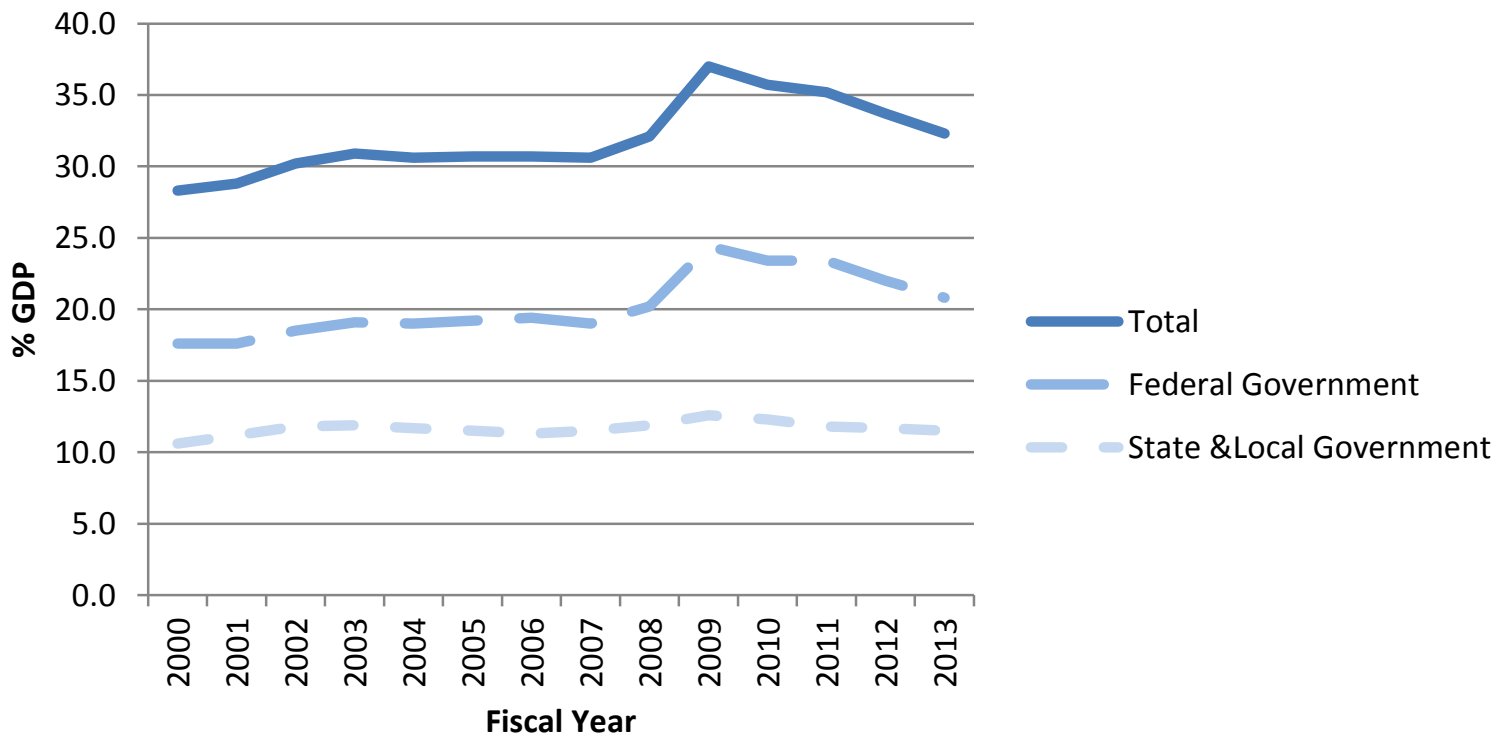

Source: Graph constructed from data downloaded from Congressional Budget Office (2014) 
The US public sector, as well as the broader US economy, is not achieving its potential in terms of innovation and economic growth. Since 2000, US GDP has had an average annual growth rate of only 1.78 per cent and since 2008 that annual growth rate has averaged only 0.96 per cent. While studies of the overall growth in productivity in the public sector are hard to come by, a 1996 Bureau of Labor Statistics study (Bureau of Labor Statistics, 2006) that is summarized in Figure 8.3 suggests that public sector productivity growth, at least for the federal government, is low and not improving.

Figure 0.9 Annual productivity growth, US federal government, 1968-1994

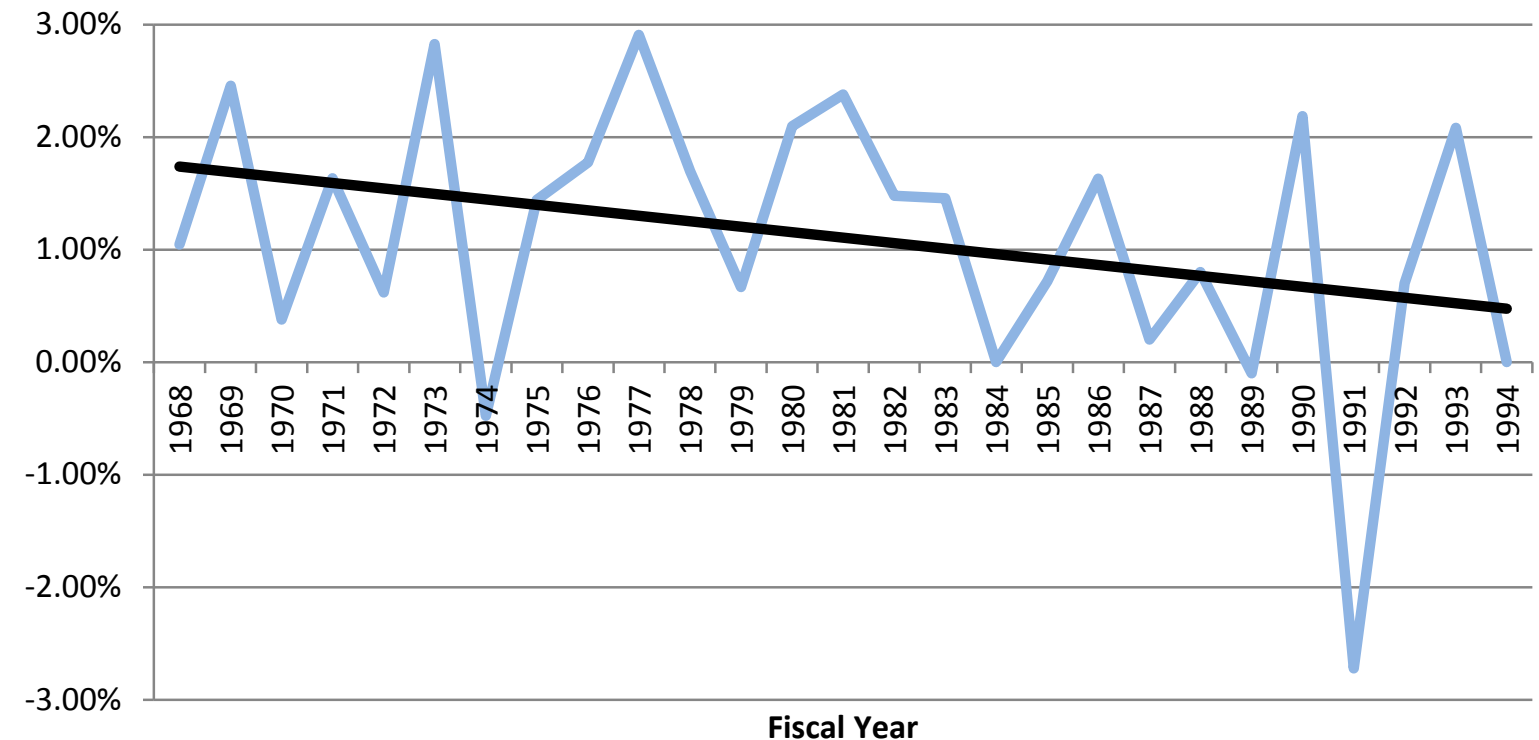

Source: Graph constructed from data in Bureau of Labor Statistics (2006)

Thus, innovation in the US public sector has the potential for contributing significantly to both public sector output and productivity, and more generally to the entire nation's economic growth and prosperity. Such benefits could be manifest in a variety of ways - by reducing the cost of delivering public goods and services that directly affect those who live in the country (for example, health care, public safety, and public welfare), by increasing the quality and array of those same goods and services, and by improving private sector productivity through expansion and improvement of publicly-provided goods and services (for example, physical infrastructure such as roads, human capital via education, and administration of regulations) on which the private sector depends. These innovations reflect the result of what Leyden (2015) refers to elsewhere in this volume as direct public sector entrepreneurial behavior, that is, the innovative manipulation of the public sector environment (particularly the expenditure, management, and service mechanisms of government) for the public good. It is also possible for there to be indirect public sector entrepreneurship which operates by innovatively altering the private sector economic environment to induce desirable behaviors on the part of private sector entrepreneurs, again for the public good. However, that is not the focus of this volume. ${ }^{96}$

\footnotetext{
${ }^{96}$ Leyden and Link (2015) provide a theoretical and empirical analysis of indirect public sector entrepreneurial activity
} 


\subsection{Examples of United States public sector innovation programmes}

There is no comprehensive innovation policy in place at any level of government in the United States that provides guidance on the formulation and adoption of specific innovation programmes. Instead, what exists is a disconnected set of individual innovation programs, each focused on a specific and often limited part of the public sector environment. The innovation programmes described below are a small sample of those efforts and are organized according to whether they were initiated by the public sector itself or by others outside of the public sector. ${ }^{97}$ In most but not all cases they are focused on public sector innovation at the national level.

\section{Public sector initiated innovation policies}

Table 8.1 provides a summary list of the public sector-initiated innovation programmes examined below along with an indication of the manner in which they modify the public sector environment in order to foster innovation.

Table 0.1 Examples of public sector innovation programs: public sector initiated

\begin{tabular}{|c|c|c|c|}
\hline Programme & Purpose & Mechanism & $\begin{array}{c}\text { Environmental } \\
\text { Changes Fostered }\end{array}$ \\
\hline $\begin{array}{l}\text { White House Open } \\
\text { Government } \\
\text { Initiative }\end{array}$ & $\begin{array}{l}\text { Create more open } \\
\text { government primarily } \\
\text { through digitization of } \\
\text { information }\end{array}$ & Administrative directive & $\begin{array}{l}\text { Social networks } \\
\text { Feedback loops } \\
\text { (institutional } \\
\text { structures that mimic } \\
\text { competitive markets) }\end{array}$ \\
\hline $\begin{array}{l}\text { White House } \\
\text { Champions of } \\
\text { Change }\end{array}$ & $\begin{array}{l}\text { Encourage public } \\
\text { sector innovation }\end{array}$ & Public recognition & $\begin{array}{c}\text { Social networks } \\
\text { Incentives for } \\
\text { Pursuing Innovations }\end{array}$ \\
\hline $\begin{array}{l}\text { Entrepreneur-in- } \\
\text { Residence Act of } \\
\quad 2012\end{array}$ & $\begin{array}{c}\text { Enhance governmental } \\
\text { innovation }\end{array}$ & $\begin{array}{l}\text { Placing established } \\
\text { entrepreneurs in } \\
\text { government departments }\end{array}$ & Social networks \\
\hline $\begin{array}{l}\text { Office of Personnel } \\
\text { Management's } \\
\text { Innovation Lab }\end{array}$ & $\begin{array}{l}\text { Enhance day-to-day } \\
\text { government office } \\
\text { functions }\end{array}$ & $\begin{array}{l}\text { Establish experimental } \\
\text { lab and incubator }\end{array}$ & Social networks \\
\hline $\begin{array}{l}\text { State Innovation } \\
\text { Models Initiative }\end{array}$ & $\begin{array}{c}\text { Transform government } \\
\text { health care funding and } \\
\text { delivery }\end{array}$ & $\begin{array}{l}\text { Pilot project competition } \\
\text { with two-stage funding }\end{array}$ & Social networks \\
\hline $\begin{array}{c}\text { EERE Public R\&D } \\
\text { Evaluation } \\
\text { Programme }\end{array}$ & $\begin{array}{l}\text { Measure and evaluate } \\
\text { EERE projects }\end{array}$ & $\begin{array}{l}\text { Merit reviews, process } \\
\text { evaluations, impact } \\
\text { evaluations, } \& \\
\text { programme reviews }\end{array}$ & $\begin{array}{c}\text { Feedback loops } \\
\text { (institutional } \\
\text { structures that mimic } \\
\text { competitive markets) }\end{array}$ \\
\hline
\end{tabular}

Source: See text

\footnotetext{
${ }^{97}$ Note that this section provides examples of general programmes intended to foster the innovation process in the public sector and does not contain examples of specific public sector innovations. For examples of the latter, see Sahni, Wessel, and Christensen (2013)
} 


\section{White House Open Government Initiative e $^{98}$}

The White House Open Government Initiative is an initiative developed by the Office of the President of the United States of America. It currently involves approximately 30 executive departments and offices, and includes approximately 11 programmes (most notably the data.gov open-source/open-data programme). The purpose of this initiative is to increase public access to high value, machine-readable datasets generated by the executive branch of the US federal government, and to create virtual "communities" of like-minded individuals in the hope of fostering innovation in both the private sector" and public sector. To that end, the initiative requires federal government programmes in the executive branch to publish government information online, improve the quality of government information, create and institutionalize a culture of open government, and create an enabling policy framework for open government (Office of Management and Budget, 2009). While this initiative does nothing to provide funding, it does authorize public sector entrepreneurial action directed at enhancing social networks used by both the public and private sectors. Thus, this initiative fosters both the creation and exploitation of entrepreneurial social networks and the creation of institutional structures that mimic competitive markets through the creation of feedback loops.

\section{White House Champions of Change $\mathbf{e}^{100}$}

The White House Champions of Change programme was also developed by the Office of the President of the United States. The purpose of this program is to highlight and reward through recognition public-focused innovative activity of individuals and organizations, governmental and non-governmental. It works primarily by soliciting nominations. Winners are chosen and typically presented in groups defined by a common theme (e.g., public health, open science, youth jobs, immigration, the National Aeronautics and Space Administration (NASA), the Peace Corp). To date, several hundred have been recognized. This programme does not provide funding; nor does it authorize public sector entrepreneurs to act. But it does enhance entrepreneurial social networks and provides incentives for pursuing public sector innovation.

\section{Entrepreneur-in-Residence Act of 2012}

The Entrepreneur-in-Residence Act of 2012 is an example of an interesting, but failed, attempt to enhance entrepreneurial social networks in the public sector by placing 30 established entrepreneurs (most likely from the private sector) in US federal government agencies. ${ }^{101}$ Although the proposed act died in committee, it is interesting because it proposed to enhance public sector entrepreneurial networks not by broadening the range of connections between individuals but by inserting individuals who have experience pulling such connections together.

\section{Office of Personnel Management's Innovation Lab}

Innovation Lab is an initiative of the US Office of Personnel Management to serve as an experimental lab and incubator for improving the day-to-day operations of the civil service,

\footnotetext{
98 www.whitehouse.gov/open

${ }_{99}$ Thus, for example, the app FlyOnTime.us uses statistics from the Bureau of Transportation to identify the best on-time flights.

${ }^{100}$ www.whitehouse.gov/champions

${ }^{101}$ The Act was proposed by US Congressman Mike Honda (Silicon Valley, California) and Senator Mary Landrieu (Louisiana), and has some of the structure of the US National Science Foundation's Innovation Corps programme discussed in Leyden (2015).
} 
and it is based on the premise that the most fruitful way to get results is by starting at the bottom with individual civil servants and building up. While it has been slow in being developed, it is remarkable for its attempt to provide support in three areas needed for public sector entrepreneurship - funding, authority to act, and enhancement of social networks.

\section{State Innovation Models Initiative being run by the US Department of Health and Human Services ${ }^{102}$}

The State Innovation Models Initiative is a program of the Centers for Medicare \& Medicaid Services in the US Department of Health and Human Services. The purpose of this program is to improve the national health care system by transforming the method by which government funds health care services and represents an effort to make significant changes in large public sector organizations. The programme provides funding and other support for states to develop and test innovative payment and health care delivery systems. Funding is provided in two stages with learning from the first stage used to inform funding decisions in the second stage. The programme is currently in its second stage and has already awarded approximately $\$ 300$ million. Thus, by providing support to explore possible innovations, this program fosters the creation and exploitation of entrepreneurial social networks.

\section{EERE Public R\&D Evaluation Programme ${ }^{103}$}

The Energy Efficiency and Renewable Energy (EERE) Public R\&D Evaluation Programme is sponsored by the US Department of Energy's Office of EERE. Its purpose is to measure and evaluate EERE projects and programs, particularly with regard to assessing whether planned technical goals were met and commercialization and market results achieved, and to identifying opportunities for continuous improvements in its programmes. To date, approximately 11 programmes have been evaluated. As such it does not directly enhance public sector social networks, nor provide funding, neither authority to act. However, given the constitutional, legal, and political constraints that public sector entrepreneurs operate under and the lack of market feedback on the social value of their innovations, evaluative programmes such as this one are valuable.

\section{Private sector-Initiated Innovation Policies}

Table 8.2 provides a summary list of the private sector-initiated innovation programmes examined below along with an indication of the manner in which they modify the public sector environment in order to foster innovation. All of these programmes have a similar structure - individuals inside and outside of government are brought together to share experiences and perspectives, define issues, and engage in research to develop innovative ideas and methods of application. The emphasis is clearly on the expansion and strengthening of the weak ties that are part of the entrepreneurial social network that are so critical to the innovation process.

\footnotetext{
$102 \mathrm{http} / / /$ innovation.cms.gov/initiatives/state-innovations/

103 www1.eere.energy.gov/analysis/pe_index.html
} 
Table 0.2. Examples of public sector innovation programs: private sector initiated

\begin{tabular}{|c|c|c|c|}
\hline Policy & Purpose & Mechanism & $\begin{array}{c}\text { Environmental Changes } \\
\text { Fostered }\end{array}$ \\
\hline $\begin{array}{l}\text { Partnership for } \\
\text { Public Service }\end{array}$ & $\begin{array}{l}\text { Revitalize US } \\
\text { federal } \\
\text { government by } \\
\text { encouraging and } \\
\text { facilitating } \\
\text { innovations }\end{array}$ & $\begin{array}{l}\text { Attract high quality talent, } \\
\text { leadership programmes, } \\
\text { improve administrator } \\
\text { assessment \& } \\
\text { accountability, modernize } \\
\text { management systems, \& } \\
\text { build support networks for } \\
\text { government administrators }\end{array}$ & $\begin{array}{c}\text { Social networks } \\
\text { Feedback loops } \\
\text { (institutional structures } \\
\text { that mimic competitive } \\
\text { markets) }\end{array}$ \\
\hline Deloitte GovLab & $\begin{array}{l}\text { Foster practical } \\
\text { innovations in the } \\
\text { public sector }\end{array}$ & $\begin{array}{l}\text { Research in collaboration } \\
\text { with government } \\
\text { administrators and thought } \\
\text { leaders }\end{array}$ & $\begin{array}{c}\text { Social networks } \\
\text { Feedback loops } \\
\text { (institutional structures } \\
\text { that mimic competitive } \\
\text { markets) }\end{array}$ \\
\hline $\begin{array}{l}\text { Ash Center for } \\
\text { Democratic } \\
\text { Governance \& } \\
\text { Innovation }\end{array}$ & $\begin{array}{l}\text { Promote } \\
\text { innovation in the } \\
\text { public sector }\end{array}$ & $\begin{array}{l}\text { Develop, recognize, \& } \\
\text { disseminate information } \\
\text { about public sector } \\
\text { innovations }\end{array}$ & $\begin{array}{c}\text { Social networks } \\
\text { Incentives for Pursuing } \\
\text { Innovations } \\
\text { Feedback loops } \\
\text { (institutional structures } \\
\text { that mimic competitive } \\
\text { markets) }\end{array}$ \\
\hline $\begin{array}{l}\text { Alliance for } \\
\text { Innovation }\end{array}$ & $\begin{array}{l}\text { Promotes local } \\
\text { government } \\
\text { innovation }\end{array}$ & $\begin{array}{l}\text { Disseminate information } \\
\text { about innovations \& } \\
\text { support networking among } \\
\text { local government officials }\end{array}$ & Social networks \\
\hline $\begin{array}{c}\text { Bloomberg } \\
\text { Philanthropies' } \\
\text { Mayors Project }\end{array}$ & $\begin{array}{l}\text { Foster city } \\
\text { government } \\
\text { innovation }\end{array}$ & $\begin{array}{l}\text { Provide information, } \\
\text { technical assistance, \& } \\
\text { networking opportunities }\end{array}$ & $\begin{array}{c}\text { Social networks } \\
\text { Incentives for Pursuing } \\
\text { Innovations } \\
\text { Feedback loops } \\
\text { (institutional structures } \\
\text { that mimic competitive } \\
\text { markets) }\end{array}$ \\
\hline
\end{tabular}

Source: See text

\section{Partnership for Public Service}

Partnership for Public Service is a nonprofit, nonpartisan organization that seeks to revitalize the US federal government by encouraging and facilitating innovations. Governed by a board of directors and an advisory board composed of corporate executives, politicians, academics, and past government administrators, its efforts focus on five strategies - helping government hire high- quality talent, providing leadership programs for government administrators, helping improve government administrator assessment and accountability programs, helping 
modernize management systems, and building support networks for government administrators.

\section{Deloitte GovLab ${ }^{104}$}

GovLab is the international consulting firm Deloitte's in-house think-tank located administratively within its US federal government management consulting practice. GovLab focuses on the analysis of practical innovations in the public sector in collaboration with government administrators and thought leaders.

\section{Innovations in Government Programme ${ }^{105}$}

The Innovations in Government Programme is a research programme focused on promoting innovation in the public sector. The programme is run by the Ash Center located in Harvard University's Kennedy School and supports a variety of initiatives that focus on the development, recognition, and dissemination of public sector innovations. Among its initiatives are the Innovations in American Government Awards programme, the Government Innovators Network, the public sector innovation blog Better, Cheaper, and the urban policy directors' network Project on Social Innovation.

\section{Alliance for Innovation ${ }^{106}$}

The Alliance for Innovation is a membership organization of local governments dedicated to local government innovations. Sponsored by the International City/County Management Association and Arizona State University, the organization disseminates information about innovations and supports networking among local government officials.

\section{The Mayors Project}

The Mayors Project is a collection of initiatives run by Bloomberg Philanthropies to foster city-government innovation. Among the initiatives supported that provide information, technical assistance, networking opportunities, recognition for innovative efforts, and feedback on innovative efforts are the international Mayors Challenge competition, the Cities of Service volunteer programme, the Innovation Delivery Teams consulting programme, and the Financial Empowerment Center's counseling programme.

\subsection{Conclusions}

Public sector innovation, like its private sector counterpart, is driven by goal-oriented entrepreneurial behaviour. However, unlike its private sector counterpart, there is no natural environment that stimulates public sector innovation. Instead, specific programmes need to be adopted to create a public sector environment that enables and encourages those in the public sector to create and exploit an entrepreneurial social network, containing within it incentives to engage in the innovation process, and with a set of institutional arrangements that mimic important competitive-market forces.

While there is no comprehensive innovation policy in place at any level of government in the United States that guides the creation of public sector innovation programmes, there are various individual innovation programmes, each of which is focused on part of the public sector environment and that work by making one or more of the public sector environmental

\footnotetext{
${ }^{104}$ www.deloitte.com/us/govlab

105 www.ash.harvard.edu/Home/Programs/Innovations-in-Government

${ }^{106}$ transformgov.org/en/home
} 
changes described above. This chapter provides a description of some of these programmes, some of which find their origins inside the US public sector, others of which find their origins in the private sector.

None of these programmes addresses all the public sector environmental needs that a comprehensive public sector innovation policy would require. But they provide valuable examples of how that effort might be pursued by others. And with time, they will provide valuable experience that allows for future improvement. The potential value of public sector innovation in the United States, and indeed in other countries as well, is large; most directly because it would mean an ability to better serve the needs and aspirations of its citizens. But with such improved ability might also come an additional benefit - an increased recognition that the public sector can and should play an important role in the general welfare of people. 


\subsection{References}

Barnett, J. L., and P.M. Vidal, 2012 Census of Governments: Finance-State and Local Government Summary Report, July 2011. Washington, DC: US Census Bureau. 2013, available at: http://www2.census.gov/govs/local/summary_report.pdf

Bureau of Labor Statistics, Federal government productivity - historical data, 22 August 2006, available at: http://www.bls.gov/lpc/iprpfftp.htm.

Bureau of Labor Statistics, Employees on nonfarm payrolls by industry sector and selected industry detail, Employment, hours, and earnings (CES), Table B-1, 9 October, 2014, available at: http://www.bls.gov/webapps/legacy/cesbtab1.htm.

Congressional Budget Office, The budget and economic outlook: 2014 to 2024, February 2014, available at: http://www.cbo.gov/publication/45010.

Leyden, D. P., A theory of public sector innovation policy, in Heinrich, R., (Ed.), Public sector innovation, United Nations Economic Commission for Europe, 2015, Geneva

National Science Foundation (n.d.), NSF Innovation Corps, available at: http://www.nsf.gov/news/special_reports/i-corps/index.jsp.

Office of Management and Budget, Open government directive (Memorandum for the heads of executive departments and agencies). 8 December, 2009, available at: http://www.whitehouse.gov/open/documents/open-government-directive

Sahni, N. R., M. Wessel, and C.M. Christensen, Unleashing breakthrough innovation in government, Stanford Social Innovation Review, 2013, 11, 27-31.

US Census Bureau, Census Bureau reports there are 89,004 local governments in the United States, Press release, 30 August, 2012, available at: https://www.census.gov/newsroom/releases/archives/governments/cb12-161.html 


\section{Chapter 9}

\section{New Evidence on the Innovation Climate in the Swedish Public Sector}

Irene Ek, Swedish Agency for Growth Policy Analysis

\subsection{Introduction}

Swedish policymakers give increasing attention to understanding the role of the public sector in regard to innovation dynamics. It is widely acknowledged that the public sector can act as a catalyst for business innovation. Recently, however, attention has shifted to better understand how innovation takes place within public sector organizations. The reasoning behind this is the recognition that innovation is needed for the public sector to address the many challenges that it faces. On the one hand, it must respond to increasing pressure due to rising costs, increasing demands from citizens and businesses, demographic changes, environmental risks, and the process of globalization. On the other hand, the public sector has transformed, by adopting both technological and organizational changes to improve public services, while addressing concerns of efficiency.

Everyone seems to think that Sweden needs a more innovative public sector to promote inclusive growth i.e. to involve the whole labour force in order to boost economic growth. So we have a profusion of somewhat competing government initiatives that offer solutions. The e-Government Delegation was launched to enhance the development of digitalized public services. The Committee for Digitalization was established in 2012, to monitor progress in terms of meeting the policy goals of the Swedish Digital Agenda. The National Council for Innovation and Quality in the Public Sector was active between 2011 and 2013. A specific innovation council dedicated to the public sector was established to improve the efficiency and quality of public activities at national, regional and local levels.

What aspects of public sector innovation is it possible to measure and monitor today? What does the latest evidence say that can be used to develop a policy rationale for interventions in the public sector? Which policy holds up to scrutiny and which ones should be discarded? There could be serious consequences if these questions remain unanswered. The current chapter is a first attempt to show how new evidence can be used to guide policy.

\section{Box 0.1 Swedish government initiatives}

\section{Government initiatives - The Swedish delegation for e-Government}

In 2009 the Swedish government launched the e-Government delegation to enhance the development of digitalised public services and create good opportunities for inter-agency coordination in the area.

The delegation has now been working for four years and recently delivered recommendations on a renewed governance model for future e-Government. The delegations official report states that the Swedish public administration should be built on a 'life events' perspective where the citizen's needs are in focus. In order to move in this direction, it is argued that a critical success factor is increased interaction between the central and local government sectors.

The current governance model consists of independent agencies and local self-government. As the current governance model is firmly established, and almost impossible to change, the e-Government delegation proposes a new body of cooperation based on a membership structure. The new organization should reenforce the collaboration between the central and local government. 
This chapter outlines the main trends and features related to innovation in the public sector in Sweden. The Swedish government increasingly acknowledges the importance of public sector innovation. To guide the government the Swedish Agency for Growth Policy Analysis produced the report "The Swedish Innovation Climate", which monitors the implementation of the Swedish Innovation Strategy, especially highlighting the need for more innovative public services. Although the development of data on innovation in the public sector is in its infancy the data that does exist has been evaluated and critically analysed.

\section{The public sector's contribution to growth}

The Swedish public sector plays a key economic role as regulator, service provider and employer. It accounts for more than 30 per cent of total employment and about 20 per cent of GDP (Knutsson and Thomasson 2013). Additionally, an efficient and productive public sector can be a strong driver of economic growth through its support of innovation in the private sector as well as a procurer of innovative goods and services.

The Swedish Association of Local Authorities and Regions (SALAR) estimates that local government costs will increase by one per cent per annum until around 2035, which will lead to a gap between costs and revenue equivalent to raising the local government tax rate by 13 per cent. This means that, to be able to finance public consumption, productivity growth in the public sector needs to increase over the coming 20 years.

\section{Putting innovation in the public sector on the policy agenda in Sweden}

This section presents a short policy mapping with the key features of Swedish policies used to support innovation in the public sector. The focus is on how Swedish policy makers go about putting innovation in the public sector on the agenda. New evidence, which elaborates on a qualitative content analysis of the selected policy reports, is presented here for the first time. An in-depth analysis of the policy reports listed in table 9.1 shows a number of initiatives across several ministries which all give somewhat similar recommendations but appear to lack inter-ministry coordination.

Traditionally the Swedish research and innovation agendas have focused on science and technological developments that benefit business innovation, particularly product innovation in manufacturing firms. A content analysis of the most important Swedish policy documents shows that the Swedish government has recognized that this focus is too narrow (Table 9.1). A policy with a too narrow focus misses the potential benefits of new innovation sources such as citizens' and employees. Co-development is vital as the public sector is the largest service provider in Sweden and service delivery should ultimately create value for the citizens. In addition the pressure on the Swedish public sector to innovate and change, is mounting as many "public tasks" are increasing in volume and/or complexity, while the available resources are not.

The present policy mapping also shows that public sector innovation is increasingly placed in a broader perspective as several government ministries, as well as the prime minister's office, produce policy documents (Table 9.1). An interpretation of the policy documents is that step by step the Swedish government is trying to work towards a coherent policy framework, which implies the take-up of public sector innovation policy goals by other policy areas. This is a serious challenge when public sector innovation policy is supposed to be accommodated by other policies such as procurement policy, general innovation policy, ICT-policy, as well as general social affairs policy. The difference between policy areas is reflected in the instruments typically employed within a specific policy area. Such differences can increase the tension among policy areas. 
Table 0.3 Policy mapping - Sweden

\begin{tabular}{|c|c|c|}
\hline Policy report & \begin{tabular}{|l} 
Ministry \\
responsible
\end{tabular} & Description \\
\hline $\begin{array}{l}\text { National Innovation } \\
\text { Strategy (2012) }\end{array}$ & $\begin{array}{l}\text { Ministry of } \\
\text { Enterprise, Energy } \\
\text { and Communication }\end{array}$ & $\begin{array}{l}\text { To contribute to a climate with the best } \\
\text { possible conditions for innovation in Sweden } \\
\text { by the year } 2020 \text {. Public sector innovation is } \\
\text { one of the six focus areas. }\end{array}$ \\
\hline $\begin{array}{l}\text { Future challenges for } \\
\text { Sweden by the Commission } \\
\text { on the Future of Sweden } \\
(2013)\end{array}$ & $\begin{array}{l}\text { The Prime Minister's } \\
\text { office }\end{array}$ & $\begin{array}{l}\text { To identify the challenges facing Sweden in } \\
\text { the longer term (2050). Particular attention is } \\
\text { given to sustainable growth, demographic } \\
\text { development, labour market integration and } \\
\text { social cohesion. }\end{array}$ \\
\hline $\begin{array}{l}\text { ICT for everyone }- \text { A } \\
\text { digital agenda for Sweden } \\
\text { (2011) }\end{array}$ & $\begin{array}{l}\text { Ministry of } \\
\text { Enterprise, Energy } \\
\text { and Communication }\end{array}$ & $\begin{array}{l}\text { To enhance Sweden's role as a prominent ICT } \\
\text { nation - but as ICT spans many policy areas } \\
\text { the aim is to highlight ICT as an enabler in } \\
\text { order to attain various policy goals (e.g. } \\
\text { regional growth, green growth). }\end{array}$ \\
\hline $\begin{array}{l}\text { Organise the future e- } \\
\text { government, by the e- } \\
\text { Government Delegation }\end{array}$ & $\begin{array}{l}\text { Ministry of } \\
\text { Enterprise, Energy } \\
\text { and Communication }\end{array}$ & $\begin{array}{l}\text { To propose an e-gov strategy and coordinate } \\
\text { the selected innovation support in the area. } \\
\text { Finally to coordinate standardization issues. }\end{array}$ \\
\hline $\begin{array}{l}\text { A digital agenda to serve } \\
\text { the citizens; a bright future } \\
\text { can be ours, by The } \\
\text { Committee for Digitization } \\
(2014)\end{array}$ & $\begin{array}{l}\text { Ministry of } \\
\text { Enterprise, Energy } \\
\text { and Communication }\end{array}$ & $\begin{array}{l}\text { To monitor progress in terms of meeting the } \\
\text { policy goal of the Swedish Digital Agenda; } \\
\text { that Sweden should become the best in world } \\
\text { at exploiting the opportunities of digitization. }\end{array}$ \\
\hline $\begin{array}{l}\text { Think new to create } \\
\text { benefits, by the National } \\
\text { Council for Innovation and } \\
\text { Quality in the Public Sector } \\
\text { (2013) }\end{array}$ & $\begin{array}{l}\text { Ministry of Health } \\
\text { and Social Affairs }\end{array}$ & $\begin{array}{l}\text { To improve the efficiency and quality of } \\
\text { public activities at national, regional and local } \\
\text { level. }\end{array}$ \\
\hline
\end{tabular}

Source: See text

The Future Commission of Sweden point out that Sweden is facing major demographic challenges to adapt to an ageing society. By the year 2030 it is estimated that more than one in five citizens will be over 65 (Commission 2013). In order to adapt to these conditions, innovations are needed to deliver public services with increased quality and efficiency. The Swedish government believes that innovation in the public sector can lower costs and increase efficiency and quality, with better use of existing resources.

Despite the increasing level of policy interest in Sweden, and unlike for the private sector, indicators to better understand how public sector organizations innovate are either in their infancy or lacking. In the case of firms, there are two main frameworks used to define and measure research and innovation i.e. the Oslo Manual and the Fascati Manual (OECD 2002). These frameworks have been developed, implemented and improved over time. As attention turns to innovation in the public sector it is appropriate to consider how the extensive experience with business innovation surveys can help in defining and measuring innovation in the public sector. 


\subsection{What constitutes innovation in the public sector and how is it measured?}

Presently Swedish policy makers have somewhat limited evidence of how public sector organizations innovate. Unlike for the private sector, indicators to better understand how the public sector innovates are rare.

In the case of firms there is already a framework for defining and measuring innovation (the Oslo Manual), in use since the early 1990s. As attention turns to innovation in the public sector it is appropriate to consider how the experience with business innovation surveys can help.

Sweden has contributed to the international measurement agenda by participating in the European pilot study of MEPIN (NordicInnovation 2010) which suggested a framework for collecting internationally-comparable data on innovation in the public sector. Results from the pilot study suggest that the four modes of innovations identified in the Oslo Manual could be modified to reflect the nature of public sector services and activities.

Building on the European pilot study the OECD defines innovation in the public sector as follows:

- An innovation is the implementation of a new or substantially changed method aimed at improving an organization's operations or outcomes. Innovations comprise new or substantially changed services and goods, operational processes, organizational or communication methods.

- Innovations must be new to an organization, although they may have been developed by others. They can either be the result of decisions within the organization or in response to new regulations or policy measures.

- Sweden generally follows the international measurement agenda. Still, there are a number of methodological issues the need to be considered when analysing the data put forward in this chapter. In particular:

- The target population: given the heterogeneity of the public sector as a whole, it may not be desirable to generalize the MEPIN results to the whole public sector as the data consist of only a few selected sub-sectors. Still MEPIN is the only CIS-like pilot we know of at the moment.

\subsection{Evidence to guide policy makers}

Efforts to improve how the public sector functions and the services it delivers require detailed knowledge of how public sector organizations innovate. Still, unlike for the private sector, indicators to better understand how Swedish public sector organizations innovate are few, whereby the Swedish Agency for Growth Analysis continuously updates the evidence base every year. Below the most recent indicators available are presented in depth. The focus is on individual indicators which are so specific that they could guide Swedish policy makers in the decision-making process as well as present UN-member states with an opportunity for policy learning.

To guide the government, the Swedish Agency for Growth Policy Analysis produced the report "The Swedish Innovation Climate", which monitored the implementation of the Swedish Innovation Strategy that especially highlighted the need for more innovative public 
services. Although the development of data on innovation in the public sector is in its infancy the data that does exist has been evaluated and critically analysed.

The current indicators focus on, the degree of innovative activity, the use of public procurement to drive innovation, and e-Services development. The evidence base draws heavily on data from Statistics Sweden, the European Commission's community innovation survey as well as work performed by international organizations such as the OECD and the United Nations.

Growth analysis uses a whole battery of indicators to measure how innovative the public sector is in Sweden and can present the following evidence:

- Surprisingly, a higher degree of public sector organizations respond that they conduct innovative activity, compared to the lessons learnt from the indicators on firms in the private sector (78 per cent for public sector organizations and 53 per cent for private firms)

- Today 85 per cent of Swedish firms with a procurement contract do not perform any innovation within the scope of the contract.

- Existing policy initiatives prioritize digital infrastructure thus paying less attention to the e-Services development

\section{Lessons learnt from the indicators}

\section{E-service development}

Several policy documents acknowledge that e-Government can provide opportunities to transform public administration into an instrument of sustainable economic development. eGovernment covers the use of information technologies in public administration to streamline and integrate workflows and processes, to effectively manage data and information, enhance public service delivery, as well as expand communication channels for engagement and empowerment of people.

Back in 2008 Sweden was ranked No. 1 in the United Nations' e-Government Survey. However, Sweden has not been able to keep its position as world leader. In 2014 Sweden is far behind the current leader South Korea, with Sweden gradually slipping into 14th place.

The United Nations e-Gov index consists of three dimensions: a) the availability of online services, b) telecommunication infrastructure and c) human capacity. An in-depth analysis of the Swedish results shows that infrastructure and human capital are strong areas. Sweden's weakness is the availability of online services.

The online services dimension is a composite indicator measuring the use of ICT by governments to deliver public services at national level. Figure 8.1 shows the index values for selected countries on a scale from one to zero. The value one corresponds to the performance of the highest rated country. The Swedish results show a continuous downward trend. In 2012 the Swedish value was above 0.8 which has decreased in 2014 to 0.7. In other words Sweden's distance to leading country has increased. 
Figure 0.10 Selected results from the on-line service index (OSI) in the UN e-Gov survey

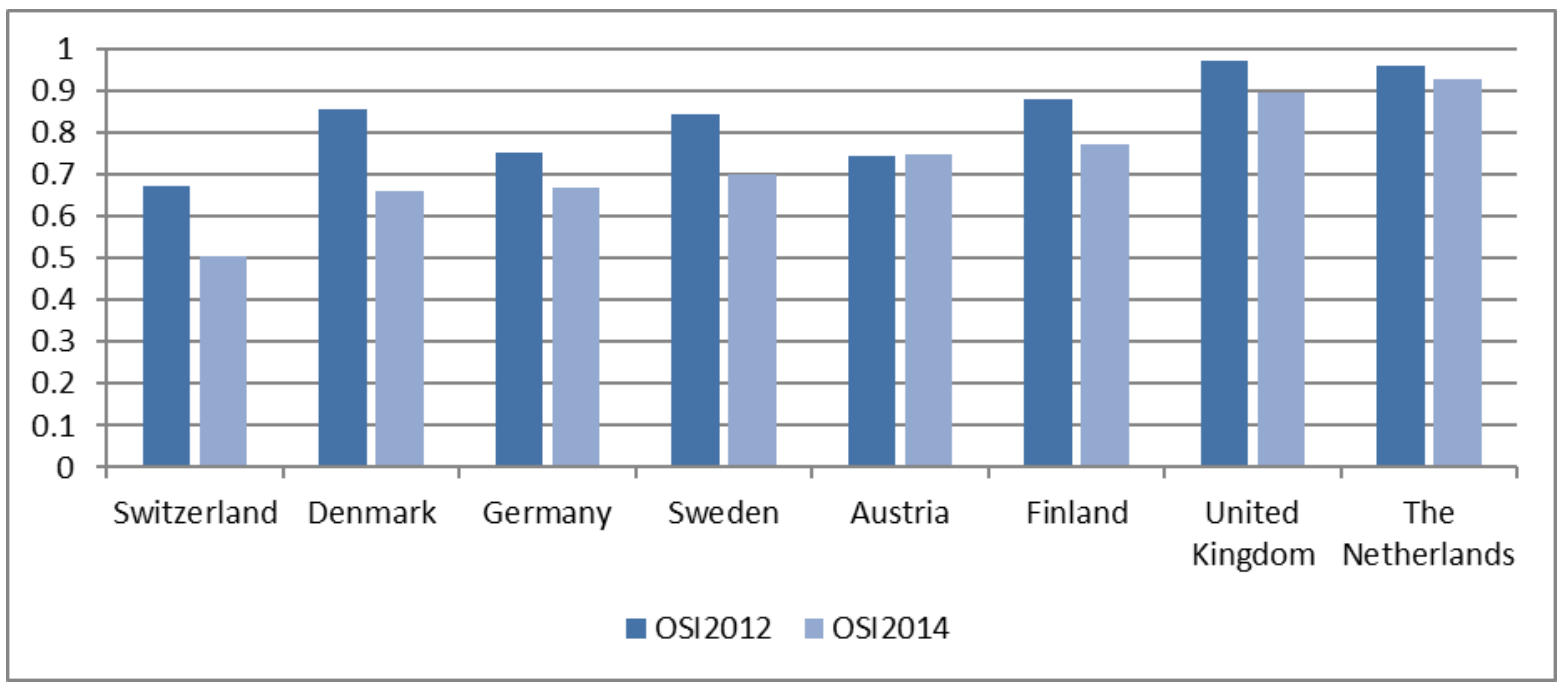

Source: UN e-Gov survey 2012 and 2014

An in-depth examination reveals that the on-lines service component is based on a four-stage development model. Each stage demands a higher level of sophistication and, often, increased commitment of resources. Stage 1 corresponds to emerging information services as governments have websites where citizens are able to obtain information. Stage 2 refers to enhanced information services where government websites deliver two-way communication as citizens can download application forms. Stage 3 covers transactional services where governments engage in a two-way communication with citizens on their websites. In this type of communication, the citizen's identity is required as the government can, for example, request and receive inputs on policies, programmes and regulations. Finally, stage 4 corresponds to connected services as government websites have changed the way governments communicate with their citizens. They are proactive in requesting information and opinions from the citizens using interactive tools. e-Services cut across the ministries in a seamless manner. Finally, governments have moved from a government-centric to a citizencentric approach.

Figure 9.2 show that Sweden has lower values on Stages 3 and 4, thus highlighting that Sweden experiences difficulty in supplying more advanced e-Services to its citizens. Although Sweden is a country with highly advanced ICT infrastructures and human resources, the evidence supports the view that it is difficult for Sweden to move to the higher stages with transactional and connected e-Services. The more advanced stages typically require robust data protection and online payment systems, as well as secure data-sharing across government institutions. It is clear that factors other than the infrastructure are equally important, including a high-level of coordinated political leadership, strengthened institutional capacity, citizen engagement, as well as adequate e-Government programmes. 
Figure 0.11 Sweden's values on the four stages of the on-line service index

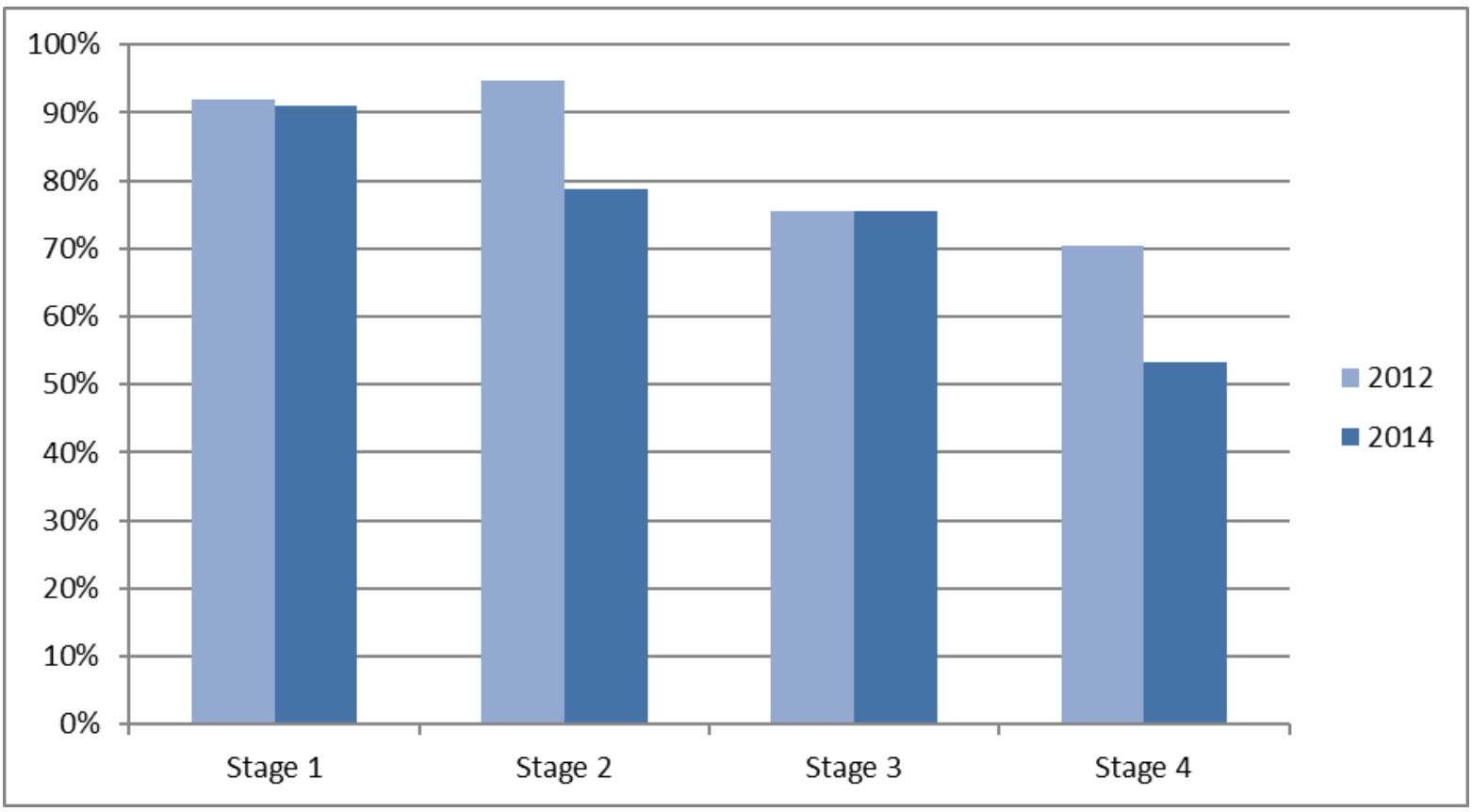

Source: UN e-Gov survey 2012 and 2014

\section{Innovation in the public sector in general}

Knowledge of how Sweden implements innovative approaches in the public sector is still fragmented. Still, Sweden has played an active part in trying to develop the knowledge base, e.g. through joint Nordic efforts to improve the measurement of public sector innovation (NordicInnovation 2010).

Results from the Nordic pilot study show that 78 per cent of public sector organizations have introduced an innovation. A similar question is asked in the Swedish innovation survey which targets private firms. Table 9.2 shows that 53 per cent of the Swedish firms have introduced an innovation.

Table 0.4 Comparison of the degree of innovation activity in the public and private sector

\begin{tabular}{|l|l|}
\hline Type of organization & Percentage that conduct some form of innovation activity \\
\hline Public sector & 78 \\
Private sector & 60 \\
\hline
\end{tabular}

Source: Measuring public innovation in the Nordic countries (2011) and (SCB 2014)

A comparison between the sectors reveals that the public sector organizations perceive themselves as more innovative than the firms in the private sector. As the results are surprising complementary evidence is analysed to gain a fuller picture. Table 9.3 compares the $R \& D$ expenses for the public- and private sector in Sweden. The figures reveal another picture that the private sector spent SEK81,1 billion on R\&D while the public sector spent SEK6,7 billion. 
Table 0.5 Comparison of $R \& D$ expenses in the public and private sector

\begin{tabular}{|l|l|}
\hline Sector & R\&D expenses \\
\hline Public sector & SEK6,7 billion \\
Private sector & SEK81,1 billion \\
\hline
\end{tabular}

Source: Statistics Sweden

\section{Procurement in the Swedish innovation survey}

Innovation procurement has a long history in Sweden and was commonly used until the 1980s. Well known examples are the collaboration between government agencies such as The Swedish State Railroads and The Royal Telegraph Agency on the one hand, and on the other hand, innovative private companies like Swedish electric company ASEA and LM Ericsson. Sweden, however, is a different country in 2014 than it was 30 years ago, and it is not possible to return to the type of relations between state and private firms that existed up until the 1980 s.

Public procurement amounts to approximately SEK600 billion per year and offers an enormous potential market for innovative products and services.

The Swedish innovation strategy underlines the importance of Public Procurement of Innovation:

"An innovation policy based on current knowledge combines initiatives geared towards stimulating both the supply of and demand for new solutions.... The demand perspective is intended to stimulate the demand for new solutions, e.g., via innovation procurement, standardization and legislation."

Support of public procurement is a potentially significant policy lever with which to unlock the innovation potential of the public procurement budgets in Sweden. Still, the current policy context is immensely fluid. The context is changing with the revisions of the new EC public procurement directive which is adapted in the Swedish Government Official Report on new rules for procurement. New evidence points towards a shift in policy focus from innovation support instruments towards making regular procurement more innovation friendly. Evidence of this can be found in the Swedish Ministry decision to move the responsibility to provide support in all aspects of innovation procurement from the Swedish innovation agency to the Swedish competition authority.

Still the community innovation survey's results for Sweden show that there is a long way to go to make public procurement for innovation friendly. Results show that 85 per cent of Swedish enterprises, with a procurement contract, do not perform any innovation activity at all.

An in-depth analysis reveals that a large company with over 250 employees is both more likely to have procurement contract as well as undertake innovation activity within the scope of that contract, than a small company (Table 9.4). 
Table 0.6 Share of innovation activity in procurement contracts

\begin{tabular}{|l|l|l|l|l|}
\hline Size & $\begin{array}{l}\text { Share of } \\
\text { enterprises with } \\
\text { procurement } \\
\text { contracts }\end{array}$ & $\begin{array}{l}\text { Innovation was } \\
\text { performed and } \\
\text { required in the } \\
\text { contract }\end{array}$ & $\begin{array}{l}\text { Innovation was } \\
\text { performed but } \\
\text { not required in } \\
\text { the contract }\end{array}$ & $\begin{array}{l}\text { No } \\
\text { innovation } \\
\text { activity was } \\
\text { performed }\end{array}$ \\
\hline Total & $\mathbf{2 5}$ & $\mathbf{7}$ & $\mathbf{1 2}$ & $\mathbf{8 5}$ \\
$10-49$ employees & 23 & 7 & 12 & 87 \\
$50-249$ employees & 28 & 7 & 12 & 82 \\
250 employees or more & 41 & 13 & 18 & 76 \\
\hline
\end{tabular}

Source: Statistics Sweden's survey on innovation in Sweden 2014

\section{Public procurement and innovation}

The Swedish public sector is a large buyer of a broad range of goods and, in particular, services. In Sweden alone, the public sector spending in 2009 accounted for almost 30 per cent of the gross national product (GNP) (Knutsson and Thomasson 2013). At the same time, the Swedish public sector is increasingly squeezed between an ageing population and a shrinking tax base. This situation implies a need for innovation.

\section{Best practice - The case of the Swedish Transport Administration}

The Swedish Transport Administration must, by Swedish law, procure goods and services in competition based on EU Procurement Directives. Currently the Transport administration procures goods and services for $€ 4.4$ billion every year. A number of fundamental EU principles have to be observed when carrying out public procurement in the EU. It means that the Transport Authority must treat all suppliers in a non-discriminatory way while at the same time procure in an innovation-friendly way.

In June 2014 the Transport Authority reported to the Swedish Government how the agency's regular procurement could be converted to procurement leading to innovation. This ministry assignment supports the view that the Swedish government is beginning to recognize that regular procurement can potentially be a powerful innovation support instrument without adding any additional budget.

To spur innovation in its regular procurement, the Swedish Transport Authority is in the process of introducing new innovation friendly procurement procedures. An overhaul reveals that the procurements are very heterogeneous and that the following categories are of specific interest from an innovation perspective:

Innovation-friendly regular procurement

- Mainly functional procurement i.e. describing the function, rather than the product, to be achieved by the procurement

- Life- cycle costing, which describes all the phases through which a product passes from its design to its marketing and the discontinuation of its production 
Pre-commercial procurement (which is not innovation procurement)

In its government report the Swedish Transport Authority states that the call for tenders needs to be designed so that the suppliers can offer innovative products in their proposal.

The success factors are:

- Focus on the contract agencies specific needs and not existing solutions

- Articulate functions which could be verified and evaluated

- Create evaluation models that support innovation

- Develop procedures that encourage innovation and disseminate good results

- Innovation partnerships - a new support instrument

In February 2014, the European Commission adopted a new procurement directive (2014/24/EU 2014). The new directive, which will be implemented in 2016, changes the procurement procedures to increase the uptake of public procurement of innovation. The document states that public authorities should make the best strategic use of public procurement to spur innovation. Buying innovative products could play a key role in improving the efficiency and quality of public services. It could also generate new ideas and contribute to translating them into innovative products.

These changes include a new procedure that allows the contracting authorities to establish a long-term partnership with companies for the development and subsequent purchase of a new product without the need for a separate procurement procedure for the purchase.

The difference between innovation partnerships and existing instruments such as PreCommercial Procurement (PCP) is that PCP deals with the procurement of R\&D services that does not fall within the scope of neither the new nor old procurement directive. The framework below compares the two instruments and reflects on the differences. The first difference is that PCP is an R\&D exception and thus not part of the Swedish procurement law. This is reflected in the framework with a continuous black line. On the left side the PCP procedure is divided into four phases starting with research and ending up with a commercial product. The downside in a PCP procedure is that the final product cannot be purchased within the scope of the procedure as it is not part of the Swedish procurement law and subsequently not part of the EC procurement directive. The final product can be procured but then the company which developed the product will experience extreme difficulties to participate in the tender. All suppliers should be treated equally. If one supplier has more information about the product to be purchased, that firm should be excluded from the tender.

On the right hand side the framework reveals that innovation partnerships fall within the scope of the Swedish procurement law and the European Commission's new procurement directive. An interpretation of article 31 in the new EC procurement directive suggests that Innovation Partnerships can be divided into 3 stages. From Stage 1 where a potential partner is invited and evaluated to Stage 3 where the development process is initiated and finally the end product is purchased. What is different about innovation partnerships is that this new procedure can bridge the development process and the subsequent purchase of the new and innovative product. It follows that a company which is a partner from start to finish can also win the contract and sell the final product to the contracting agency. 
Figure 0.12 Comparison between the new innovations partnerships and the old PCP procedure

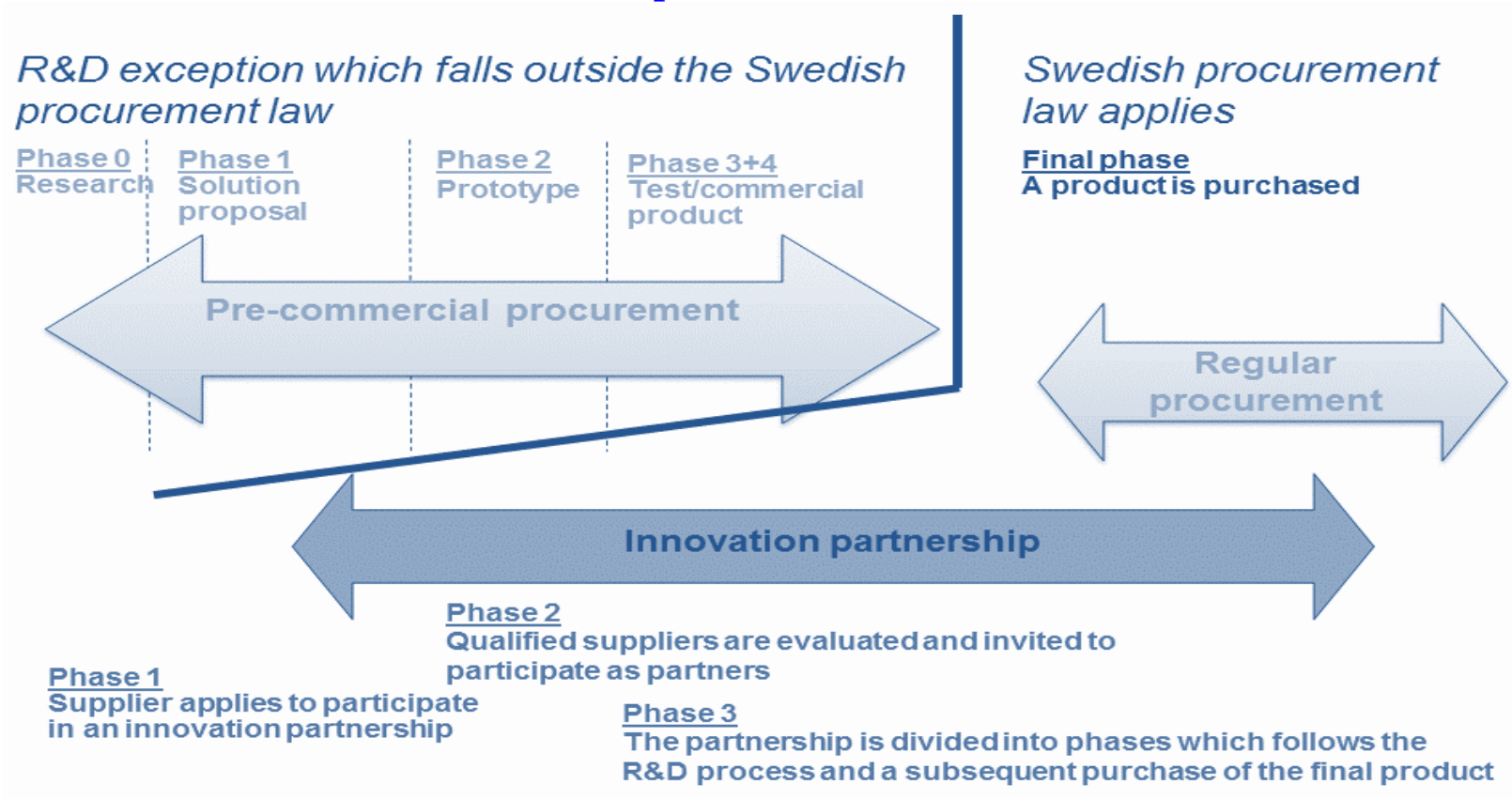

Source: Development of the Framework in Growth Analysis Report 2014:06

The conventional view, in the Swedish policy discussion, is that the link between the innovation and public procurement procedures is unproblematic. An interpretation of the Government's official report outlining the Swedish adaption of the new EC procurement rules, lends little or no support to such a statement.

On the one hand the Swedish innovation strategy promoted a non-linear and broad view of innovation. On the other hand, the Swedish adaptation of the new EC procurement directive states that the criteria for selecting the candidates that can participate in an innovation partnership is that partners must have separate R\&D activities. According to the new procurement directive:

"The contracting authority may decide to set up the innovation partnership with one partner or with several partners conducting separate research and development activities."

An interpretation of the text suggests that only firms with a separate R\&D unit can participate in an innovation partnership. This may be a barrier as many service firms and smaller firms do not have a separate R\&D unit but develop new products within the scope of their regular business with the assistance of customers and employees.

\subsection{Policy implications}

Sweden was an early adopter of comprehensive broadband penetration with a large number of advanced users. This infrastructure is a good steppingstone towards a more advanced eGovernment, but not necessarily an innovation driver in its own right. 
The policy mapping suggests that although there are numerous policy initiatives in place to make the public sector more innovative, government institutions and their functions are still largely shaped by early 20th century models of public administration in which ministries and their leaders work in "silos" and issues are tackled through a sectoral rather than a collaborative perspective. The policy mapping suggests collaborative public governance issues as the key to address societal challenges which require integrated responses.

Support of public procurement is a very significant policy lever with which the Swedish Government could unlock the innovation potential of the public procurement budget. This chapter has found evidence that such a policy could be beneficial. However, such a policy framework should have a broad view of innovation which should be mirrored in the instruments used to support procurement, including the new innovation partnerships.

Success in encouraging more widespread use of procurement of innovation will require leverage in the form of support from the Swedish state. However, it may well be that success will result only when there are widely available and easily understood procedures that are legally certain, and that can be used by contracting authorities and entities to carry out innovation friendly regular procurement. It follows that a prioritized question for Swedish policy makers could be to embed procurement of innovation into the practice of contracting authorities and ensure that the procurement of innovation is the rule and not the exception. 


\subsection{References}

European Union, EUROPAPARLAMENTETS OCH RÅDETS DIREKTIV av den 26 februari 2014 om offentlig upphandling och om upphävande av direktiv 2004/18/EG (antaget), 2014/24/EU, D. 2014

Commission, F., Future Challenges for Sweden - Final Report of the Commission on the Future of Sweden. DS 2013:19

Knutsson, H., and A. Thomasson, Innovation in the Public Procurement Process: A study of the creation of innovation-friendly public procurement, Public Management Review 2013, 16(2): $242-255$

NordicInnovation, Measuring Public Innovation in the Nordic Countries, MEPIN, 2010, Oslo, Norge

OECD, Frascati Manual, 2002, OECD Publishing

SCB, Innovationsverksamhet i svenska företag 2010-2012, 2014 


\section{Chapter 10}

\section{Swiss Federalism and Public Sector Innovation}

Peter Grünenfelder and Matthias Schnyder, Canton of Aargau, Switzerland ${ }^{107}$

\subsection{Introduction}

The public sector is under increasing pressure. First, there is the changing nature of government itself with a continuous pressure on public expenditure. The growing complexity of the tasks, the growing number of involved actors and the increasing forms of interplay between the state, private enterprises and civil society is all part of the changing nature of government.

Second, the changing demographic challenges such as an aging population and the tight labour market, but also economic, societal and technological changes need to be named. These are the challenges most public administrations are facing. With this constantly changing environment, the public sector is forced to increase outputs and improve outcomes, while simultaneously improving efficiency and effectiveness. Pressure comes from a variety of stakeholders demanding accountability for spending and wanting high-quality services.

To meet the manifold challenges, the public sector must come forward with innovative public sector reforms. Literature emphasizes that a federal political and fiscal structure is not only more likely to lead to higher economic growth and decreasing regional inequalities owing to the optimal provision of public services but serves also as a stimulus for innovation in the public sector, due to the laboratory effect of the competition between the federal units.

This article presents an analysis of the features of the Swiss federal structure (linked to a system of direct democracy), as important prerequisites for public sector innovation. After an overall analysis of the character of the political structure, this article will present two cases of public sector innovation that are based on the decentralized and participatory federal structure of Switzerland: a) the case of cantonal debt break rules and b) the case of cantonal outcomeoriented public management systems. The two examples will be further illustrated by the concrete practice of the canton of Aargau.

\subsection{Federalism in Switzerland}

Switzerland is a multi-ethnic, multilingual and multi-confessional nation. The unity of the state is not rooted in a single language and culture. Shared historical experience, a powerful political will and a constitutionally-based balance between self-rule and shared rule, linked with a consensus-driven direct democracy hold the country together. The referent object, defining people's identity, is the canton or the municipality, not the confederation. This peculiar understanding of identity can be explained by the late creation of the modern Swiss state which made it finally possible to surmount 'a loose confederation of (...) independent cantons, considering themselves as sovereign states'. ${ }^{108}$

The federal structure of Switzerland with three political levels, the confederation, the cantons and the municipalities, is one of the basic principles of the Swiss confederation.

\footnotetext{
${ }^{107}$ President of the Swiss State Chancellors Association, and Head of External Relations, Canton of Aargau, and Co-President of the Swiss Cantonal Delegates for External Relations.

${ }^{108}$ Fleiner (2005 I), 1.
} 
Article three of the federal constitution guarantees the cantons' sovereignty in all the spheres in which the constitution does not explicitly provide for the federal government's competence. ${ }^{109}$ Consequently, the confederation has only authority in areas in which it is empowered by the federal constitution, such as foreign and security policies, customs duties and nationally-applicable legislation. Tasks which do not expressly fall within the domain of the confederation are matters of the cantons. In principle, the confederation assumes tasks that require uniform regulation. Cantons, in turn, are responsible for important parts of public order, education, welfare, health, and both regional and local planning. ${ }^{110}$

Thus, article three of the federal constitution contains the basic principle of self-rule in Switzerland: all competences are cantonal, unless otherwise stated within the federal constitution. Due to the diversity among the cantons with respect to size, culture, economic performance, geography, and demographics, it is nearly impossible for the federal government to take the distinctiveness of each canton into account. Therefore, it is the cantons' duty to implement federal law. Many federal laws also expressly reserve large areas of jurisdiction to the cantons which includes independent shaping of policy. ${ }^{111}$ Each canton has the right to self-organization of the assigned tasks and their autonomy includes organizational and financial autonomy. The cantons can decide on the organization and political structure of their territory as well as on how their institutions will be set up and how they will operate. ${ }^{112}$

This decentralized division of power (linked to direct democracy) and the attempt to solve issues at the lowest possible level (the principle of subsidiarity) constitutes the basis of the confederation and keeps the state as close as possible to the people. The most important power of the cantons and municipalities concerns their fiscal autonomy. This fiscal autonomy is based on the idea that the territorial units which have the power and responsibility to perform and implement public services, must also have the means to finance this public service through taxation. ${ }^{113}$

Except for the expenditures on defence and foreign affairs (federal level), all major public expenditure functions are shared among the three levels of government. On the revenue side, taxation is the most important revenue source for all three levels. The federal government collects the value-added tax, a part of direct taxes, as well as the major consumer taxes. The cantons also participate in the direct taxation and enjoy great sovereignty in the design of their tax systems: although they cannot define the tax base on their own, they decide the rates and the amounts of tax abatements. For the rest, they mainly rely on shared revenues and other transfers. With regard to the budget, the federal constitution does not impose any constraint on cantonal budgets. ${ }^{114}$

The system of bottom-up federalism is linked to a system of direct democracy. On all levels of government, there exist instruments of direct democracy such as popular initiatives and referenda including financial referenda. Contrary to nearly all other OECD

\footnotetext{
${ }^{109}$ Schweizerische Eidgenossenschaft (1998), Article 3.

${ }^{110}$ Rhinow (2002), 20.

${ }^{111}$ Rhinow (2002), 20.

${ }^{112}$ Fleiner (2005 II), 8.

${ }^{113}$ Fleiner (2005 II), 7.

114 Toth (2005), 10-11.
} 
countries, the Swiss system has two special features: a strong bottom-up federalism which is organized in a competitive way and direct popular rights in political decision-making. ${ }^{115}$

\subsection{Competition and laboratory effect}

As stated above, cantons enjoy a high degree of responsibility for their own affairs. Consequently, Switzerland has 26 different institutional and legal frameworks and every federal unit addresses the assigned tasks as it thinks best. As production factors such as money, jobs, or machinery become ever more mobile, the competition between cantons and municipalities to secure their comparative advantages has become increasingly intense. Hence, federalism in Switzerland contributes greatly to the effective and efficient execution of tasks and strengthens the competitiveness of the Swiss economy. ${ }^{116}$

Being quite free to design their own policies, cantons are often seen as innovative "laboratories". The risk of failure rests with the cantonal authorities. The federal government provides no guarantee to bail out failed cantons. The sub-federal levels are characterized by both co-operation and competition, with strong competition especially for tax bases. Cantons with bad fiscal management can easily lose ground against the other cantons. Voters protest against bad policies by means of instruments of direct democracy (initiatives and referenda), or they simply move to another jurisdiction ("voting by feet"). ${ }^{117}$

The competition between the cantonal "laboratories" produces incentives for innovation and improvements in productivity in the political sphere. In effect, 'innovations that follow a bottom-up pattern are said to be cheaper and more successful than experiments imposed top-down ${ }^{118}$, as competition generates better information and incentives for politicians to produce public goods not only in better accordance with the preferences of the voters but also in a more efficient way. Many scholars argue therefore that tax competition giving local politicians more responsibility leads politicians to manage their budgets more carefully and in accordance with the preferences of their constituents. ${ }^{119}$ The competitive pressure is so high, that the mechanisms restraining deficits mostly work on the expenditure side. ${ }^{120}$ The level of expenditures and revenues on the side of the confederation is only at around 30 per cent. Switzerland is thereby the fiscally most decentralized country of the OECD. ${ }^{121}$

Competition is not only a prerequisite for the successful working of economics but also has an impact upon policy outcomes and policy innovations. The great deal of autonomy the cantons and municipalities are enjoying gives them the possibility to shape their policies individually. ${ }^{122}$

\subsection{The case of cantonal debt breaks}

\footnotetext{
115 OECD 2005, 42-43.

${ }^{116}$ Adamovich, Hosp (2003), 4.

117 Toth (2005), 9-11.

${ }^{118}$ Adamovich, Hosp (2003), 4.

${ }^{119}$ Adamovich, Hosp (2003), 3.

${ }^{120}$ Stalder (2005), 15.

${ }^{121}$ Schaltegger (2009), 44.

${ }^{122}$ Lars P. Feld (2007), 24.
} 
The case of the cantonal debt breaks is a good example of public sector innovation based on a combination between federalism (strong autonomy of the cantons especially also in fiscal matters) and direct democracy.

In 1981, the conference of the cantonal ministers of finance edited a handbook of public budgeting that contained a model law for the cantonal budgets. According to article 2, the principle of a balanced budget has to be observed. This is stated more concretely in article 4 , according to which the current budget has to be balanced in the medium term, and in article 18 that demands that cantonal accumulated debt has to be cut back in the medium term (within about ten years). Today, such rules can be found in nearly all cantonal constitutions and in the corresponding budget laws. The cantons are obliged (at least today) to balance their budgets over the business cycle, and also to cut down accumulated debt. ${ }^{123}$

Most of the first balanced budget rules in the cantons were introduced already in the 1980s and early 1990s. The first budget rules were, however, quite ineffective. The first reason is that tax incomes were heavily reduced by the economic decrease in the 1980s. Second the budget rule mechanisms in those years did not take into account the business cycle so that expenses were not anti-cyclical but almost pro-cyclical. Third, the direct democratic instrument of the fiscal referendum was ineffective because the areas in which public expenditure increased most in those years (especially social security and health spending), consist of entitlement programmes that could not be changed by fiscal referendums. ${ }^{124}$

In the 1990s public expenditure in Switzerland increased by 50 per cent and spending priorities changed. The expenditure on health care, social welfare/security, public safety and education increased whereas expenditure in defence, culture and environment was reduced. The first policy areas are mainly in the competence of the cantons (and municipalities), the latter in the competence of the confederation.

Fiscal rules (that is, balanced budget rules) had no big influence on the spending patterns of the cantons in the 1980s and early 1990s. As a reaction stricter debt brake rules were introduced in some of the cantons in the 1990s and in the 2000s that took into account the business cycle so that expenses were anti-cyclical.

As we can see from figure 10.1 the spending evolution in cantons which adopted a strict debt brake rule is smoother than the one of the other cantons (without any debt brake). ${ }^{125}$ Other empirical results, such as Kirchgässner, Gebhard (et al., 2006 "On the effectiveness of debt brakes: the Swiss experience") confirm that cantons with such strict debt brake rules are less indebted than those without rules. ${ }^{126}$

\footnotetext{
${ }^{123}$ Kirchgässner (2006), 3-4.

${ }^{124}$ Stalder (2005), 8-9.

125 Stalder (2005), 25.

${ }^{126}$ Kirchgässner (2006).
} 
Figure 0.13 Comparison of cantons with debt brakes and without any or weak debt brakes

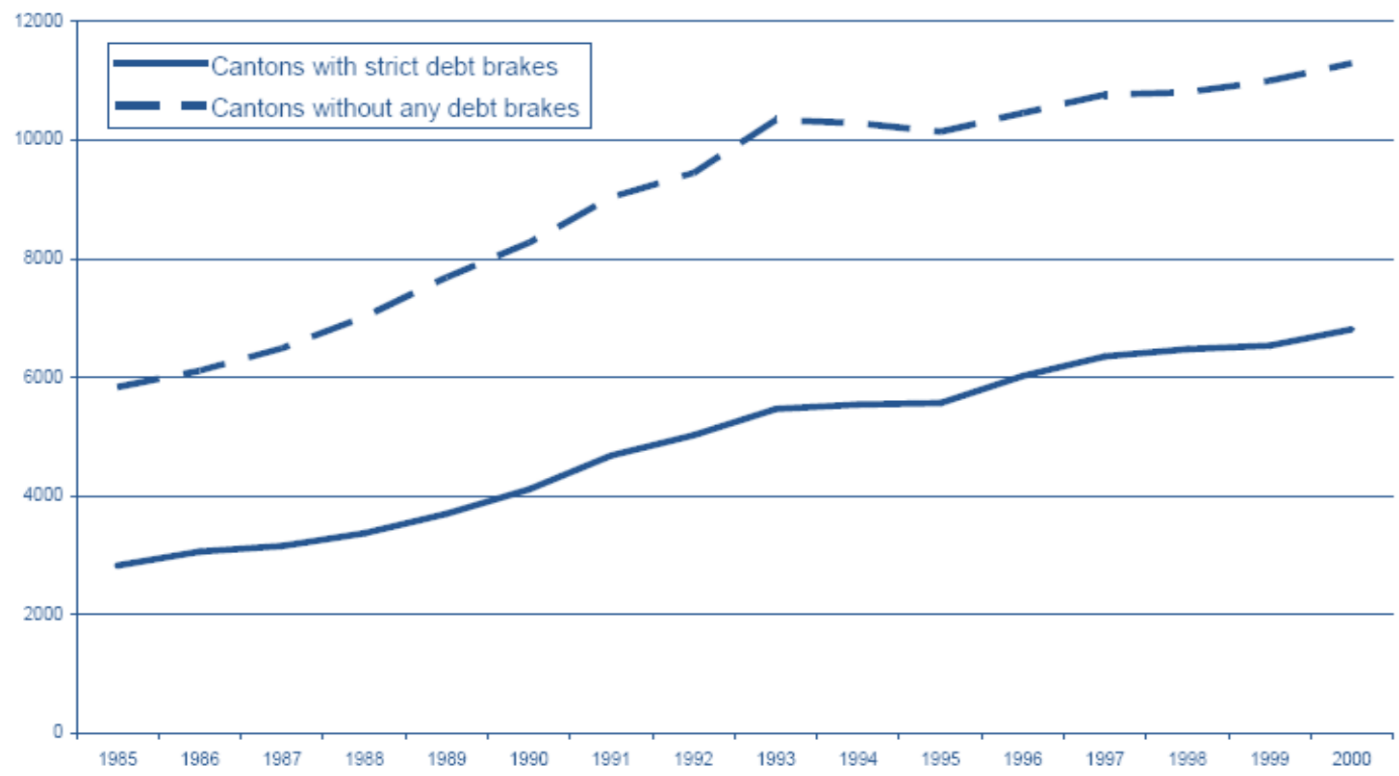

Source: Stalder (2005), 27

Today, such rules can be found in nearly all cantonal constitutions and in the corresponding budget laws. Of the 26 Swiss cantons, 19 have a debt brake rule today. ${ }^{127}$ The debt brake forces the cantons first of all to balance the current budget (including depreciations of investment projects), but also to save some amount of money if there is a surplus, as in boom times. The surplus can be spent if there is a deficit (as in a recession), before taxes are increased. This allows the canton to undertake some anti-cyclical fiscal policy, while at the same time ensuring that the budget is balanced in the long run. ${ }^{128}$

The state sector (including cantons and the municipalities and the confederation which also introduced a debt brake on the basis of the cantonal models in 2004) was able to reduce its debt from over 50 per cent of GDP in 2004 to less than 35 per cent in 2011-2015 (Figure 10.2).

The canton of Aargau has also introduced a budget rule in its constitution. ${ }^{129}$ A debt brake rule was introduced in the corresponding budget law, which was adapted by the cantonal parliament in 2005. ${ }^{130}$ The new budget law had more than just a financial focus. It is the basis of a wider public service reform that introduced a broad set of new public management instruments in the canton of Aargau (see chapter 5).

The introduction of the debt brake in the canton of Aargau was launched through a popular initiative in 2002. The government, under pressure by the initiative, suggested a counter-

\footnotetext{
${ }^{127}$ Schaltegger (2009), 41.

${ }^{128}$ Schaltegger (2009), 35-36.

${ }^{129}$ Kanton Aargau (2009 I), 31.

${ }^{130}$ Kanton Aargau (2005).
} 
proposal which was accepted by the initiating party. The counter-proposal of the government for the new debt brake was accepted by the parliament in 2003 and introduced into the new budget law in 2005. As described in paragraphs 27 and 43 of the new budget law, the principal goal of the debt brake rule in the canton of Aargau is a stabilized level of public debt and of government expenditure relative to GDP. With regard to corrective actions, the deficit must be amortized over five years. Extraordinary expenses are not amortized. A tax increase is possible only with a qualified majority of the parliament. Corrections with regard to the business cycle are possible. ${ }^{131}$

Figure 0.2 Development of debt - confederations, cantons and municipalities

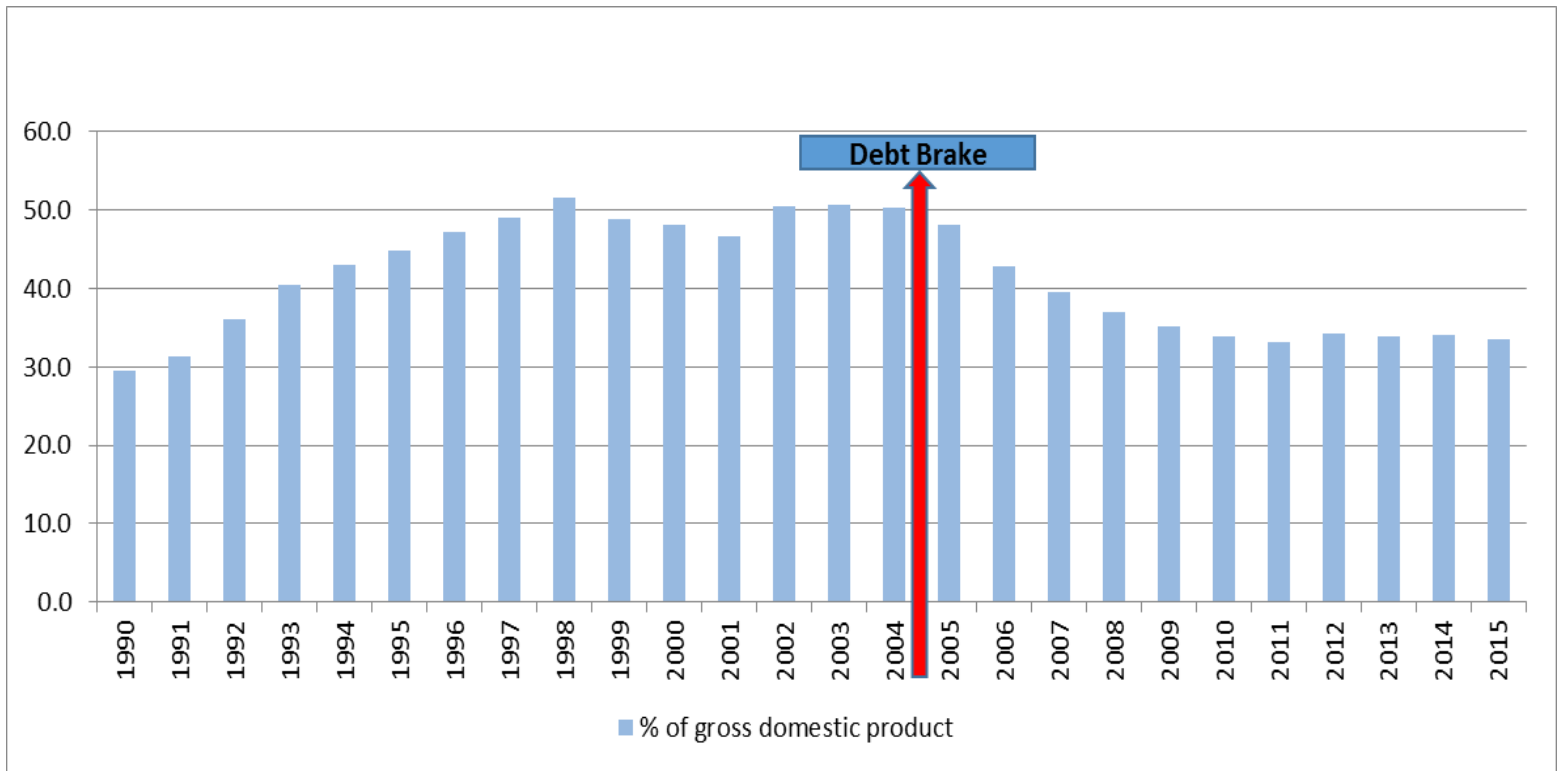

Source: author's own calculations based on data from the Federal Financial Administration "Eidgenössische Finanzverwaltung"

\section{The case of cantonal outcome-oriented public management: long- and medium-term planning and budget control}

The second example illustrating the unique laboratory effect of Swiss federalism for public sector innovation is the cantonal reforms in the field of new public management (NPM).

In Switzerland, most reforms conducted in the field of NPM were first introduced on a cantonal level and are addressed under the so-called "Wirkungsorientierte Verwaltungsführung (WOV)" - outcome-oriented public management. Outcome-oriented public management is focusing mainly on the outcomes of public services rather than the output level. ${ }^{132}$

NPM reforms have been implemented in Switzerland at the cantonal and municipal level since the early 1990s. NPM in Switzerland is not based on a uniform theory, but it developed out of different conceptions and practical experiences in administration. ${ }^{133}$ Together with the implementation of NPM, mid-term control has been enhanced in several cantons and cities in Switzerland (see figure 10.3).

\footnotetext{
${ }^{131}$ Kanton Aargau (2005), 11, 16.

132 Proeller (2007), 22.

${ }^{133}$ Proeller (2007), 22.
} 
Figure 0.3 Cantons with an integrated task and finance plan

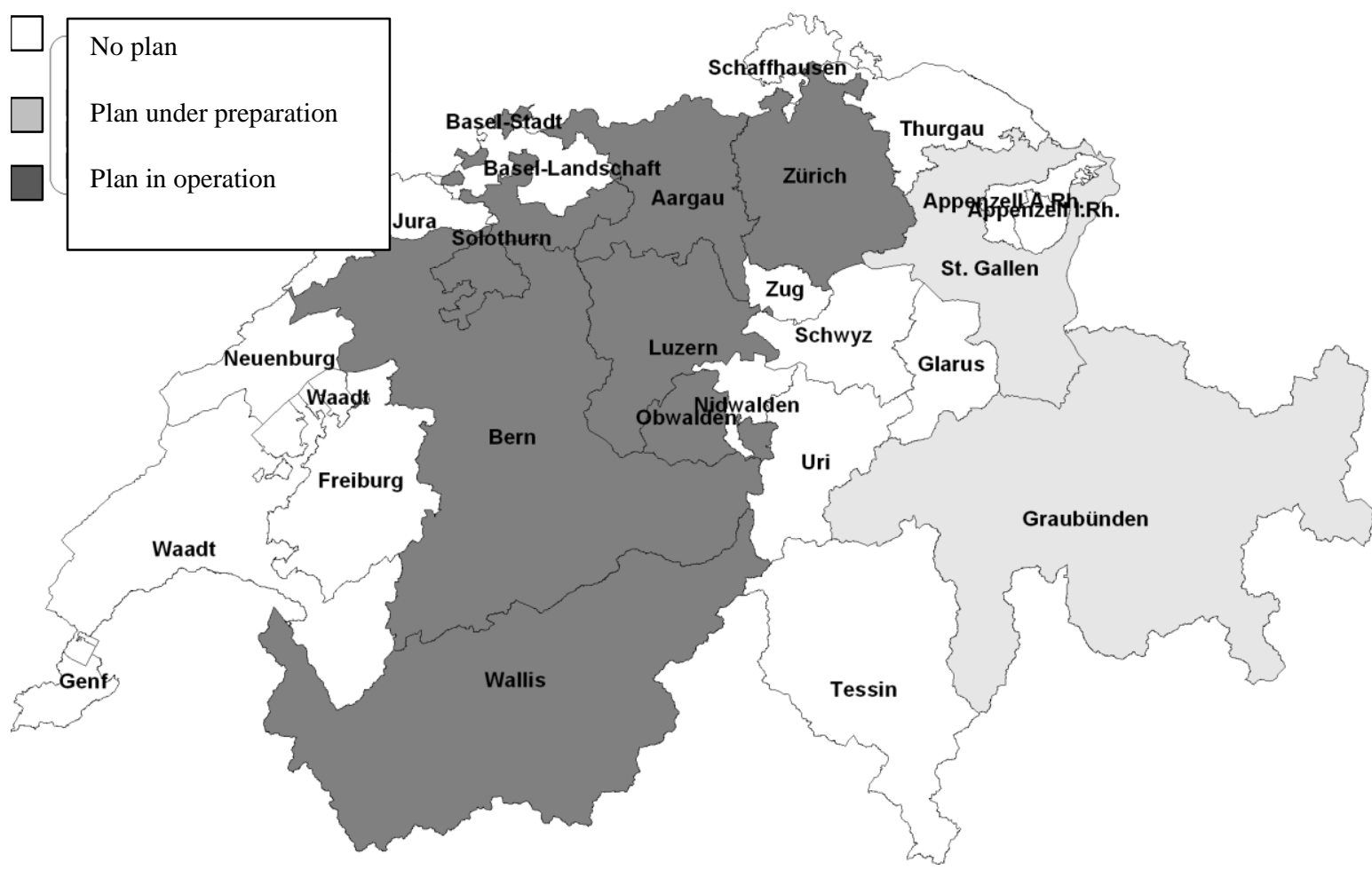

Source: Schedler/Summermatter (2009)

The canton of Aargau had already introduced a WOV pilot project in 1996. A comprehensive implementation of WOV started on 1st January 2006. ${ }^{134}$ The reform was introduced through ordinary legislation and is based on the "law on performance-oriented steering of tasks and finances". 135

What is unique about the model of outcome-oriented public management in the canton of Aargau is the fact that it is based on a strategic long-term planning (strategic management) approach - a unique approach in Switzerland. This example, again, illustrates the importance of the decentralized structure of Switzerland for public sector innovation.

As it is described by Schedler and Siegel (2005) (see figure 10.4) and in the article on "Strategic Management for the State; International Approaches in Comparison" by Proeller $(2007)^{136}$, strategic long-term planning (strategic management) is a long-term process that involves integrating four basic dimensions. These dimensions are a) contents, b) instruments, c) processes and d) actors. Strategic management assumes that strategic change will be influenced by the shaping of these elements and especially their integration and coordination. ${ }^{137}$

In this article we will use this analytical approach in order to illustrate the model of outcomeoriented public management in the canton of Aargau.

\footnotetext{
${ }^{134}$ ECONCEPT (2009), 15.

${ }^{135}$ Kanton Aargau (2005).

${ }^{136}$ Proeller (2007), 4.

${ }^{137}$ Proeller (2007), 9.
} 


\section{Figure 0.4 Conception of strategic long-term planning}

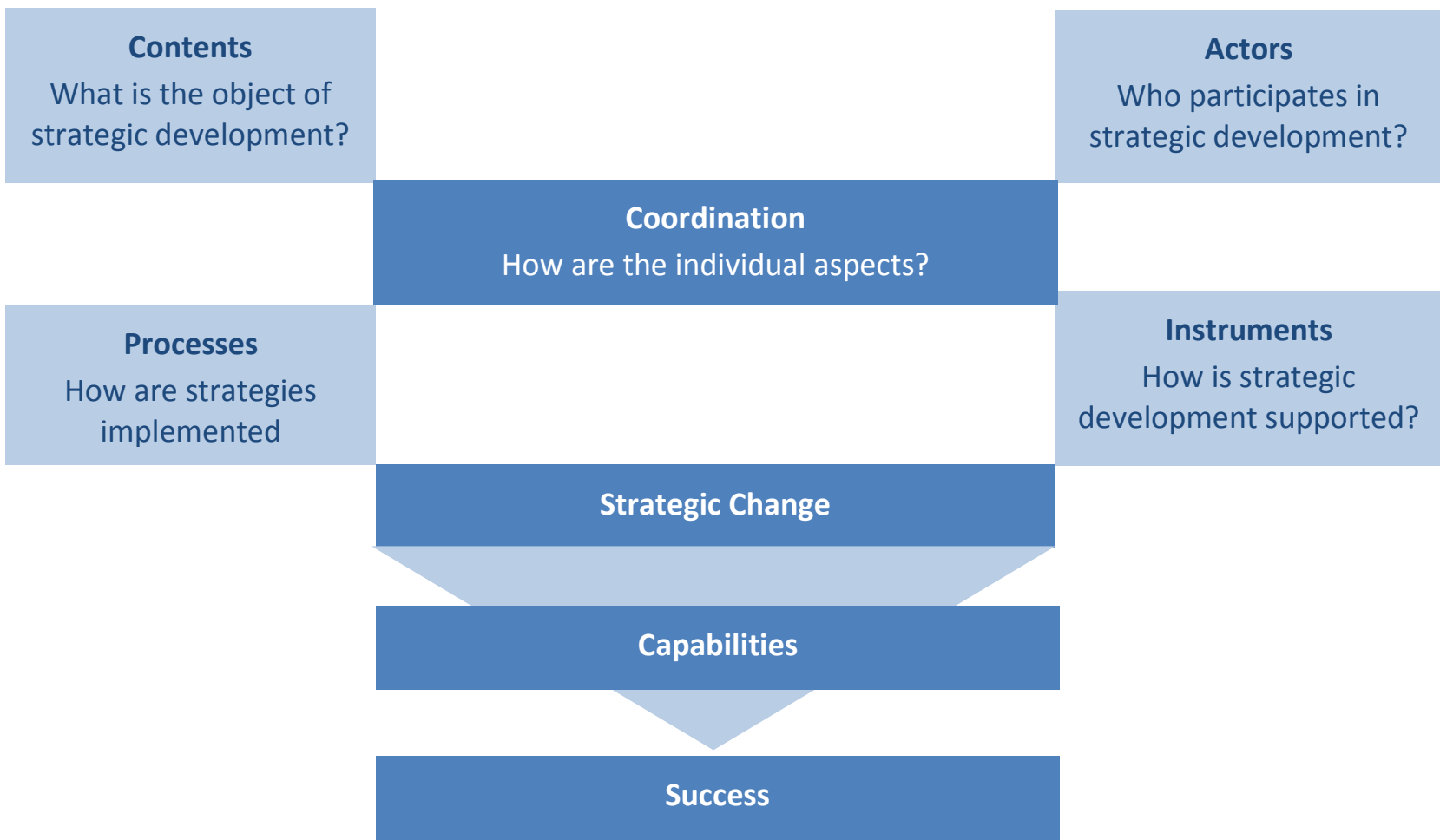

Source: Schedler, Siegel (2005), 18ff.

\section{Contents}

The dimension of "contents" describes the purposes of outcome-oriented public management. The key question is: "What is the strategy about and how is it framed"? 138

The dimension of "contents" for the outcome-oriented public management approach in the canton of Aargau can best be understood with the image of a strategic planning pyramid (see figure 10.5)

${ }^{138}$ Proeller (2007), 10. 
Figure 0.5 Planning pyramid

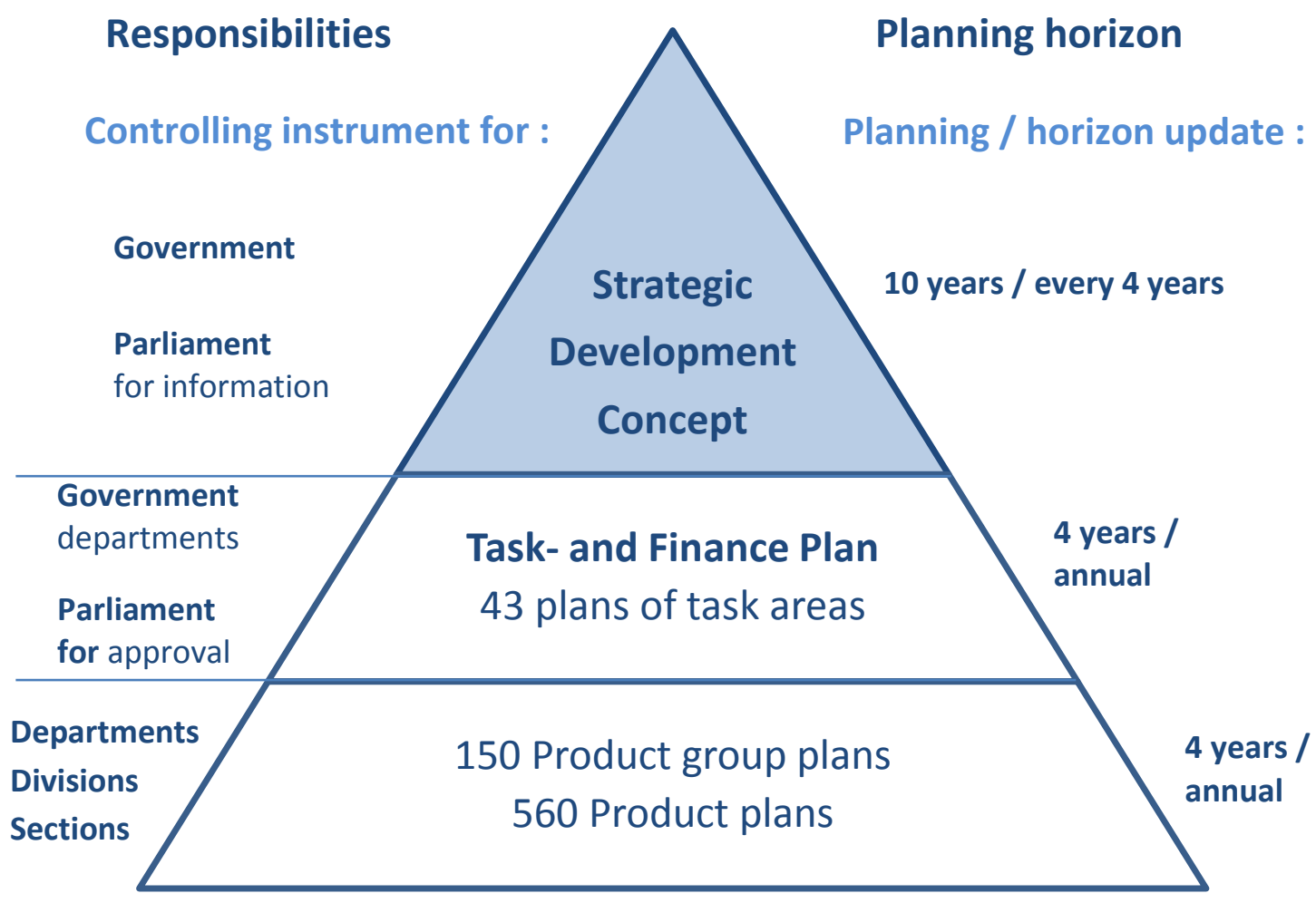

Source: www.ag.ch

\section{Strategic development concept (long-term perspective):}

Strategic priorities (nine policies) are defined in a strategic development concept. The concept has a planning-horizon of ten years and is updated at the beginning of a legislature period every four years (rolling planning). The strategic priorities are defined by the government and are sent to the parliament only for information. The concept is developed based on an in-depth analysis of present and future challenges and trends. The priorities are mostly crosscutting. The strategic development concept is the instrumental basis for an anticipatory and long-term oriented strategic policymaking of the cantonal government.

\section{Task and finance plan (medium-term perspective):}

On the basis of the strategic development concept, the integrated task and financial plan defines 43 tasks which constitute the main public services of the state of the canton of Aargau. As the name says, task planning and financial planning/budgeting are no longer separated but are linked together and presented in one single document. In order to improve results-orientation, the integrated task and financial plan integrates one-line budgets (instead of the traditional line-itemized budgets) and links performance to resources (performance budget).

Each of the 43 tasks is linked to a one-line budget. This means that in the task and financial plan the presentation of the costs is no longer grouped along cost types but along tasks. The task and financial plan has a planning horizon of four years and is updated annually (rolling planning). The rolling planning guarantees that the reform approaches are adapted to evolving circumstances. 
The first year of the plan contains the actual yearly budget which is approved by the parliament. The following three years contain the medium-term plan which is structured exactly the same way as the one-year-budget. It is also approved by parliament.

The systematic linking between budgetary and performance figures is done not only in the "budget year" but also for the following three years thereby reflecting the basic idea of the performance budget in the multi-year-plan. For each task, expected outputs with output indicators and outcomes with outcome indicators, are defined, thereby introducing performance information into the budgeting process.

On the one hand, the new "budget structure" increases the strategic focus of government and the administration but also the managerial freedom and responsibility of the managers. On the other hand, the expected outputs and outcomes are made transparent to the parliament but also to the public (the latter having access to all information with regard to the task and financial plan over the Internet). Linking tasks and finances and having a medium-term perspective creates a new form of parliamentary supervision, giving the parliament the possibility to have an influence on state services (and not just finances) and thereby the possibility for "results-oriented steering".

\section{Product group plans/product plans:}

On the basis of the 43 tasks, division-, and section-specific objectives and strategies/operations are defined on the level of so-called product group plans (150) and product plans (560). As with the task and finance plan, the planning horizon of the product group plans and product plans is four years. The plans are updated annually (rolling planning).

\section{Box 0.2 Pyramid}

There is a direct link between the three major planning levels of the planning pyramid that is the strategic development concept (strategic issues), the task and finance plan (objectives) and the product group plans and product plans (strategies).

\section{Instruments}

The dimension of "instruments" describes the "tools" that have become established for the different tasks and challenges affected within the framework of outcome-oriented public management. The key question is: "How are strategy processes supported?"139

As it is described by Schilling (2009), the analysis of future trends and issues and the linking of the results of this analysis with the overall strategic management process form the basis of a sustainable strategic management system. ${ }^{140}$ The canton of Aargau has introduced such an instrument, called strategic monitoring, as an important instrumental basis for its outcomeoriented public management process (see figure 10.7).

On the basis of a continuous strategic monitoring, the state chancellery is preparing a strategic monitoring report for the government (two - three - times a year). Based on a broad set of sources (think tanks, science, external experts, conferences, other polities etc.) the

\footnotetext{
${ }^{139}$ Proeller (2007), 10.

${ }^{140}$ Schilling (2009), 8.
} 
relevance of future trends and issues on cantonal policies are analysed. The results of the monitoring are presented in a report that is structured on the basis of the nine policies of the strategic development concept. This report presents to the government a set of suggestions which should be implemented and also integrated into the different plans of the aforedescribed planning pyramid.

Figure 0.6 Strategic monitoring process

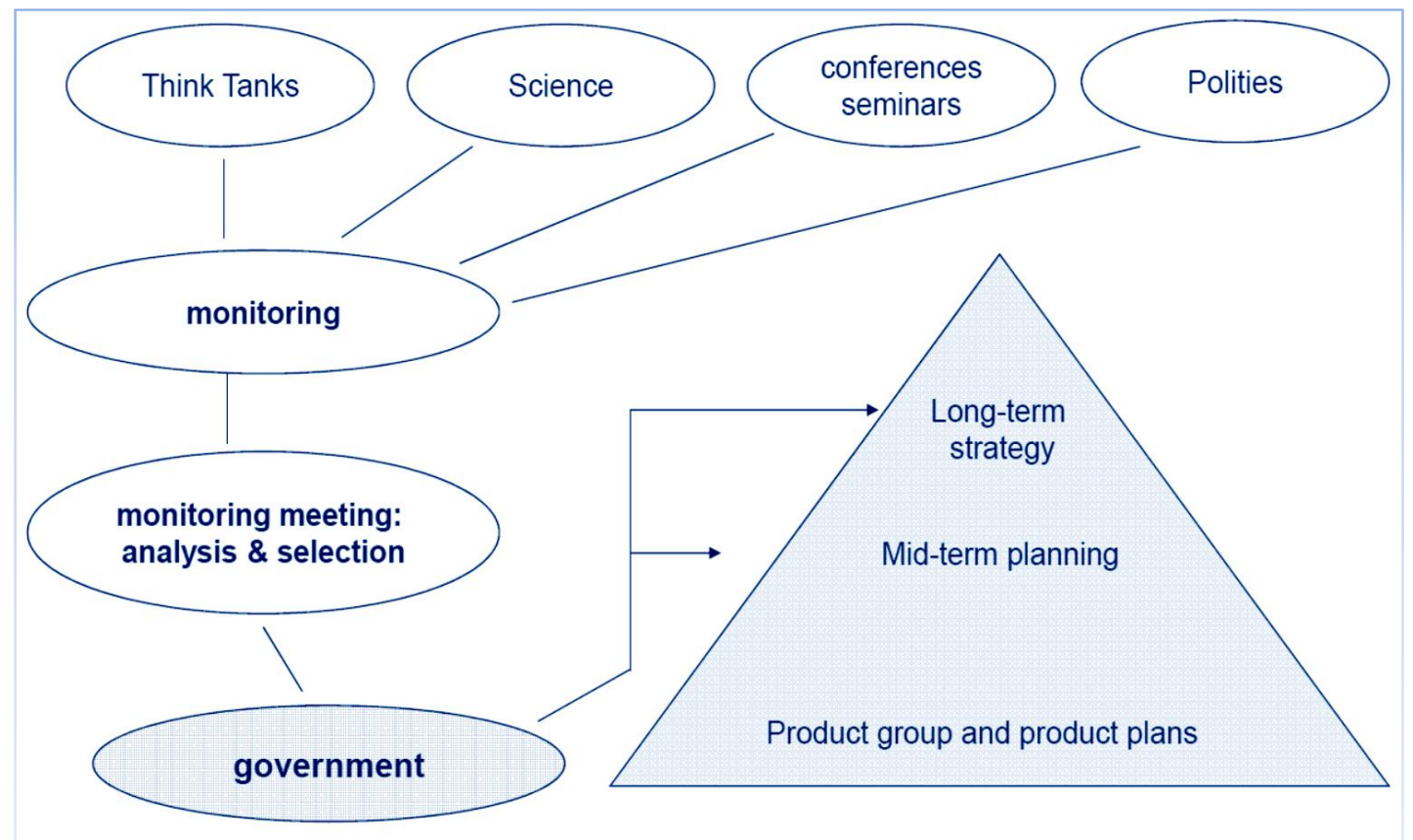

Source: See text

The relevance of the strategic monitoring with regard to the outcome-oriented public management process in the canton of Aargau can be described as follows:

- It forms the basis for the continuous examination of the strategic objectives in the strategic development concept. It is also an "examination instrument" for the other plans (strategic plan, task and finance plan etc.)

- It leads to a higher problem-solving competence with regard to crosscutting issues

- It serves as an early-warning instrument for the government

- It leads to better agenda setting for the government

- It gives the government more freedom of scope

- It helps government to think of alternatives in complex decision making processes

\section{Processes}

The concept of strategic management is not static but a process. The dimension of "processes" describes the phases of strategic development or formulation, implementation and evaluation. The phases are usually represented in ideal form as a control circuit. The key question is: "How are strategies realized?"141

${ }^{141}$ Proeller (2007), 10. 
The phases of the outcome-oriented public management process in the canton of Aargau can also be illustrated with a control circuit (see figure 10.7).

Figure 0.7 Strategic control circuit

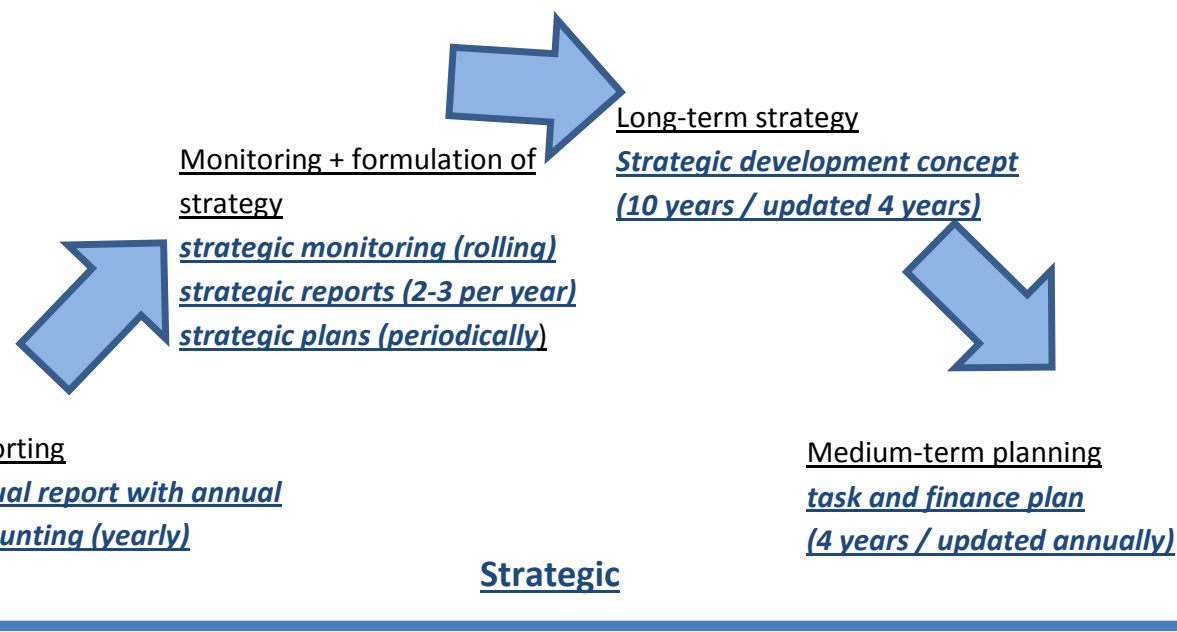

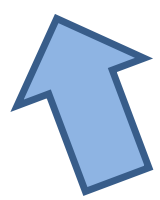

Controlling of implementation Implementation of annual planning (rolling)

\section{Operational}

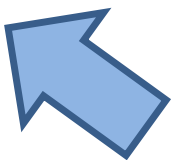

Implementation report for gov. meetings (rolling)

Short-term planning

Yearly planning

Operational planning (weekly)

Source: See text

As we have explained, there is a strong focus on the conception phase (analysis and formulation) in the control circuit of the canton of Aargau (strategic monitoring of future trends and early-warning as the basis of the strategic management process). The strong focus on this phase is very relevant for the successful implementation of a system of outcomeoriented public management. Furthermore, the canton of Aargau has institutionalized instruments for strategic management with a medium- and long-term horizon which are a precondition for an integrated control process. In addition, there is a clearly defined strategic organization (state chancellery) with the necessary instruments and resources coordinating the process horizontally (inter-departmental). Last but not least, we find a close interaction between the strategic leader and the strategic enabler (government) actively supporting the process.

\section{Actors (Coordination)}


The dimension of "actors" describes the participant organizations, groups and individuals in the outcome-oriented public management process. The key question is: "Who is involved and what are their roles?"142

For the coordination of the above illustrated process (control circuit) in the canton of Aargau, there is a clearly defined strategic leader with the necessary instruments and resources (especially internal experts) coordinating the process inside the administration horizontally (inter-departmental). The role of this strategic leader is with the state chancellery in cooperation with the ministry of finance (and the spending ministries). Besides coordinating the process, the role of the state chancellery is mainly to control the task side of the task and financial plan (including the performance information), and the annual report. The role of the ministry of finance is to control the finance side. Both, of course, work closely together.

The relationship between the strategic leader (state chancellery) and the government is quite strong but complementary. The government can be called a strategic enabler which is supporting the process.

\section{Integration}

The dimension of "integration" describes the process of integrating and shaping the four elements; contents, instruments, processes and actors in order to bring about strategic change and a continuous improvement of the process. Besides the "formal process of integration", "informal features" such as leadership need to be taken into account. ${ }^{143}$

The "formal process of integration" in the canton of Aargau has already mostly been described. Last but not least, we would like to concentrate on the above-mentioned informal feature of integration "leadership".

Implementing and integrating outcome-oriented public management is about leadership and leading change. To bring about change requires strong leadership capacities from the strategic leader and strategic management skills from the involved persons. The abovedescribed development of strategic management in public administration and the changing requirements for the involved actors makes it necessary to develop a new professional profile. The strategic leader of the process needs to be a "public manager" with management skills on the one side and close knowledge of the political processes on the other side. These skills need to go together with strong communication skills (strategic management as a communication process). A further key to an increased strategic competence is a strategyoriented human resource management in order to develop the strategic capacities of the collaborators who are involved in strategic management processes. ${ }^{144}$

\section{Lessons learnt}

As demonstrated in the critical analysis of the outcome-oriented public management system, its introduction definitely moved the focus of decision making away from inputs and towards measurable results for all actors involved (government, administration and parliament). The priority setting and the strengthening of the medium- and long-term direction of public services (especially by the government) was improved. Linked to that, it provided more and better information on the goals and priorities of the state and on how the different projects (or tasks) contribute to achieve these goals. The performance information figures as a sort of

\footnotetext{
${ }^{142}$ Proeller (2007), 10.

${ }^{143}$ Proeller (2007), 10.

${ }^{144}$ Grünenfelder (2009), 30ff.
} 
"plausibility check," testing if the defined expected outputs and outcomes are actually realistically achievable. Furthermore, outcome-oriented public management improved transparency by providing more and better information especially to the parliament but also to the public. And by introducing performance agreements and giving more (budgetary) autonomy to the public managers it increased the managerial freedom and responsibility of the public managers.

\subsection{Conclusion}

It this article, we have illustrated that the great deal of autonomy the cantons and municipalities are enjoying in the frame of the Swiss federal system gives them the possibility to shape their policies individually. The decentralized federal system, linked to direct-democratic institutions, creates competition and a "laboratory" effect between the federal units thereby serving as a stimulus for innovation in the public sector. Large differences between the Swiss cantons make Switzerland therefore a unique laboratory, where the effects of regional public sector innovation can be studied. The two cases of cantonal debt brake rules and outcome-oriented public management are illustrative examples of this effect. 


\subsection{References}

ADAMOVICH, I. B., and G. HOSP, Fiscal Federalism for Emerging Economies: Lessons from Switzerland, Publius: the Journal of Federalism, 2003, 33:1, 1-12.

ECONCEPT, Schlussbericht Evaluation der Wirkungsorientierten, 2009

Feld, L. P., Swiss Cantons Still Compete for Taxpayers, Forum of Federations, 2007, Vol.6, No.1, 23-25.

Fleiner, T., and S. Byrne, Switzerland: a Balance between Shared Rule and Self Rule, in: Bindenbacher, R., and A. J. Ostien, (eds.), Distribution of Powers and Responsibilities in Federal Countries, a Global Dialogue on Federalism, 2005 I, Volume 2, McGill-Queens University Press, Montreal

Fleiner, T., Swiss Confederation, in: Akhtar, M., L. Watts, and D.M. Brown, (eds.), Distribution of Powers and Responsibilities in Federal Countries, a Global Dialogue on Federalism, 2005, Volume 2, McGill-Queens University Press, Montreal

Grünenfelder, P., Zeitgemässe Ausgestaltung der Führungsunterstützung, in: Perspektive Staat. Herausforderungen für staatliche Führungskräfte, Schweizerische Staatsschreiberkonferenz und Staatskanzlei Kanton Aargau, Zürich, 80ff, 2009

Urs, S., Erfolgreiche Politik verlangt gute Mitarbeiter, in: Perspektive Staat. Herausforderungen für staatliche Führungskräfte, Schweizerische Staatsschreiberkonferenz und Staatskanzlei Kanton Aargau, Zürich, 30ff, 2009

Kanton Aargau, Gesetz über die wirkungsorientierte Steuerung von Aufgaben und Finanzen (GAF) vom 1. August 2005

Kanton Aargau, Verfassung des Kantons Aargau vom 25. Juni 1980, Stand am 28. Mai 2009

Kanton Aargau, Stand und Entwicklung der öffentlichen Finanzen des Kantons Aargau und interkantonale Vergleiche, Dezember 2009

Kirchgässner, G. et al., On the Effectiveness of Debt Brakes: The Swiss Experience, University of St. Gallen (SIAW-HSG), Paper to be presented at the Annual Meeting of the European Public Choice Society, Durham, March 31 to April 3, 2005, Revised Version, June 2006

OECD, Budgeting in Switzerland, OECD Journal on Budgeting, 2005, Volume 5, No. 1

OECD, Performance Budgeting in OECD Countries, 2007

Proeller, I., Strategic management for the state, Gütersloh, 2007

Proeller, S., Die Rolle der Regierungszentrale in der strategischen Steuerung - internationale Perspektiven, in: Perspektive Staat. Herausforderungen für staatliche Führungskräfte, Schweizerische Staatsschreiberkonferenz und Staatskanzlei Kanton Aargau, Zürich, 2007

Rhinow, R., Swiss Reform and the long tradition of federalism, Forum of Federations, 2002, Vol.2, No.5, 19-20 
Schaltegger; C. et al., Verschuldungsprobleme als Herausforderung nach der Krise, Publikation von economiesuisse, economiesuisse 2009.

Schedler, S., Strategisches Management in Kommunen. Düsseldorf, Hans Böckler Stiftung, 2005

Schedler, S., der moderne staat, Zeitschrift für Public Policy, Recht und Management, Heft 2/2009, S. 391-410.

Schilling, M. et al., Strategische Steuerung in Regierungszentralen deutscher Bundesländer, in: Zukunft Regieren. Beiträge für eine gestaltungsfähige Politik, Gütersloh, 2009

Schweizerische Eidgenossenschaft, Bundesverfassung der Schweizerischen Eidgenossenschaft vom 18. April 1999.

Stalder, K., et al., Answers to OECD Questionnaire: Fiscal rules for cantons and communes, 18 May, 2005

Krisztina, T., The Impact of Legislature and Citizens on the Budgeting Process in Switzerland: Lessons for Central and Eastern Europe, FSES Working Papers 387, Faculty of Economics and Social Sciences, University of Freiburg/Fribourg, Switzerland, Working Paper no. 387, July 2005 


\section{Chapter 11}

\section{Innovation in the Public Sector of Ukraine: Problems of Identification, Measurement and Promotion}

Igor Yegorov, Institute of Economy and Forecasting, National Academy of Sciences of Ukraine

\subsection{Introduction}

Public sector innovation is a relatively new phenomenon, which was identified in recent years in scientific literature. Many countries still have no corresponding instruments, financial resources or incentives to study such innovations (OECD, 2013). On the other hand, innovation is needed for the public sector to address many challenges that it faces: it must respond in new ways to increasing pressure from a number of directions - rising costs, increasing demands from citizens and businesses, demographic changes, environmental risks, and the process of globalization have all increased the difficulty of maintaining high levels of public services. The public sector has undergone continuous transformations adopting both technological solutions as well as organizational changes to continue improving the delivery of public services while addressing concerns of efficiency and equity (EC, 2013). Efforts to improve public sector functions and the services it delivers require detailed knowledge of how public sector organizations innovate but unlike the private sector, indicators to better understand how public sector organizations innovate are lacking.

While some countries have conducted special surveys on public sector innovation the general picture is still not clear, as different definitions and approaches for obtaining initial data and interpretations have been used. Results from pilot surveys and interviews with respondents in public sector organizations suggest that the four types of innovations identified in the Oslo Manual could also be appropriate for the public sector, but that the actual wording of definitions would require modification to reflect the nature of public sector services and activities.

In principle, it is possible to obtain data from different sources, not only from the specialized surveys of public sector organizations. These sources could include: surveys of citizens and other users of public services (e.g. businesses); employee and employer-employee surveys; qualitative data approaches (e.g. innovation awards, case studies, examples) and other existing public sector data sources (e.g. budgetary data, data on public sector outputs/productivity, data from other surveys such as ICT/e-government, procurement). However, in practice, it is difficult to find even one reliable source of data on public sector innovation and there is still no consensus on the exact definition of this type of innovation, with the Oslo Manual stressing commercialization as an important attribute. (Bloch (2013) and Kattel et al., (2013)).

\subsection{Identification of innovation in the public sector of Ukraine}

In Ukraine, the problem of identification of public sector innovation is even more complicated to solve, than in some other, more advanced countries. Ukrainian statistics does not use the word 'public' in its publications. It prefers to refer to the 'state' and 'non-state' sectors, which create substantial difficulties in international comparative analysis. Most experts have a clear understanding of the differences between private and public sector innovation. The lack of a market is typically cited as the most fundamental difference 
between the two. This is in general very true and it would seem reasonable to expect that this should have an important impact on how public sector organizations innovate. For example, the lack of market competition may motivate a different approach when considering the objectives and incentives for innovation. However, other characteristics of innovations and other aspects of the innovation process may not be that different. A framework for measurement and analysis is likely to consider alternatives to the market tests generally built into business innovation measurement.

The Ukrainian case differs from similar cases, as well, as those of other post-Soviet states. In reality, it would be important to consider both governmental organizations and enterprises, which belong to the state sector.

Government organizations begin to recognize and to promote initiatives which facilitate change, for example, through the use of ICTs (e.g. e-Government). In the 1990s and 2000s, there was a growing interest in the dynamics of public sector innovation as a tool for modernization as well as the development of innovation "awards" to highlight examples of best practices. However, public sector organizations are increasingly aware of the inherent barriers they face with regard to innovation. The disruptive nature of innovation appears to be at odds with the fundamental role of government institutions with regard to reducing uncertainty and introducing stable routines. At the same time, promoting innovation in the state sector, and by the enterprises of the state sector, becomes an explicit goal in many countries. Given existing barriers, public (state) sector innovation must be institutionalized and embedded as a core activity within digital governance.

However, there are a lot of so-called 'borderline innovations' that are included in considerations. They just barely meet criteria and thus are often considered to have minor importance for the organization's performance. International experts propose to use a 'broad' definition of innovation, as mentioned in the last edition of Oslo Manual (2005) but by adding specific 'communication' innovation to it. A communication innovation is the implementation of a new method of promoting an organization or its services and goods, or new methods to influence the behaviour of individuals or others. They must differ substantially from existing communication methods in your organization. Taking into account this definition, innovation activities can be defined as all activities conducted inhouse or externally through acquisitions, which actually, or are intended to, lead to the implementation of innovations. Thus, these activities include:

- in-house activities, such as in-house research; planning and design; market research and other user studies; feasibility studies, testing and other preparatory work for innovation;

- contract research to universities or public research institutions;

- training and education of staff for innovation;

- consultancy or other business services for innovation;

- acquisition of new equipment and software for innovation.

In the Ukrainian case these activities must include innovation production on state enterprises in the interest of the state.

An additional dimension of public sector innovation is that it has to be planned. Innovations are often seen as the result of intentional actions and the requirement that innovations must be implemented generally implies that at least part of the innovation process must be planned. Planned innovations that are developed indirectly through the resolution of some problem, as 
opposed to being the result of a planned process, have been argued to be of particular importance in the public sector (Fuglsang, 2010).

For businesses, market forces intricately link a firm's performance with user satisfaction. If users are not satisfied with the goods or services offered by a business, they may choose other providers. The lack of a market means that this connection is typically missing for the public, and sometimes public sector organizations are perceived as less attuned to user needs. This can potentially have an important influence on incentives to innovate. However, there is a lack of actual evidence on how user needs affect public sector innovation, how users perceive the quality and responsiveness of public services and to what extent they are involved in efforts to improve them. And, despite the lack of market forces, there are signs that the public sector is increasingly concerned with user needs and customer satisfaction. However, there were no specific surveys on the attitude of users to public (state sector) innovations in Ukraine in recent years.

\subsection{Role of state in supporting innovation activities}

The state plays a diminishing role in supporting innovation activities in Ukraine. This is demonstrated by the tendency of budgetary financing of innovation. The share of the state was the second most important among all other financing sources (10 per cent) at the beginning of 1990s. Afterwards, the share of budgetary spending has exceeded the level of three per cent only once - in 2003, and this share dropped down to an insignificant 1.9 per cent in 2012.

The state still preserves its positions in financing $R \& D$, related to innovation. However, recent academic analysis of empirical evidence on the innovation process has shown no mechanical relationship between investment in $R \& D$ and innovation; rather, new products and processes appear to be the result of the involvement of many companies and institutions in a common endeavor (Gault, 2012). Innovation is therefore seldom an outcome of the effort of a single company or institution.

In Ukraine, however, there is no comprehensive provision of innovation and business support services from the side of the state. Innovation and business support infrastructure actors in Ukraine are underfunded and not equipped with tools, methodologies and knowledge to provide state of the art support services. Startups and SMEs (whose potential customers are increasingly demanding and globalised), are most affected by this lack as they often cannot develop international networking on their own hereby often not being able to tap into knowledge needed to innovate and to develop commercially-viable products and services at the speed and quality imposed by increasingly competitive and complex markets.

Formally, the country has a substantial number of innovation support organizations, created with state support, including more than 440 business centres, 70 business incubators, and hundreds of investment and innovation centres. Creation of such organizations could be considered as organizational innovation, initiated by the state. However, very few of them are really involved in innovation activities.

The Ministry of Science and Education of Ukraine has provided less impressive information on specific organizations, which are created with direct state support, and which are focused on innovation (see Table 11.1). 
Table 0.7 Organizations of innovation infrastructure in Ukraine, 2011

\begin{tabular}{|c|c|}
\hline Organizations of innovation infrastructure & Number \\
\hline Technoparks & 16 \\
\hline Innovation business incubators & 15 \\
\hline Innovation centres & 14 \\
\hline Centres of IP commercialization & 4 \\
\hline Innovation and TT Centres & 14 \\
\hline Centres of science, engineering and economic \\
information & 3 \\
\hline Science educational centres & 4 \\
\hline Education-research-production centres & 1 \\
\hline Investment (innovation) venture fund & 15 \\
\hline Non-bank finance and credit organizations & 21 \\
\hline Research implementation enterprises & 2 \\
\hline Consultancy centres & 4 \\
\hline Innovation research centres & 124 \\
\hline Total & \\
\hline
\end{tabular}

Source: Ministry of Science and Education of Ukraine, 2013

These figures are also heavily overrated. According to the Ukrainian Association of Investment Business Association (UBICA) only eight Technoparks (out of 16 registered) are operating. It is worth mentioning that creation of the first Technoparks in the late 1990s was the most successful experience of the undertaking and commercialization of research projects. However, this experience is associated with the functioning of Technoparks in 19992005 only. In fact, Technoparks looked more like 'clusters' of high-tech companies and groups of scientists and engineers, who could receive favourable regime for realization of their research and innovation projects. The best Technoparks were created by the institutes of the National Academy of Sciences of Ukraine with strong technological orientation (Paton Institute Electric Welding and the Institute of Mono-crystals ${ }^{145}$ ). Tax privileges could be received not by the institutes themselves but by the specific (specially registered) innovation projects.

Technoparks were successful in innovation activities in the first years of their existence (1999-2004). However, after abolishment of tax privileges in 2005, the number of innovation projects has not grown, and the importance of Technoparks for national innovation development has started to decline (Yegorov, 2009).

According to UBICA, there are only ten active business incubators in Ukraine at the moment. Moreover, for being commercially viable themselves they focus on purely commercial activity, leaving no resources to dedicate efforts to innovative companies, let alone start-ups. While start-ups are a vulnerable species everywhere in the world they face particular

${ }^{145}$ This is an official title of the institute in English 
challenges in an economy of transition like in Ukraine. As a result, the Ukrainian National Innovation System is lacking a fresh supply of high tech start-ups. The state is trying to arrange different networks of researchers, innovators, universities and other organizations, but its efforts are not very successful. Networks usually organize information exchange mechanisms: meetings, conferences, training, access to expertise, databases, and other types of information. They establish benchmarks of best practice, against which members can rate their performance against their local or international peers. They support professionalization of organizations and individuals within their sphere of interest. The networks themselves become learning organizations that promulgate good practice. Ukrainian innovation and business support infrastructure is "under-networked", when compared to their Western counterparts, neither is Ukrainian innovation and business support infrastructure actively engaged in networks. Having in mind the chronic underfunding of most business-support organizations, missing international links might seem as a minor problem. However, being cut off from accumulated international learning experiences, best practices, methodologies and tools ignites a virtuous circle. The downward spiral of professionalism of provided innovation and business support services creates an increasing loss of incentives for assisting Ukrainian business in helping it to become more competitive. Ukrainian innovation and business-support infrastructure must be equipped with appropriate resources and with international state of the art business-support services methodology and tools to help to minimize the 'gap' between Ukrainian organizations and potential foreign partners.

\subsection{Organizational innovation}

Ukraine urgently needs organizational innovations to stimulate innovation activities at different levels. Horizontal innovation policy coordination is thus necessary because modern government and administration are complex organizations with complex tasks. To make diverse players coordinate their activities in and beyond their policy field (horizontalization) is a complex and dynamic process that must take into account both internal and external factors and influences. Thus, coordination is treated as a process, not as an outcome. This is a highly complicated task and requires an advanced level of coordination between the various policy instruments. By the term 'policy instruments' we refer to 'the programmes, organizations, rules and regulations with an active involvement in the public sector, which intentionally or unintentionally affect R\&D investments". This usually involves some public funding, but not always as, for example, regulatory changes affect R\&D investments without the intervention of public funds. More analytically such instruments include subsidies, tax incentives, loans and regulations (e.g. environmental regulation can have a significant impact on innovation).

Another organizational form of support of innovation in the state sector is implementation of so-called state-targeted S\&T (Science and Technology) programmes. This science and innovation policy instrument has its roots in the former Soviet Union' science system, but has undergone certain changes to be adjusted to the needs of the transition to market economy. Special legal acts regulate initiation and performance of state target programmes in all spheres of the economy and society (general state programmes, regional programmes, branch of industry programmes, economic, cultural, environmental, health care, defence programmes etc.), according to which the development of priority science and technology fields is carried out by the R\&D and innovation projects (selected on a competitive basis) within the state target science and technology programmes. These programmes have to combine capacities of the private sector and the state. However, in Ukraine, enterprises participate in less than one per cent of state science and technology programmes. In developed countries, project cofunding by the private sector is often a criterion for funding decisions. There are neither 
effective instruments nor mechanisms to install public-private-partnerships in Ukraine. It is also important to stress that in Ukraine international research or innovation projects are rare phenomena. Another problem is that very often programmes are developed by ministry, state committee or agency staff, not by special agencies in collaboration with the business sector. As a result, many programmes are not well designed with regard to financial planning, coordination between different projects or general implementation. In addition, funding decisions are not taken by groups of independent decision makers, according to transparent procedures and selection criteria, as in developed countries.

To great extent, the problem of relatively low innovation activities in the country is associated with an underdeveloped innovation culture. At the same time, the level of development of innovation culture is dependent on other cultural factors, such as the level of social capital and trust in the society. If there is lack of trust among the citizens and organizations of the society and the effectiveness of government is not well established, support measures that function well in the EU or other areas of the developed world are not likely to succeed in the advancement of innovation culture. Ukraine faces great challenges in these respects and supporting the functioning of civic society should be prioritized, since it is a necessary condition of innovation culture, if, for instance, public-private collaboration is considered. Nevertheless, it is also possible that support for innovation culture may have a positive impact on civic society at large. From the point of view of social and economic development, there is evidence suggesting that innovation activities are liable to cluster within certain areas, and cultural factors, such as openness and tolerance of the people in a region, affect this clustering. Ukraine could make use of the finding that this implies, looking beyond the provision of supply-side resources, such as investments in training and education. The state could also search for possibilities to provide a mixture of vibrant cultural spaces and more relaxed urban infrastructures and suburbs that may be attractors of a talented work force. It is, however, very difficult to imitate or apply innovation cultures found in the state sector (public organizations). Organizational research is only about to start to address these issues.

Concerning governmental organizations, the Ukraine could make use of the lessons learned about the barriers hindering the advancement of innovation culture in a bureaucracy. Advancement of innovation culture in governmental organizations is dependent on many factors. Clarification of organizational goal setting procedures, provision of sufficient resources, monitoring and communicating good practices, as well as effective human resource management, including recognition and reward mechanisms, are found to be important and mutually reinforcing support measures of innovation culture in governmental organizations. It is likely that the situation is not different in Ukrainian governmental organizations. Unfortunately, the idea of knowledge - based economy driven by innovation has been seriously discredited in Ukrainian society due to the ineffective and inconsistent actions of the authorities and advertised measures that have never materialized. In addition, responsibilities of key actors were not well defined. There were several state ministries and agencies in Ukraine, which were responsible for support of innovation activities in the country but their competences were, and still are overlapping, and not clearly defined. Some of these agencies had no sufficient resources to conduct innovation policy effectively. In addition, mechanisms for implementing innovation policy tended to suffer because innovation policy has not been given a high priority by the state authorities. Legal acts on innovation support have, in many cases, a lower priority when compared to some other state regulations (e.g. Law on the State Budget). This results in innovation initiatives being blocked. Such unfavourable developments have created a gap between science, education and the economy. 


\subsection{Private public partnership and innovation in the state sector}

Special attention should be paid to the development of PPP. In Ukraine there are neither effective instruments, nor mechanisms to install public-private-partnerships. In the Act of Ukraine "On Public-Private-Partnership" dated July the 1st of 2010, R\&D and innovation are not foreseen in the list of areas of PPP enforcement. In Ukraine there is no mechanism of cofinancing the projects included in the state scientific and technical programmes at the expense of enterprises, private investors, business angels, or community funds. There are no state programmes targeted at new business or other ways of commercialization of R\&D results. Innovation in the business sector is mainly financed from companies' own funds, which tends to reflect on the lack of available other sources of innovation funding. This is a structural challenge particularly to small and medium-sized companies.

The only exception is the innovation in the state sector, mainly related to the production of military equipment and armaments. Ukraine has preserved a large part of the Soviet militaryindustrial complex with its innovative potential. It is difficult to assess its real size, as corresponding information is classified, but the fact that the country ranks among the top ten exporters of military goods in the world, shows that this potential is substantial. A number of machine-building companies are still under state control, working in the interests of the state and with a relatively high level of innovation. It is hard to find direct correspondence to the situation in other countries but, it seems that such innovations could be considered as public sector innovations.

According to the results of the CIS-type survey in Ukraine, more than 20 per cent of enterprises were involved in innovation activities in 2010-2012. At the same time, only 2.1 per cent of all Ukrainian companies (water, gas and electricity supplies and so on), which are usually associated with the public sector, had innovations in 2010-2012. It is also worth mentioning, that less than six per cent of state organizations (universities, research institutes and so on) were mentioned as partners in innovation activities. This means that general involvement of the state sector in innovation processes remains low. This conclusion could be supported by the data on created and used new technologies in different 'public-related' sectors of the Ukrainian economy (see Table 11.2).

Table 0.8 'High technologies' introduction in Ukrainian economy, 2011

\begin{tabular}{|l|c|c|}
\hline Sector & $\begin{array}{c}\text { Number of created high } \\
\text { technologies }\end{array}$ & $\begin{array}{c}\text { Number of used high } \\
\text { technologies }\end{array}$ \\
\hline State governance & - & 2 \\
\hline Education & 145 & 943 \\
\hline Health care & - & 5 \\
\hline Sport and culture & - & 1 \\
\hline
\end{tabular}

Source: State Service of Statistics of Ukraine, 2012

Ukraine is trying to exploit opportunities, related to innovation development in more 'traditional' areas of public innovation. One of them is the special state programme on 'electronic government'. It was designed in 2004 in order to provide the citizens of Ukraine with operational and unbiased information on the activities of state authorities. The main idea of this project is to use international experience, solutions, and methodological developments in information technology to improve the transparency and efficiency of public 
administration in Ukraine, development of e-business, and to strengthen the dialogue between governmental institutions, the private sector and the citizens of Ukraine. The main components of the system include: Internet operation with state bodies at all levels, with access to electronic information resources of the government; utilization of digital signature of state officials, with a reliable and secure information interaction between the customer of the state services and executive authorities; and the introduction of electronic procurement of goods and services for state needs. Total investment in the programme was to reach up $€ 1$ billion over eight years. However, due to the economic crisis and political instability this programme has not been completed. While some elements of e-Government are in operation, it is still a long way till all tasks of the programme will be fulfilled.

\subsection{Conclusion}

Ukraine is a country, which is trying to 'catch-up' and to accelerate its economic development. Intensification of innovation in the public (state) sector could contribute substantially to the success of its efforts. However, a lot of work remains to be done.

First, a strict approach to identification of public and private sectors in assessment of innovation activities (using KVED classification) has to be implemented. As a part of this process, changes in standards of book-keeping, aimed at identification of innovation expenditures should be introduced. As innovations in the public sector are not always straightforward, a multi-level approach has to be used for collecting information on innovation in this sector and producing indicators. Special attention must also be paid to the service sector and especially to services provided by the state.

Second, our analysis illustrates the potential need for undertaking special surveys in capturing public sector innovation. These surveys could potentially be modified to cover selected issues concerning innovation. Samples can be taken from a range of sources or populations. Introduction of special surveys and two-stage interviews for respondents in the public sector (the first stage should help to clarify definitions and provide guidelines for answering further questions) are important for obtaining reliable data.

Third, providing innovation financing more on a competitive and collaborative basis is likely to dynamize the innovation system and to improve its performance. Competitive and transparent, project-based funding with clear innovation objectives in the state (public) sector is needed.

Fourth, public-private partnership is important for implementation of public sector innovation. Such partnerships provide the framework not only for shared funding of the technology transfer process but also for shared use of R\&D outcomes, information, new technologies, intellectual property, etc. They are commonly used for pre-market development of new public research findings and ideas, supporting new innovative companies including creation of incentives for public bodies to establish start-up companies, facilitation of commercial exploitation of new public R\&D products, information services, etc. Publicprivate partnerships are considered one of the principal mechanisms to improve innovation efficiency and attract R\&D investments. Co-funding by the private sector and the participation of enterprises in research programmes and projects are often a criterion for funding decisions.

Fifth, public-private partnerships in technology and innovation must be promoted by launching special state programmes. Bridging programmes between research and industry should be created. Sector- or technology-specific competitive state co-financed collaborative 
programmes for SME participation should be developed. The collaboration for new innovative products, high-tech products, radical innovations and technology areas important for the national economy should also be co-financed, with 100 per cent coverage of the research sector.

\subsection{References}

Bloch, C., Measuring innovation in the public sector, Chapter 17 in F. Gault (ed.) Handbook of Innovation Indicators and Measurement, 2013, Cheltenham, UK: Edward Elgar

European Commission, Powering European Public Sector Innovation: Towards a New Architecture, Report of the Expert Group on Public Sector Innovation, 2013, DG Research and Innovation.

Fuglsang, L., Bricolage and invisible innovation in public service innovation, Journal of Innovation Economics, 2010, Vol 1, p.67-87.

Gault, F., User Innovation and the Market, Science and Public Policy, 2012, vol. 39, N.1, p. 118-128.

Kattel, R., et al., Can we measure public sector innovation? A literature review, LIPSE Project paper, 2013

OECD, Key elements for a measurement framework for public sector innovation, document DSTI/EAS/STP/NESTI, (2013)10, Paris

OECD, Measuring public sector innovation: proposals for preliminary measurement guidelines, document DSTI/EAS/STP/NESTI (2014)16, Paris

OECD/Eurostat, Oslo Manual - Guidelines for Collecting and Interpreting Innovation Data, 2005, Third Edition, Paris.

Yegorov I., Post-Soviet Science: Difficulties in the Transformation of the R\&D Systems in Russia and Ukraine, Research Policy, 2009, vol. 38, issue 4, p. 600-609 